\title{
DRY SEDIMENTATION PROCESSES IN THE HIGH-ELEVATION MCMURDO DRY VALLEYS, ANTARCTICA: A CASE STUDY IN UNIVERSITY VALLEY
}

By

Cassandra Anh Trinh-Le

A thesis submitted to Victoria University of Wellington

in fulfilment of the requirements for the degree of

MASTER OF SCIENCE

in

Geology

School of Geography, Environment, and Earth Sciences in conjunction with the Antarctic Research Centre

Victoria University of Wellington

New Zealand 



\section{Abstract}

The hyper-arid, cryotic, wind-dominated conditions in the high-elevation McMurdo Dry Valleys of Antarctica are among Earth's most extreme environments and represent the closest terrestrial analog to the surface of Mars. These unique conditions result in complex surface processes that occur in the overall absence of liquid water. However, since water is typically believed to be required for these processes to occur, the mechanisms responsible for how these processes can persist in this environment are poorly understood. Previous studies that focused on individual processes of sedimentation in the Dry Valleys leave questions regarding the role of water in dry cryotic sedimentation as well as the rates at which these processes occur. This thesis addresses these questions by combining Optically Stimulated Luminescence (OSL) dating, meteoric Beryllium-10 $\left({ }^{10} \mathrm{Be}\right)$ measurements, soil geochemistry analysis, and petrographic microscopy analysis on ice-cemented permafrost cores taken from University Valley, one of the high-elevation Dry Valleys, where the availability and effects of liquid water are minimal. These analyses were used to explore four main sedimentation processes that occur in the Dry Valleys: chemical weathering, fine particle translocation, eolian transport, and physical weathering. Analyzed together, findings from these analyses comprehensively describe the complex processes involved in dry cryotic sedimentation and determine the roles of different phases of water in this environment.

Sediments in University Valley have accumulated at a rate of approximately 2.1 $\mathrm{mm} / \mathrm{ka}$ for the last $200 \mathrm{ka}$, as dated by OSL, from erosion of the valley walls and deposition of windblown dust. Sediment accumulation is influenced by topography of the valley floor, depth of the ice table, aspect of the valley walls, wind direction, and mechanical breakdown of rocks due to solar heating. While persistent winds constantly remobilize fine particles and dust in the upper few $\mathrm{cm}$ of the dry ground, sediment grains that are sand-sized or larger do not undergo significant remobilization, and sediments in the ice-cemented ground are unaffected by remobilization and translocation processes. Rare clay bridges seen in thin section show that small, infrequent, transient surface wetting events have occurred over the last $200 \mathrm{ka}$. High anion concentrations associated with high surface meteoric ${ }^{10} \mathrm{Be}$ measurements and 
clay bridges indicate that the source of these wetting events is the melting of windblown snow from coastal regions. Patterns in meteoric ${ }^{10} \mathrm{Be}$ measurements show that these small transient wetting events are not sufficient to translocate fine particles through the soil profile, which suggests that the role of liquid water as a transporting agent is negligible in this environment. Chemical weathering in University Valley appears to be controlled by two main components: dolerite content of the sediments, and exposure to the atmosphere at the ground surface where condensation of water vapor onto grain surfaces readily leaches ions from dolerite grains under the oxidizing conditions of the Dry Valleys. In the absence of liquid water, chemical processes that occur in this environment rely on water vapor.

Together, these results indicate that surfaces in University Valley are remarkably young and sedimentologically active. Because University Valley represents one of the closest terrestrial analogs to the surface of Mars, findings from this thesis may be applicable to understanding the timescales and the processes that control anhydrous sedimentation on the surface of Mars. 


\section{Acknowledgments}

There are so many people that I would like to thank for their continued support along the way, without which this thesis would not be possible.

First and foremost, I want to say thank you to my supervisor, Warren Dickinson. Thank you for giving me this wonderful opportunity and for your enthusiastic support of my ideas and ambitions. You have opened so many doors and given me the tools to walk through them.

To my secondary supervisor, Kevin Norton, thank you for your encouragement, helpful discussions, and for all of your time working with me in the Cosmo Lab, even before you were my supervisor.

To Alfonso Davila, thank you so much for generously donating your University Valley cores to make this thesis possible, and for allowing me to return a second time to subsample when my project expanded. Thank you for your insightful discussions and for presenting me with new and exciting opportunities. Thank you also to David Willson, Chris McKay, Joe, Heather, Rosalba, Carol, and many others at the NASA Ames Research Center for all of your help and hospitality during my time at Ames.

To Denis Lacelle, thank you for allowing me to subsample your set of University Valley cores, for funding the geochemical analyses, and for your thought-provoking email discussions. Thank you also to Alex, Brittany, Caitlin, Marielle, and Phil for giving me a place to stay and for all of the fun memories in Ottawa.

There are many staff I would like to thank from Victoria University of Wellington. Ningsheng Wang, thank you for teaching me about OSL, training me in the OSL Lab, and for your uplifting conversations. Jane Chewings, thank you for bestowing upon me your wealth of knowledge, for all of your time training me on all the different equipment (and for fixing all of the malfunctions). Stu Bush, thank you for training me how to vacuum-impregnate sediment samples with epoxy and for making my many thin sections and grain mounts. Sabrina Lange, thank you for your help in the Geochem Lab. Andrew Rees, thank you for your help with the OxCal models. Thank you, Monika Hanson, Miranda Voke, Kate King, and Patricia Stein for your support and administration help, especially during my extended period of medical leave. 
I am very grateful to the generous donors of the Antarctic Research Centre Endowed Development Fund and the Faculty Strategic Research Grant. The four grants I received during my thesis funded my cosmogenic nuclide and OSL analyses and allowed me to travel to the USA and Canada for sample collection.

My wonderful mother Kim Nguyen, thank you for always supporting my dreams, for your unconditional love, and for making sure my shoulders were properly re-secured in their sockets before releasing me back into the thesis world. You give me the courage to dive into the unknown and overcome any obstacle. Thank you for showing me a world of endless opportunities. I love you.

My loving father Donn McGinnis, thank you for always inspiring me to pursue science with a passion.

A huge thank you to Dr. King for reconstructing my shoulder capsules and thus making it possible for me to complete my MSc degree.

To Florian, thank you so much for your incredible ongoing encouragement and support, especially in the final stages of this thesis.

To Misty Marsh, thank you for your helpful comments and motivating conversations.

Finally, to Grace Frontin-Rollet, thank you for being the very best, like no one ever $\operatorname{was}(\Theta)$.

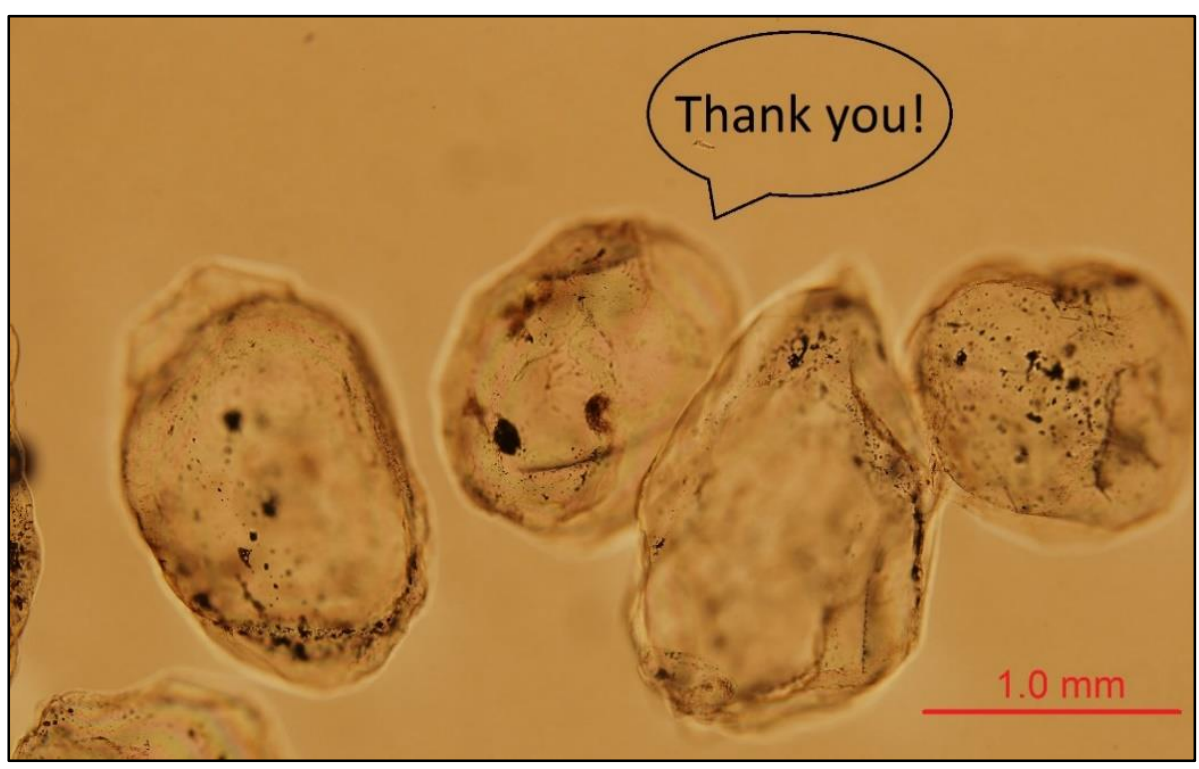

Photomicrograph of a happy quartz sand grain from University Valley, Antarctica (40x magnification, plane light). 


\section{Table of Contents}

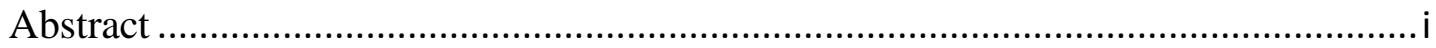

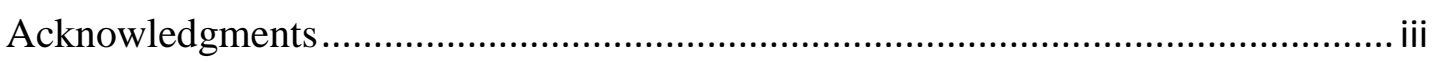

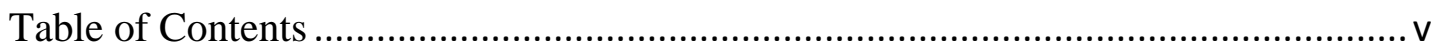

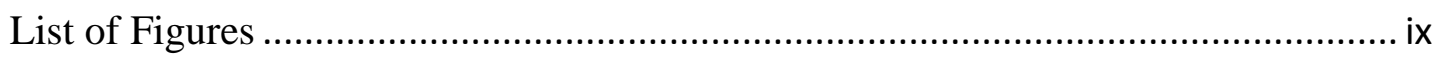

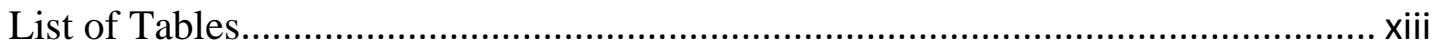

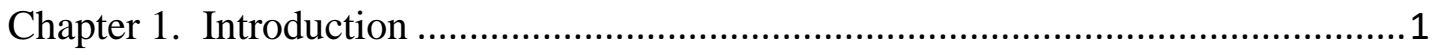

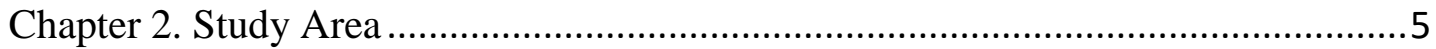

2.1. The McMurdo Dry Valleys ..................................................................... 5

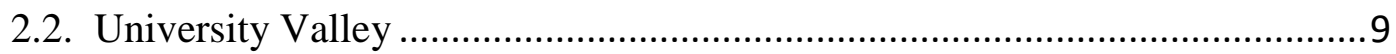

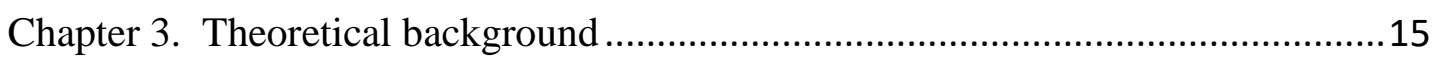

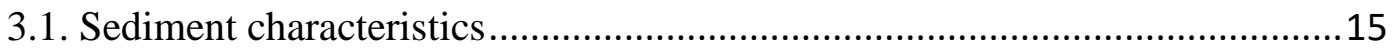

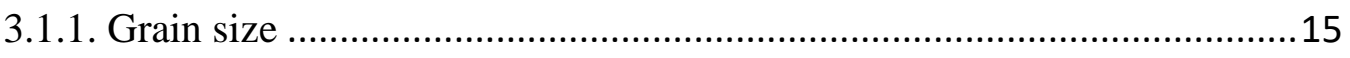

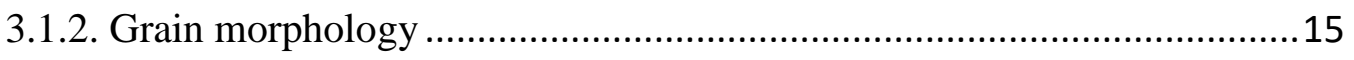

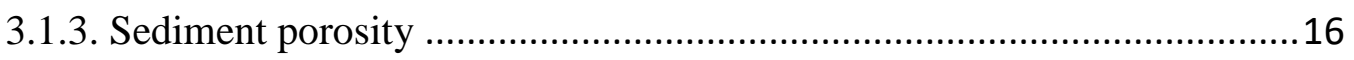

3.1.4. Sediment composition............................................................... 17

3.2. Optically Stimulated Luminescence dating ..............................................19

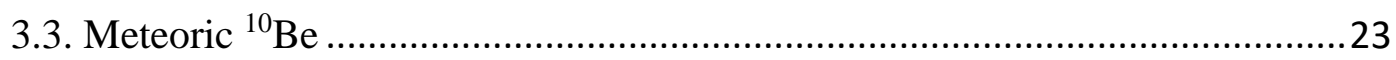

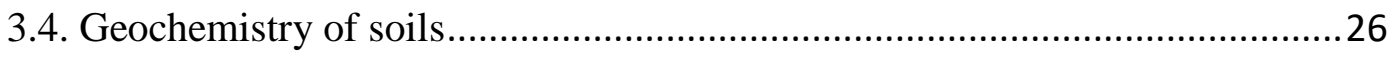

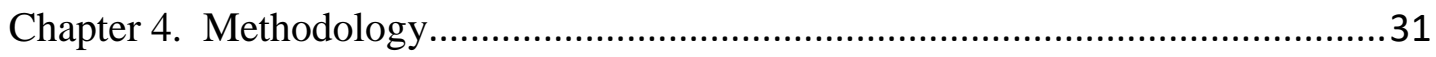

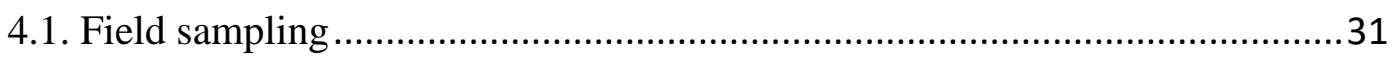

4.2. Optically Stimulated Luminescence dating .............................................34

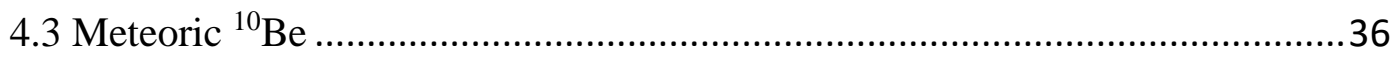

4.4. Grain size analysis: sieve stack and Laser Particle Sizer..............................39

4.5. Preparation of samples for microscopy analysis of lithology, porosity, and

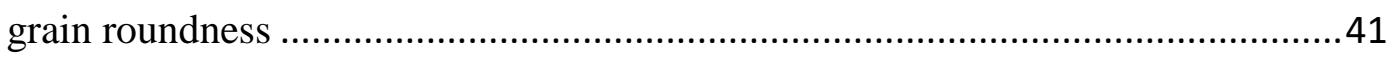


4.6. Geochemical analysis: ion leaching .43

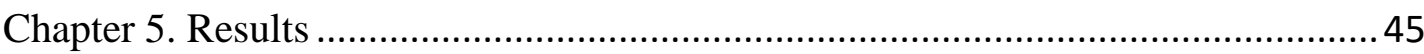

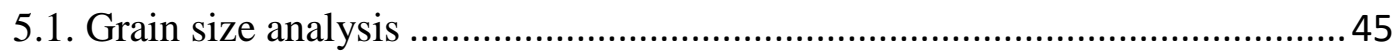

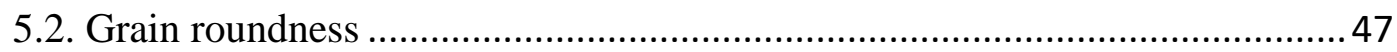

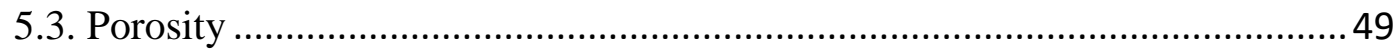

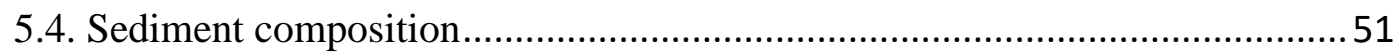

5.5. Optically Stimulated Luminescence ages ..................................................5 53

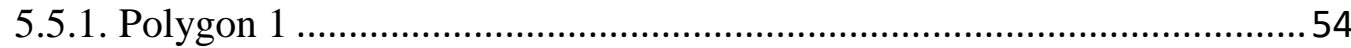

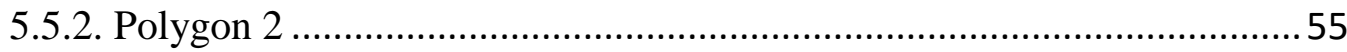

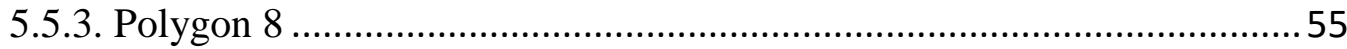

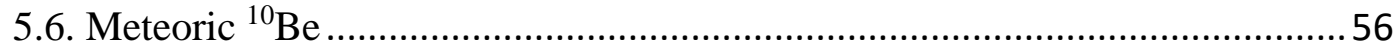

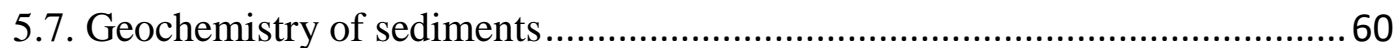

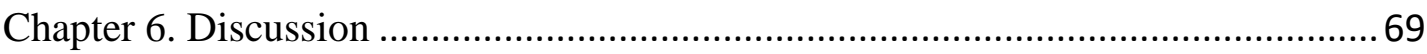

6.1. Sediment characteristics: grain size, sediment composition, grain morphology,

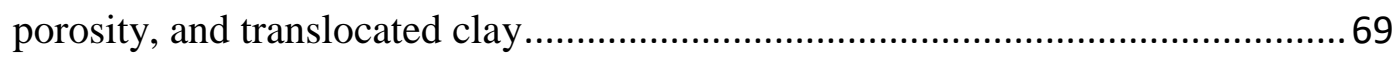

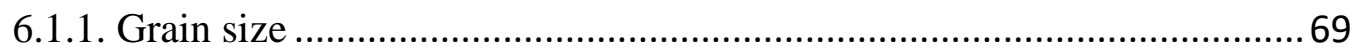

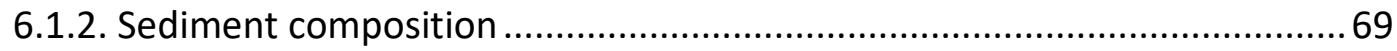

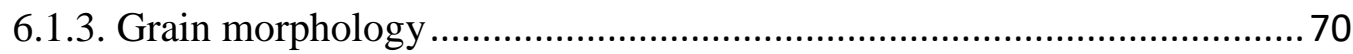

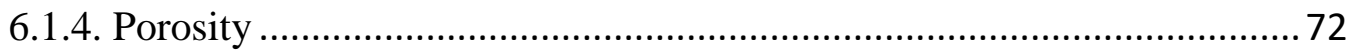

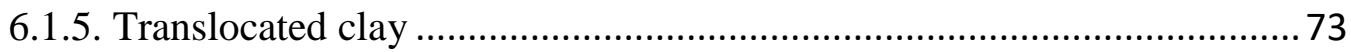

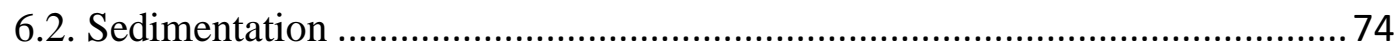

6.2.1. Sediment deposition rates and processes indicated by Optically

Stimulated Luminescence Dating .................................................................. 74

6.2.2. Fine particle deposition rates and processes determined from meteoric ${ }^{10} \mathrm{Be}$

6.3. Chemical weathering and aerosol deposition insights from geochemical analysis of sediments 


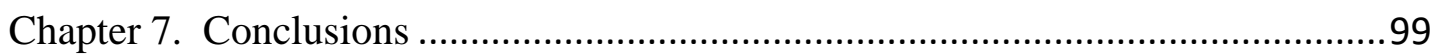

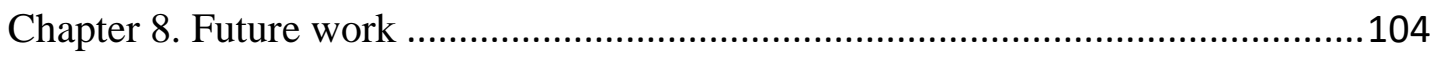

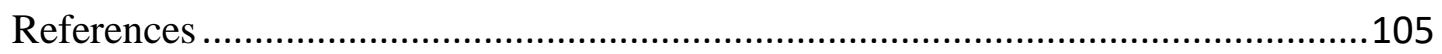

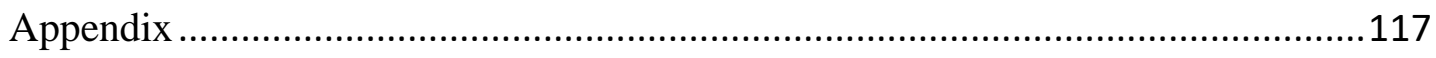

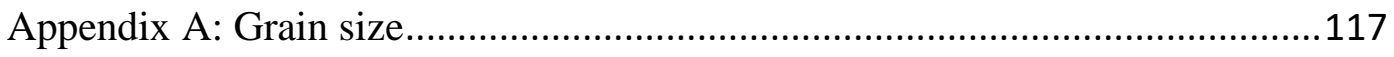

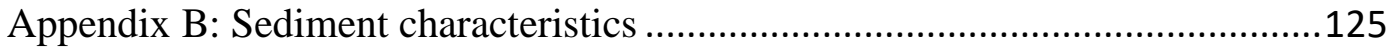

Appendix C: Optically Stimulated Luminescence .........................................128

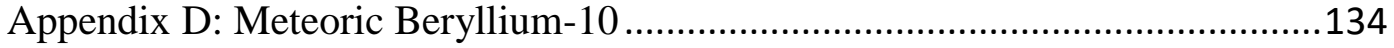

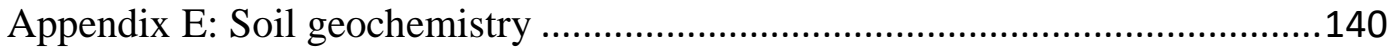




\section{List of Figures}

Figure 1: Landsat image of the McMurdo Dry Valleys, Antarctica. ..........................6

Figure 2: Types of permafrost profiles in the McMurdo Dry Valleys ......................... 8

Figure 3: Landsat image of University Valley within the McMurdo Dry Valleys.... 10

Figure 4: Photo of University Valley looking up valley toward the glacier ............... 11

Figure 5: Photo of polygonal patterned ground on the floor of University Valley.... 12

Figure 6: Depth to ground ice as a function of distance from the glacier in University

Valley

Figure 7: Features of University Valley (core locations, digital elevation model, ground surface temperature zones, and surficial sediment covers).

Figure 8: Images of sediment grains portraying different degrees of roundness and sphericity..... .16

Figure 9: The relative stability of common silicate minerals. .17

Figure 10: Schematic diagram of the accumulation of OSL signal over time..... 20

Figure 11: Effects of the orientation of earth's magnetic field lines on incoming cosmic rays

Figure 12: Latitudinal variation of meteoric ${ }^{10} \mathrm{Be}$ flux onto the earth surface. .25

Figure 13: Relative strengths of various element-oxygen bonds in common rockforming minerals

Figure 14: Aerial photograph of University Valley depicting coring locations. .32

Figure 15: Photo of field sampling in University Valley .33

Figure 16: The Udden-Wentworth grain-size classification of terrigenous sediments

Figure 17: The sediment grain roundness and sphericity scales

Figure 18: Example of sieve stack particle size distribution by weight percentage .. 45

Figure 19: Average particle size distribution for each core .46

Figure 20: Average laser sizer particle size distribution of the $<45 \mu \mathrm{m}$ size fraction by volume percentage

Figure 21: Photomicrographs showing examples of grain roundness, sphericity, and lithology.

Figure 22: Plot of roundness and sphericity of quartz, K feldspar, and dolerite grains 
Figure 23: Photomicrographs showing examples of different pore structures of

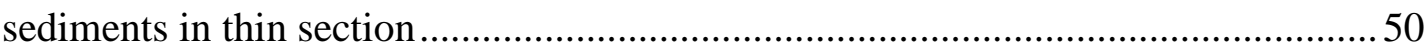

Figure 24: Plot of sediment porosity with depth................................................... 51

Figure 25: Photomicrograph of a dolerite grain showing rust-colored weathering

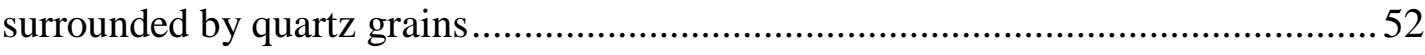

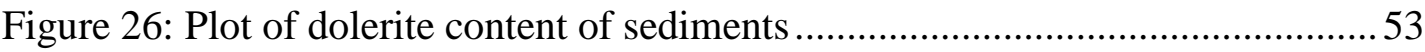

Figure 27: Plot of Optically Stimulated Luminescence ages for P1, P2, and P8.......54

Figure 28: Plot of meteoric ${ }^{10} \mathrm{Be}$ concentration for $\mathrm{P} 1, \mathrm{P} 2$, and $\mathrm{P} 8$............................58

Figure 29: Plot of meteoric ${ }^{10} \mathrm{Be}$ concentration vs. mean grain diameter ...................6 60

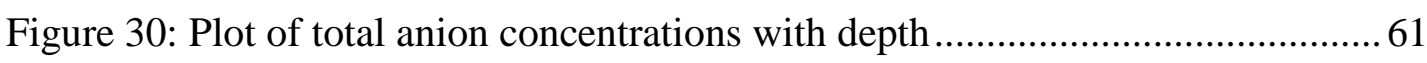

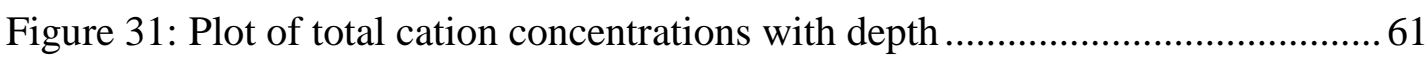

Figure 32: Ternary diagram of all measured anions $\left(\mathrm{Cl}^{-}, \mathrm{SO}_{4}{ }^{2-}\right.$, and $\left.\mathrm{NO}_{3}{ }^{-}\right)$..............6 62

Figure 33: Ternary diagram of the cations $\mathrm{Fe}^{2+}, \mathrm{Si}^{4+}$, and $\mathrm{K}^{+}$................................6 63

Figure 34: Ternary diagram of the cations $\mathrm{Mg}^{2+}, \mathrm{Ca}^{2+}$, and $\mathrm{Na}^{+} \ldots \ldots \ldots \ldots \ldots \ldots \ldots \ldots . . . . . . . . . . . . . .63$

Figure 35: Example plot of $\mathrm{Na}^{+}$and $\mathrm{Cl}^{-}$concentrations showing that most cores exhibit ion concentrations that are above the concentrations expected from seawater.

Figure 36: Example plot of $\mathrm{K}^{+}$and $\mathrm{Na}^{+}$concentrations showing that ionic concentrations for all cores are between the expected concentrations found in sea water and in dolerite rocks

Figure 37: Example plot of $\mathrm{Ca}^{2+}$ and $\mathrm{Na}^{+}$concentrations showing that ionic concentrations for certain ion pairs exhibit constant ratios for some cores but is widely variable for other cores..

Figure 38: Example plot showing that ion ratios do not exhibit trends with depth ...67

Figure 39: Photomicrographs of similarities in grain morphology between a quartz grain of the Beacon orthoquartzite and quartz grain from University Valley sediments 70

Figure 40: Photos of in-situ breakdown of rocks from thermal cycling. 71

Figure 41: Photomicrograph showing highly variable pore structures within mm scales

Figure 42: Photomicrograph showing clay bridges between loosely-packed grains and clay coatings as evidence of clay translocation.

Figure 43: Photo of OSL-dated large mass wasting deposit partially overlying the toe of University Glacier. 
Figure 44: Schematic diagram illustrating the formation of depression at P2 that resulted in comparatively younger OSL ages at deeper depths

Figure 45: Plot showing adjusted OSL depths of P2 (per the deflation scenario) and P8 (with mass wasting deposit height removed)....

Figure 46: Plot of meteoric ${ }^{10} \mathrm{Be}$ concentration for P1, P2, and P8 by distance from the glacier

Figure 47: Schematic diagram of idealized Antarctic Dry Valley soil profile with four zones: eolian, salt, active, and permanently frozen

Figure 48: Photomicrographs of rusted dolerite grains in thin section, indicating the presence of chemical weathering.

Figure 49: Ternary plots showing constant ratios of $\mathrm{Na}^{+}$to $\mathrm{Mg}^{2+}$ and of $\mathrm{Fe}^{2+}$ to $\mathrm{Si}^{4+}$ with depth for all cores

Figure 50: Aerial photograph of University Valley showing location of cores along three geochemical-trend transects

Figure 51: Photo looking down the axis of University Valley showing differing amounts of sun exposure in the valley and distribution of sediments eroding from the valley walls. 


\section{List of Tables}

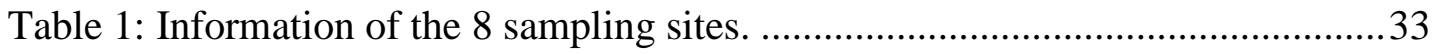

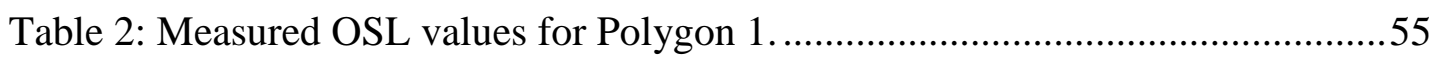

Table 3: Measured OSL values for Polygon 2 ......................................................55

Table 4: Measured OSL values for Polygon 8 ......................................................56

Table 5: Measured and calculated values of ${ }^{10} \mathrm{Be}$ for $\mathrm{P} 1, \mathrm{P} 2$, and $\mathrm{P} 8$........................59 


\section{Chapter 1. Introduction}

The hyper-arid, cryotic, wind-dominated conditions in the high-elevation McMurdo Dry Valleys of Antarctica are among Earth's most extreme environments and represent the closest terrestrial analog to the surface of Mars (Marchant and Head, 2007; McKay, 2009; Speirs, 2010; Doran et al., 2002). Due to these unique conditions, surface processes that occur in these valleys are complex and many of them remain poorly understood (Mellon et al., 2014). Most notably, widespread evidence of sedimentation processes that are believed to require liquid water, such as extensive chemical weathering, have been observed throughout the lower Dry Valleys (e.g. Bockheim, 1990; Campbell and Claridge, 1981; Cannon, 2015; Salvatore et al., 2013). Yet, the mechanisms responsible for how these seemingly water-dependent processes can persist in the overall absence of liquid water continue to be debated (Hall et al., 2002). Therefore, it is important to investigate sedimentation processes in the highelevation Dry Valleys, where effects from liquid water are minimal.

Many studies in the Dry Valleys have focused on single processes of sedimentation such as chemical weathering, eolian activity, physical weathering (mechanical breakdown of rocks), and fine particle translocation (e.g. Gibson et al., 1983; Speirs et al., 2008; Putkonen et al., 2013; Steig et al., 1995). Analyzed individually, these studies each have limitations and cannot provide a complete understanding of how sedimentation in these valleys works through time. Specifically, these studies leave questions regarding how processes such as chemical weathering, particle translocation, and ion migration occur without liquid water. Yet, studies have not been conducted that explore the direct relationships between these processes to understand sedimentation as a whole. Studying these relationships may provide answers for how these presumed to be water-dependent sedimentation processes can occur in the absence of liquid water. How these sedimentation processes work together in this unique environment must be examined by analyzing them together on the same sample set within the same location in the Dry Valleys. 
University Valley is a high-elevation hanging glacial valley in the ultraxerous region of the McMurdo Dry Valleys, which features the lowest temperatures and most extreme aridity in Antarctica (McKay et al., 1998; Lacelle et al., 2016). In this location, conditions favorable for supporting transient liquid water have not existed in over $150 \mathrm{ka}$, and ice contained in these soils is largely formed by freezing of water vapor from the atmosphere that has condensed onto sediment grain surfaces (Lacelle et al., 2013). These factors make University Valley the ideal location to study cryotic sedimentation processes in the absence of liquid water.

Although some studies have obtained radiometric ages for ground surfaces in the Dry Valleys, ages of the soils have not been established. U/Th and ${ }^{10} \mathrm{Be}$ surface exposure dating have been used estimate the maturity of sediments that are involved in these processes, but these methods have produced wide-ranging ages from $80 \mathrm{ka}$ to $7 \mathrm{Ma}$ and only provide maximum ages of the ground surface or ancient in-situ ash horizon, which could be millions of years older than the soils (e.g. Bockheim et al., 2009; Campbell and Claridge, 1981; Mellon et al., 2014; Hendy et al., 1979). Additionally, no study has yet determined rates of sedimentation processes in the Dry Valleys, which are critical for understanding the timescales over which these processes occur. These surface age studies and previous single process studies leave questions regarding ages of the sediments, rates of sediment accumulation, subsurface translocation processes, and the interactions between physical and chemical weathering processes and their effects on sediment evolution. This thesis addresses these questions by combining principles from these single-process studies with Optically Stimulated Luminescence dating.

The purpose of this thesis is to conduct multiple different analyses in University Valley and link the results to comprehensively describe the complex processes of sedimentation in the Dry Valleys. This thesis aims to answer the following three main questions:

(1) What are the roles of different phases of water in sedimentation processes that occur in cryotic hyper-arid conditions? 
(2) In the absence of liquid water, what are the main factors that control chemical weathering?

(3) What are the rates at which these sedimentation and weathering processes occur?

To answer these questions, the following objectives are achieved:

1. Obtain Optically Stimulated Luminescence ages of the sediments with depth and from different types of deposits the valley (e.g. from the main valley floor and from wasting deposits near the valley walls) and use them to determine sediment deposition rates.

2. Determine the sources of sediments, modes of sediment transport, and intensity of physical weathering in the valley by combining grain size analysis with sediment characteristics examined with thin section microscopy.

3. Determine fine particle translocation processes and fine particle deposition rates by combining Optically Stimulated Luminescence ages with meteoric Beryllium-10 measurements of the sediments.

4. Determine the intensity of chemical weathering to gain insights about the availability and role of water in the valley.

Combined, these findings provide a comprehensive understanding of past and present surface and subsurface processes in this unique environment, which may additionally be applicable to the processes that occur on the cryotic hyper-arid surface of Mars. Due to limited sample availability, this study is not an in-depth analysis of each sedimentation process, but instead explores the relationships between them to increase general understanding of the larger-scale process. This thesis provides the framework for future studies to investigate these relationships in detail. 


\section{Chapter 2. Study Area}

\subsection{The McMurdo Dry Valleys}

The McMurdo Dry Valleys (MDV) are the largest ice-free region of Antarctica, and represent a hyper-arid polar desert environment (Bockheim et al., 2008, Doran et al. 2002). Spanning $73^{\circ} 30^{\prime}$ to $78^{\circ} 30^{\prime} \mathrm{S}, 160^{\circ}$ to $164^{\circ} \mathrm{E}$, the MDV are located in Southern Victoria Land in the Transantarctic Mountains, between the East Antarctica Ice Sheet and the seasonally ice-free western coast of the Ross Sea (Figure 1) (Denton et al., 1993; Sugden et al., 1995a). Together, these valleys cover a total of $\sim 22,700 \mathrm{~km}^{2}$, with $\sim 4,500 \mathrm{~km}^{2}$ of this area being ice-free due to the Transantarctic Mountains blocking the flow of the East Antarctic Ice Sheet into the valleys (Fountain et al., 2009). Despite being generally ice-free at the surface, subsurface ground ice occurs throughout the MDV in the form of buried bodies of massive ice or as ice-cemented sediment (Bockheim, 2007). 


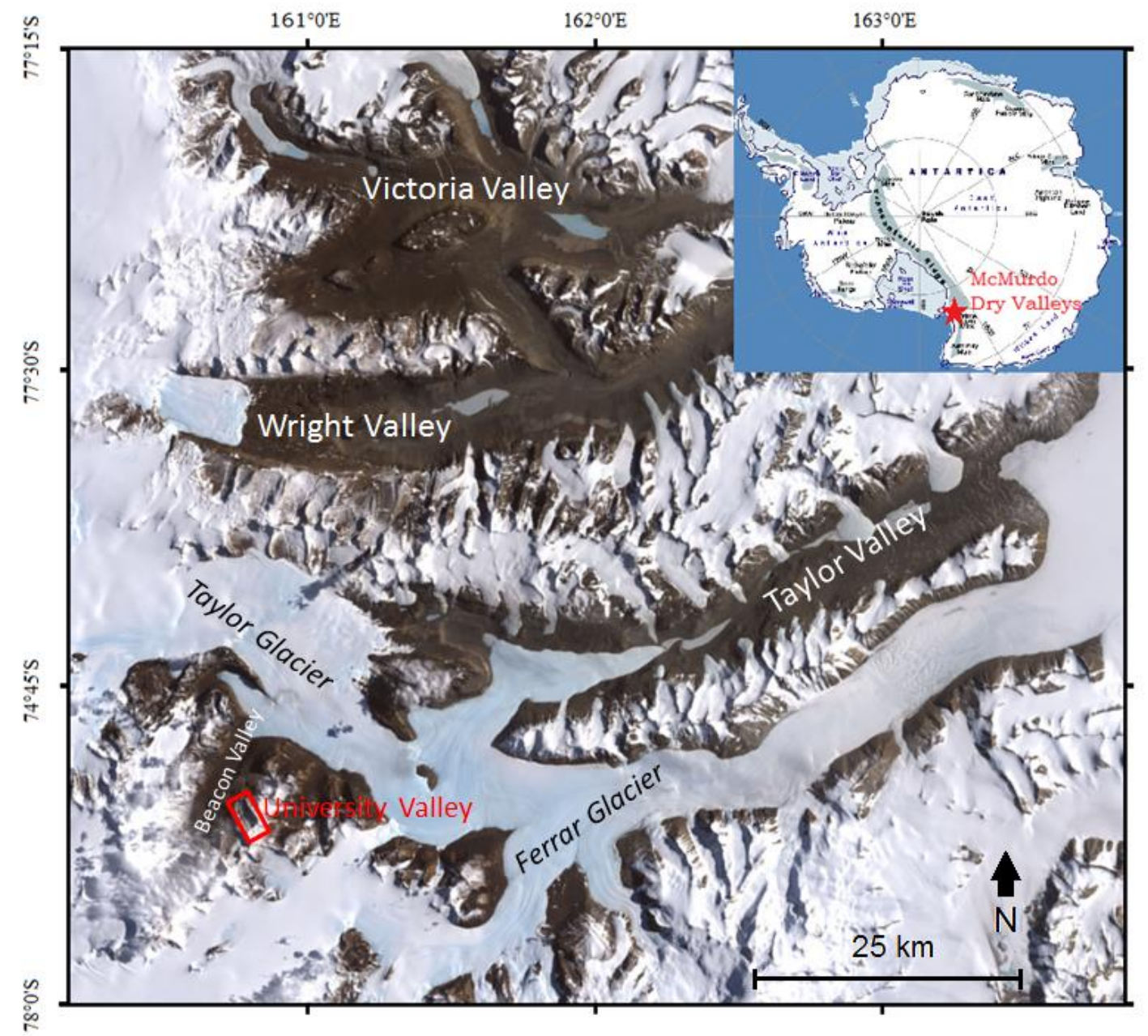

Figure 1: Landsat image showing the McMurdo Dry Valleys, Antarctica. University Valley is denoted by the red rectangle. Modified from image by Robert Simmon, based on data provided by the NASA GSFC Oceans and Ice Branch and the Landsat 7 Science Team (http://eoimages.gsfc.nasa.gov/images/imagerecords/2000/2140/landsat7_dry_valley_lrg.jpg)

In the MDV, there are three main glacially-carved east to west trending valleys: Victoria Valley, Wright Valley, and Taylor Valley. These valleys are $\sim 80 \mathrm{~km}$ long and up to $15 \mathrm{~km}$ wide (Marchant and Head, 2007). The bedrock of the MDV consists of a basement complex that includes early Paleozoic to pre-Cambrian age granite, gneiss, and migmatite. Overlying the bedrock are sedimentary rocks of the Beacon Supergroup, which are composed of Devonian to Triassic sandstones, siltstones, and conglomerates, as well as Jurassic intrusions of Ferrar Dolerite sills and dykes (Barrett, 1981; Elliot and Fleming, 2004). 
Mean annual air temperatures in the MDV range from $-14.8^{\circ} \mathrm{C}$ to $-30^{\circ} \mathrm{C}$ (Doran et al., 2002). Annual precipitation, in the form of snow, is less than $100 \mathrm{~mm}$ water equivalent on the coastal regions and decreases inland to $3 \mathrm{~mm}$ water equivalent (Bromley, 1985). Strong adiabatically-warmed winds flow from inland out to the Ross sea (Marchant and Denton, 1994). These gravitationally-driven winds, which are often referred to as katabatic, have been found to be Foehn winds and have a significant influence on the climate of the valleys (Speirs et al., 2010). Due to the pronounced topography of the MDV, these strong, warm airflows are directed and funneled, resulting in frequent strong westerlies, especially during the winter months (Nylen et al., 2004; Doran et al., 2002). Wind strength is stronger inland, decreasing in strength toward the coast. Strong winds, which remove moisture from the air, combined with low surface albedo and high levels of sublimation that exceed precipitation result in hyper-aridity in the MDV (Doran et al., 2002).

Three outlet glaciers flow over the Transantarctic Mountains and into the MDV. The Ferrar Glacier flows from the East Antarctic Ice Sheet and reaches the coast, while the Taylor and Upper Wright Glaciers terminate on land approximately 50 to $75 \mathrm{~km}$ before the coast (Denton et al., 1993). Alpine glaciers, which form and persist through accumulation of wind-blown snow from the Polar Plateau, are found in hanging valleys that are elevated in the walls of the main valleys (Marchant and Head, 2007).

Elevation of the MDV ranges from sea level at the coast to $2000 \mathrm{~m}$ above sea level on the Polar Plateau. The climate of the MDV varies with elevation and distance inland. The regions are classified into three moisture zones that decrease in humidity, precipitation, and temperature from subxerous, to xerous, and ultraxerous (Campbell and Claridge, 1969). Lower elevation coastal regions of the MDV are subxerous, and experience average air temperature, relative humidity, and annual precipitation of approximately $-17^{\circ} \mathrm{C}, 75 \%$, and nearly $80 \mathrm{~mm}$ water equivalent, whereas the highelevation inland areas are classified as ultraxerous, and experience approximately $-27^{\circ} \mathrm{C}$ average air temperature, $45 \%$ relative humidity, and nearly $10 \mathrm{~mm}$ water equivalent (Marchant and Denton, 1994). The xerous zone is intermediate between the subxerous and ultraxerous zones. 
Although air temperatures in the MDV remain below freezing, ground surface temperatures reach above $0^{\circ} \mathrm{C}$ in summer months due to low albedo of the surface rocks combined with continuous solar heating. The uppermost layer of soil that reaches above $0^{\circ} \mathrm{C}$ is called the active layer, the thickness of which is controlled by several factors such as surface albedo, soil color, air temperatures, rock polish, and surface roughness (Campbell and Claridge, 2006). Underneath the active layer, dry or ice-cemented permafrost, which is the layer of soil that remains annually frozen, may exist (Figure 2) (Marchant and Head, 2007; Campbell and Claridge, 2006; Bockheim et al. 2007). Ice-cemented permafrost is common throughout the MDV, but in the high-elevation valleys where temperatures and humidity are lowest, dry permafrost often overlies ice-cemented permafrost. The depth beneath the surface to which ice-cemented permafrost is found is called the ice table.

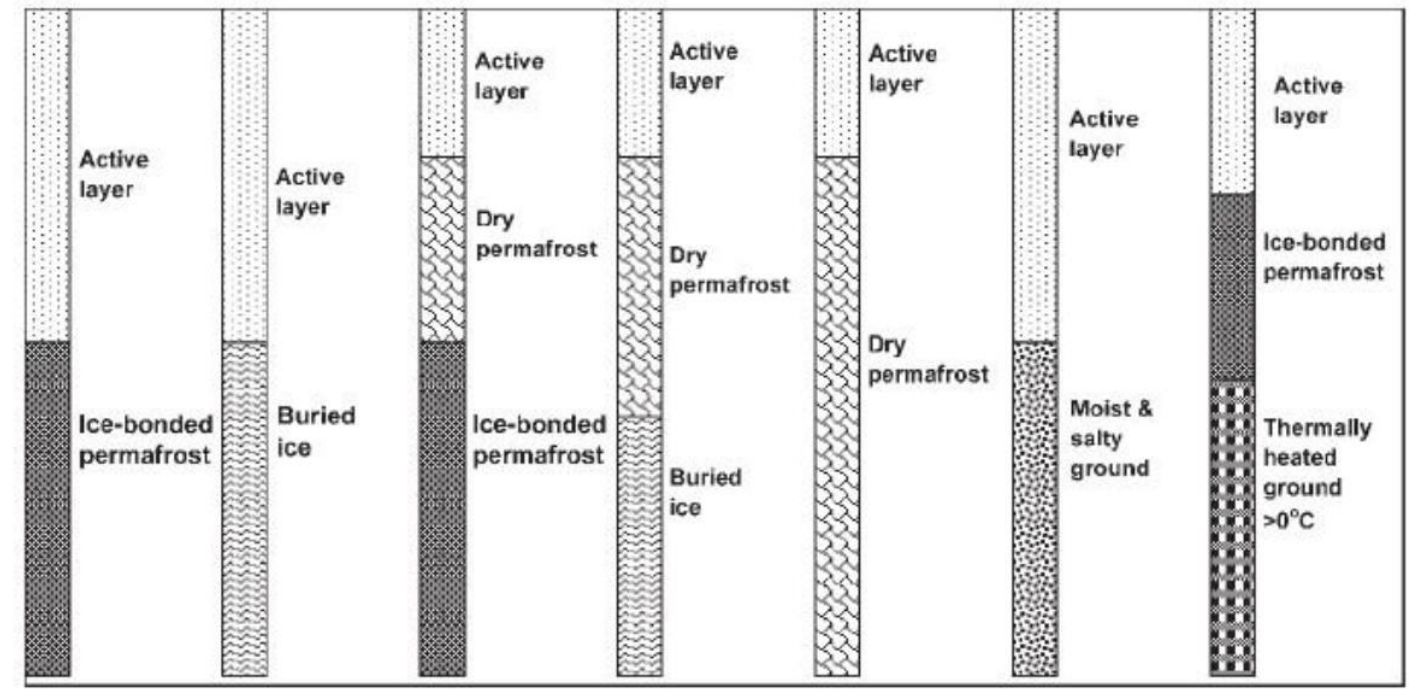

Figure 2: Types of permafrost profiles in the McMurdo Dry Valleys. From Campbell and Claridge (2006).

Ground surfaces in the MDV typically show advanced desert pavement formation and polygonal patterned ground, which are indicative of thermal cracking and sublimation of underlying ice (Bockheim, 1990; Marchant et al., 2002). Widespread evidence of chemical and physical weathering is apparent on MDV floors, and includes features such as ventifaction, iron-oxide staining of rocks, rubifaction, and salinization (Bockheim, 1990). Because levels of evaporation exceed precipitation, salts deposited from wind-transported precipitation slowly accumulate over time, with the additional 8 
input of salts released through chemical weathering of rocks (Campbell and Claridge, 2006). Salts in the Dry Valleys generally consist of chlorides, nitrates, and sulfates,

with the main cations consisting of sodium, potassium and magnesium (Marchant and Head, 2007). High concentrations of salts, which lower the freezing temperature of water, can allow small amounts of liquid water to exist as brine, and surface liquids having been observed at temperatures below freezing temperatures in small salt-rich hollows and in rare larger amounts such as Don Juan Pond (Campbell and Claridge, 2006). Soil ages in the MDV are estimated to be between $80 \mathrm{ka}$ to $270 \mathrm{ka}$ based on U/Th dating, to as old as 7 Ma (Hendy et al., 1979; Bockheim, 1990; Bockheim 1982).

\subsection{University Valley}

University Valley is a small $1500 \mathrm{~m}$ long and $500 \mathrm{~m}$ wide hanging glacial valley located at $77^{\circ} 52^{\prime} \mathrm{S}, 163^{\circ} 45^{\prime} \mathrm{E}$ approximately $450 \mathrm{~m}$ above the floor of Beacon Valley (1600 to $1800 \mathrm{~m}$ above sea level), located in the Quartermain Range of the MDV (Figure 1 and Figure 3). Located in the ultraxerous zone, the average annual air temperature is $-25^{\circ} \mathrm{C}$, with ground surface temperatures occasionally reaching above $0^{\circ} \mathrm{C}$, resulting in an active layer that is generally less than $10 \mathrm{~cm}$ below the surface (McKay et al., 1998). A layer of dry permafrost lies below the active layer above the ice table (Marinova et al., 2013). At the head of the valley is a small alpine glacier that is sustained by wind-blown snow (Figure 4) (Chinn, 1980). 


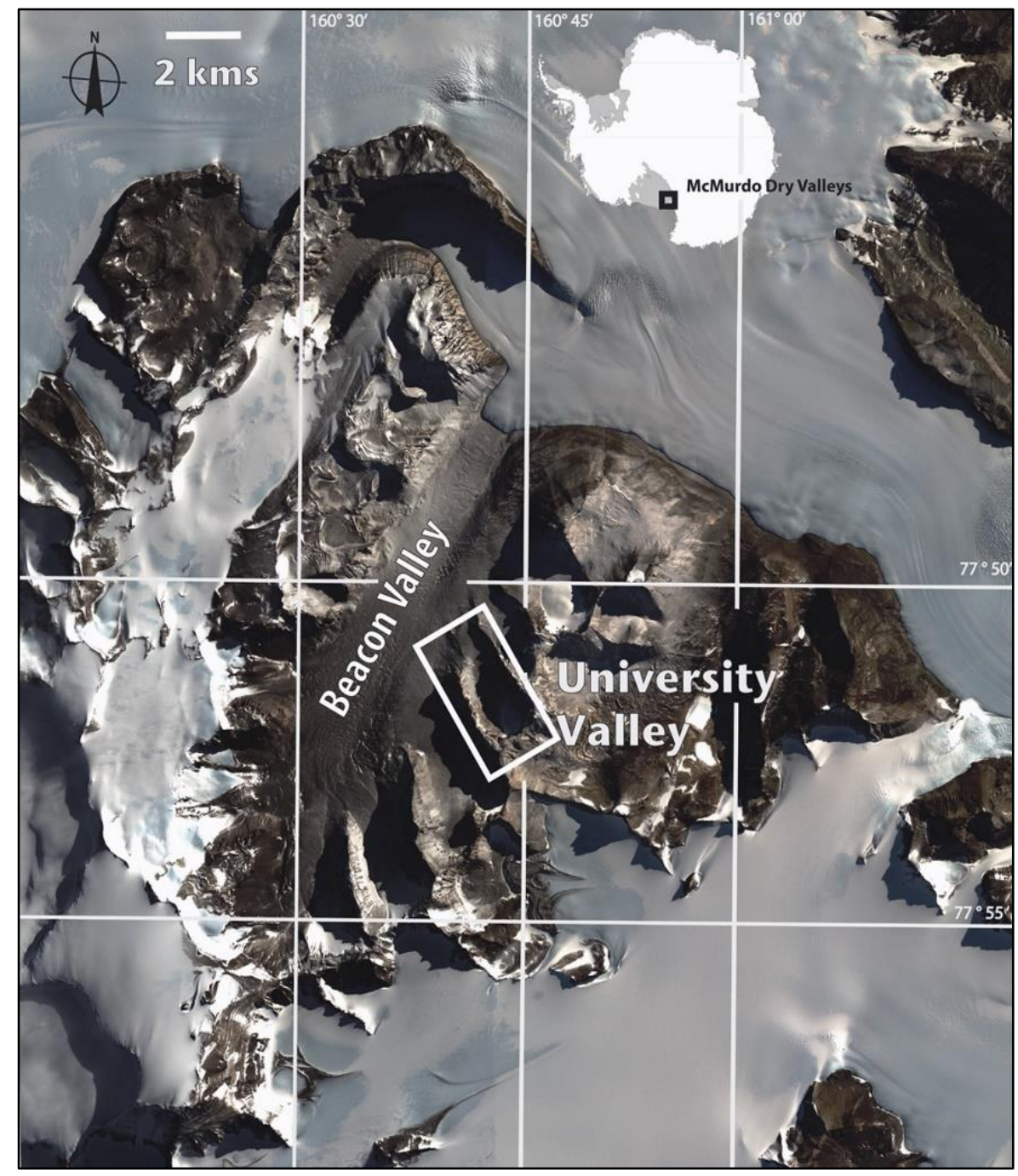

Figure 3: Landsat image of University Valley within the McMurdo Dry Valleys. From Heldmann et al. (2013). 


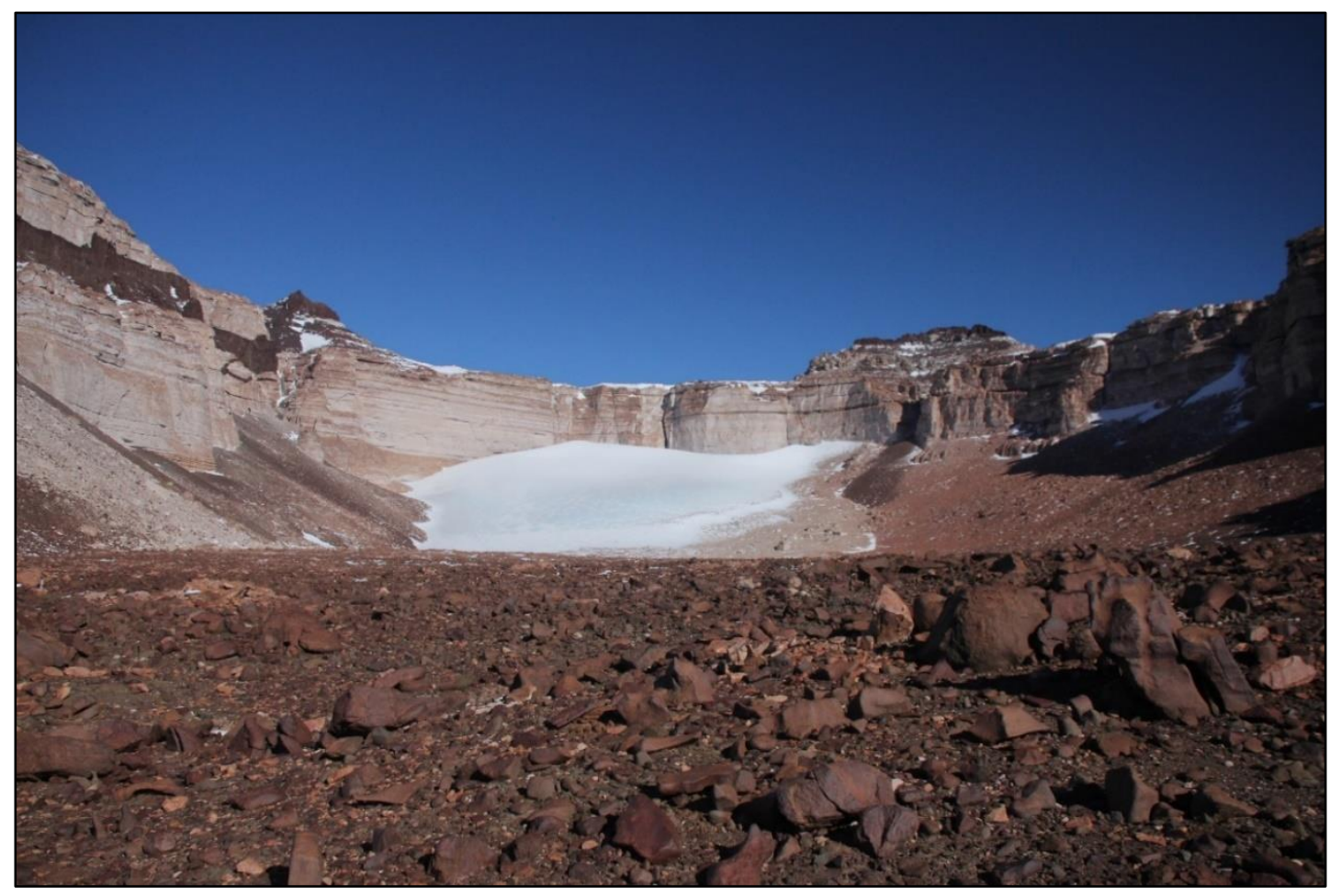

Figure 4: Photo of University Valley looking up valley toward the glacier. North facing wall is on the right. Courtesy of Alfonso Davila (2009).

The local geology in University Valley consists of Devonian to Triassic age sedimentary rocks of the Beacon Supergroup and intrusive dykes and sills of Jurassic age Ferrar Dolerite (Barrett, 1981; Elliot and Fleming, 2004). Undifferentiated till and alpine drift blanket the valley floor, scattered with rust-covered rocks and boulders, with colluvium and scree slopes along the base of the valley walls (Figure 4, Figure 5, Figure 7).

Well-formed polygonal patterned ground characterizes the valley floor (Figure 5). These sand-wedge polygons form where sediment overlies ice-cemented permafrost due to the sublimation and thermal cracking of icy sediments, and the size of these polygons is tied to the depth of the ice table (Mellon et al., 2013; McKay, 2009). Over time, deep troughs form where cracks cause increased rates of sublimation, which outline sediment-covered mounds of ice (Marchant et al., 2002; Marchant and Head, 2003). 


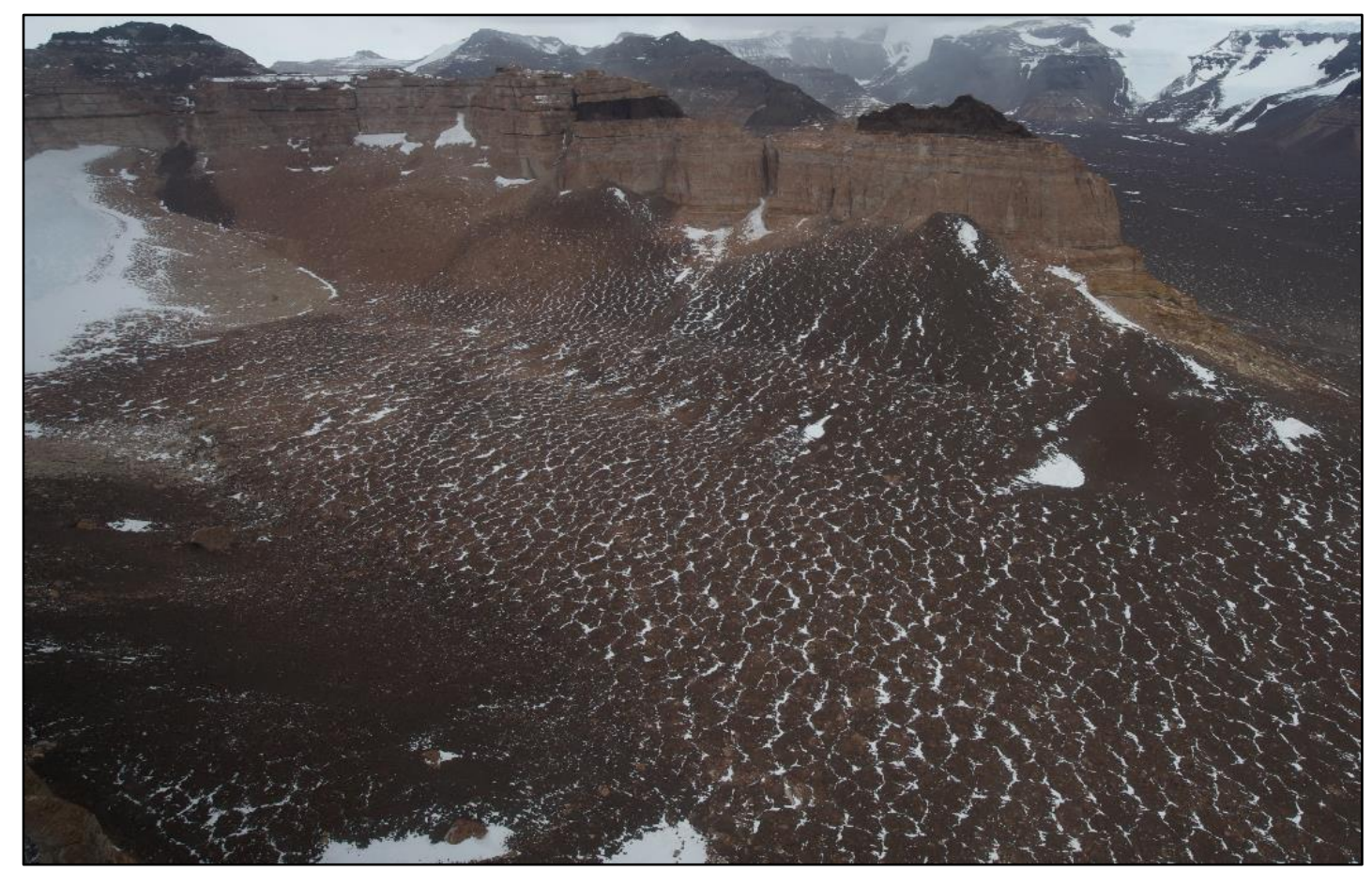

Figure 5: Photo looking down at the floor of University Valley showing polygonal patterned ground. Courtesy of Alfonso Davila (2009).

In University Valley, McKay (2009) found that the depth to the ice table generally increases as a function of distance from the glacier, with variations in ice table depth likely influenced by factors such as snow recurrence, air temperature, amount of solar radiation, ground surface albedo, and available moisture (McKay, 2009; Campbell and Claridge, 2006). At the foot of the glacier, ice table depth is as shallow as $1 \mathrm{~cm}$, which increases to over $35 \mathrm{~cm}$ depth $500 \mathrm{~m}$ away from the glacier near the mouth of the valley (Figure 6) (McKay 2009, Marinova et al., 2013). Based on the timescale required for polygon development, Mellon et al. (2014) have proposed that the ice table has been stable at its current depth below the surface for more than $10 \mathrm{ka}$. 


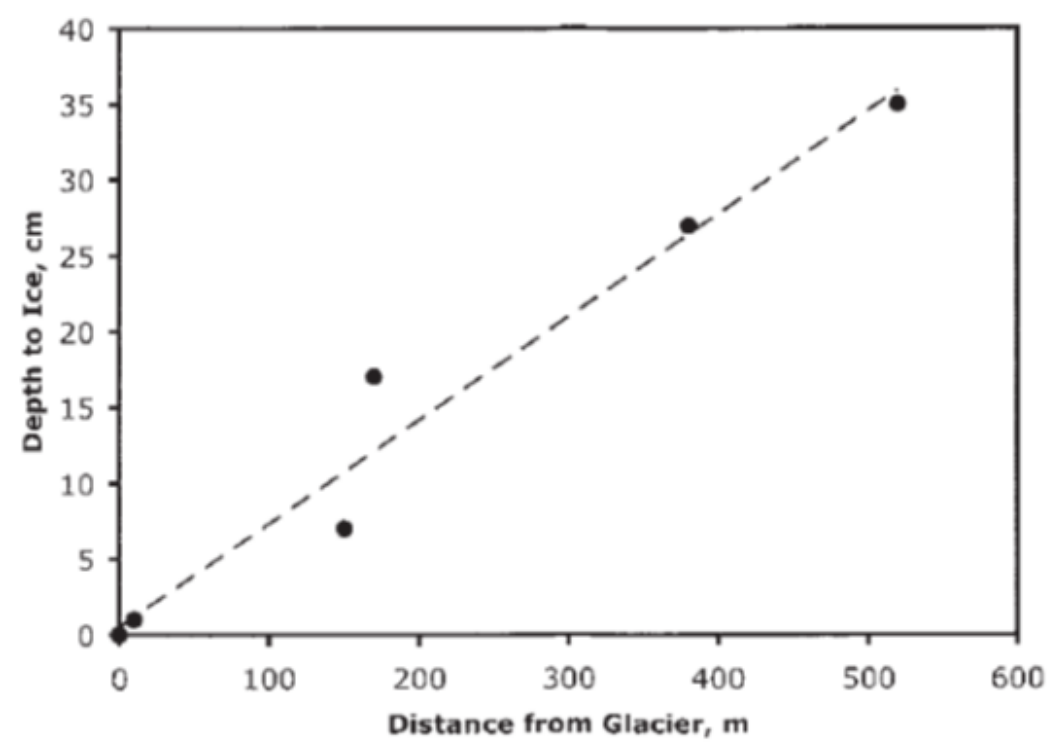

Figure 6: Depth to ground ice as a function of distance from the glacier in University Valley, as measured in January 2008. From McKay (2009).

Using ground surface temperature measurements combined with potential incoming solar radiation, Lacelle et al. (2016) classified three ground surface temperature zones in University Valley (Figure 7). In the perennially cryotic zone, ground surface temperatures remain below $0^{\circ} \mathrm{C}$ all year round. In this zone, surface melting of snow patches does not occur and hydrologic processes occur solely through vapor diffusion (Lacelle et al., 2013; Fisher and Lacelle, 2014). In the seasonally non-cryotic zone, ground surface temperatures rise above $0^{\circ} \mathrm{C}$ for at least a few hours during cloudless summer days. In this zone, small amounts of transient liquid water are possible from melting of sporadic snow blown into the valley from coastal regions. The Intermediate zone is the transition zone between the perennially cryotic zone and the seasonally non-cryotic zone, where surface temperatures and water phase may exist under either of the two zone conditions. 

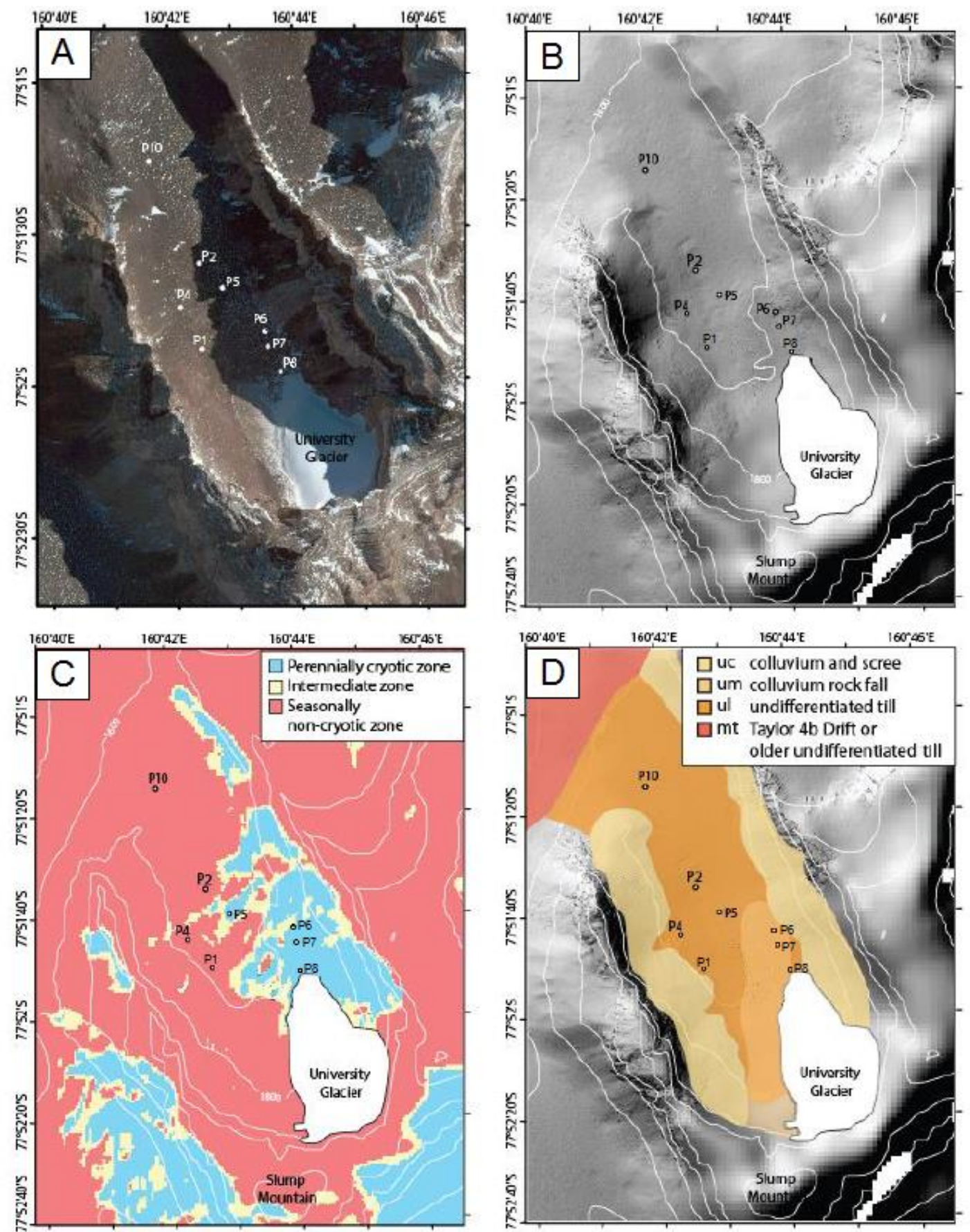

Figure 7: Features of University Valley. (A) Aerial image of University Valley with sampling locations. (B) Hillshade image with digital elevation model. (C) Ground surface temperature zones derived from ground surface temperatures and potential incoming solar radiation. (D) Surficial sediment covers in University Valley. Contour lines are at 100 m intervals. Modified from Lacelle at al. (2016). 


\section{Chapter 3. Theoretical background}

\subsection{Sediment characteristics}

Physical characteristics of sediment are important indicators of weathering processes and spatial transport. As rocks are continuously subjected to weathering over time, they break down into smaller grains that are imprinted with distinguishing features that are indicative of different physical weathering processes (Boggs, 2009). Grain size, grain morphology, sediment porosity, and sediment composition are features that will be explored in University Valley to understand the sedimentation processes within the Dry Valleys.

\subsubsection{Grain size}

Grain size analysis of sediments can be used to estimate wind strength and spatial transport in the Dry Valleys (Boggs, 2009). Because fine grain sediments are easily transported by wind and water, sediments in the fine fraction may originate from nonlocal sources due to remobilization; with decreasing grain size, the distance that particles can be transported increases (Boggs, 2009; Syvitski, 1991). Therefore, measuring grain size of sediments in University Valley will help determine the modes of deposition and degree of spatial transport.

\subsubsection{Grain morphology}

Grain morphology is the physical shape of individual sediment grains, which can be modified during sediment transport or after deposition (Boggs, 2009). Grain morphology generally considers two main factors: roundness and sphericity. Grain roundness refers to the sharpness of the corners of a grain surface, and sphericity refers to the degree to which the grain is sphere-shaped (Wadell, 1932). As sediment grains are transported and undergo saltation or repeated wave action over time, grain edges become smoother as sharp edges become chipped off and worn away. In contrast, cementation of grains after deposition can create new grain surfaces and increase the 
sharpness of grain edges, causing grains to become less round (Boggs, 2009). A sediment grain is considered to exhibit the highest degree of rounding if all edges are smooth and round (Figure 8). As sediment grains are continually transported, the shape of the grain becomes more spherical, and is considered to have the highest degree of sphericity when its shape is that of a perfect sphere (Figure 1) (Boggs, 2009). Analysis of grain morphology in University Valley will determine the degree of spatial transport and material recycling within the valley.

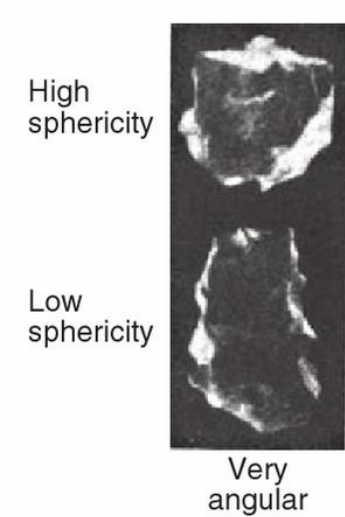

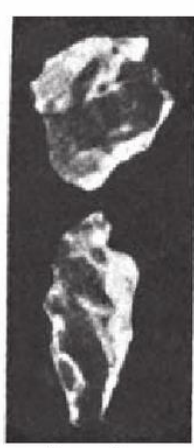

Angular

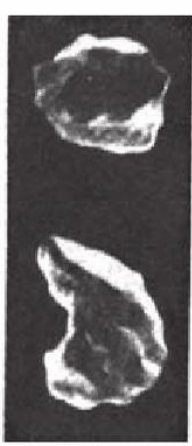

Subangular

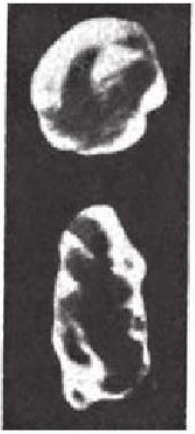

Subrounded

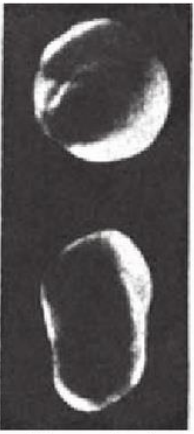

Rounded

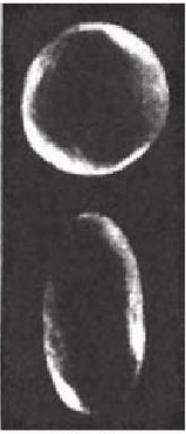

Well rounded

Figure 8: Images of sediment grains portraying different degrees of roundness and sphericity. From Boggs (2009) Petrology of Sedimentary Rocks, p. 41, Fig. 2.12., after Powers (1953) A new roundness scale for sedimentary particles: J. Sediment. Petrol., 23, Fig. 1, p. 118.

\subsubsection{Sediment porosity}

Porosity is an important sediment characteristic which can influence how the sediment and soil profile develops over time. Sediment porosity is the ratio of pore space to the total volume of sediments, which can be affected by other sediment characteristics such as grain size, grain sorting, and depositional processes such as grain packing (Boggs, 2006). The orientation, size, and interconnection of pore spaces can control the movement of water through the soil profile (Burt and Williams, 1976; Boggs, 2006). In frigid environments, sediment porosity may possibly influence the growth and distribution of ground ice (Burt and Williams, 1976). Measuring porosity of sediments in University Valley is important to understanding the movement of 
transient liquid water, as well as the translocation of clays and soluble ions throughout the soil profile.

\subsubsection{Sediment composition}

Sediment composition can be useful for identifying source rocks, degree of chemical weathering, or maturity of sediments (Boggs, 2006). In general, sediments tend to have similar composition to their source rocks. However, as chemical weathering occurs, sediment composition can change over time (Nichols, 2009). Minerals that form at high temperatures (e.g. olivine) are unstable at temperature and pressure conditions at the earth surface, and are subsequently more susceptible to degradation by the atmosphere than stable minerals that form at lower temperatures (e.g. quartz) (Figure 9) (Boggs, 2006; Nichols, 2009).

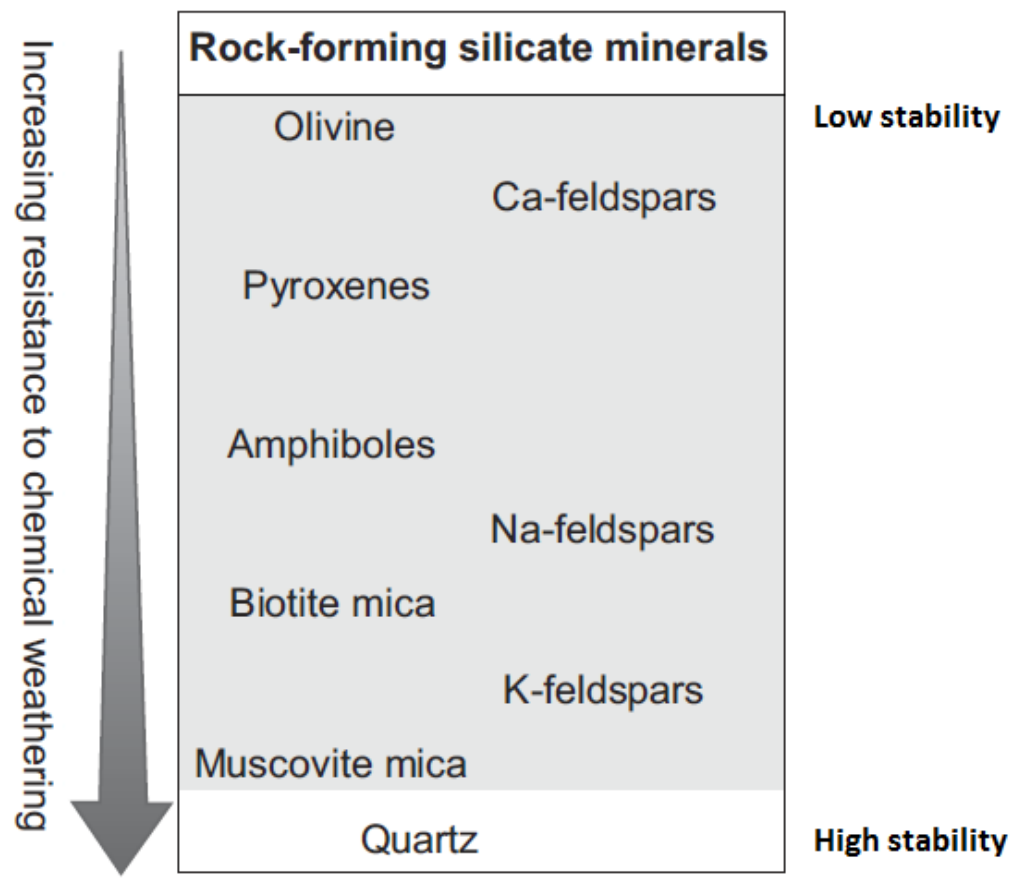

Figure 9: The relative stability of common silicate minerals in order of increasing resistance to chemical weathering. Modified from Nichols (2009) Sedimentology and Stratigraphy, p. 92, Fig 6.6. 
As chemical weathering occurs, unstable minerals are destroyed as new minerals are created such as clays and metal oxides (Boggs, 2006; Nichols, 2009). Over time, composition of the sediments becomes dominated by quartz as unstable minerals are chemically broken down and removed, leaving behind only stable minerals that are more resistant to chemical weathering. Therefore, maturity of the sediments can be extrapolated from sediment composition, since relative quartz content increases with increasing sediment maturity (Boggs, 2006; Nichols, 2009). Analyzing sediment composition in University Valley will determine the source(s) and maturity of the sediments, which are critical to understanding chemical weathering in the valley.

\section{$\underline{\text { Recent sediment characteristics research in the Dry Valleys }}$}

Many studies have focused on the physical breakdown of rocks and boulders in the Dry Valleys and have established that the main modes of boulder cracking and disintegration are horizontal and vertical jointing (Campbell and Claridge, 1987), expansion of salts in rock pores and joints (Selby, 1971; Selby and Wilson, 1971), and strong temperature differentials on rock surfaces (e.g. Putkonen et al., 2013; McFadden et al., 2005; Hall, 1999; Hall and Andre, 2003; Hall et al., 2008; McKay et al., 2009; Eppes and Griffing, 2010).

Grain size studies have found that sand, silt, and dust-sized particles represent firstorder weathering of parent material in the Dry Valleys, and that the observed abundance of fine materials is due to strong and persistent wind activity (e.g. Deuerling, 2010; Lancaster, 2002; Speirs et al., 2008; Sepälä, 2004; Marra 2015). Gillies et al. (2015) found that these winds cause frequent saltation activity of sandsize particles, lasting up to 24 continuous hours at a time. However, findings by Witherow et al. (2006) suggest that overall eolian redistribution rates in the Dry valleys are amongst the lowest of all desert environments, which support findings by Putkonen et al. (2013) that the main mode of particle transport in the Dry Valleys appears to be gravity instead of wind. Therefore, while it has been observed that eolian mobilization of particles in the Dry Valleys is high, spatial transport of particles in the Dry Valleys seems to be localized. 
Though recent studies in the Dry Valley have not directly focused on sediment structure or porosity, Lacelle et al. (2013) measured ground ice in University Valley that occurred in amounts that exceed calculated natural pore-filling capacity of sandsize sediments, indicating that processes such as micro-cracking from thermal contraction and expansion can modify the structure of sediments, subsequently affecting ground ice growth. Additionally, Dickinson et al. (2012) observed evidence of clay translocation in the subsurface using petrographic thin sections of sediment samples from Table Mountain, which provide insights into small-scale sediment structures and suggest that small degrees of water activity can occur in the subsurface.

These studies leave questions regarding ages of the sediments, rates of sediment accumulation, subsurface translocation processes, and the interactions between physical and chemical weathering processes and their effects on sediment evolution. This thesis investigates these questions by combining principles from these previous studies with OSL dating of the subsurface sediments.

\subsection{Optically Stimulated Luminescence dating}

Optically Stimulated Luminescence (OSL) dating is a method that measures the amount of time elapsed since mineral grains such as quartz and feldspar were last exposed to light, which determines the burial age of the sediments. This method of age dating works on the basis that electrons, when provided with enough energy, are able to move between molecular energy bands (Preusser et al., 2008).

In nature, electrons within buried quartz and feldspar grains are exposed to energy in the form of naturally occurring radiation from radioactive decay within the mineral and from the surrounding sediment, as well as from radiation of incoming cosmic rays (Preusser et al., 2008). Some electrons are exposed to enough radiation to allow them to move from their normal valence bands to conduction bands, where they can then move freely throughout the crystal lattice. Due to impurities or structural defects in the crystal lattice, some electrons are unable to reach the next energy band and become 
captured at an energy level between energy bands, called electron traps. These trapped electrons are the OSL signal.

Over time, the number of trapped electrons increases with continuing exposure to natural radiation (Preusser et al., 2008). When mineral grains are exposed sunlight during transportation, all electron traps are emptied as sunlight provides the required energy to stimulate the electrons, allowing them to break free of electron traps and recombine within molecular energy bands (Preusser et al., 2008). This emptying of electron traps is called "resetting" of the mineral, and thus the mineral at that time has been cleared of any OSL signal. After these minerals are buried by sediment and are no longer exposed to sunlight, the OSL signal begins to accumulate (Figure 10) (Preusser et al., 2008). Depending on sediment grain size, burial depths as little as 4 $\mathrm{mm}$ in soil or up to $2.9 \mathrm{~cm}$ in sand are sufficient for blocking out all light (Tester and Morris, 1987).

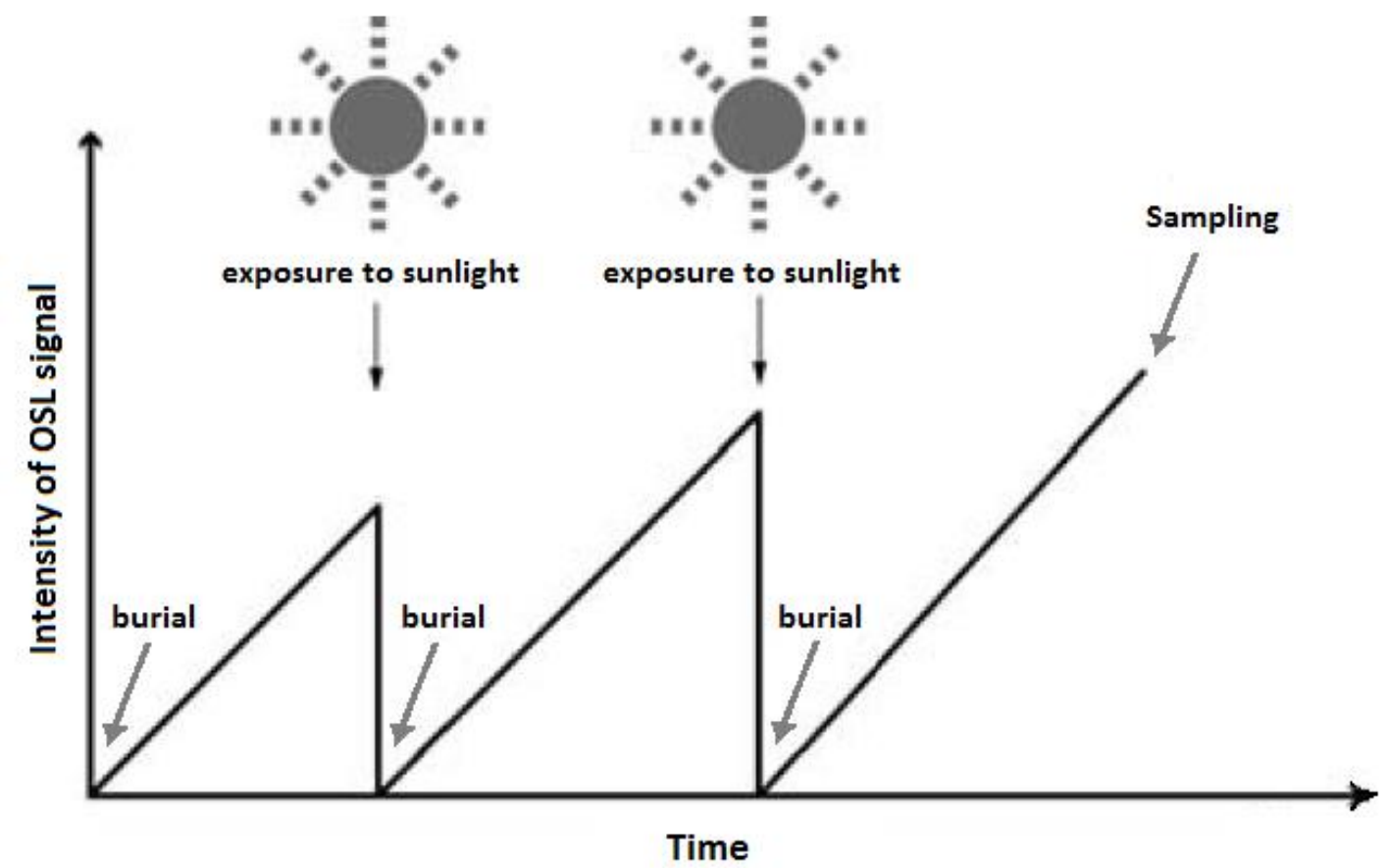

Figure 10: Schematic diagram of the accumulation of OSL signal over time. Modified from Preusser et al. (2008). 
In a dark laboratory setting, trapped electrons can be stimulated with artificial light to break free of electron traps, move to conduction bands, and then recombine within molecules. Luminescence is produced during this last stage when the electrons recombine into their normal valence bands. This luminescence is measured and then used to estimate the number of electrons that were trapped. Under the assumption that the radiation dose that the mineral receives over time is constant, the amount of time that passed since burial of the mineral can be calculated using Equation 1 (Preusser et al., 2008; Aitken et al., 1968).

$$
\text { Luminescence age }[\mathrm{ka}]=\frac{\text { Equivalent dose }[\mathrm{Gy}]}{\text { Total ambient rate }[\mathrm{Gy} / \mathrm{ka}]}
$$

Where:

Luminescence age is the time elapsed since burial of the sediments (in ka),

Equivalent dose is the amount of radiation measured in the laboratory required to produce the amount of measured luminescence, which is equal to the amount of radiation that the sample received in nature (in Gy, which is the unit of ionizing radiation dose, where $1 \mathrm{~Gy}=1 \mathrm{~J} / \mathrm{kg}$ ),

Total ambient dose rate is the total radiation that the sample receives per ka from within the mineral, from the surrounding sediment, and from cosmic rays (in Gy/ka). Because water attenuates incoming radiation and thereby reduces the amount of radiation that the sample receives over time, the ambient dose rate factors in measured water content of the sediments.

This calculation assumes that the radiation dose that the mineral receives over time is constant due to the long half-lives of the radioactive elements Uranium, Thorium, and Potassium (Pawlay et al., 2010). Additional detailed information regarding OSL dating methods, equations, and limitations can be found in Aitken et al. (1968), Preusser et al. (2008), and Pawlay et al. (2010).

OSL dating typically produces reliable burial ages up to maximums of $150 \mathrm{ka}$ to 200 ka, but age measurements older than $200 \mathrm{ka}$ are possible in exceptional environmental 
conditions (Pawlay et al., 2010). In the Dry Valleys, OSL has been used only rarely because many surfaces have been dated to be millions of years old using surface exposure dating methods such as cosmogenic Helium and ${ }^{10} \mathrm{Be}$, as well as ${ }^{40} \mathrm{Ar} /{ }^{39} \mathrm{Ar}$ dating of volcanic ashes (e.g. Schäfer et al., 1999; Margerison et al., 2005; Marchant et al., 1996). Therefore, it has been assumed that sediments in much of the Dry Valleys are out of OSL age range. However, eolian-dominated environments are ideal for the application of OSL dating due to the transport processes of sediment grains (e.g. creep, saltation, etc.), which ensure complete resetting of the OSL signal by exposure to sunlight prior to burial (Preusser et al., 2008; Duller, 2008). Thus, in University Valley where eolian activity is high, sediments have the possibility of being within OSL age range.

Currently, the rates of sedimentation processes occurring in the Dry Valleys are unknown. Successful OSL dating in University Valley will put age constraints on these sediments, which can then be used to determine the rates at which these processes occur.

\section{Recent OSL research in the Dry Valleys}

Of the few studies in the Dry Valleys that use OSL dating, none of have focused on sedimentation processes. Zamora (2013) and Ramsey (2014) dated alluvial fans in Wright Valley and McKelvey Valley and found sediment ages to be $1 \mathrm{ka}$ to $106 \mathrm{ka}$; these studies correlated melting events along margins of the East Antarctic Ice Sheet to periods of increased insolation. Bristow et al. (2010) dated sand dune deposits in Lower Victoria Valley to determine dune migration rates, and found dune ages ranging from $0 \mathrm{ka}$ to $1.3 \mathrm{ka}$. In University Valley, Lacelle et al. (2013) dated one sediment core to estimate the age of ground ice formation within the sediments, which were measured to be up to $170 \mathrm{ka}$. Although Lacelle et al. (2013) did not directly study sedimentation processes, ages from this permafrost core are the first step to understanding sedimentation rates in University Valley. Because the sediment core in Lacelle et al (2013) was sampled from near the glacier where sediments are assumed to be youngest in the valley, this thesis obtained OSL ages of several sediment cores sampled from throughout the valley and at varying depths. Wide spatial distribution 
of OSL-dated cores is crucial to determining sediment ages for the entire valley and the general rate of sedimentation processes. This study increases the applications of OSL in the Dry Valleys, and increases the OSL-dated age range in the Dry Valleys.

\subsection{Meteoric ${ }^{10} \mathrm{Be}$}

Beryllium-10 $\left({ }^{10} \mathrm{Be}\right)$ is a rare radioactive isotope of Beryllium that is formed by nuclear reactions induced by cosmic radiation (Lal, 1991). With a half-life of $\sim 1.39 * 10^{6}$ years,

${ }^{10} \mathrm{Be}$ is used to understand earth surface processes (Dunai, 2010). ${ }^{10} \mathrm{Be}$ can be divided into two different types: in-situ ${ }^{10} \mathrm{Be}$ and meteoric ${ }^{10} \mathrm{Be}$. In-situ ${ }^{10} \mathrm{Be}$ is produced within minerals on the ground surface and in the shallow subsurface, and is commonly used for surface exposure dating. Meteoric ${ }^{10} \mathrm{Be}$ is produced in the atmosphere mainly by the spallation of oxygen atoms caused by high-energy cosmic rays reacting with the atmosphere (McHargue and Damon, 1991; Tuniz et al., 1983; Nishizumi et al., 1984; Gosse and Phillips, 2001); due to its widespread occurrence and high affinity for clay, meteoric ${ }^{10} \mathrm{Be}$ is commonly used as a tracer for erosion, soil residence times, and movement of water throughout the soil profile.

Meteoric ${ }^{10} \mathrm{Be}$ has a residence time of about 1 to 2 years in the atmosphere before it is deposited onto the earth surface by wet precipitation (e.g. rain or snow) or dry fallout (Stuiver, 1994; Willenbring and von Blanckenburg, 2010). Because precipitation and dry fallout are processes that occur globally, there is negligible variation in the meteoric ${ }^{10} \mathrm{Be}$ flux onto the earth surface within spatial distances of a few hundred kilometers. Instead, large variations in ${ }^{10} \mathrm{Be}$ flux to the earth surface, which are a result of differing orientation of the earth's magnetic field lines, occur primarily with significant changes in latitude (Darvill, 2013; Dunai, 2001; Masarik and Beer, 1999). At the equator, earth's magnetic field lines are perpendicular to the angle of incoming cosmic rays, which causes greater deflection of cosmic rays than at the poles where the magnetic field lines are parallel to the angle of incoming cosmic rays (Figure 11) (Darvill, 2013). Therefore, the production and flux of ${ }^{10} \mathrm{Be}$, which rely on cosmic rays entering the atmosphere, decrease as a function of distance from the geomagnetic poles (Figure 12) (Masarik and Beer, 1999). 


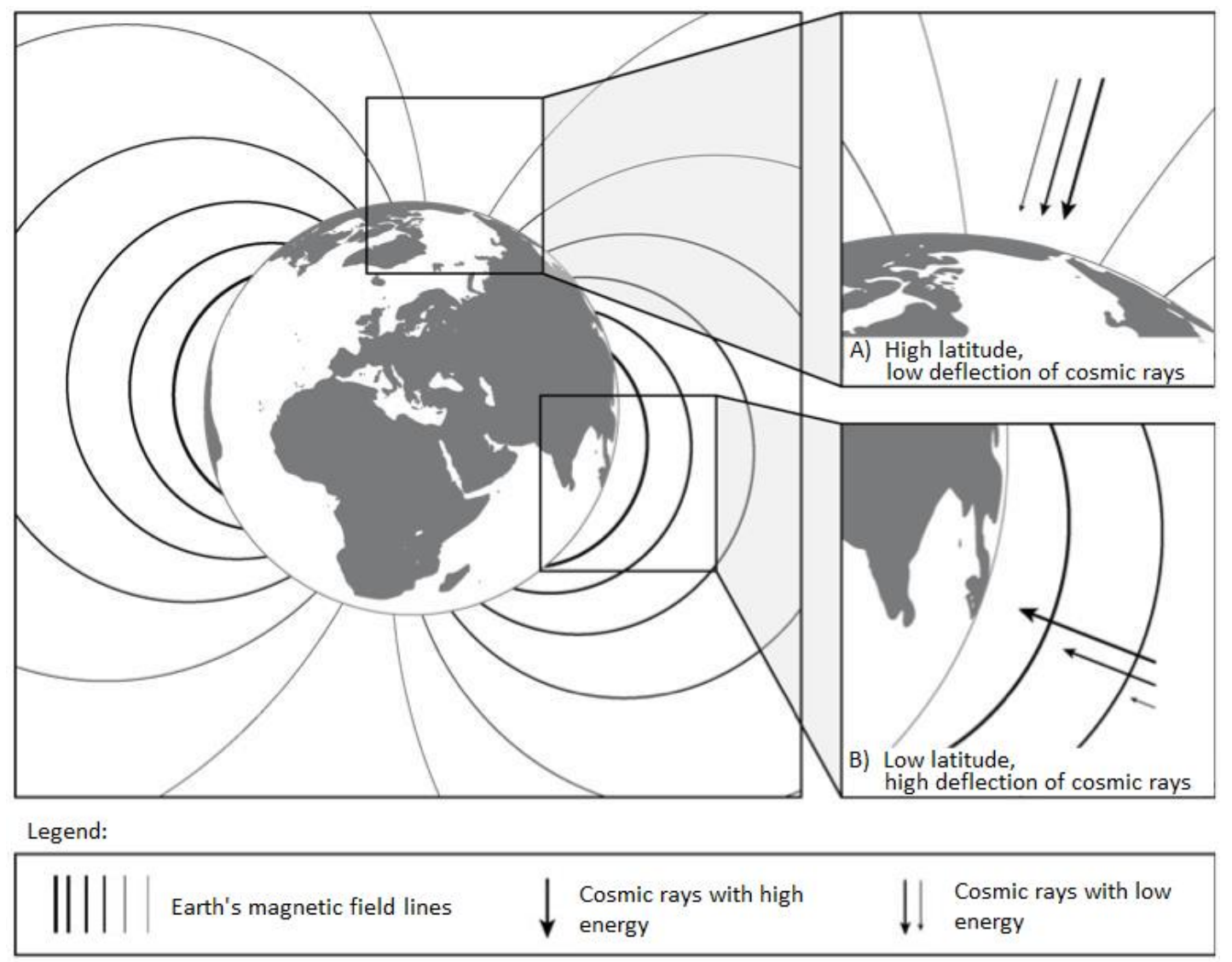

Figure 11: Effects of the orientation of earth's magnetic field lines on incoming cosmic rays. A) Magnetic field lines at high latitudes are parallel to the angle of incoming cosmic rays and therefore less deflective of cosmic rays. B) Magnetic field lines at low latitudes are perpendicular to the angle of the incoming cosmic rays and therefore more deflective of cosmic rays. Modified from Darvill (2013). 


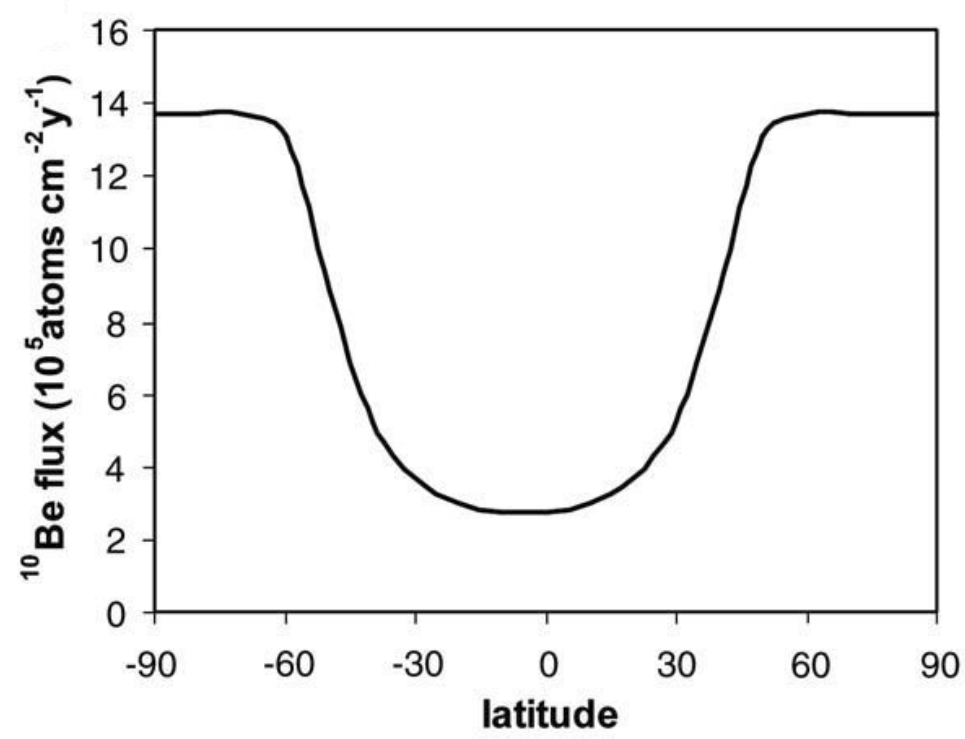

Figure 12: Latitudinal variation of meteoric ${ }^{10}$ Be flux onto the earth surface. From Masarik and Beer (1999).

While in the atmosphere, and after deposition onto the earth surface, meteoric ${ }^{10} \mathrm{Be}$ quickly adsorbs onto grain surfaces and especially onto fine particles such as dust ad clays. Meteoric ${ }^{10} \mathrm{Be}$ is generally only soluble in very acidic conditions ( $\mathrm{pH}$ values less than $\sim 3.5$ ), and so it remains strongly affixed to fine particles and grain surfaces in most conditions (You et al., 1989). Therefore, because these fine particles are easily translocated by liquid water, meteoric ${ }^{10} \mathrm{Be}$ measurements can be used to trace and understand the movement of water throughout the soil profile, which is especially important in hyper-arid regions such as the Dry Valleys where liquid water is scarce.

\section{$\underline{\text { Recent meteoric }}{ }^{10} \mathrm{Be}$ research in the Dry Valleys}

Few studies have been conducted in the Dry Valleys that investigate meteoric ${ }^{10} \mathrm{Be}$. Valletta et al. (2015) used ${ }^{10} \mathrm{Be}$ to date lake sediments at Friis Hills. Dickinson et al. (2012) calculated minimum closure ages at Table Mountain of 6 Ma when sediments became permanently frozen, and observed evidence of clay translocation. Schiller (2006) measured meteoric ${ }^{10} \mathrm{Be}$ profiles in Wright Valley and found that ${ }^{10} \mathrm{Be}$ deposition in Antarctic soils appears to be independent of precipitation due to ${ }^{10} \mathrm{Be}$ being deposited by both snow and dry aerosols from the atmosphere. Steig (1995, 1996, 2000) measured ${ }^{10} \mathrm{Be}$ concentrations in snow at Taylor Dome and obtained 
separate flux rates for ${ }^{10} \mathrm{Be}$ deposited by snow $\left(\sim 0.3 * 10^{5}\right.$ atoms $\left./ \mathrm{cm} / \mathrm{a}\right)$ and ${ }^{10} \mathrm{Be}$ deposited from dry fallout $\left(\sim 1.0 * 10^{5}\right.$ atoms/cm/a), and surmised that hyper-aridity and strong wind conditions likely prevent deposition of ${ }^{10} \mathrm{Be}$ attached to dry particles due to their constant remobilization. However, concerns have been raised about the accuracy of applying these measured flux rates from Taylor Dome, which represents an active accumulation area, to other areas of the Dry Valleys where ${ }^{10} \mathrm{Be}$ removal by decay or erosion play a role in the total ${ }^{10} \mathrm{Be}$ inventory (Dickinson et al., 2012; Graham et al. 2002; Schiller et al., 2009).

Therefore, these studies leave questions regarding how other sedimentation processes in the Dry Valleys may affect ${ }^{10} \mathrm{Be}$ incorporation into the soil profile, translocation, or profile preservation through time. This thesis will combine ${ }^{10} \mathrm{Be}$ measurements with petrographic microscopy of sediment samples to explore these aspects, and use OSL dating to estimate rates of ${ }^{10} \mathrm{Be}$ incorporation into the subsurface.

\subsection{Geochemistry of soils}

Breakdown of rocks by chemical weathering processes such as oxidation, hydrolysis, and carbonation alters the mineral composition of the rocks, creating new minerals (e.g. clays and metal oxides) and soluble salts (i.e. ions) (Boggs, 2006). Because moisture is critical to these processes, investigating geochemistry of the sediments in the Dry Valleys will increase understanding of how these processes occur in areas with limited moisture availability.

The combination of water and dissolved atmospheric gases (e.g. oxygen) can cause certain elements in minerals to oxidize and become ions, which are then removed from the crystal lattice and subsequently leached out of the mineral. These ions are then easily mobilized by water (Boggs, 2006). However, different elements are bound to the crystal lattice with different strengths, which are dependent on the element-oxygen bond strength (Figure 13). These bond strengths control how resistant different elements are to undergoing chemical reactions (Nicholls, 1963). Elements with weaker chemical bonds are most susceptible to chemical weathering, which react first 
and get leached out of minerals (as ions), followed by elements with stronger bonds. After being leached out of the minerals, ions with higher solubility tend to be washed away by water before ions with lower solubility (Nicholls, 1963).

In University Valley, the main rock types present are quartz sandstone and dolerite. Dolerite is a mafic rock and tends to rapidly oxidize and then undergo hydrolysis. The role of water in this process is often as a transporting agent that removes ions from the mineral surface, driving continued chemical weathering. Therefore, analyzing the geochemistry of sediments in University Valley indicates the intensity of chemical weathering, as well as the activity of water in the valley.

\begin{tabular}{|l|l|lll|l|}
\hline \multicolumn{3}{|c|}{ Bond } & & & Approximate relative strength \\
\hline Decreasing strength of \\
element-oxygen bond
\end{tabular}

Figure 13: Relative strengths of various element-oxygen bonds in common rockforming minerals in order of decreasing bond strength. Modified from Nicholls (1963).

\section{$\underline{\text { Recent soil geochemistry research in the Dry Valleys }}$}

In the Dry Valleys, widespread evidence of alteration and chemical weathering is apparent by the characteristic reddish-brown color of soils, rust-covered rock surfaces, and weathering rinds (e.g. Cannon, 2015; Salvatore et al., 2013, 2014). Salvatore et al. $(2013,2014)$ have shown in Beacon Valley that certain ions are preferentially moved to rock surfaces not by liquid water but due to the strong oxidation gradient. These studies show that chemical processes can persist despite the overall absence of liquid water, and that when liquid water is present it can accelerate these processes 
and assist in the removal and remobilization of leached ions and chemical alteration products.

Numerous studies have investigated ion concentration of sediments in the Dry Valleys, which found that different ion species can be derived from several separate sources. Cations are generally derived from weathering of local dolerite rocks (e.g. Dickinson and Grapes, 1997; Campbell and Claridge, 1998; Gibson, 1983). However, the major sources of anions in the Dry Valleys are from marine aerosols and snow blown in from the East Antarctic Ice Sheet, which is apparent by the patterns in the distribution of ion species that vary with elevation and distance from the coast (e.g. Ugolini and Bockheim, 2007; Gibson et al., 1983; Bao et al., 2000; Bockheim and McLeod, 2006; Salvatore et al., 2013; Witherow et al., 2006; Michalski et al., 2005; Campbell and Claridge, 1998; Dickinson and Rosen, 2003).

Patel (2013) observed evidence of chemical weathering due to liquid water, and measured the highest concentrations of ions in the form of salt in the upper few centimeters of dry sediment. Many studies observed ion concentration trends with depth that are indicative of ion migration through frozen ground by means of interfacial water layers or brine films (e.g. Dickinson, 2006; Salvatore et al., 2013; Patel, 2013; Gibson et al., 1983; Ugolini and Anderson, 1972, 1973, 1981). Fisher (1987) proposed recrystallization of ice as a mode for ions to migrate through ice and accumulate on grain surfaces, contributing to the formation of brine films that allow ions to translocate along grain boundaries. However, several studies have found that trends in ion concentration with depth disappear at the ice table, which suggests that there is limited vertical transport in the icy permafrost (e.g. Jackson et al., 2015; Dickinson and Rosen, 2003).

Due to the complexity of the different processes involved in chemical weathering, ion deposition, and ion migration through the soil profile in the extreme environment of the Dry Valleys, these processes remain poorly understood. Weathering rates, deposition rates, and the activity of water are still critical unknowns. This thesis combines geochemical analysis, meteoric ${ }^{10} \mathrm{Be}$ measurements, observations of clay 
structures in thin section, and OSL dating to better understand the nature of the chemical weathering processes in the valley. 


\section{Chapter 4. Methodology}

\subsection{Field sampling}

Two different sets of ice-cemented permafrost cores were collected from 8 different polygons along the floor of University Valley in January 2013 by researchers from the NASA Ames Research Center and the University of Ottawa (Figure 14). Because ice content can vary significantly within even small spatial differences (e.g. Lacelle et al., 2013), this study uses cores only from the polygon centers where the ice content of the sediments is most stable over time, as opposed to the shoulders of the polygons where freeze-thaw cycling and sublimation are apparent (Marchant et al., 2002; Marchant and Head, 2003). Additionally, because the depth to ice-cemented ground varies throughout the valley, a soil pit was dug at each coring site to remove the top layer of loose dry soil. The thickness of the dry surface soil layer was measured and recorded, and each sediment core was taken starting at the ice table. A $13.5 \mathrm{~cm}$ diameter Cold Regions Research and Engineering Laboratory (CRREL) corer was used to acquire the ice-cemented sediment cores (Figure 15). Each of the retrieved core segments were individually wrapped in plastic Whirl-Pak ${ }^{\circledR}$ bags. For each polygon, two cores were taken within 1 meter apart, with the intention of producing two nearly-identical sets of cores. One set of cores was shipped frozen to the University of Ottawa, Canada, and the other set was shipped frozen to the NASA Ames Research Center, USA. Both sets were stored at $-20^{\circ} \mathrm{C}$ until time of analysis. To increase the sample availability and number of analyses possible, this thesis used both core sets from the 8 different polygons. 


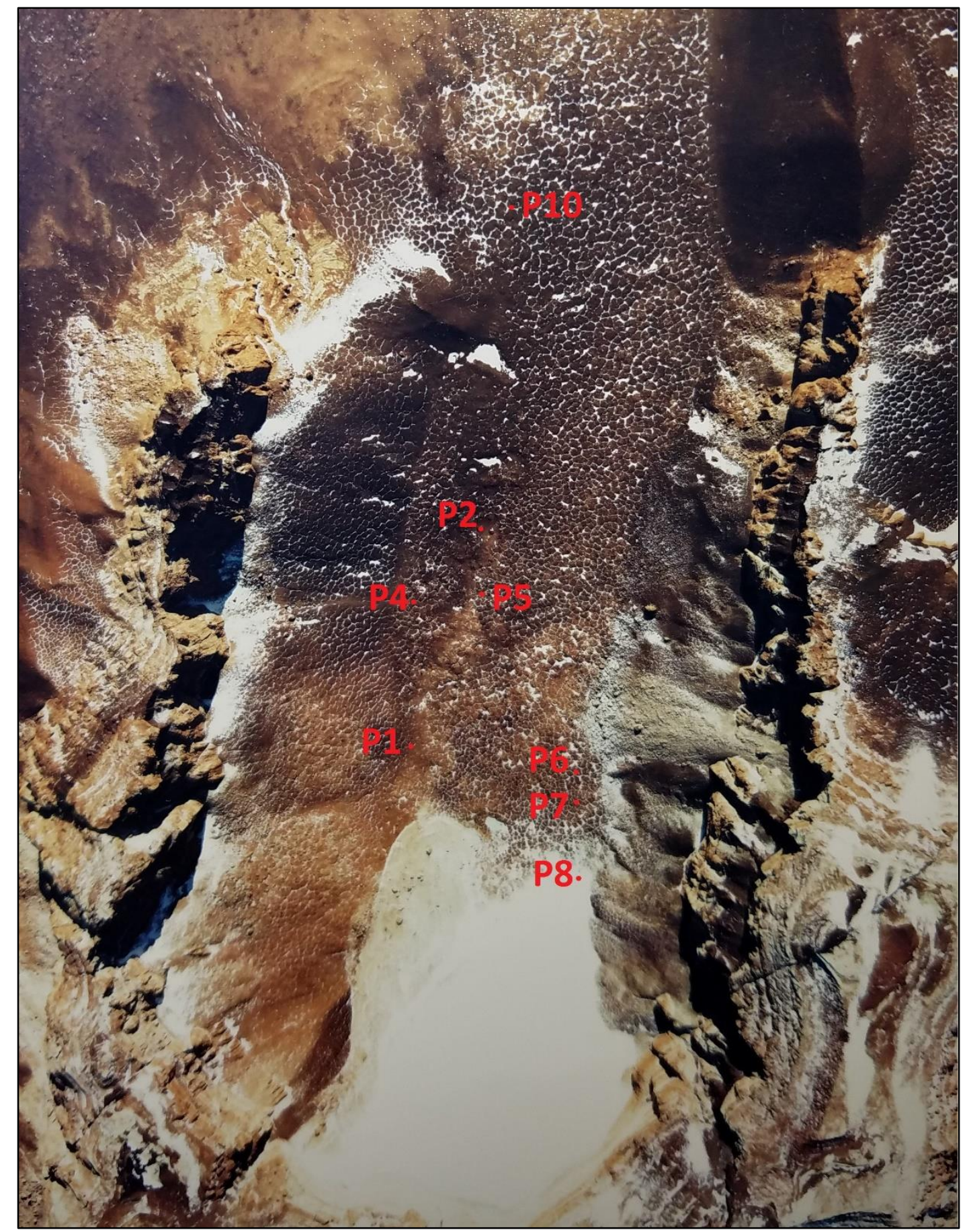

Figure 14: Aerial photograph of University Valley depicting coring locations. Modified from photo by NZ Aerial Mapping Limited for the Long-Term Ecological Research (LTER) program of Taylor Valley (photo taken November 1993). 


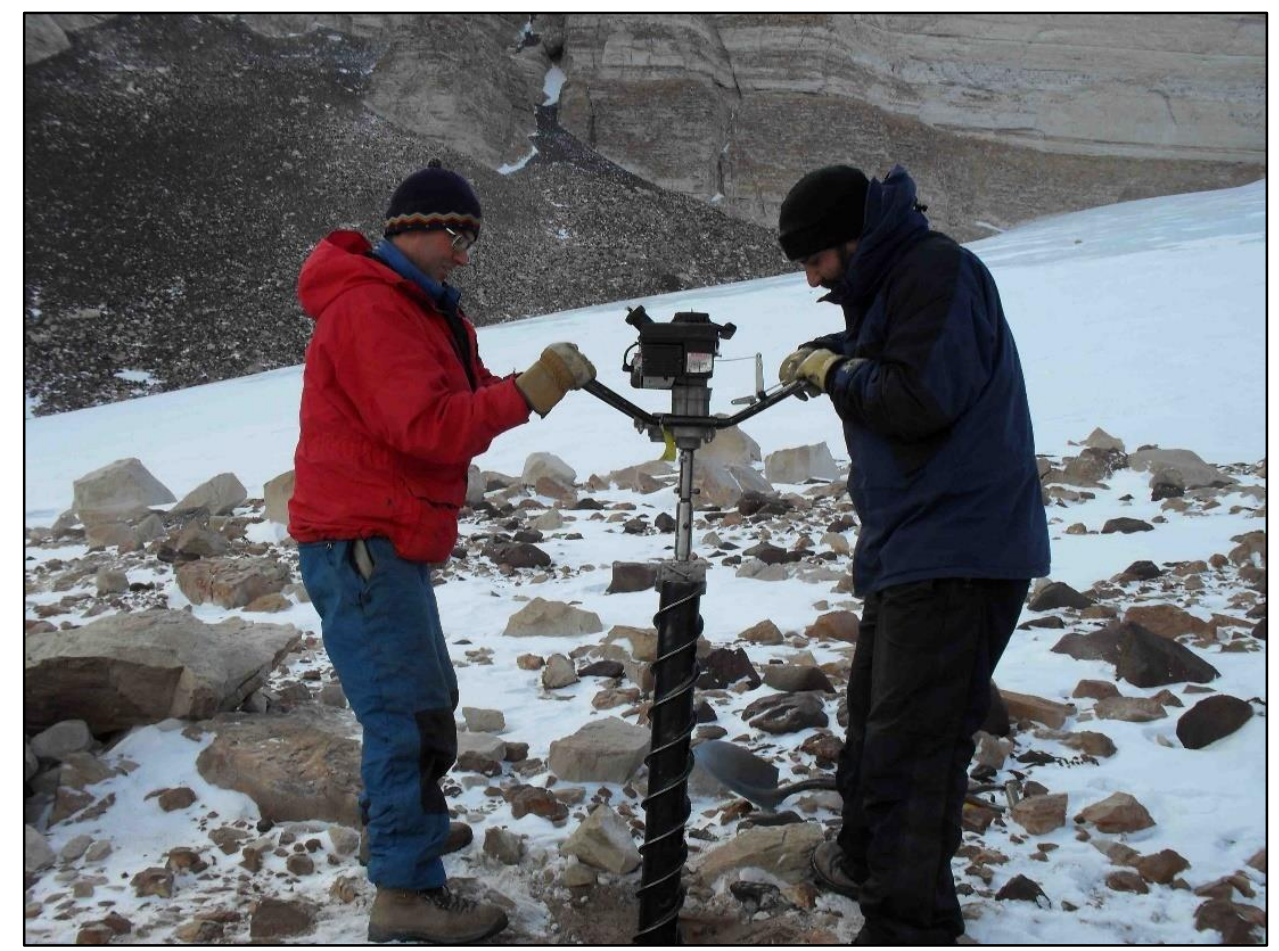

Figure 15: Photo of field sampling in University Valley. Courtesy of Denis Lacelle (2013).

\begin{tabular}{|l|l|l|l|l|l|}
\hline Core site & $\begin{array}{l}\text { Core } \\
\text { ID }\end{array}$ & $\begin{array}{l}\text { Latitude } \\
(\text { South })\end{array}$ & $\begin{array}{l}\text { Longitude } \\
(\text { East })\end{array}$ & $\begin{array}{l}\text { Ice table } \\
\text { depth }(\mathrm{cm})\end{array}$ & $\begin{array}{l}\text { Distance from } \\
\text { glacier }(\mathrm{m})\end{array}$ \\
\hline Polygon 1 & P1 & 77.865 & 160.702 & 25 & 860 \\
\hline Polygon 2 & P2 & 77.859 & 160.709 & 20 & 1076 \\
\hline Polygon 4 & P4 & 77.862 & 160.704 & 50 & 943 \\
\hline Polygon 5 & P5 & 77.861 & 160.715 & 19 & 566 \\
\hline Polygon 6 & P6 & 77.863 & 160.722 & 25 & 545 \\
\hline Polygon 7 & P7 & 77.864 & 160.723 & 22 & 466 \\
\hline Polygon 8 & P8 & 77.865 & 160.726 & 2 & 304 \\
\hline Polygon 10 & P10 & 77.853 & 160.696 & 16 & 1771 \\
\hline
\end{tabular}

Table 1: Information of the 8 sampling sites. 


\subsection{Optically Stimulated Luminescence dating}

To obtain wide spatial distribution of sediment deposition ages along the valley, OSL dating was performed on three different polygons to produce three age-depth profiles with three to five ages per profile. The selected polygons were: Polygon 8 from the head of the valley near the glacier, Polygon 1 from the middle of the valley, and Polygon 2 near the mouth of the valley. This widespread distribution of polygons creates a transect of University Valley and allows for the possibility of observing spatial trends as well as trends with depth.

\section{$\underline{\text { On-site preparation at the NASA Ames Research Center }}$}

Because the cores were ice-cemented, all sample preparation needed to be performed on-site at the NASA Ames Research Center before the samples could be mailed to Victoria University of Wellington for age measurements. Apart from cutting the frozen cores with a circular saw, which was done by David Willson, I performed all sample preparation myself. At the NASA Ames Research Center, each $13.5 \mathrm{~cm}$ diameter frozen core was cut into segments 4 to $6 \mathrm{~cm}$ in length using a circular saw with diamond coated blade. In a dark room, the segments were tightly wrapped in two layers of aluminum foil and left to partially thaw at room temperature for approximately 15 to 20 minutes. The outer "light-contaminated" 1 to $2 \mathrm{~cm}$ outer shell of material was scraped off using a clean stainless steel knife. To prevent contaminating the "dark" inner sample with light-exposed sediment grains, the knife was cleaned with milliQ water between each scraping. Finally, the inner sample (outer

shell removed) was tightly wrapped in two layers of aluminum foil, secured by several wrappings of tape, and then sealed in a waterproof bag within a lightproof black bag. Separately, the light-exposed outer scrapings were sealed in waterproof bags. Both the prepared inner samples and outer scrapings were then shipped to the Optically Stimulated Luminescence Laboratory at Victoria University of Wellington for processing by Ningsheng Wang. 


\section{Water content measurements}

In the darkroom setting of the Optically Stimulated Luminescence Laboratory at Victoria University of Wellington, small amounts of outer scrapings were used for water content measurements. For each sample, material from the corresponding outer scrapings were gently packed into a $1 \mathrm{~cm}^{3}$ plastic cube with a small pinhole on each side. Each filled cube was weighed and then the weight of the plastic cube was subtracted, yielding the net weight of sample with its natural water content. The cube was then placed in a cup of water and weighed every day until the weight no longer increased. This final weight, minus the weight of the plastic cube, is the weight of sample with saturated water content. The sample was then dried completely in an oven at $50^{\circ} \mathrm{C}$ for 24 hours and weighed again, yielding the dry weight of the sample. The initial net weight of sample with its natural water content minus the weight of the dry sample yields the water content of the original sediments, and the net weight of water-saturated sample minus the weight of the dry sample yields the maximum water content at up to pore-filling capacity.

\section{Gamma Ray Spectrometry}

The remainder of the outer scrapings were oven-dried at $50^{\circ} \mathrm{C}$ for 24 hours until completely dry. For each sample, about $90 \mathrm{~g}$ of the dry scrapings were gently packed and sealed into an airtight acrylic dish, weighed, and left to rest undisturbed for 4 weeks to allow the noble gas ${ }^{226} \mathrm{Ra}$ in the sediments to reach equilibrium with its radiogenic daughter isotopes ${ }^{210} \mathrm{~Pb}$ and ${ }^{214} \mathrm{Bi}$. After equilibrating, the disks were then measured for 24 hours on a high resolution and broad energy Canberra High-Purity Germanium (HPGe) detector for gamma-ray spectrometry analysis to determine dose rate from the burial environment.

\section{Preparation for Equivalent Dose measurements}

In the Optically Stimulated Luminescence Laboratory darkroom, each of the "dark" inner samples was treated with $10 \%$ hydrochloric acid $(\mathrm{HCl})$ for 24 hours to remove all carbonate matter, then rinsed 3 times with distilled water to remove the $\mathrm{HCl}$. The 
samples were then treated with $10 \%$ hydrogen peroxide $\left(\mathrm{H}_{2} \mathrm{O}_{2}\right)$ for 24 hours to remove all organic matter, and rinsed 3 times with distilled water to remove the $\mathrm{H}_{2} \mathrm{O}_{2}$. The samples were then oven-dried at $50^{\circ} \mathrm{C}$ for 72 hours.

The dry sediment samples were composed of predominantly coarse grain sand, and thus the coarse grain quartz preparation method was used. Each sample was sieved to the 125 to $200 \mu \mathrm{m}$ size fraction. Quartz grains in this size fraction were isolated from feldspars and heavy minerals by density separation using heavy liquids $(2.62 \mathrm{~g} / \mathrm{mL}$ and $2.75 \mathrm{~g} / \mathrm{mL}$ lithium heteropolytungstate solutions). The quartz grains were then etched for 45 minutes using $48 \%$ hydrofluoric acid to remove the outer grain surface, rinsed 3 times with distilled water, treated for 30 minutes with $10 \% \mathrm{HCl}$ to remove fluoride salts, and rinsed 3 times with distilled water. These samples were sieved again to 125 to $200 \mu \mathrm{m}$ and coated onto $1 \mathrm{~cm}$ stainless steel disks using silicon oil. All disks were then subjected to the Single Aliquot Regenerative Method (SAR) (Murray and Wintle, 2000) to determine the equivalent dose. 12 to 24 aliquots per sample were measured in order to obtain reliable luminescence ages. See Appendix C for radioactive nuclide measurements, water content, luminescence growth curves, and equivalent dose distributions.

\subsection{Meteoric ${ }^{10} \mathrm{Be}$}

Meteoric ${ }^{10} \mathrm{Be}$ measurements were performed on the ice-cemented sediment cores P1, P2, and P8, which were also used for OSL dating, in order to allow the possibility to incorporate definitive ages into the ${ }^{10} \mathrm{Be}$ soil profiles. At the NASA Ames Research Center, I additionally subsampled the loose dry soil layer that was collected from above the ice-cemented ground at each polygon, to create complete soil profiles that extend above and below the ice table. The ${ }^{10} \mathrm{Be}$ sediment samples were mailed from the NASA Ames Research Center to Victoria University of Wellington, where I performed all sample preparation myself aside from the final measurement of ${ }^{10} \mathrm{Be}$ on the mass spectrometer at ETH Zurich.

Willenbring and von Blanckenburg (2010) have shown that meteoric ${ }^{10} \mathrm{Be}$ concentration has a strong grain size dependence that is inversely proportional to grain 
diameter for certain size fractions. To eliminate this grain size dependence, all samples were oven dried at $110^{\circ} \mathrm{C}$ for 24 hours and then dry sieved to the 45 to 125 $\mu \mathrm{m}$ size fraction. Approximately $0.75 \mathrm{~g}$ of each sieved sample was then precisely weighed to 4 decimal places.

\section{Beryllium Leaching}

Meteoric ${ }^{10} \mathrm{Be}$ was leached from the sediments in two separate leaches using the method by Willenbring and von Blanckenburg, which was adapted from Tessler et al. (1970), Bourlés et al. (1989), Guelke-Stelling and von Blanckenburg (2012), and Wittmann et al. (2012). The first leach was to bring amorphous oxide-bound beryllium into solution. In a $50 \mathrm{ml}$ centrifuge tube, $10 \mathrm{ml}$ of $0.5 \mathrm{M} \mathrm{HCl}$ solution was added to the samples, and then the samples were gently agitated continuously for 24 hours. The samples were centrifuged at 4000 RPM for 15 minutes, and the supernatant solution was decanted into a Teflon beaker. The sediment was rinsed with $10 \mathrm{ml}$ milliQ water, centrifuged once more, and the supernatant solution was decanted into the same Teflon beaker. The Teflon beaker was then dried down on a hotplate for 24 hours at $110^{\circ} \mathrm{C}$, and dissolved in $10 \mathrm{ml}$ of $3 \mathrm{M} \mathrm{HNO}_{3}$. Aliquots were taken at the end of this leach for major and minor element analysis.

The second leach was to bring crystalline oxide-bound Beryllium into solution. Sediments used for the previous leach were treated with $10 \mathrm{ml}$ of $1 \mathrm{M}$ hydroxylaminehydrochloride $\left(\mathrm{HN}_{2} \mathrm{OH}-\mathrm{HCl}\right)$ solution, and then heated at $80^{\circ} \mathrm{C}$ for 4 hours in an ultrasonic bath, shaken once every hour. Samples were then centrifuged at 4000 RPM for 15 minutes, and the supernatant solution was decanted into a $50 \mathrm{ml}$ centrifuge tube. The sediments were rinsed with milliQ water, centrifuged, and the supernatant solution was decanted into the same $50 \mathrm{ml}$ centrifuge tube. A 1:1 mixture of concentrated $\mathrm{HNO}_{3}$ and $30 \% \mathrm{H}_{2} \mathrm{O}_{2}$ was added to the solution in order to remove the $\mathrm{HN}_{2} \mathrm{OH}-\mathrm{HCl}$, and the solutions were dried down at $70^{\circ} \mathrm{C}$ for 24 hours. This step of adding the $\mathrm{HNO}_{3}$ and $\mathrm{H}_{2} \mathrm{O}_{2}$ and drying down on a hot plate was repeated 4 times until the solution appeared clear. The dried solution was then dissolved in $10 \mathrm{ml}$ of $3 \mathrm{M}$ $\mathrm{HNO}_{3}$, and then aliquots were taken for major and minor element analysis. 
After both leaches, the two final leached solutions from each sample were combined, and 0.7 to $1.0 \mathrm{~g}$ of ${ }^{9} \mathrm{Be}$ carrier solution precisely weighed to 4 decimal places was added. The solutions were then dried down on a hot plate at $70^{\circ} \mathrm{C}_{2} \mathrm{O}_{2}$ for 24 hours, and then the samples were acidified with $10 \mathrm{ml} 6 \mathrm{M} \mathrm{HCl}$ and centrifuged at $3500 \mathrm{RPM}$ for 5 minutes in preparation for anion exchange columns. At this point, the remaining sediments were discarded, since meteoric ${ }^{10} \mathrm{Be}$ is found only on the grain outer surface, whereas in-situ ${ }^{10} \mathrm{Be}$ is found within the sediment grain.

\section{Column Chemistry}

Each sample solution was passed through one anion exchange column and then one cation exchange column to isolate ${ }^{10} \mathrm{Be}$ and ${ }^{9} \mathrm{Be}$. First, the solutions were dripped through $2 \mathrm{ml}$ of Biorad AG1-X8 100-200 mesh anion resin in $15 \mathrm{ml}$ Eichron columns to remove Fe from solution. $0.4 \mathrm{M}$ oxalic acid was added to the solutions to bind $\mathrm{Al}$ and Ti. Solutions were warmed on a hotplate at $60^{\circ} \mathrm{C}$ for 2 hours and then centrifuged at 3000 RPM for 5 minutes. The solutions were then dripped through $5 \mathrm{ml}$ Biorad AG50-X8 200-400 mesh cation resin in $15 \mathrm{ml}$ Eichron columns to remove $\mathrm{Fe}, \mathrm{Al}$, Ti, and $\mathrm{Na}$, leaving only $\mathrm{Be}$ in solution. The solutions were then dried down at $120^{\circ} \mathrm{C}$ overnight, and then $5 \mathrm{ml}$ of $1 \mathrm{M} \mathrm{HNO}_{3}$ was added to dissolve the samples.

\section{Beryllium Precipitation}

$550 \mu$ of concentrated ammonia solution was added to each sample solution, which formed a Beryllium hydroxide $(\mathrm{BeOH})$ precipitate at $\mathrm{pH} \sim 9$. The samples were centrifuged at 3000 RPM for 5 minutes, the supernatant liquid was decanted, the precipitate was rinsed with milliQ water, and the samples were centrifuged again at 3000 RPM for 5 minutes. This process was repeated 3 more times to remove ammonia from the $\mathrm{BeOH}$ precipitate. The supernatant liquid was decanted, and then $5 \mathrm{M} \mathrm{HNO}_{3}$ was mixed into the $\mathrm{BeOH}$ precipitate. The samples were then poured into quartz crucibles and dried down on a hotplate at $100^{\circ} \mathrm{C}$ for 24 hours. Using Platinum coated tongs, each sample was oxidized over a Bunsen burner for approximately 2 minutes to form Beryllium oxide $(\mathrm{BeO})$. The $\mathrm{BeO}$ was then scraped from the walls of each crucible using a metal spatula, and then mixed with $3 \mathrm{mg}$ Niobium $(\mathrm{Nb})$ powder. 


\section{$\underline{\text { Targets }}$}

The final step of the preparation process was pressing the samples into targets to be measured on the Accelerator Mass Spectrometer (AMS) at ETH Zurich. Using tools that were cleaned by soaking in $0.25 \mathrm{M} \mathrm{HCl}$ and sprayed with ethanol, the $\mathrm{Nb}$ and $\mathrm{BeO}$ mixtures were scraped into target holders, packed down, and sealed shut by small aluminum balls hammered into both ends of the target. The samples were then mailed to ETH Zurich, Switzerland and measured on the 0.5MV compact AMS (Tandy).

\subsection{Grain size analysis: sieve stack and Laser Particle Sizer}

Sediments for grain size analysis was subsampled from cores stored at the University of Ottawa. These cores were previously thawed and dried at $110^{\circ} \mathrm{C}$ for 24 hours. At the University of Ottawa, I collected approximately $15 \mathrm{~g}$ of sediment per sample at intervals of about $10 \mathrm{~cm}$ depth for all cores (P1, P2, P4, P5, P6, P7, P8, and P10). The samples were mailed to Victoria University of Wellington where I performed all sample preparation, sieve stack analysis, and Laser Particle Sizer analysis myself.

At Victoria University of Wellington, each sample was mixed to homogenize the sediments, and then split into two sample sets using a sample splitter. This created two identical working sets of sample material. One of the sets was used for grain size analysis using the stacked sieve method, a method that Lacelle et al. (2013) used to classify sediments from different cores in University Valley. Sieve stacks are especially useful for classifying sand to pebble sized grains. Approximately $7 \mathrm{~g}$ of sediment per sample was washed with Reverse Osmosis (RO) water and retained in a $45 \mu \mathrm{m}$ sieve to remove clays and silts. The $<45 \mu \mathrm{m}$ fine fraction was then dried in an oven at $100^{\circ} \mathrm{C}$ for 24 hours, while the $>45 \mu \mathrm{m}$ samples were dry sieved in a series of stacked sieves at 0.5 phi intervals from 4.0 phi $(45 \mu \mathrm{m})$ to -1.0 phi $(2 \mathrm{~mm})$. The washed-off $<45 \mu \mathrm{m}$ fine fraction was retained in plastic containers and allowed to settle overnight, the clear supernatant water was siphoned off, and the remaining fine fraction in water was transferred to $50 \mathrm{ml}$ centrifuge tubes and frozen at $-15^{\circ} \mathrm{C}$ for 5 days and then dried in a freeze drier for 3 days. Sediments retained in each sieve, as well as the $<45 \mu \mathrm{m}$ fine fraction, were weighed and classified by the Udden- 
Wentworth grain-size classification of terrigenous sediments (Figure 16) (Wentworth, 1922).

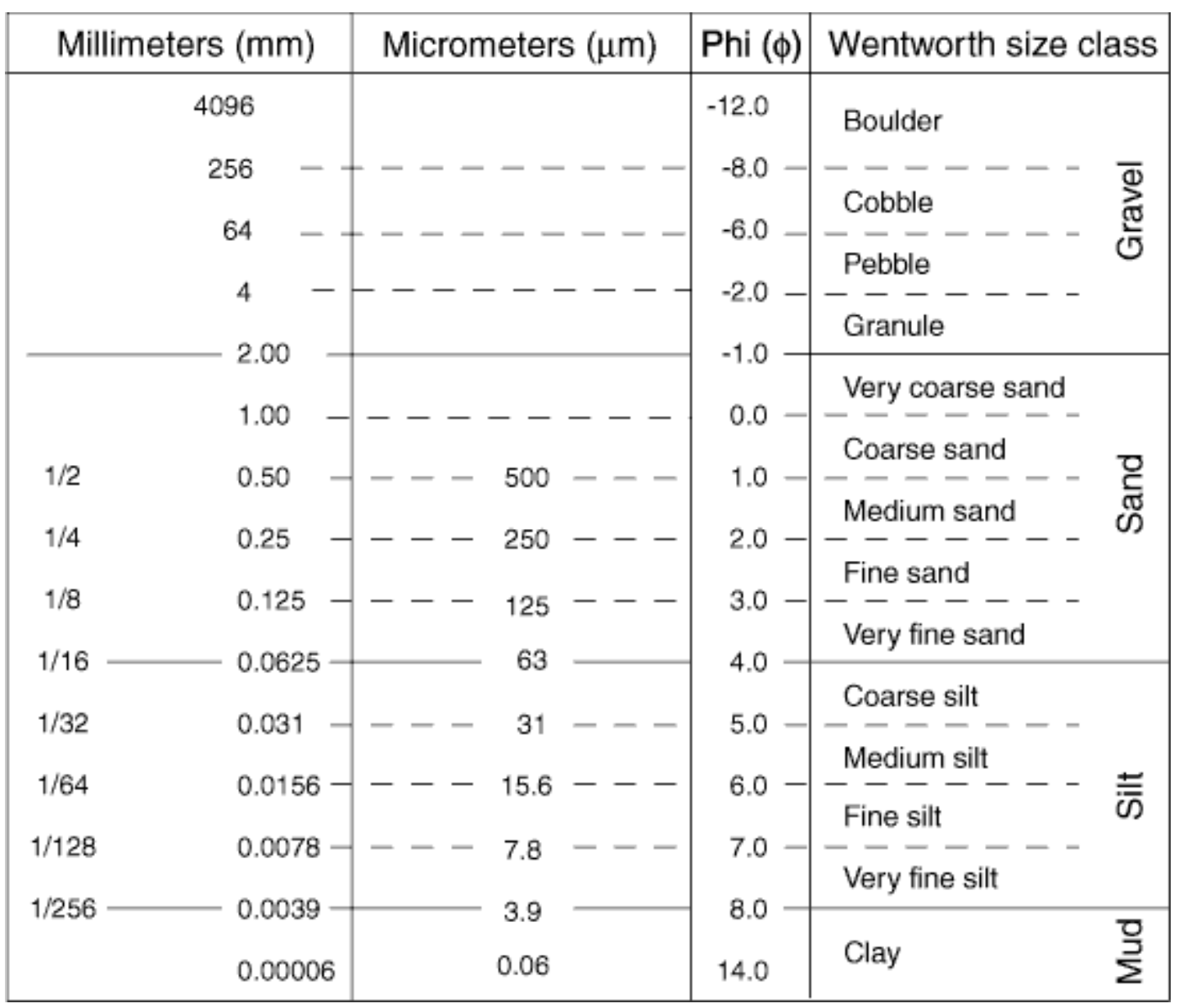

Figure 16: The Udden-Wentworth grain-size classification of terrigenous sediments. From Wentworth (1922).

After sediments from the sieve stack were weighed, it was discovered that the sediment cores contained an abundance of fine material $(<45 \mu \mathrm{m})$, sometimes composing up to $33 \%$ of the total sample mass. Therefore, a Laser Particle Sizer was used to measure the unwashed split set to get a more detailed and accurate particle size distribution, especially for the $<45 \mu \mathrm{m}$ fine fraction, since it is able to accurately measure grain sizes down to $0.5 \mu \mathrm{m}$. Samples were homogenized by dry mixing, then grains larger than $2 \mathrm{~mm}$ were removed by use of a sieve, and approximately 1/8 teaspoon of sediment was added to $300 \mathrm{ml}$ of DI water in a glass beaker. No chemical 
deflocculating agent was used. The beakers were submerged in an ultrasonic bath up to the sample-water level, and stirred using an automatic stirrer. Each sample was stirred while being ultrasonicated for 30 minutes to ensure complete disaggregation of clays, and then the samples were measured on the Laser Particle Sizer. Every $10^{\text {th }}$ sample was subsampled 3 times and measured 3 times to demonstrate reproducibility of results.

\subsection{Preparation of samples for microscopy analysis of lithology, porosity, and grain roundness}

Vacuum impregnation with epoxy and thin section

Samples used for microscopy analysis were sampled from the set of frozen cores stored at the NASA Ames Research Center. Apart from cutting the frozen cores with a circular saw, which was done by David Willson, I performed all sample preparation and microscopy analyses myself.

At the NASA Ames Research Center, the frozen sediment cores were cut into $2 \mathrm{~cm}$ thick slices using a circular saw with diamond coated blade. The frozen slices were then tightly wrapped in heavily perforated aluminum foil, and were placed into an oven at $50^{\circ} \mathrm{C}$ to dry for 24 hours. To retain the original pore structure, the temperature $50^{\circ} \mathrm{C}$ was selected to prevent boiling of the core segments, and the dried core segments were handled delicately to minimize structural disturbance after the ice evaporated. The samples were placed into small plastic containers, which were then filled with an epoxy and blue dye mixture, and placed into a vacuum chamber. A vacuum was applied for 2 minutes to completely impregnate the samples with epoxy and preserve the original pore structure of the sediments. The samples were then transferred back to a $50^{\circ} \mathrm{C}$ oven and left undisturbed for 24 hours to harden. The samples were sent back to the Thin Section Laboratory at Victoria University of Wellington where Stuart Bush cut them to a thickness of $5 \mathrm{~mm}$ and then made them into $30 \mu \mathrm{m}$ thin sections to be used for petrographic microscopy to observe pore structure. Additionally, samples that were wet sieved to the 125 to $250 \mu \mathrm{m}$ size fraction were made into grain mount thin sections to be used for determining lithology of the sediments. 


\section{Point counting}

A point counter was used to determine porosity of the samples from thin sections of the frozen cores that preserve their natural pore and sediment structure. Classifying grains by use of a point-counter ensures unbiased ratios. For porosity measurements, points were classified into one of three categories: matrix, pore, or grain. 300 point counts were measured for each sample to obtain a representative data set. Only those points where the viewing crosshairs landed completely within the pore space counted as "pore." Points where crosshairs landed on the border between pore-and-grain and pore-and-matrix were skipped. 300 point counts were taken per sample to obtain a large data set, and the porosity was taken as a percentage using Equation 2.

$$
\frac{\text { number of porosity counts }}{300} \cdot 100=\operatorname{porosity}(\%)
$$

This point counting method was also used to determine lithology of the sediment grains. Grain mount thin sections were observed under 10x magnification in plane light and cross polarized light. 300 point counts were taken per sample to obtain a representative data set. Grains were classified into one of three categories: quartz, potassium (K) feldspar, and dolerite. Because both quartz and $\mathrm{K}$ feldspar come from the Beacon Sandstone, which composes the three surrounding valley walls, only the dolerite content was analyzed to explore changing conditions in the valley, since dolerite sills crop out in different locations within the valley walls. The dolerite content was taken as a percentage using Equation 3.

$\frac{\text { number of dolerite counts }}{300} \cdot 100=$ dolerite content $(\%)$ 


\section{Grain roundness}

Sediments were washed with RO water, sieved to 125 to $250 \mu \mathrm{m}$, and then mounted to glass microscope slides with clear resin to be observed under 10x magnification. Using the sediment grain roundness and sphericity scales from Schneiderhohn (1954) modified from Russell and Taylor (1937), each sand grain was given one value between 1 and 5 for roundness, and one value between 1 and 5 for sphericity (Figure 17). Up to 100 grains of each lithology per slide sample were counted, depending on the grains present on the microscope slide.

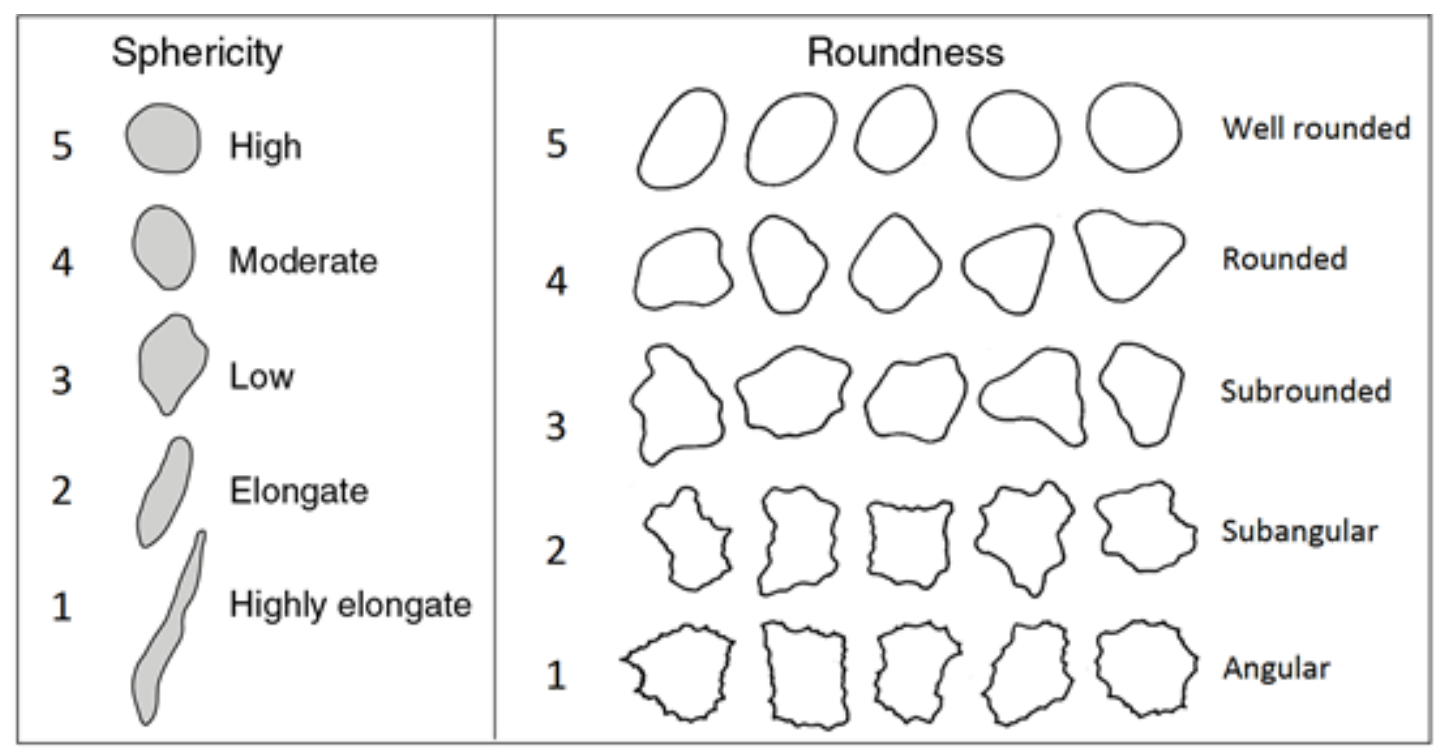

Figure 17: The sediment grain roundness and sphericity scales from Schneiderhohn (1954) modified from Russell and Taylor (1937).

\subsection{Geochemical analysis: ion leaching}

Samples for geochemical analysis were prepared myself on-site at the University of Ottawa. Subsamples were taken at approximately $10 \mathrm{~cm}$ depth intervals for the upper $100 \mathrm{~cm}$ from all cores (P1, P2, P4, P5, P6, P7, P8, and P10). The sediments were leached of major anions and cations using a 1:10 ratio of sediment:milliQ water, using the leaching method from previous geochemical studies such as Dickinson and Rosen (2003) and Toner and Sletten (2013). This method leaches water-soluble ions that are 
adsorbed to the sediment grain surface without dissolving the sediment grain itself, allowing for the analysis of chemical weathering processes and atmospheric processes that the sediments were exposed to. Approximately $4 \mathrm{~g}$ of sediment and $40 \mathrm{~g}$ of milliQ water per sample were mixed into a $50 \mathrm{ml}$ centrifuge tube, and mixed continuously for one hour using an automatic wrist action shaker. The samples then centrifuged at 4500 RPM for 5 minutes, and then the supernatant liquid was decanted into a $50 \mathrm{ml}$ syringe. Electrical conductivity of the supernatant liquid was measured, and then supernatant liquid was filtered through a $0.45 \mu \mathrm{m}$ pore diameter cellulose filter into two $10 \mathrm{ml}$ centrifuge tubes per sample for geochemical analyses of major anions $\left(\mathrm{Cl}^{-}, \mathrm{SO}_{4}{ }^{2-}\right.$, $\left.\mathrm{NO}_{3}{ }^{-}\right)$and cations $\left(\mathrm{Mg}^{2+}, \mathrm{K}^{+}, \mathrm{Na}^{+}, \mathrm{Ca}^{2+}, \mathrm{Fe}^{2+}, \mathrm{Si}^{4+}, \mathrm{P}^{3+}\right)$. The cation samples were then acidified with $2 \mathrm{ml}$ dilute nitric acid $\left(\mathrm{HNO}^{3}\right)$. Cations were measured on a Varian Vista-Pro Inductively Coupled Plasma Atomic Emission Spectrometer (ICP-AES) and anions were measured on a Dionex Ion Chromatography System, with a 5\% analytical error, by Ping Zhang at the University of Ottawa Geochemistry Laboratory. 


\section{Chapter 5. Results}

\subsection{Grain size analysis}

Polygons 1, 2, 8, and 10 were selected for grain size analysis due to their widespread positions down the length of the valley. Sediments from these cores were analyzed using the sieve stack method and categorized using the Udden-Wentworth grain-size classification of terrigenous sediments (Wentworth, 1922). Sieve stack analysis showed that all sediments were composed mainly of medium to coarse-grain sand, with a significant amount of fine-fraction (all particles smaller than $45 \mu \mathrm{m}$ ) that composed up to $23 \%$ of the total sample by weight (Figure 18). These findings prompted the use of a Laser Particle Sizer to obtain a detailed particle size distribution of all cores (P1, P2, P4, P5, P6, P7, P8, and P10). See Appendix A for full sieve stack data.

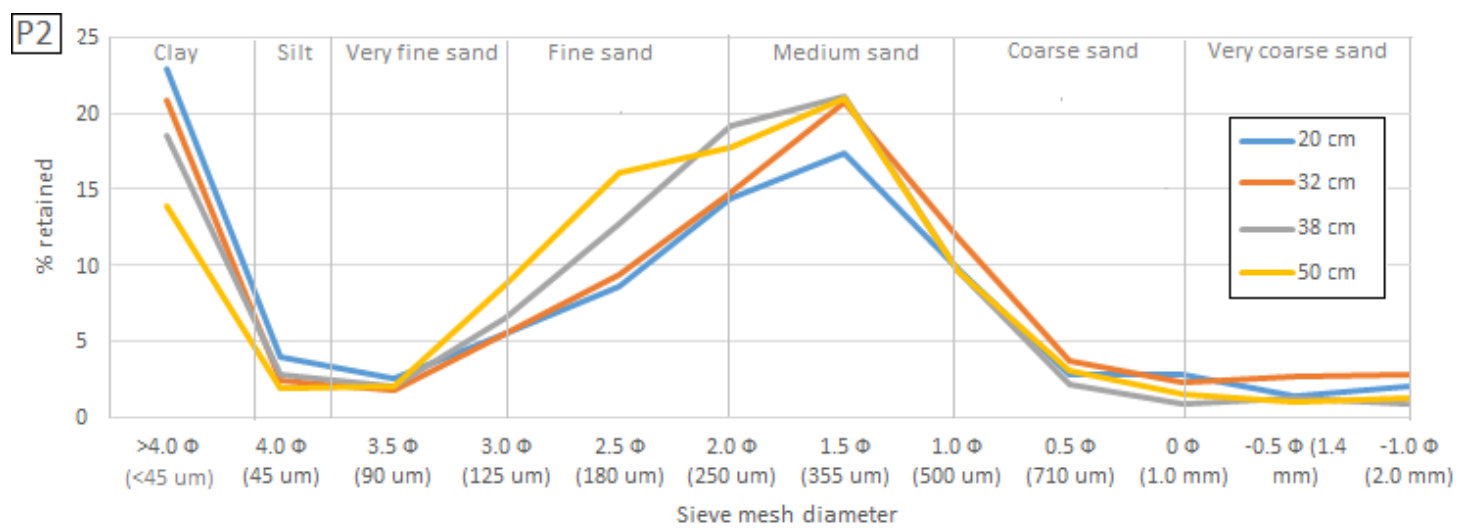

Figure 18: An example of sieve stack particle size distribution by weight percentage, showing high amounts of fine-fraction. (Data from P2).

The Laser Particle Sizer was used to determine particle size distribution by volume percentage. To the maximum depth of coring (between 50 and $183 \mathrm{~cm}$ depending on the polygon), and with a sampling resolution of about $10 \mathrm{~cm}$, sediments from all cores in University Valley were found to be predominantly medium to coarse-grain sand, with the highest volume of material (up to $52 \%$ of the total volume) composed of 355 
to $655 \mu \mathrm{m}$ medium-grain sand (Figure 19 ). The $<45 \mu \mathrm{m}$ fine-fraction made up $18 \%$ of the total volume. The observed peaks between sizes $355 \mu \mathrm{m}$ and $655 \mu \mathrm{m}$ varied slightly in height across cores, but no significant variations in general grain size across cores or with depth were observed. See Appendix A for Laser Particle Sizer data of each core.

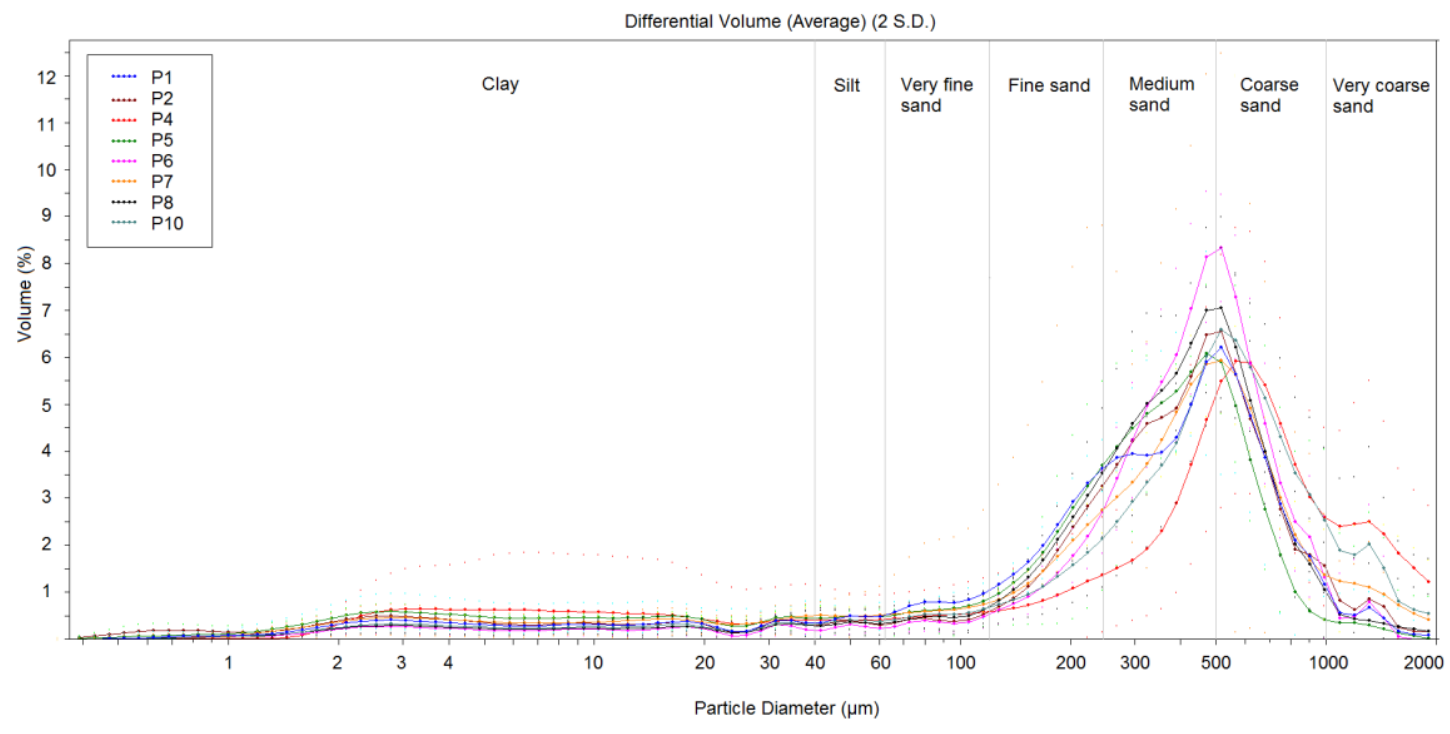

Figure 19: Average particle size distribution for each core, with dotted outlines showing absolute minimum and maximum values measured for each core.

Laser particle size analysis of the $<45 \mu \mathrm{m}$ fine-fraction from P1, P2, and P8 showed that all cores exhibited the same particle size distribution for particles smaller than $45 \mu \mathrm{m}$, with small to moderate peaks in volume at $3 \mu \mathrm{m}, 18 \mu \mathrm{m}$, and $45 \mu \mathrm{m}$ (Figure 20). 


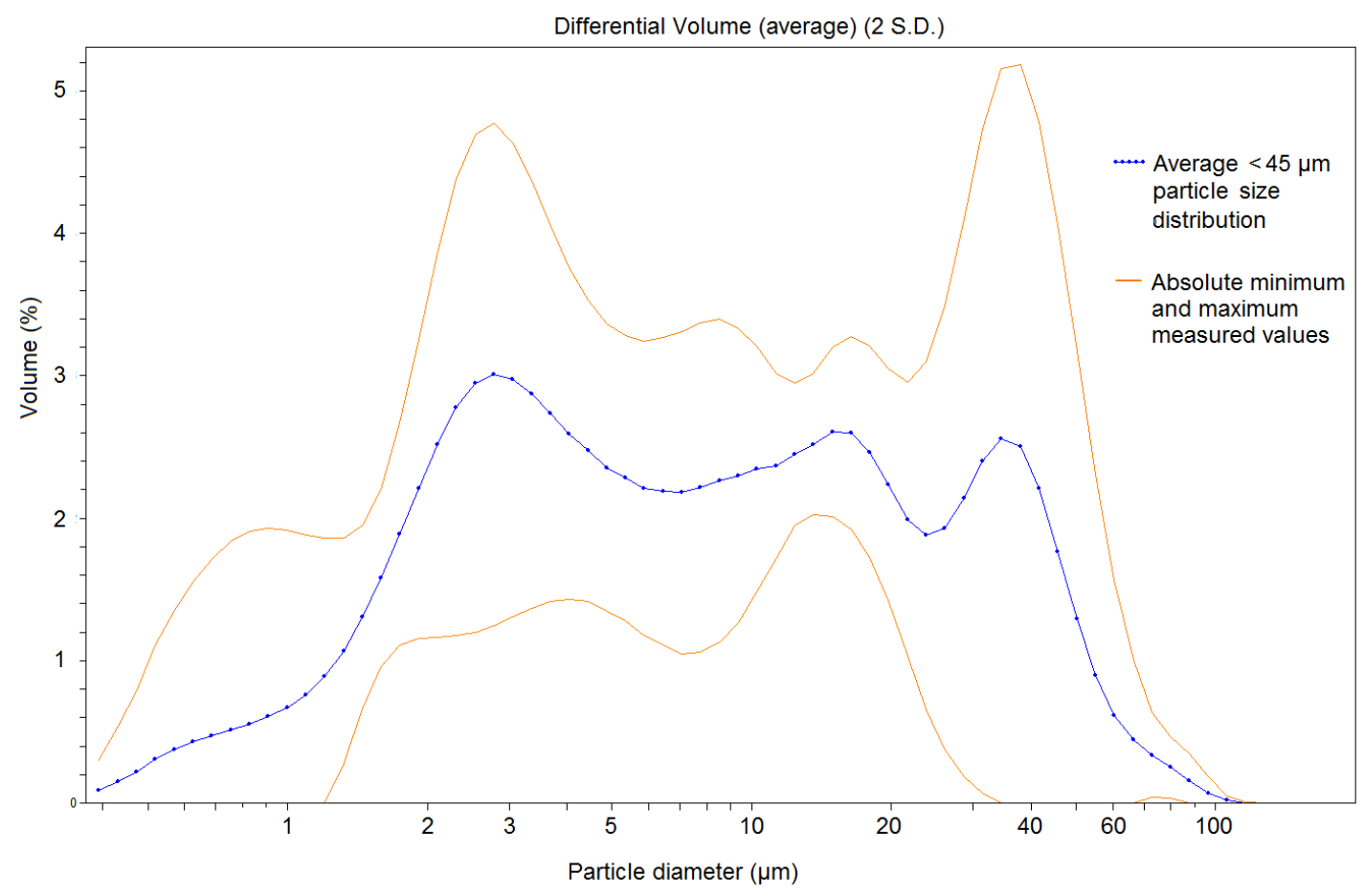

Figure 20: Average laser sizer particle size distribution of the $<45 \mu \mathrm{m}$ size fraction by volume percentage.

\subsection{Grain roundness}

Average values for grain roundness ranged between 3.5 and 4.3 for quartz, 3.0 and 4.3 for $\mathrm{K}$ feldspar, and 2.1 to 3.1 for dolerite. Average values for grain sphericity ranged between 3.5 and 4.4 for quartz, 3.3 and 4.3 for $\mathrm{K}$ feldspar, and 2.6 to 3.6 for dolerite. In general, measured values were about equal for quartz and $\mathrm{K}$ feldspar, with grains classified as being rounded to well-rounded with moderate to high sphericity. Dolerite grains typically were sub-angular to sub-rounded with low to moderate sphericity. Roundness measurements for quartz and $\mathrm{K}$ feldspar were about equal to the corresponding sphericity measurements, while dolerite grains exhibited slightly higher roundness than sphericity (Figure 21 and Figure 22). See Appendix B for full grain roundness and sphericity data. 


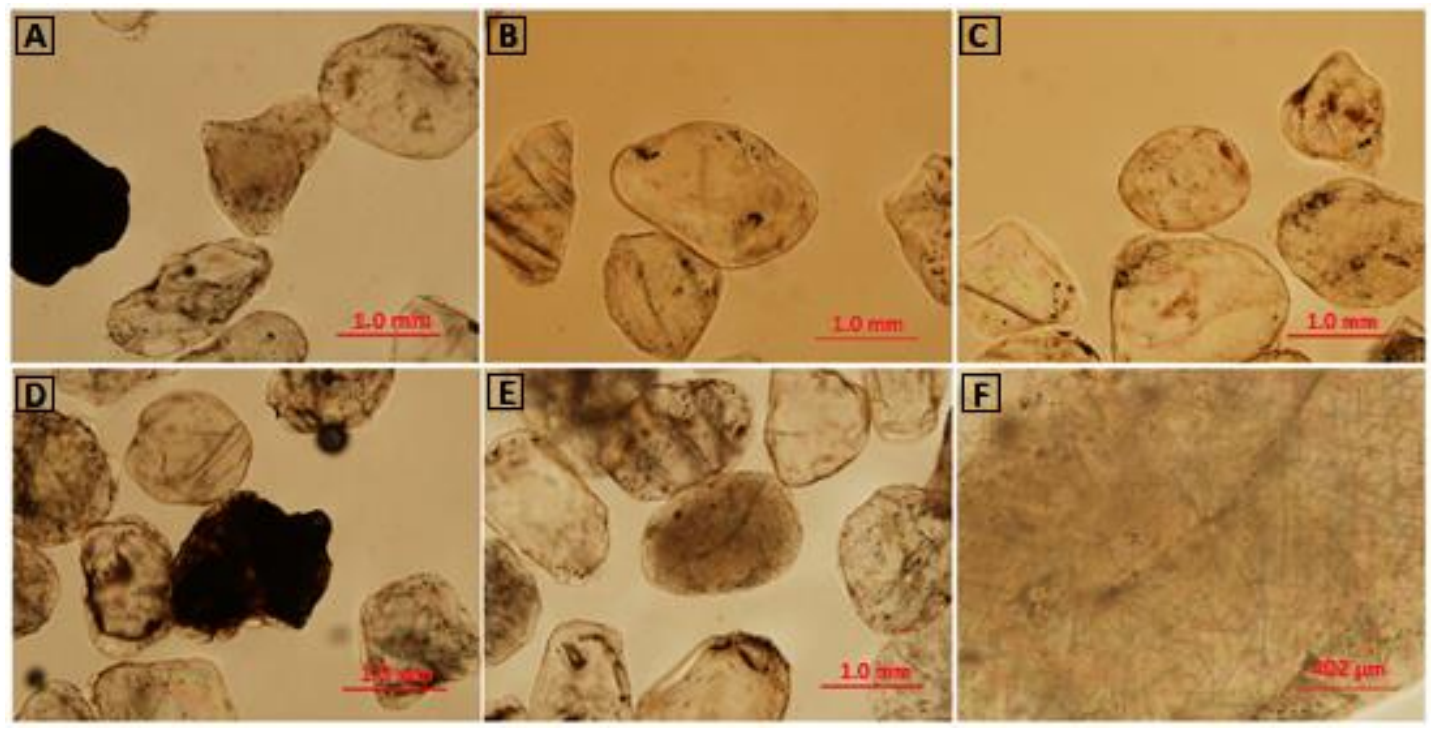

Figure 21: Photomicrographs under 40x magnification showing examples of grain roundness, sphericity, and lithology. (A) A feldspar grain (center) exhibiting roundness 2, sphericity 2. (B) A quartz grain (center) exhibiting roundness 5, sphericity 3. (C) A quartz grain (center) exhibiting roundness 5, sphericity 5. (D) A dolerite grain (center) exhibiting roundness 2, sphericity 3. (E) A $K$ feldspar grain (center) exhibiting roundness 3, sphericity 4. $(F)$ A close-up of crosshatched cleavage planes in a feldspar grain, the presence of which distinguishes $K$ feldspar from quartz. 


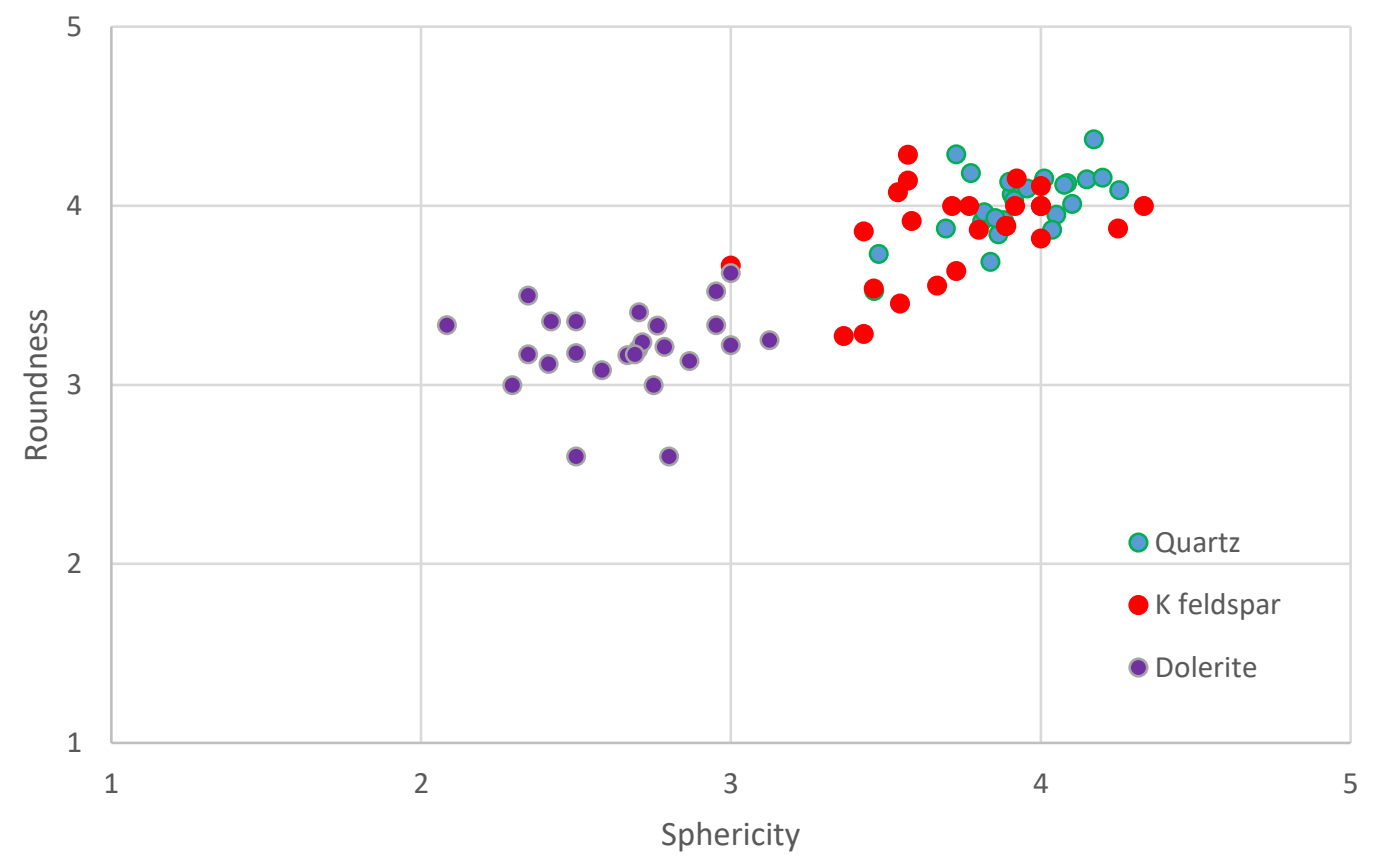

Figure 22: Roundness and sphericity of quartz, K feldspar, and dolerite grains, where a value of 5 denotes the highest degree of roundness (surface smoothness) or sphericity (how spherical a grain is), and a value of 1 denotes high angularity or elongation. Each data point represents the average of up to 100 grains.

\subsection{Porosity}

Internal structures of the sediments were observed in thin section under $40 \mathrm{x}$ and $100 \mathrm{x}$ magnification, with pore spaces shown as blue-colored epoxy (Figure 23). Porosity of the sediments ranged between $10.7 \%$ and $35.3 \%$ (Figure 24). Porosity measurements for all samples were highly scattered and showed no trends with depth or location. A possible trend was observed only in P8, in which porosity was highest toward the surface (about $32.7 \%$ at $2 \mathrm{~cm}$ depth) and decreased with depth to about $11.66 \%$ at $28 \mathrm{~cm}$ below the surface. See Appendix B for full porosity data. 


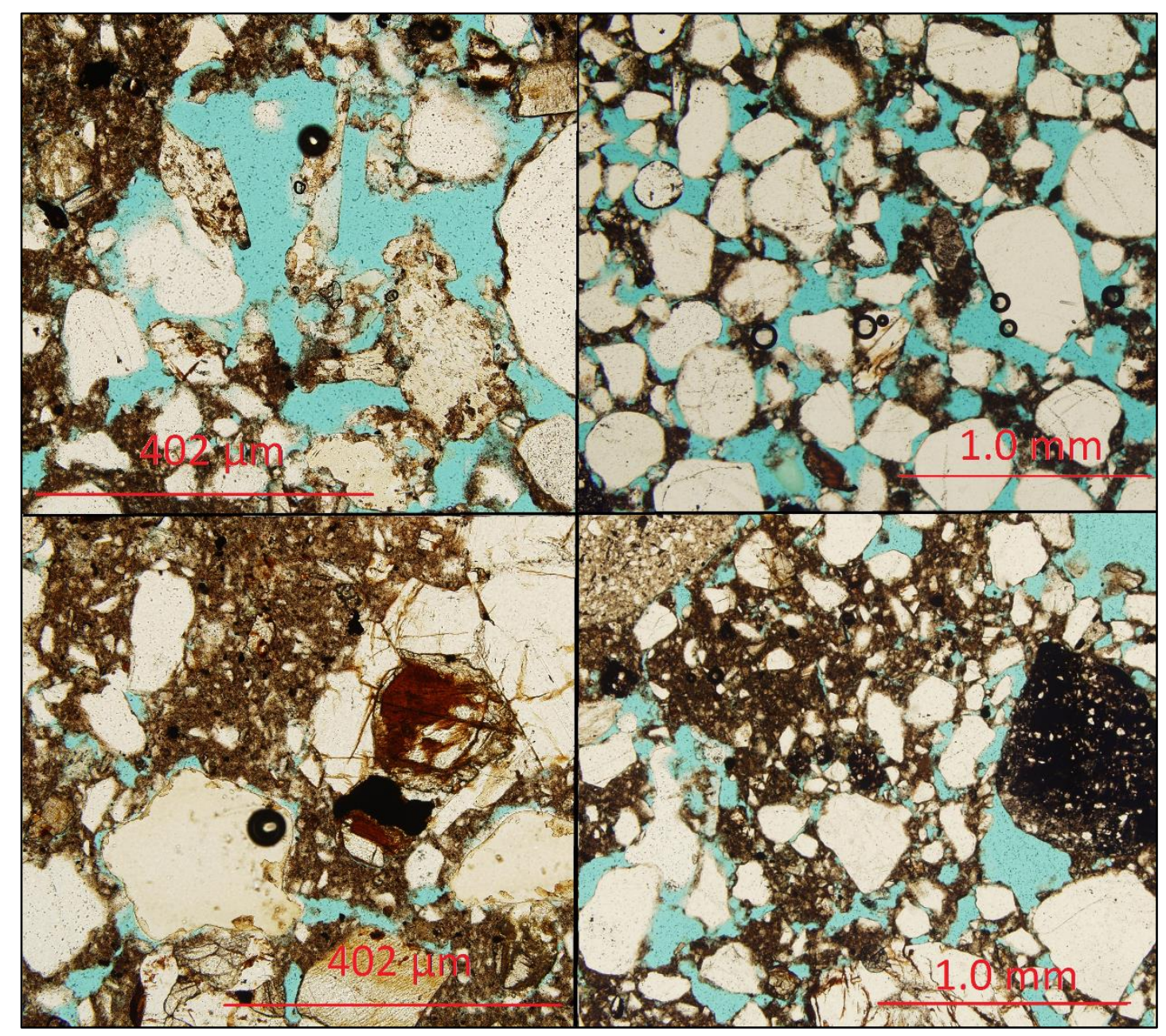

Figure 23: Photomicrographs showing examples of varying porosity of sediments in thin section. Pore spaces are identified by light blue epoxy. Small black circles are bubbles that were caught underneath the glass slide cover during the process of making a thin section. Samples (clockwise from top left): $P 828 \mathrm{~cm}$ depth (100x magnification); P5 $0-3 \mathrm{~cm}$ depth (40x magnification); $P 828 \mathrm{~cm}$ depth (100x magnification); P2 $20 \mathrm{~cm}$ depth (40x magnification). Plane light. 


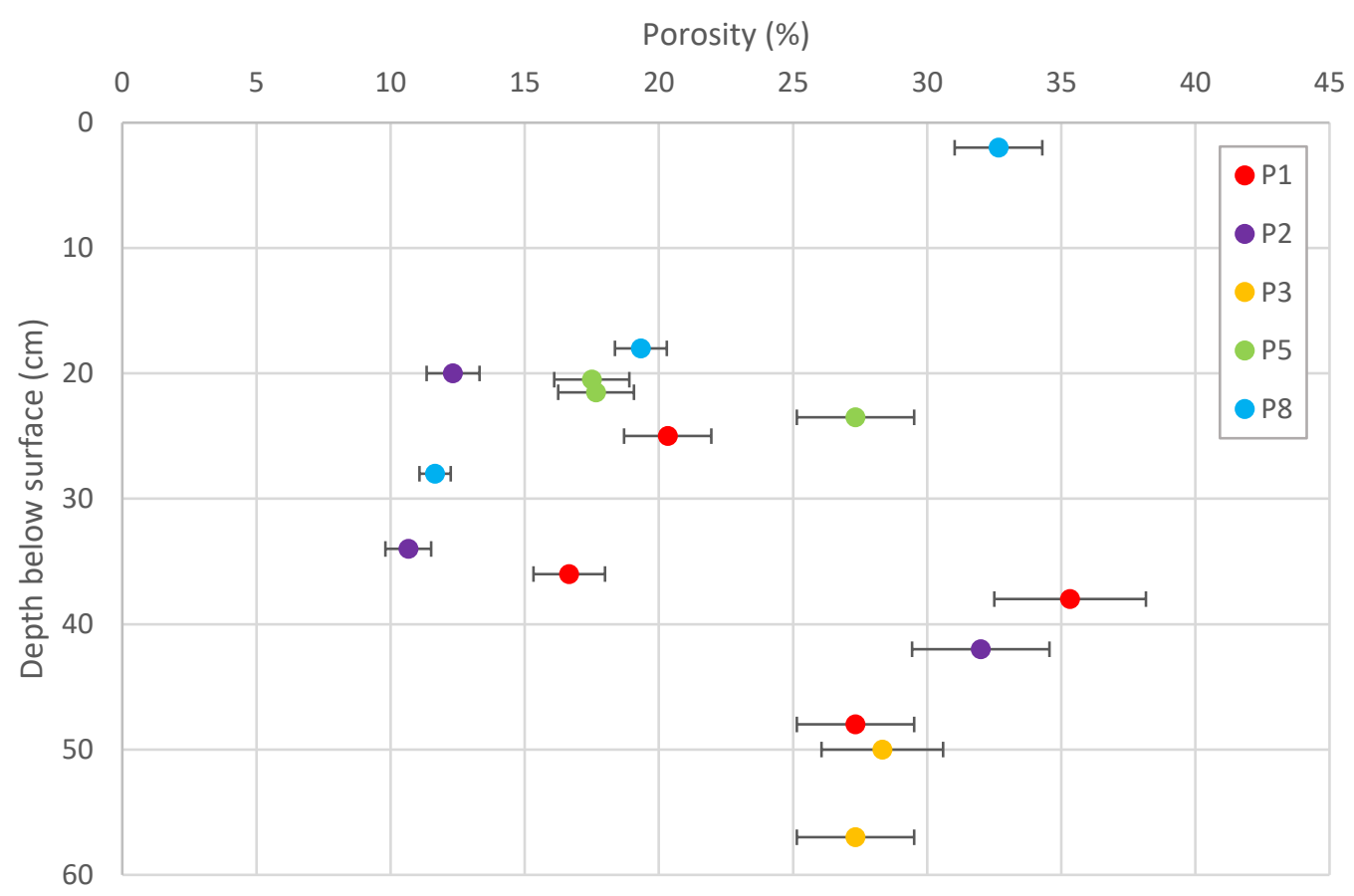

Figure 24: Porosity of the ice-cemented sediments with depth. The shallowest plotted depth of each core was sampled at the ice table. Each data point represents the average of 300 point counts. Error bars were determined by the statistical pointcounting guidelines set forth by Van der Plas and Tobi (1965).

\subsection{Sediment composition}

Sediment composition was determined by observing thin sections of sand grains under 100x magnification from $\mathrm{P} 1, \mathrm{P} 2, \mathrm{P} 8$, and $\mathrm{P} 10$, which were chosen due to their widespread positions down the length of the valley. 300 point counts were taken per microscope slide (one microscope slide per sample depth within the core), identifying the sand grains as either quartz, $\mathrm{K}$ feldspar, or dolerite (Figure 25). Because quartz and feldspar originate from the same source, sediment composition was generalized to the dolerite content in order to observe changes in wind or weathering conditions. Dolerite content was taken as the percentage of dolerite grains counted within each microscope slide. The average of all 300 point counts per slide are plotted in Figure 25 , with error bars determined by the statistical point-counting guidelines set forth by Van der Plas and Tobi (1965). See Appendix B for full dolerite content data. 
Average dolerite content of the sediments ranged from $1 \%$ to $26 \%$ (Figure 26). Dolerite content measurements of P1, P2, and the top half of P8 were similar, ranging from about $5 \%$ to about $12 \%$. Dolerite content of P1 and P2 remained roughly constant with depth, while P8 showed a shift in dolerite content to about $1 \%$ for depths below $40 \mathrm{~cm}$. Dolerite content in P10 was about 2 to 3 times higher than measured in the other cores (up to $30 \%$ dolerite), and appeared to gradually increase with depth until about $110 \mathrm{~cm}$, after which dolerite content appeared to decrease slightly with depth.

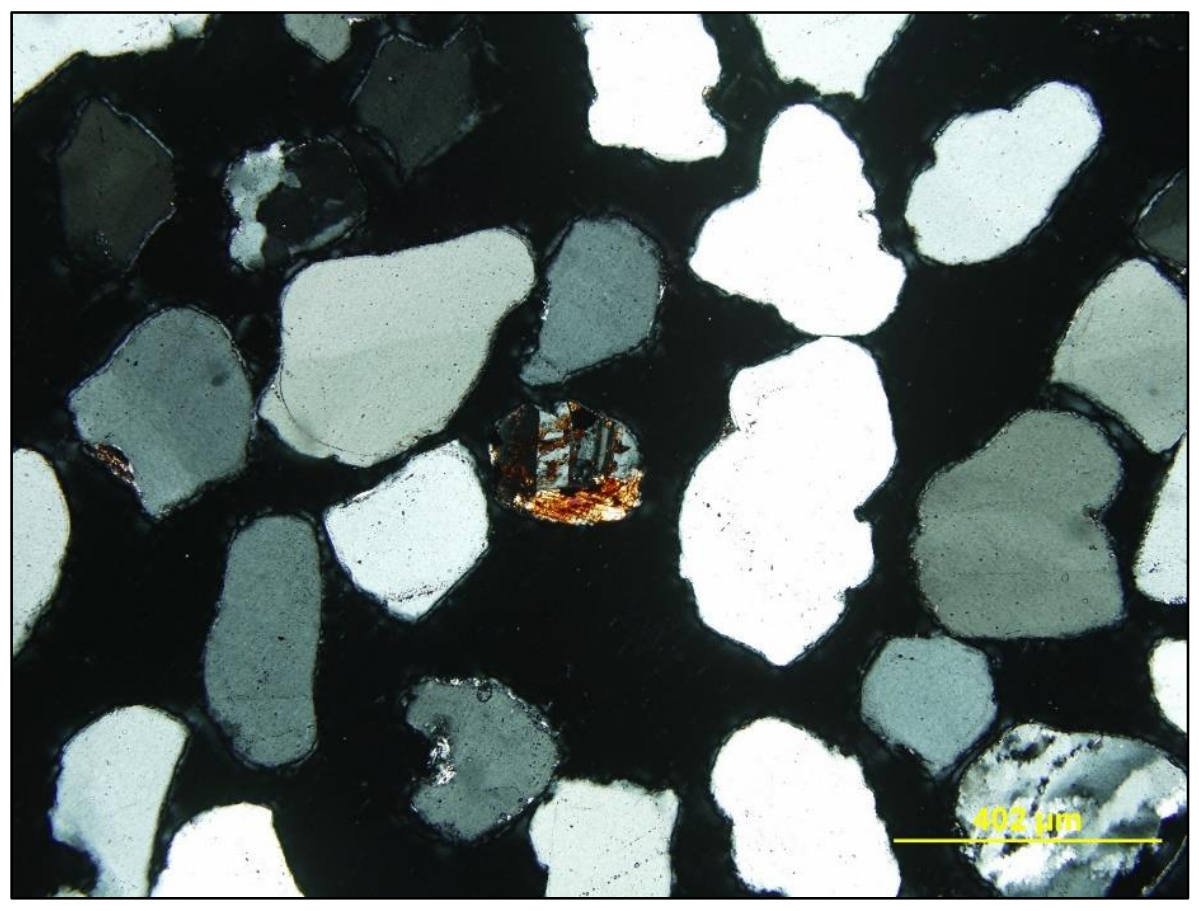

Figure 25: Photomicrograph of a dolerite grain displaying rust-colored weathering (center) surrounded by quartz grains, as seen in thin section. Sample: P8 $66 \mathrm{~cm}$ depth, 100x magnification, cross polarized light. 


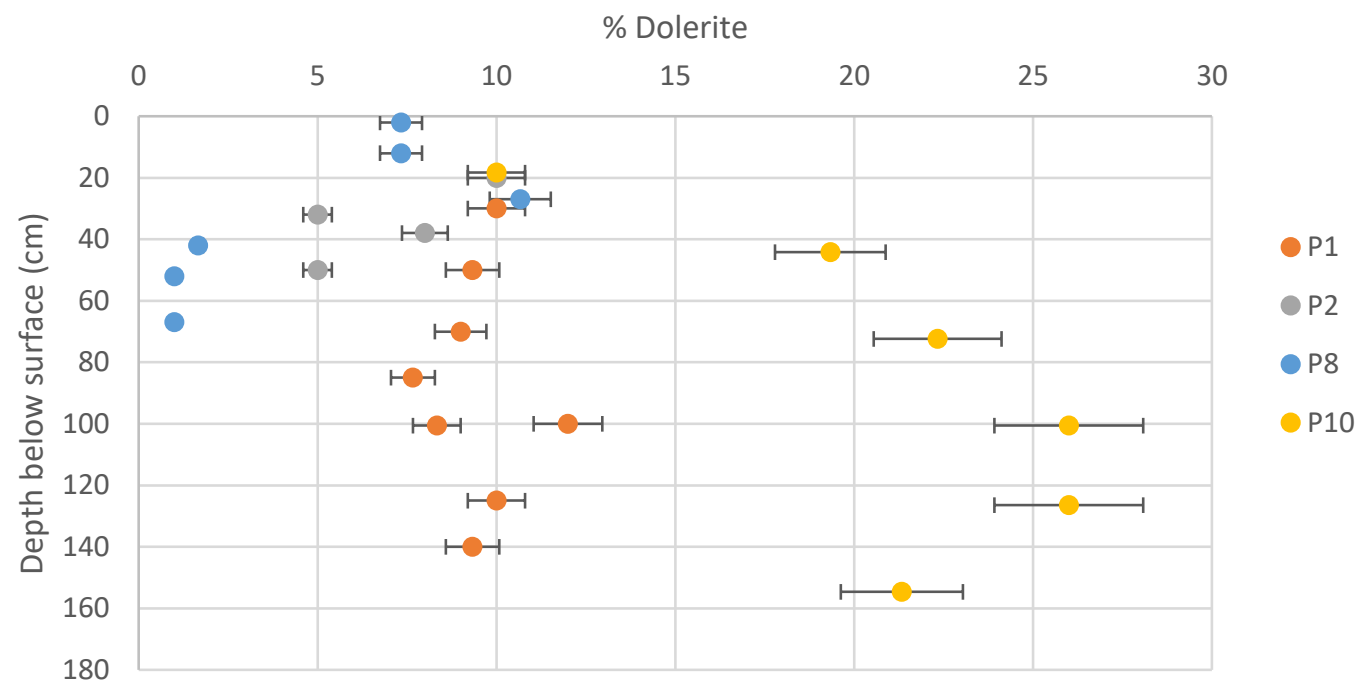

Figure 26: Dolerite content of sediments expressed as a percentage. The shallowest plotted depth of each core is sampled at the ice table. Each data point represents the average of 300 point counts. Error bars were determined by the statistical pointcounting guidelines set forth by Van der Plas and Tobi (1965).

\subsection{Optically Stimulated Luminescence ages}

All samples measured from P1, P2, and P8 produced OSL ages in stratigraphic order, increasing in age with depth. Luminescence ages of the sediments ranged from $85.8 \pm 6.7 \mathrm{ka}$ BP to $191.8 \pm 20.2 \mathrm{ka} \mathrm{BP}$. (Figure 27). Measured water content for all cores was between $12.3 \%$ and $17.5 \%$ by weight. See Appendix C for radioactive nuclide measurements, luminescence growth curves, and equivalent dose distributions. Measured luminescence ages will be discussed by polygon in the following sections. 


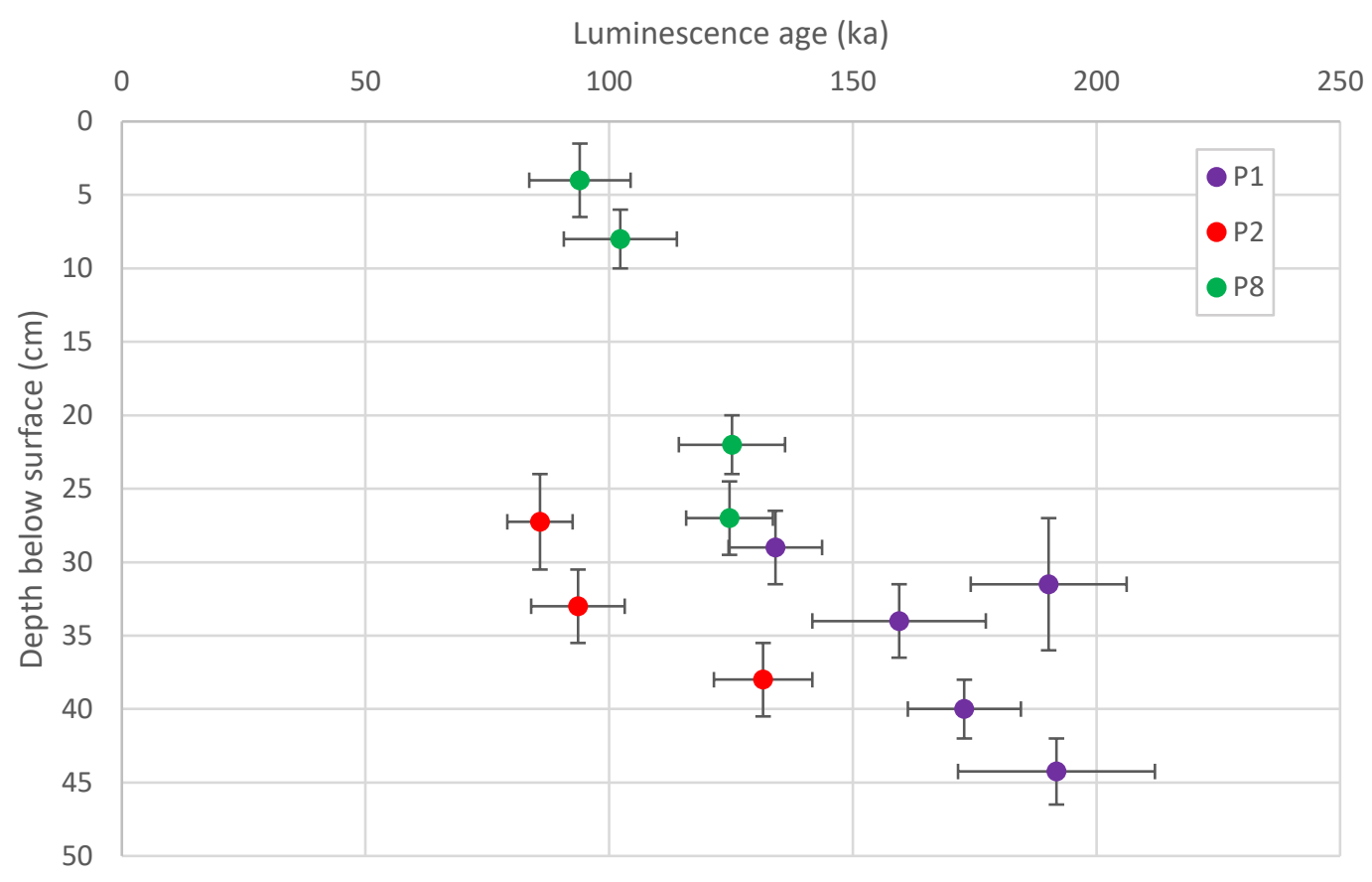

Figure 27: Optically Stimulated Luminescence ages for P1, P2, and P8. Vertical bars represent the top and bottom depths of a single sample segment. Horizontal bars represent calculated uncertainty in luminescence age.

\subsubsection{Polygon 1}

One primary core (20 cm long) and one smaller secondary core ( $9 \mathrm{~cm}$ long) were obtained from the center of Polygon 1 within $1 \mathrm{~m}$ distance of each other. The primary core produced 4 OSL ages, spanning 26.5 to $46.5 \mathrm{~cm}$ below the surface. The shallowest core segment had a luminescence age of $134.1 \pm 9.6 \mathrm{ka} \mathrm{BP}$. Luminescence ages of the sediments gradually increased to $191.8 \pm 20.2 \mathrm{ka}$ BP for the deepest segment. Water content varied slightly throughout the core between $13.2 \%$ and $15.7 \%$ (Table 2). The secondary core had slightly higher water content than the primary core, and was dated as one entire segment, producing an age of 190.2 $\pm 16.0 \mathrm{ka} \mathrm{BP}$. The luminescence age of the secondary core is marginally older than that of the same depth range from the primary core, but ages from the primary and secondary core overlap within the error margins at 2- $\sigma$ (Figure 27). 


\begin{tabular}{|l|l|l|l|}
\hline Core & $\begin{array}{l}\text { Depth below surface } \\
(\mathrm{cm})\end{array}$ & $\begin{array}{l}\text { Luminescence age } \\
(\mathrm{ka} \mathrm{BP})\end{array}$ & Water content $(\%)$ \\
\hline P1 primary & $26.5-31.5$ & $134.1 \pm 9.6$ & 14.1 \\
\hline P1 primary & $31.5-36.5$ & $159.5 \pm 17.8$ & 14.1 \\
\hline P1 primary & $38-42$ & $172.9 \pm 11.6$ & 13.2 \\
\hline P1 primary & $42-46.5$ & $191.8 \pm 20.2$ & 15.7 \\
\hline P1 secondary & $27-36$ & $190.2 \pm 16.0$ & 17.5 \\
\hline
\end{tabular}

Table 2: Measured OSL values for Polygon 1.

\subsubsection{Polygon 2}

Three OSL ages were obtained from one core $(16.5 \mathrm{~cm}$ long) taken from the center of Polygon 2, spanning 24 to $40.5 \mathrm{~cm}$ below the surface. The shallowest core segment produced a luminescence age of $85.8 \pm 6.7 \mathrm{ka} \mathrm{BP}$, slightly increasing to $93.6 \pm 9.6 \mathrm{ka}$ BP for the subsequent core segment, followed by a jump 131.6 $\pm 10.1 \mathrm{ka}$ BP for the deepest core segment (Figure 27, Table 3). Water content varied slightly throughout the core, between $12.3 \%$ and $14.9 \%$.

\begin{tabular}{|l|l|l|l|}
\hline Core & $\begin{array}{l}\text { Depth below surface } \\
(\mathrm{cm})\end{array}$ & $\begin{array}{l}\text { Luminescence age } \\
(\mathrm{ka} \mathrm{BP})\end{array}$ & Water content (\%) \\
\hline P2 & $24-30.5$ & $85.8 \pm 6.7$ & 14.9 \\
\hline P2 & $30.5-35.5$ & $93.6 \pm 9.6$ & 13.5 \\
\hline P2 & $35.5-40.5$ & $131.6 \pm 10.1$ & 12.3 \\
\hline
\end{tabular}

Table 3: Measured OSL values for Polygon 2.

\subsubsection{Polygon 8}

Two core segments $(8 \mathrm{~cm}$ and $10 \mathrm{~cm}$ long) were obtained from the same drill hole from the center of Polygon 8, spanning 2 to $10 \mathrm{~cm}$ depth and 19.5 to $29.5 \mathrm{~cm}$ depth. 
The 2 to $10 \mathrm{~cm}$ depth segment produced a luminescence age of $94.0 \pm 10.1 \mathrm{ka} \mathrm{BP}$ for the top half of the segment, increasing to $102.3 \pm 10.9 \mathrm{ka} \mathrm{BP}$ for the bottom half. The 19.5 to $29.5 \mathrm{~cm}$ depth segment produced two nearly identical ages for the top and bottom half of the segment, and is thus considered to be uniform age for the entire segment, approximately $124.7 \pm 10.4$ ka BP (Figure 27; Table 4). Water content was $15.5 \%$ throughout the core.

\begin{tabular}{|l|l|l|l|}
\hline Core & $\begin{array}{l}\text { Depth below surface } \\
(\mathrm{cm})\end{array}$ & $\begin{array}{l}\text { Luminescence age } \\
(\mathrm{ka} \mathrm{BP})\end{array}$ & Water content (\%) \\
\hline P8 & $2.0-6.0$ & $94.0 \pm 10.1$ & 15.5 \\
\hline P8 & $6.0-10.0$ & $102.3 \pm 10.9$ & 15.5 \\
\hline P8 & $19.5-24.5$ & $125.2 \pm 8.9$ & 15.5 \\
\hline P8 & $24.5-29.5$ & $124.7 \pm 10.4$ & 15.5 \\
\hline
\end{tabular}

Table 4: Measured OSL values for Polygon 8.

\subsection{Meteoric ${ }^{10} \mathrm{Be}$}

Measured ${ }^{10} \mathrm{Be} /{ }^{9} \mathrm{Be}$ ratios for $\mathrm{P} 1, \mathrm{P} 2$, and $\mathrm{P} 8$ ranged between $1.21 * 10^{-12}$ and $1.16^{*} 10^{-10}$, with errors ranging from $1.80 \%$ to $2.99 \%$ for all samples. Meteoric ${ }^{10} \mathrm{Be}$ concentrations were determined from these measured values using the Equation 4.

$$
\frac{\left({ }^{10} \mathrm{Be} /{ }^{9} \mathrm{Be}\right)_{\text {measured }} \cdot\left(\frac{N_{A} \cdot \text { weight }}{9{ }^{9} \mathrm{Be}_{\text {carrier }}}\right)-{ }^{10} \mathrm{Be}_{\text {blank }}}{M\left({ }^{9} \mathrm{Be}\right)}
$$

Where:

$\left({ }^{10} \mathrm{Be} /{ }^{9} \mathrm{Be}\right)_{\text {measured is }}$ the ratio of ${ }^{10} \mathrm{Be}$ to ${ }^{9} \mathrm{Be}$ measured directly from the sample, 
$\mathbf{N}_{\mathbf{A}}$ is Avogadro's number, or the number of atoms in one mole of a substance,

weight ${ }^{9} \mathbf{B e}_{\text {carrier }}$ is the weight of ${ }^{9} \mathrm{Be}$ in the added carrier solution

$\mathbf{M}\left({ }^{9} \mathbf{B e}\right)$ is the molar mass of ${ }^{9} \mathrm{Be}$ in $\mathrm{g} / \mathrm{mol}$,

${ }^{10} \mathrm{Be}_{\text {blank }}$ is the number of ${ }^{9} \mathrm{Be}$ atoms added by the carrier solution multiplied by the average ${ }^{10} \mathrm{Be} /{ }^{9} \mathrm{Be}$ ratio measured from laboratory blanks.

All three cores exhibited a general trend of having high meteoric ${ }^{10} \mathrm{Be}$ concentration at the surface, followed by an abrupt decrease in concentration by one to two orders of magnitude immediately below the surface, which then remained roughly constant with depth (Figure 28).

$\mathrm{P} 1$, situated mid-distance from the glacier, had meteoric ${ }^{10} \mathrm{Be}$ concentrations in the order of $10^{8}$ atoms/g for all depths. The highest concentration was at the surface ( 0 to $5 \mathrm{~cm}$ depth) with $9.13^{*} 10^{8}$ atoms $/ \mathrm{g}$, decreasing abruptly to $3.65^{*} 10^{8}$ atoms/g at 15 to $20 \mathrm{~cm}$, which then stayed about constant with depth (Table 5).

$\mathrm{P} 2$, situated farthest from the glacier, had the highest surface concentration of ${ }^{10} \mathrm{Be}$ out of the 3 cores. ${ }^{10} \mathrm{Be}$ concentration at 0 to $5 \mathrm{~cm}$ depth was $2.17 * 10^{9}$ atoms $/ \mathrm{g}$, followed by a substantial decrease by almost 2 orders of magnitude to $6.25^{*} 10^{7}$ atoms/g at 20 $\mathrm{cm}$ depth. ${ }^{10} \mathrm{Be}$ concentration then stayed constant at about $1.37 * 10^{8}$ atoms/g with depth (Table 5).

$\mathrm{P} 8$, situated closest to the glacier, had the lowest surface concentration of ${ }^{10} \mathrm{Be}$ out of the 3 cores. ${ }^{10} \mathrm{Be}$ concentration at the surface ( $2 \mathrm{~cm}$ depth) was $4.99 * 10^{8}$ atoms $/ \mathrm{g}$, decreasing to $2.45^{*} 10^{7}$ atoms $/ g$ at $16 \mathrm{~cm}$, which then stayed constant with depth (Table 5). 


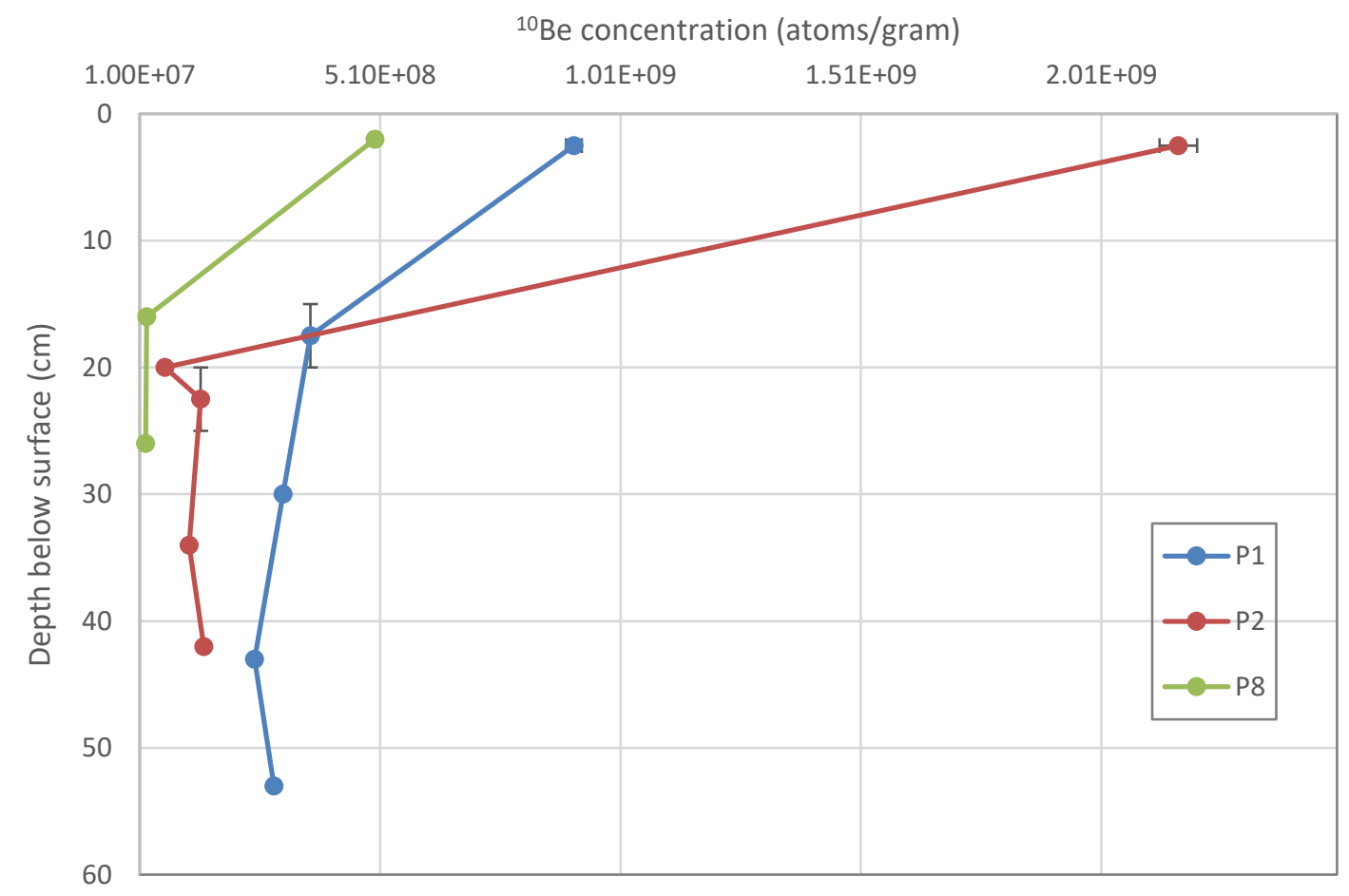

Figure 28: Meteoric ${ }^{10}$ Be concentration in atoms $/ g$ for $P 1, P 2$, and P8. Vertical bars (where present) represent the depth range from which the sediment sample was collected. Horizontal bars represent calculated uncertainty in ${ }^{10}$ Be concentration. Due to small error \%, some horizontal error bars are not visible. The near-surface sample for P1 and P2 are from the loose dry soil layer and all others are from the icecemented permafrost. 


\begin{tabular}{|l|l|l|l|l|l|}
\hline Sample ID & $\begin{array}{l}\text { Depth } \\
\text { below } \\
\text { surface } \\
{[\mathrm{cm}]}\end{array}$ & $\begin{array}{l}\text { Measured } \\
10 \text { Be/ }{ }^{9} \text { Be ratio } \\
{[\%]}\end{array}$ & $\begin{array}{l}\text { Error } \\
\text { Concentration } \\
\text { [atoms/g] }\end{array}$ & $\begin{array}{l}{ }^{10} \text { Be Sample } \\
\text { Concentration } \\
\text { Error } \\
\text { atoms/g] }\end{array}$ \\
\hline P1 0-5 & $0-5$ & $4.87 \mathrm{E}-11$ & 1.8 & $\mathbf{9 . 1 3 E + 0 8}$ & $1.64 \mathrm{E}+07$ \\
\hline P1 15-20 & $15-20$ & $1.98 \mathrm{E}-11$ & 1.8 & $\mathbf{3 . 6 5 E + 0 8}$ & $6.58 \mathrm{E}+06$ \\
\hline P1 30 & 30 & $1.50 \mathrm{E}-11$ & 1.8 & $\mathbf{3 . 0 8 E + 0 8}$ & $5.69 \mathrm{E}+06$ \\
\hline P1 43 & 43 & $1.30 \mathrm{E}-11$ & 2.0 & $\mathbf{2 . 4 9 E + 0 8}$ & $5.01 \mathrm{E}+06$ \\
\hline P1 53 & 53 & $1.49 \mathrm{E}-11$ & 2.0 & $\mathbf{2 . 8 9 E + 0 8}$ & $5.85 \mathrm{E}+06$ \\
\hline P2 0-5 & $0-5$ & $1.16 \mathrm{E}-10$ & 1.8 & $\mathbf{2 . 1 7 E + 0 9}$ & $3.91 \mathrm{E}+07$ \\
\hline P2 20 & 20 & $3.30 \mathrm{E}-12$ & 3.0 & $\mathbf{6 . 2 5 E + 0 7}$ & $1.88 \mathrm{E}+06$ \\
\hline P2 20-25 & $20-25$ & $7.41 \mathrm{E}-12$ & 2.0 & $\mathbf{1 . 3 7 E + 0 8}$ & $2.71 \mathrm{E}+06$ \\
\hline P2 34 & 34 & $6.09 \mathrm{E}-12$ & 1.8 & $\mathbf{1 . 1 3 E + 0 8}$ & $2.03 \mathrm{E}+06$ \\
\hline P2 42 & 42 & $7.52 \mathrm{E}-12$ & 1.8 & $\mathbf{1 . 4 3 E + 0 8}$ & $2.57 \mathrm{E}+06$ \\
\hline P8 2 & 2 & $2.70 \mathrm{E}-11$ & 1.8 & $\mathbf{4 . 9 9 E + 0 8}$ & $8.99 \mathrm{E}+06$ \\
\hline P8 16 & 16 & $1.21 \mathrm{E}-12$ & 2.5 & $\mathbf{2 . 4 5 E + 0 7}$ & $6.23 \mathrm{E}+05$ \\
\hline P8 26 & 26 & $1.21 \mathrm{E}-12$ & 2.7 & $\mathbf{2 . 2 3 E + 0 7}$ & $6.17 \mathrm{E}+05$ \\
\hline Lab Blank & ----------- & $9.59 \mathrm{E}-15$ & 1.7 & ---------- & ---------- \\
\hline
\end{tabular}

Table 5: Measured and calculated values of Beryllium for P1, P2, and P8.

${ }^{10} \mathrm{Be}$ concentrations plotted against mean grain size of the ${ }^{10} \mathrm{Be}$ sediment samples (determined by Laser Particle Sizer) was highly varied (Figure 29), and shows that meteoric ${ }^{10} \mathrm{Be}$ concentration is independent of grain size in the analyzed size fraction. This shows that sieving the sediments to the analyzed size fraction eliminates the grain size dependency of ${ }^{10} \mathrm{Be}$, as proposed by Willenbring and von Blanckenburg (2010), ensuring that interpretations based on measured ${ }^{10} \mathrm{Be}$ concentrations reflect transport processes and not clay content of the soils. 


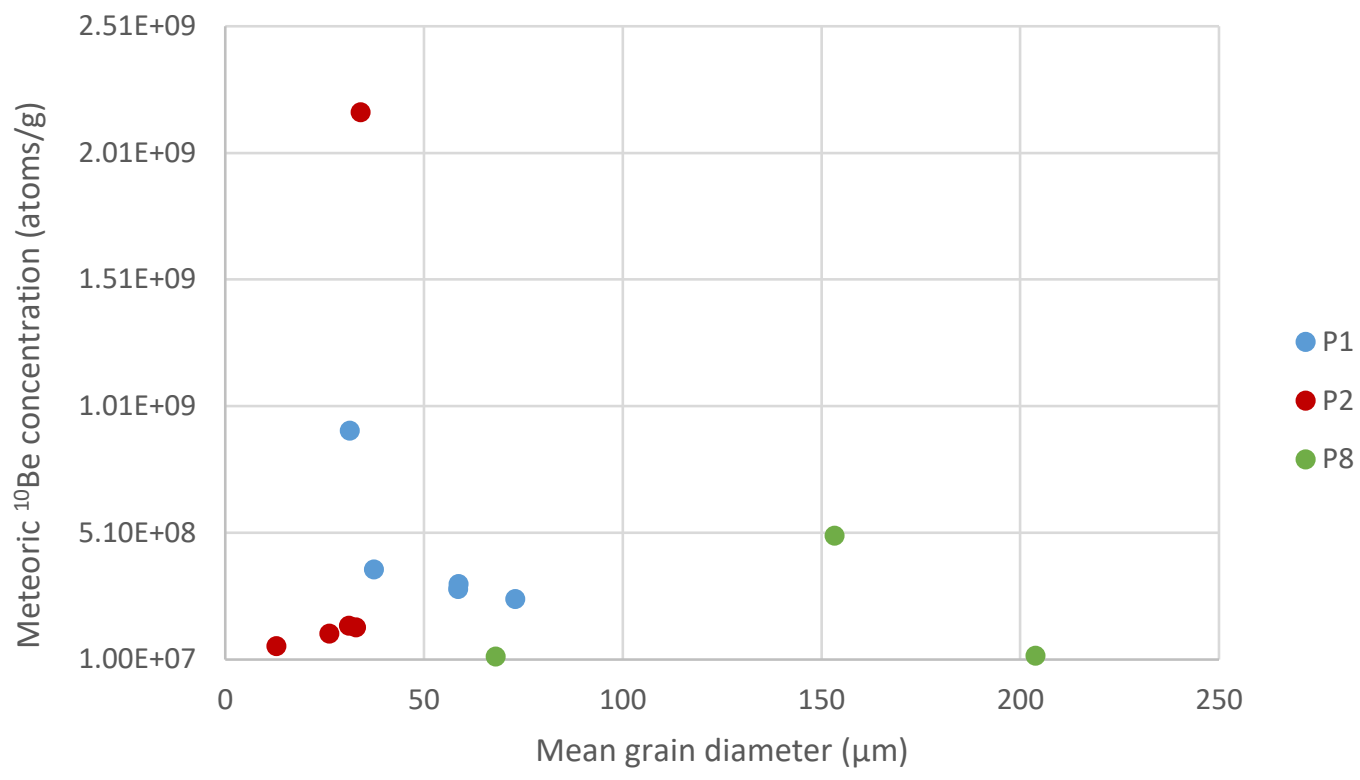

Figure 29: Plot of meteoric ${ }^{10}$ Be concentration and mean grain diameter, showing that ${ }^{10} \mathrm{Be}$ concentration is independent of grain size.

\subsection{Geochemistry of sediments}

Total anion and cation concentrations are plotted in Figure 30 and Figure 31 in units of parts per million (ppm), where each data point represents an individual depth within the core. All measured anions were detectable and generally abundant, averaging $20.34 \mathrm{ppm}$ for $\mathrm{Cl}^{-}, 81.93 \mathrm{ppm}$ for $\mathrm{SO}_{4}{ }^{2-}$, and $63.30 \mathrm{ppm}$ for $\mathrm{NO}_{3}{ }^{-}$. All measured cations were detectable except for $\mathrm{P}^{3+}$, which was below the detection threshold in all samples. For all samples, cations of highest abundance were $\mathrm{Na}^{+}$and $\mathrm{Ca}^{2+}$, reaching concentrations up to $234.39 \mathrm{ppm}$ for $\mathrm{Na}^{+}$ions and $107.49 \mathrm{ppm}$ for $\mathrm{Ca}^{2+}$ ions. $\mathrm{Sr}^{2+}$ ion concentrations were low but detectable, averaging $0.04 \mathrm{ppm}$ in all samples. Concentrations of $\mathrm{Fe}^{2+}$ ions were low (less than $1 \mathrm{ppm}$ ) for most of the cores. $\mathrm{Si}^{4+}$ ion concentrations were relatively low, ranging from $0.76 \mathrm{ppm}$ to $14.21 \mathrm{ppm}$ for all cores. P2 and P7 contained significantly higher total anion and cation concentrations compared to the other cores. No trends with depth or distance were observed within the measured depth range. See Appendix E for full geochemical data. 


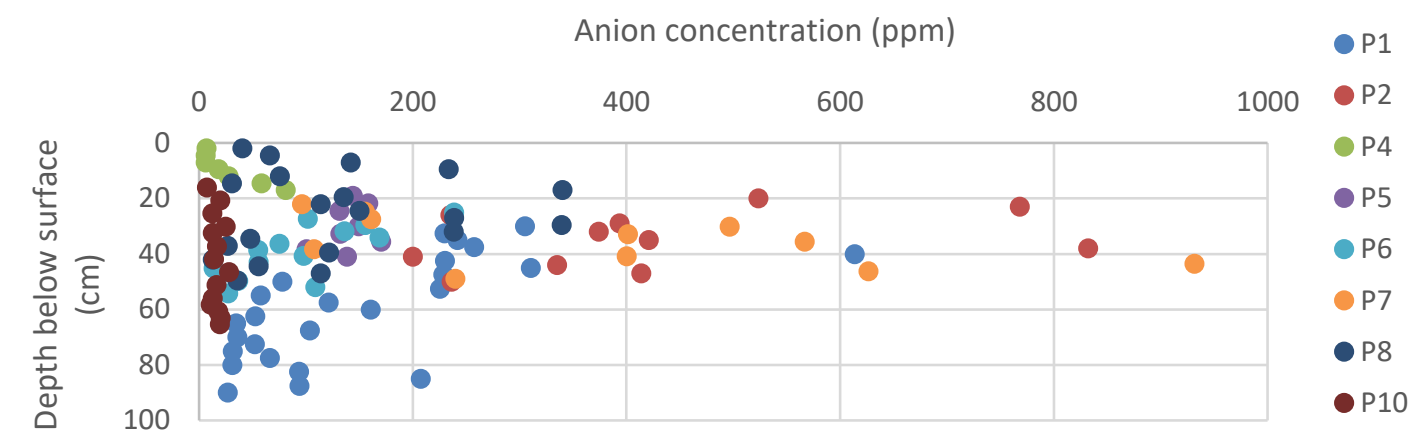

Figure 30: Total anion concentrations with depth for P1, P2, P4, P5, P6, P7, P8, and P10.

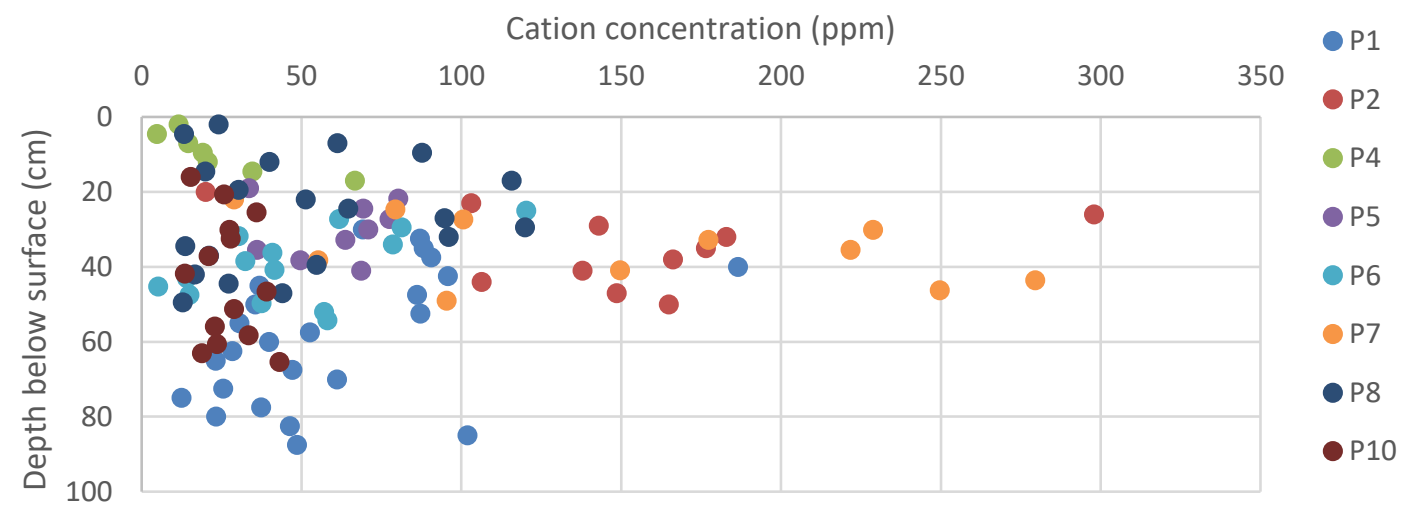

Figure 31: Total cation concentrations with depth for P1, P2, P4, P5, P6, P7, P8, and P10.

Because total ion content varied substantially between cores, calculating ratios of the main ions allows for the possibility of directly comparing ion content across all cores. A ternary plot of all anions $\left(\mathrm{Cl}^{-}, \mathrm{SO}_{4}{ }^{2-}\right.$, and $\left.\mathrm{NO}_{3}{ }^{-}\right)$shows that most cores generally fall along the same trend line, with the ratio of $\mathrm{NO}_{3}{ }^{-}$to $\mathrm{Cl}^{-}$remaining about constant while the ratio of $\mathrm{SO}_{4}{ }^{2-}$ to $\mathrm{NO}_{3}{ }^{-}$and $\mathrm{Cl}^{-}$is variable (Figure 32). P4 and $\mathrm{P} 10$ differ slightly from the main trend with a slightly higher ratio of $\mathrm{Cl}^{-}$to $\mathrm{SO}_{4}{ }^{2-}$ and $\mathrm{NO}_{3}{ }^{-}$, while $\mathrm{P} 2$ and P5 show clustering at a constant ratio for all 3 measured anions (Figure 33). 
Ternary diagrams of major cations show that all cores exhibit similar trends (Figure 33 and Figure 34). The ratio of $\mathrm{Fe}^{2+}$ to $\mathrm{Si}^{4+}$ is about constant for all cores, while the ratio of $\mathrm{K}^{+}$to $\mathrm{Fe}^{2+}$ and $\mathrm{Si}^{4+}$ fluctuates. Likewise, the ratio of $\mathrm{Mg}^{2+}$ to $\mathrm{Na}^{+}$is about constant for all cores, while the concentration of $\mathrm{Ca}^{2+}$ fluctuates. P10 shows a general clustering near the ion ratios expected from dolerite and has a higher ratio of $\mathrm{Fe}^{2+}$ to $\mathrm{Si}^{4+}$ and $\mathrm{K}^{+}$than the other cores.

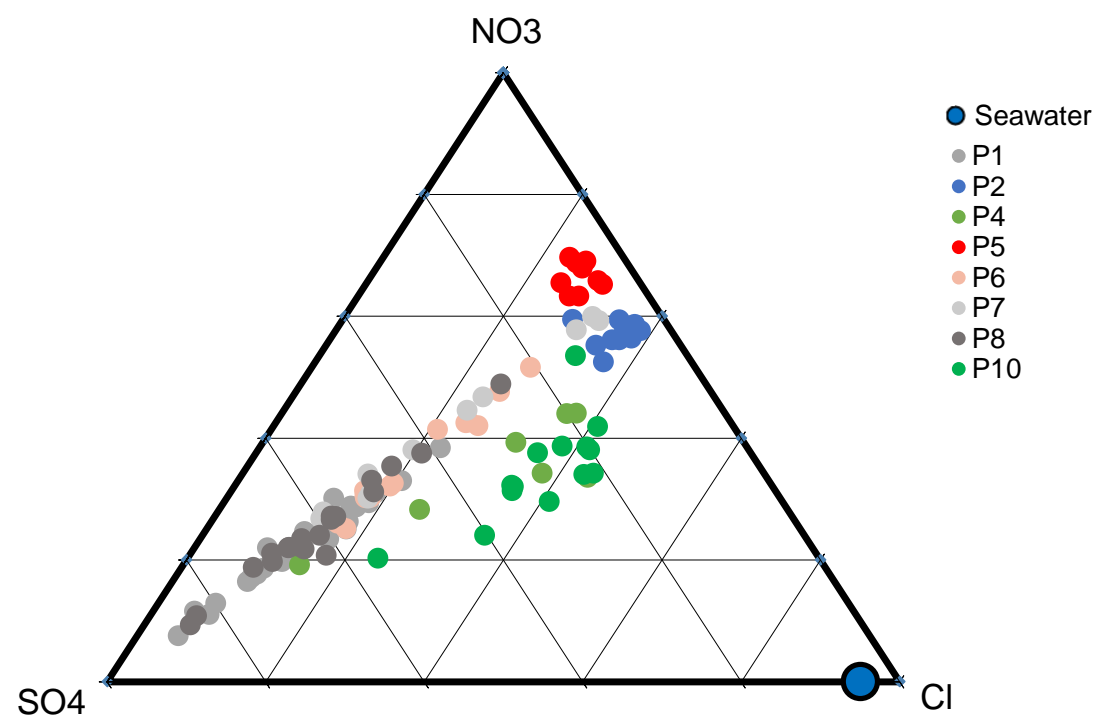

Figure 32: Ternary diagram of all measured anions $\left(\mathrm{Cl}^{-}, \mathrm{SO}_{4}{ }^{2-}\right.$, and $\left.\mathrm{NO}^{3-}\right)$ for all cores. 


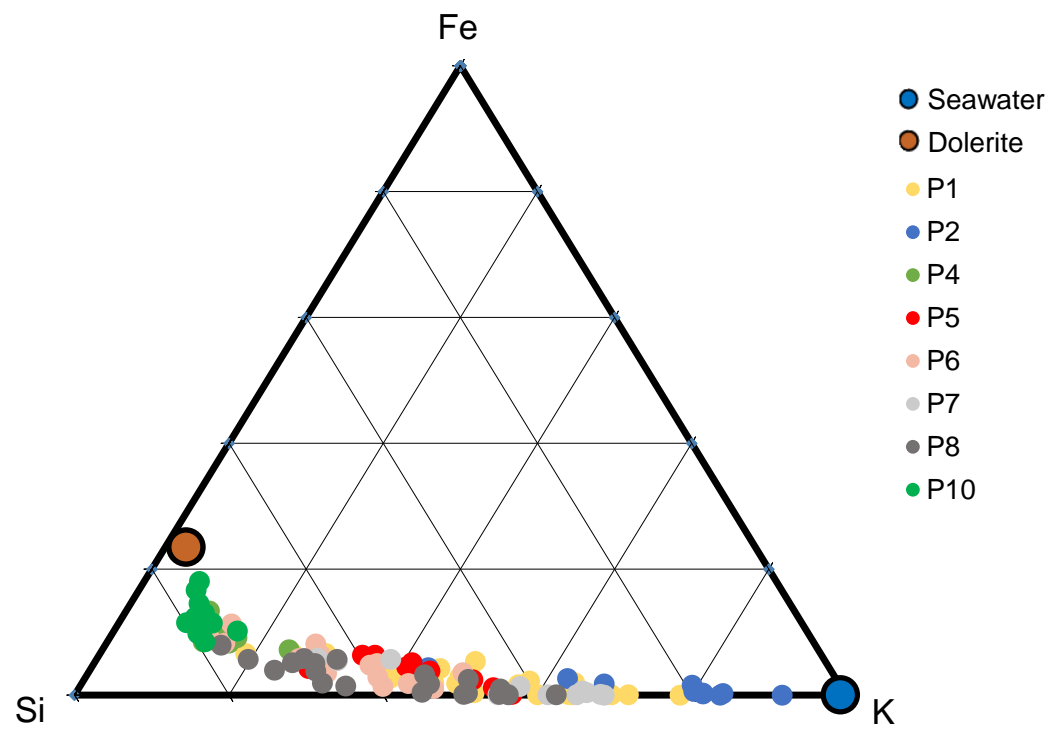

Figure 33: Ternary diagram of the cations $\mathrm{Fe}^{2+}, \mathrm{Si}^{4+}$, and $\mathrm{K}^{+}$for all cores.

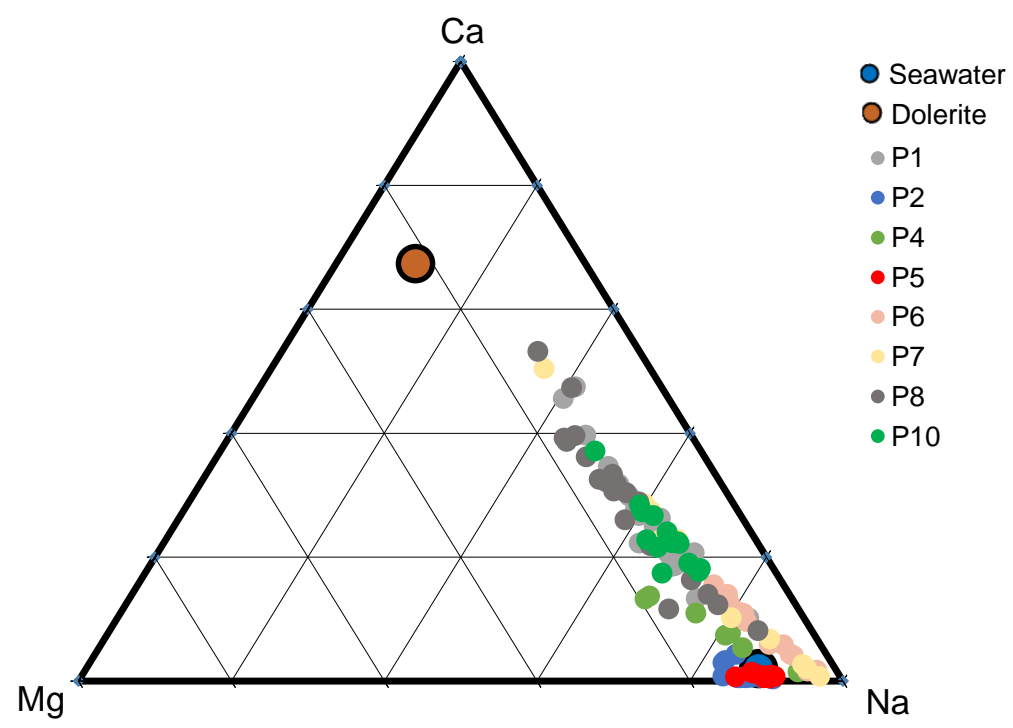

Figure 34: Ternary diagram of the cations $\mathrm{Mg}^{2+}, \mathrm{Ca}^{2+}$, and $\mathrm{Na}^{+}$for all cores. 
All cations were additionally analyzed in pairs to explore individual variations in ion ratios, in which concentrations of each cation were plotted against concentrations of each of the other cations. For the majority of cation pairs, most cores generally exhibited the same trend line, showing that ratios of each respective ion pair were nearly the same for most cores (see Figure 35 and Figure 36 for examples). Including the ion concentrations of seawater in the plots (data taken from Pawlowicz, 2013, depicted in Figure 35 the seawater dilution line) shows that the concentrations of all ions are above the expected concentration for seawater (Figure 35). Plotting the ion concentrations of dolerite weathering from the Dry Valleys (calculated from oxide concentrations measured by Salvatore et al., 2013; depicted in Figure 36 as the dolerite dilution line) showed that concentrations of all ions were between the expected concentrations of seawater and dolerite. Because this was seen in all ion pairs for all cores, an example plot of this observed trend is shown in Figure 36. See Appendix E for all other ion ratio plots.

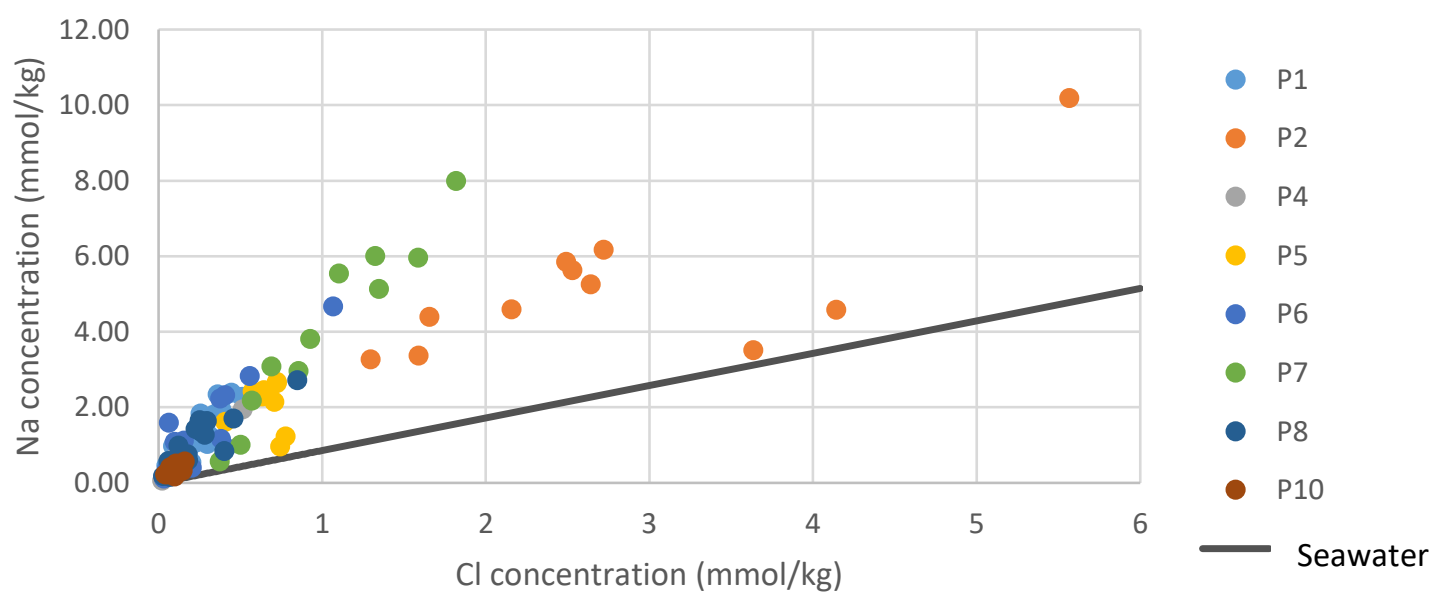

Figure 35: Example plot of $\mathrm{Na}^{+}$and $\mathrm{Cl}^{-}$concentrations showing that most cores exhibit the same general trend and that all ion concentrations are above the concentrations expected from seawater. 


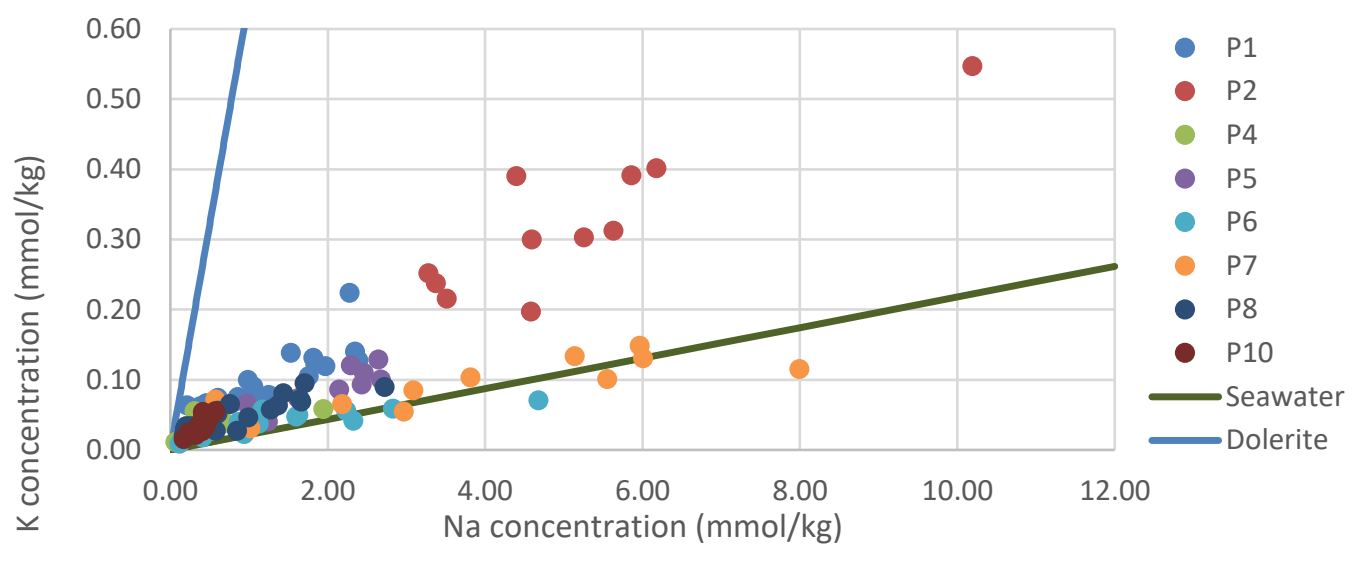

Figure 36: Example plot of $\mathrm{K}^{+}$and $\mathrm{Na}^{+}$concentrations showing that ionic concentrations for all cores are between the expected concentrations found in sea water and in dolerite rocks.

In certain ion pairs where wider variability from the general trend was observed, closer inspection revealed that ions ratios were constant with depth for some cores and substantially varied in other cores (Figure 37). P2 and P5 always plotted along the same line, signifying a constant ratio with depth. P6, P7, and P8 exhibited a similar trend, with P6 and P7 almost always plotting directly on the seawater dilution line and P8 plotting slightly above the seawater dilution line. P1 typically showed slightly more variability, and P10 exhibited its own trend with a tendency to cluster due to low concentrations of most ions. $\mathrm{Ca}^{2+} / \mathrm{Na}^{+}$is shown as an example of these observations (Figure 37); all other ion ratio plots show the same trends (Appendix E). 


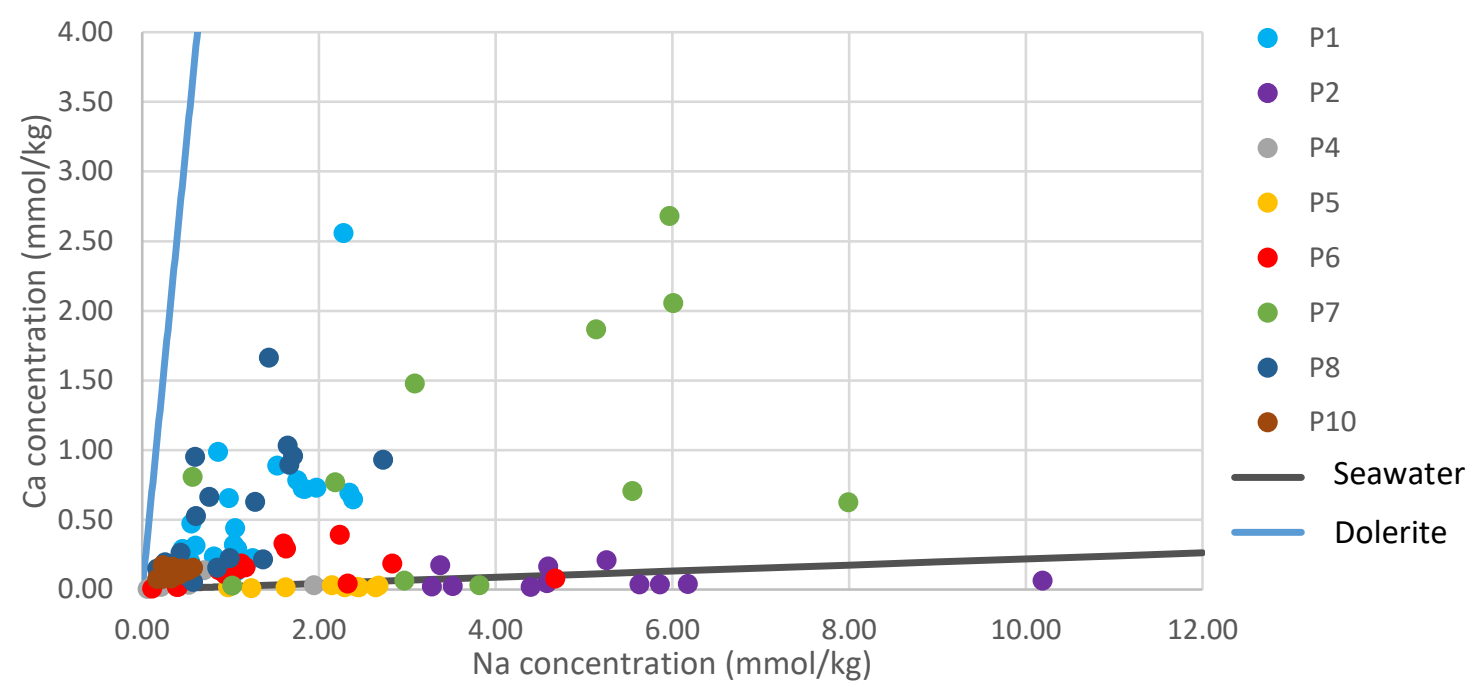

Figure 37: Example plot of $\mathrm{Ca}^{2+}$ and $\mathrm{Na}^{+}$concentrations showing that ionic concentrations of certain ion pairs were constant ratios for some cores and widely variable for other cores.

Using a color gradient to portray depths of the measured ion concentrations showed that there are no trends with depth for any of the cores (Figure 38). In cores P6, P7, and P8, which tended to have the same ratio of ions for all depths, concentrations varied seemingly randomly with increasing depth. Likewise, in cores that generally had wider variability in ion ratios (P1 and P10), these variations are not tied to depth (Figure 38). 


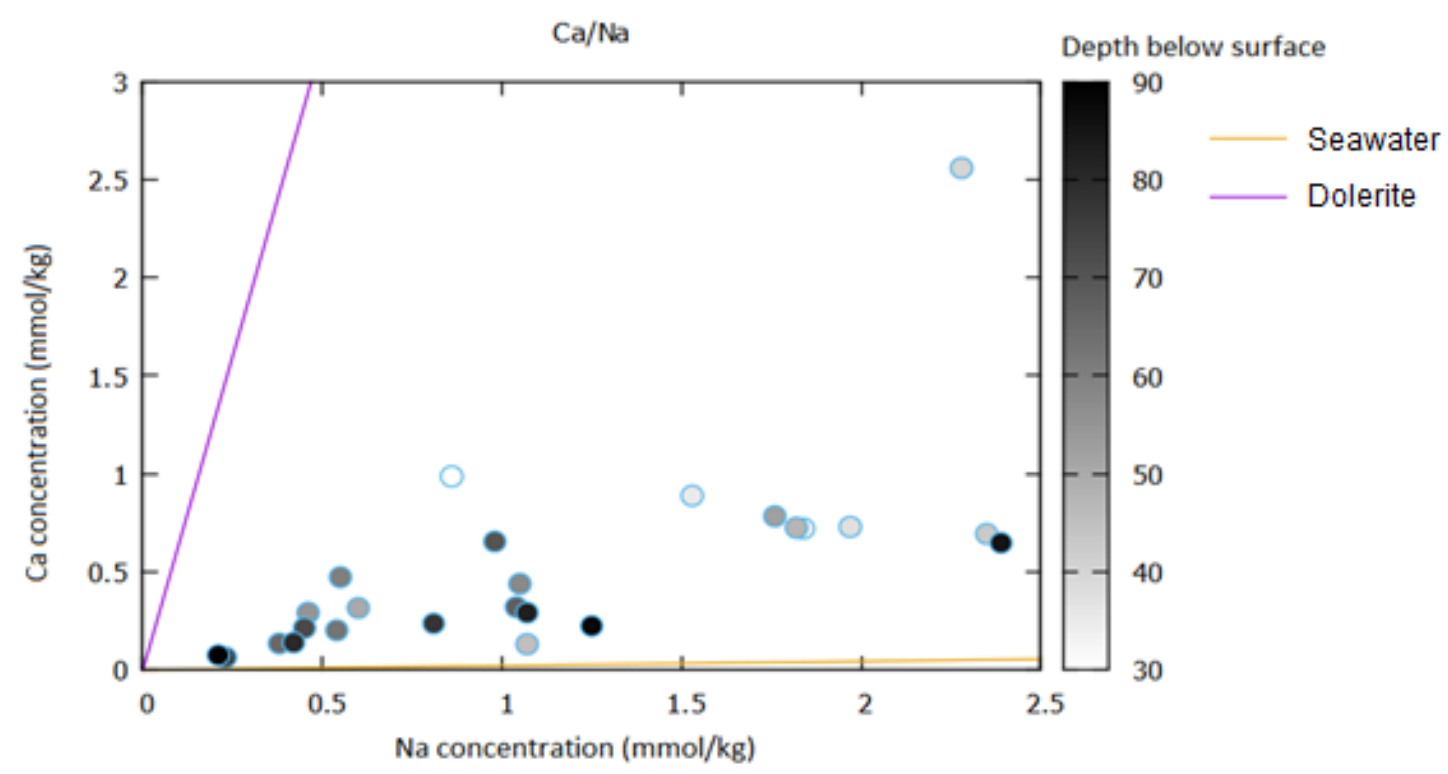

Figure 38: Example plot showing that ion ratios do not exhibit trends with depth. Data from Polygon 1. 


\section{Chapter 6. Discussion}

\subsection{Sediment characteristics: grain size, sediment composition, grain morphology, porosity, and translocated clay}

\subsubsection{Grain size}

Grain size analysis shows that sediments in the upper $183 \mathrm{~cm}$ in University Valley are composed primarily of medium-grain sand. Significant amounts of silt and clay-sized particles in the sediments indicate that there is a high degree of weathering in the valley that results in extensive breakdown of the sediments. There were no trends with depth, nor were there trends by location within the valley, suggesting that the deposition process of these sediments is similar for the entire valley and has been occurring at a steady rate for at least the last $200 \mathrm{ka}$, as determined by OSL dating of the upper 53 $\mathrm{cm}$ of sediments.

\subsubsection{Sediment composition}

Sediment composition from the floor of University Valley is reflective of the surrounding outcrops. Measured dolerite content observed in thin section correlates to the amount of dark material visible on the ground surface in aerial photographs of the valley, which is directly related to the amount of dolerite cropping out from the valley walls. As such, cores located near areas of the valley walls that have larger amounts of exposed dolerite tend to have higher amounts of dolerite in the sediment. These observations strongly suggest that downslope migration of sediment grains eroding from the valley walls are the main mode of deposition in the valley, with only minimal remobilization by wind. 


\subsubsection{Grain morphology}

$\mathrm{K}$ feldspar and quartz grains exhibited high degrees of rounding and sphericity, indicating that these sand grains are mature (Folk, 1951; Pettijohn, 1975). Highsphericity grains, despite the sediments being relatively immature ( $<200 \mathrm{ka})$, indicate that these sand grains were pre-rounded prior to deposition onto the valley floor. These mature grains most likely originate from sandstones of the Beacon Supergroup, which have well-rounded grains and are eroding from the valley walls (Figure 39). In contrast, dolerite grains, which originate as intrusive sills in the valley walls, cannot undergo prior rounding and therefore the degree of rounding exhibited by dolerite grains is most representative of sediment transport within the valley.

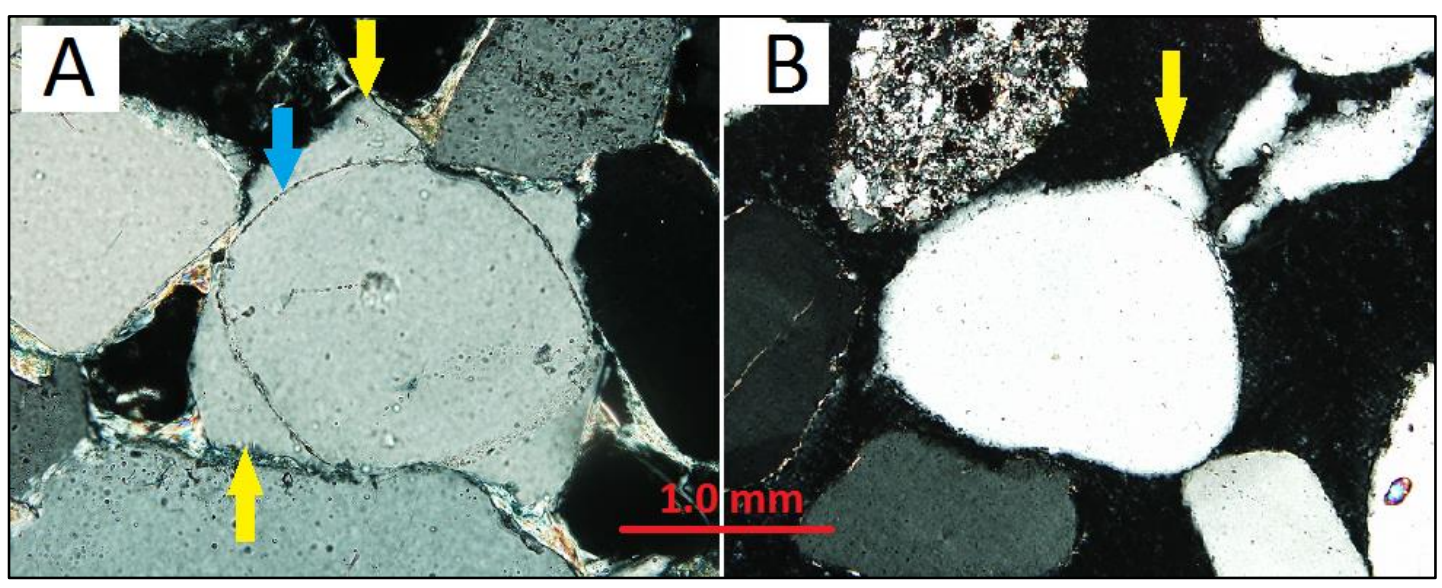

Figure 39: Photomicrographs show similarities in quartz grain morphology that suggest a common source. (A) Beacon Heights orthoquartzite member of the Beacon Supergroup, which crops out in University Valley. Well-rounded quartz grains typical of eolian deposition have quartz overgrowths. (B) Rounded quartz grain from University Valley with residual quartz overgrowth. Blue arrow indicates rounded grain surface of quartz grain, yellow arrows point out quartz overgrowths. $40 x$ magnification, cross-polarized light.

Dolerite grains in University Valley are mainly angular to sub-angular and exhibit low-sphericity, indicating that sand-sized grains are only minimally mobilized within the valley, which is also reflected in the measured geochemical data and dolerite content of the sediments. Therefore, these observations in grain morphology suggest the dominant mode of weathering in the valley is not wind-induced saltation of sand- 
sized grains or wind erosion of dolerite rocks, but is instead mechanical breakdown in place at the site of original deposition. Especially in the Dry Valleys, thermal contraction-expansion of dolerite from solar heating and salt crystallization within cracks facilitate weathering and breakdown of dolerite into smaller grains, explaining how it is possible to find small mechanically broken down particles that do not exhibit extensive rounding (Figure 40) (Selby, 1971; Selby and Wilson, 1971).
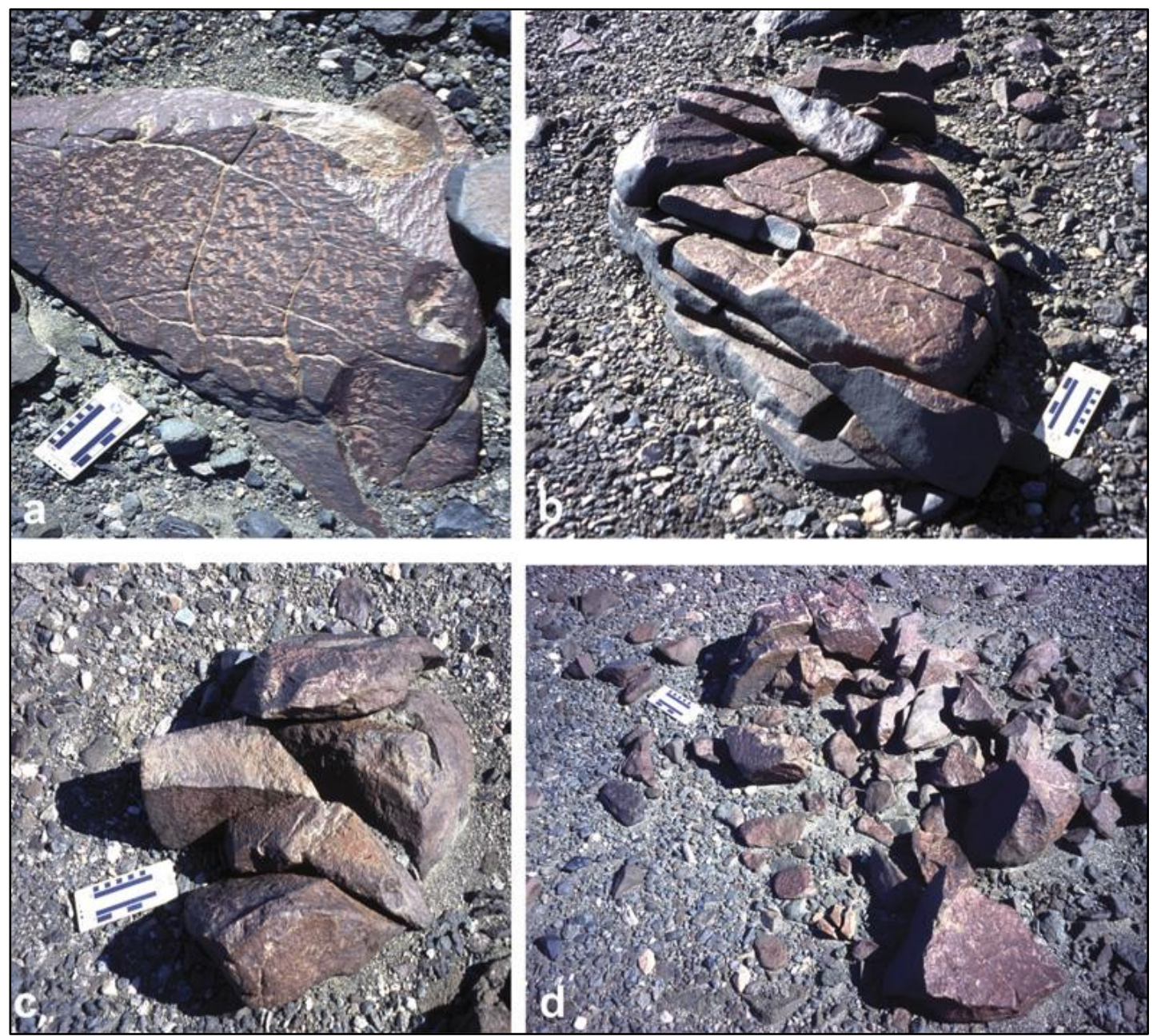

Figure 40: In-situ breakdown of rocks from thermal cycling. (a)-(d) show rocks in progressive stages of breakdown, as boulders (a) are transformed into multiple smaller pieces (d). From Bao and Marchant (2006). 


\subsubsection{Porosity}

Due to limited sample material, gravimetric water content of the sediments was not obtained to determine ice content of the sediments. However, because sediment cores were taken from below the ice table in the ice-cemented ground, thin sections that preserve the original pore structure of the sediments were used to estimate the original ice content. As observed in thin section, pore structures within the sediments were larger than what would be expected for naturally unfrozen sandy sediment, and therefore these pore space enlargements can be assumed to be the product of pore expansion due to ice growth (Figure 41). Additionally, the measured porosity values were similar to porosity values obtained by other studies in the Dry Valleys that used different methods such as mercury porosimetry and density measurements (e.g. McKay et al., 1998; Sizemore and Mellon, 2008); this confirms that the porosity measurements derived from thin section microscopy analysis were done correctly.

The observed porosities generally showed no trends with depth or distance down valley from the glacier, indicating that ice content of the sediments is highly variable throughout the valley and within the same core over micro scales of only a few millimeters (Figure 41). This variability is likely influenced by several factors including differing temperature zones in the valley, sporadic snow patches on the ground surface, downward migration of briny films of snowmelt, and past glacial activity that left buried bodies of ground ice dispersed through the subsurface (e.g. Sugden et al., 1995; Bockheim, 2002; Marchant et al., 2002; Guglielmin and French, 2004; Lacelle et al., 2011; Dickinson et al., 2011; Raffi and Stenni, 2011; Lacelle et al., 2013; Dickinson and Rosen, 2003). More data are needed to determine whether larger-scale trends in porosity exist. 


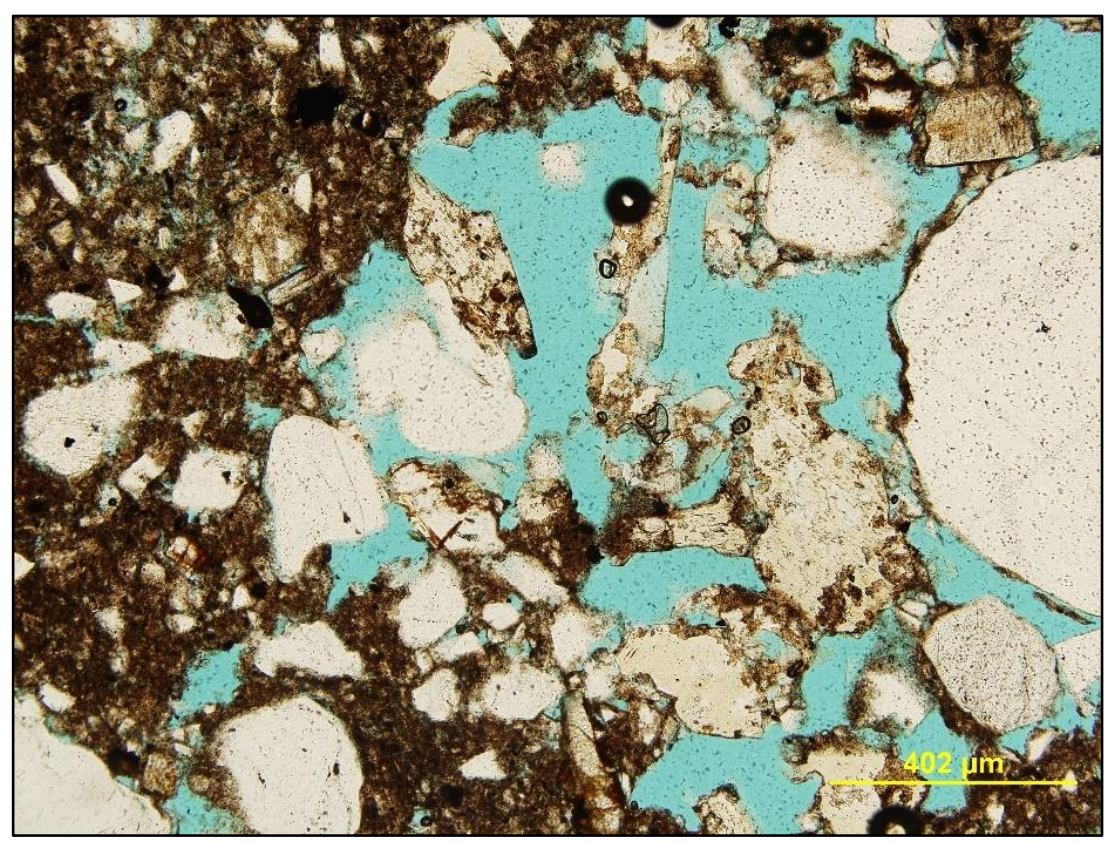

Figure 41: Photomicrograph shows highly variable pore structures within millimeter scales. Pore spaces are seen as blue epoxy, white clasts are sand and silt grains, and brown material is clay matrix. Sample: P8 $28 \mathrm{~cm}$ depth, 100x magnification, plane light.

\subsubsection{Translocated clay}

When viewed in thin section, occasional samples showed clay bridges between loosely-packed sand grains and clay coatings on sand grains, which are indicative of clay translocation by water (Figure 42) (e.g. Buurman et al., 1998; Kühn et al., 2010; Antemüller, 1962; West et al., 1987; Milodowski, 2014; McFadden et al., 1992). Although current conditions in the valley are not conducive to supporting seasonal liquid water, small amounts of transient liquid water from melting of occasional snow patches were observed by Lacelle et al. (2016), which could percolate through the near-surface dry permafrost. The infrequency of observed clay bridges suggests that these small surface wetting events are unable to translocate clays through the soil profile; instead, only minor clay translocation in the shallow subsurface is possible, the evidence of which remains preserved after surface sediments are infiltrated by the ice table and buried by ongoing sediment accumulation. 


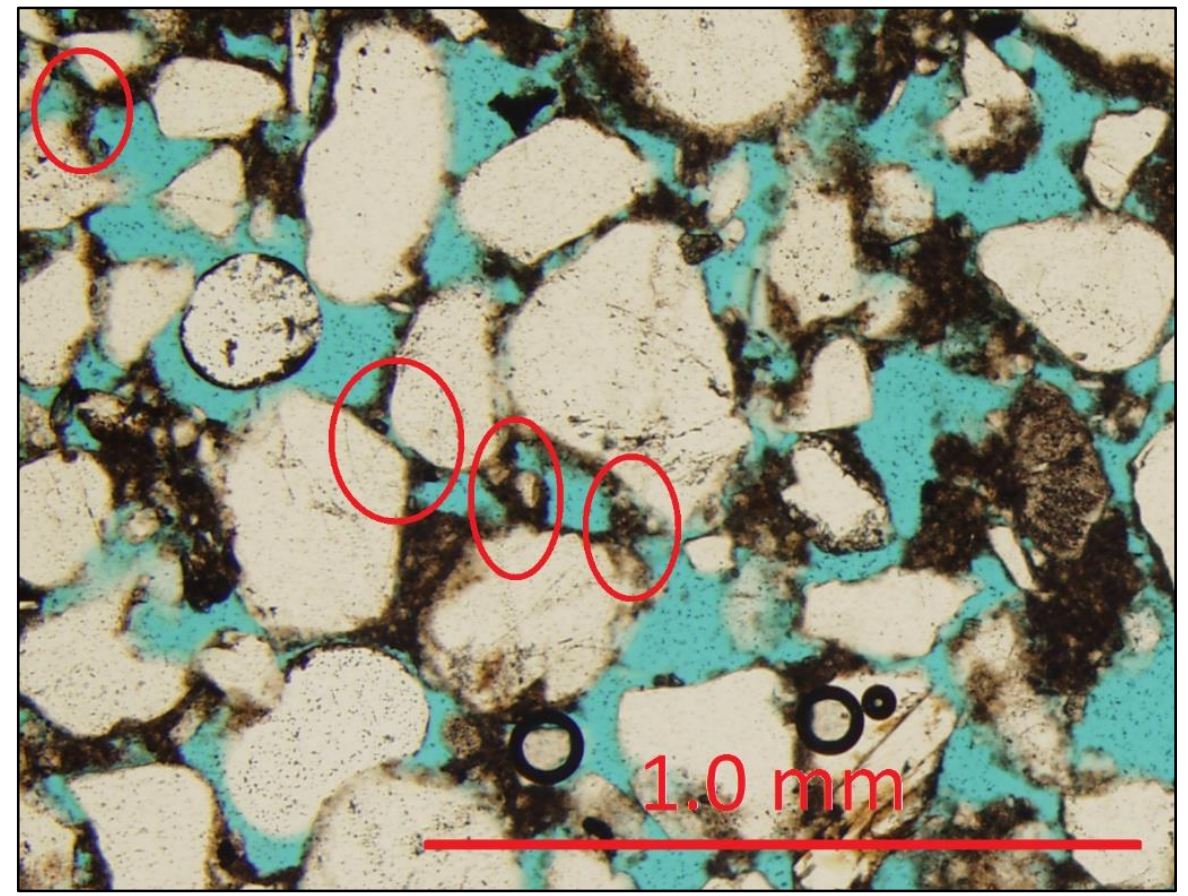

Figure 42: Photomicrograph shows clay bridges between loosely-packed grains and clay coatings on grains as evidence of clay translocation. Clay bridges are circled in red. Sample: P5 19-22 cm depth, 40x magnification, plane light.

\subsection{Sedimentation}

\subsubsection{Sediment deposition rates and processes indicated by Optically Stimulated Luminescence dating}

OSL dating shows that sediments in the upper $53 \mathrm{~cm}$ have been accumulating in University Valley for the last $200 \mathrm{ka}$. A linear regression for all the measured cores showed an accumulation rate of $2.10 \pm 0.36 \mathrm{~mm} / \mathrm{ka}$. The $\mathrm{R}^{2}$ value for regression was 0.6044 , showing that this accumulation rate can be applied to the majority of the valley. This calculated accumulation rate, as well as the measured ages in the valley, are in good agreement with ages measured by Lacelle et al. (2013) from one OSLdated sediment core taken near the toe of the glacier, which had an average accumulation rate of $2.14 \mathrm{~mm} / \mathrm{ka}$. Sediments in $\mathrm{P} 1, \mathrm{P} 2$, and the upper section of P8 show gradual accumulation of sediments over time, while the two almost identical ages in the lower section of P8 (20 to $29 \mathrm{~cm}$ depth) show instantaneous sediment 
deposition and likely represent a rapid mass wasting event that occurred at P8 approximately $125 \mathrm{ka}$ BP. Field observations note that the coring site for P8 appears to be located on a surficial mass wasting deposit originating from the valley walls, which supports the interpretation that these two identical OSL ages result from a rapid mass wasting event. Because the mass wasting deposit looks undisturbed in aerial photographs and partially overlies the toe of the glacier, it can be inferred that University Glacier retreated prior to the occurrence of this rapid mass wasting event, allowing for this surface feature to remain undisturbed for at least the last $125 \mathrm{ka}$ (Figure 43). Additionally, gradual younging to the surface at a constant rate for all cores, combined with the absence of any signs of prolonged periods without deposition, show that there was no significant glacial activity within the last $200 \mathrm{ka}$, further supporting that these sediments were deposited after the glacier retreated to its present-day location.

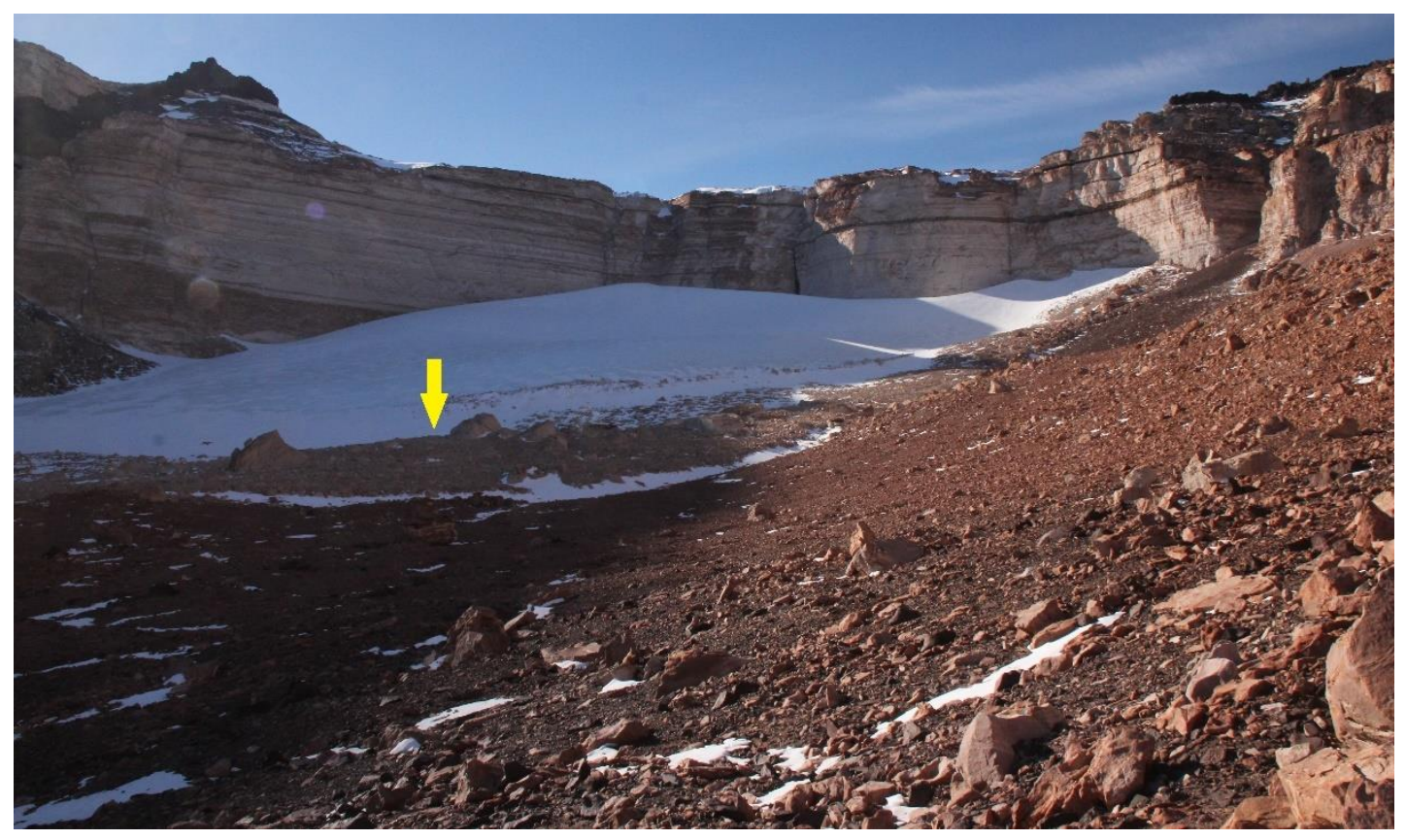

Figure 43: Photo of OSL-dated mass wasting deposit (indicated by the yellow arrow) partially overlying the toe of University Glacier. Courtesy of Alfonso Davila (2009).

Luminescence ages are in stratigraphic order for individual cores, but not across all 3 cores (Figure 27). P2 shows a peculiarity of having comparatively younger OSL ages (about 50 ka difference) than P1 and P8 for the same depths below the ground surface. 
Because P2 was sampled from a depression in the valley, the following scenario is proposed to explain this observed peculiarity in OSL ages (Figure 44):

(1) Prior to $130 \mathrm{ka}$ BP, MIS 6 glacial conditions allowed for the formation and collection of ice pockets and/or preservation of buried blocks of glacial ice in various subsurface locations throughout the valley and at P2. Meanwhile, sediments accumulated at the surface at an equal rate over the entire valley from gradual erosion of the valley walls and eolian deposition.

(2) Starting around $130 \mathrm{ka} \mathrm{BP}$, sublimation of the entrapped ice caused lowering of the ground surface at P2 along with the overlying sediments, which formed a depression similar to a glacial kettle hole at P2. Sediments from the deepest measured depth of P2 (40.5 cm depth) were deposited during this period of ablation, during or shortly after the formation of the depression.

(3) Sediments continued to accumulate at a steady rate throughout the valley from gradual erosion of the valley walls and eolian deposition, but the depression at P2 functioned as a catchment, resulting in sediments accumulating slightly faster (more volume of sediment per unit time) at $\mathrm{P} 2$ than at the other core sites. 


\section{(1) Prior to 130 ka BP}

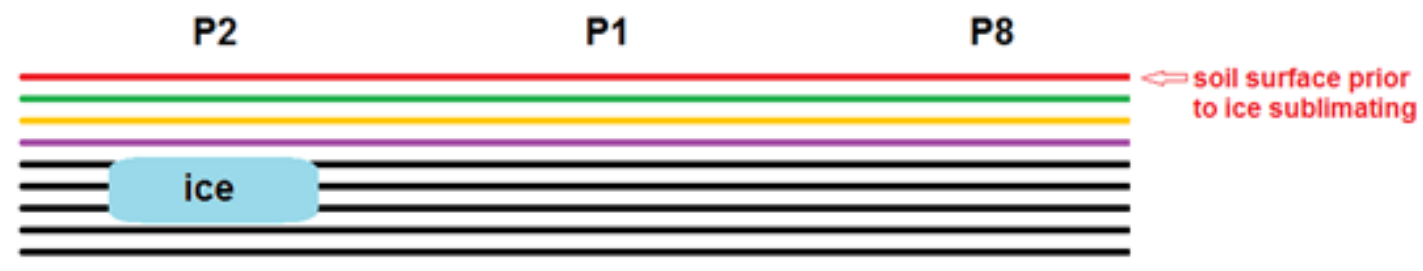

(2) 130 ka BP - 115 ka BP

$\begin{array}{lll}\text { P2 } & \text { P1 } & \text { P8 }\end{array}$

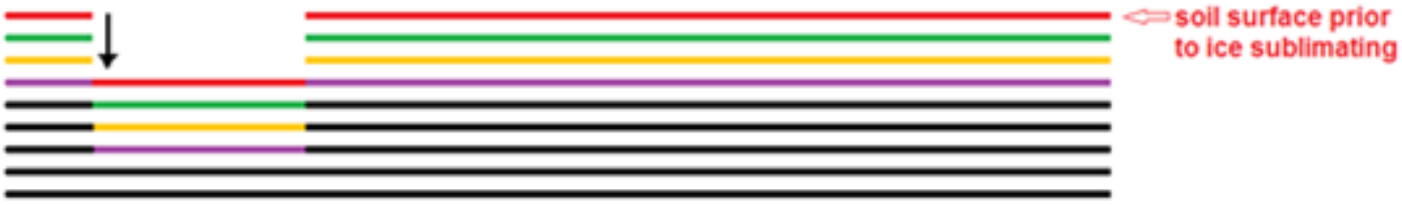

(3) 115 ka BP - present

P2

P1

P8

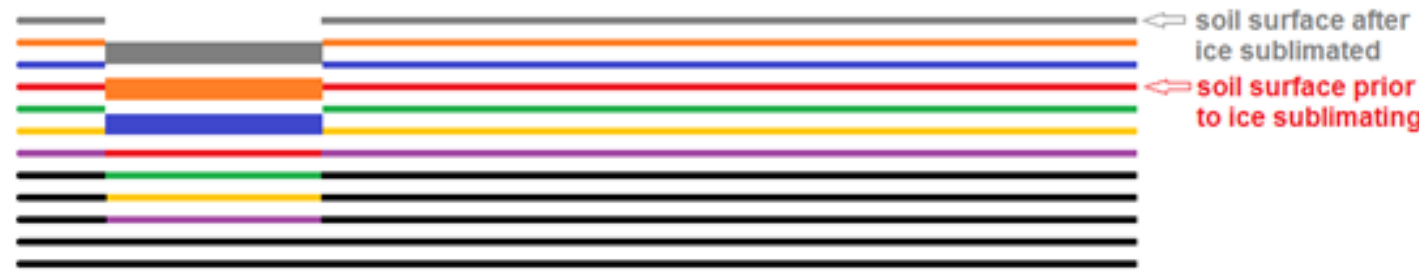

Figure 44: A schematic diagram illustrating the formation of depression at P2 that resulted in comparatively younger OSL ages at deeper depths. Different colors represent different sediment ages, with black lines representing the underlying undifferentiated till of unknown thickness. Thicker lines represent larger thickness of accumulated sediment per unit time (faster sediment accumulation). Depths and distances are not depicted to scale.

With this scenario, measured depths in P2 can be raised by the height of the ablated ice to realign the sediment ages with depth across all cores. Because the shallowest segment of P1 and deepest segment of P2 share a common age ( 134 ka BP in P1 and $\sim 132 \mathrm{ka} \mathrm{BP}$ in P2, both overlapping within error), a height difference of $9 \mathrm{~cm}$ between the two samples was calculated from the corresponding depths. Adding this $9 \mathrm{~cm}$ difference in sediment height to all measured depths in P2 realigns the sediment ages and depths with those of $\mathrm{P} 1$ and $\mathrm{P} 8$, resulting in $\mathrm{P} 2$ being in stratigraphic order with P1 and the lower section of P8 (Figure 45). 
The top section of P8 has a similar accumulation rate to that of P1 and P2, but lies about $15 \mathrm{~cm}$ above the regression line (Figure 45). This is likely due to a rapid mass wasting event $125 \mathrm{ka}$ BP that instantaneously deposited the entire bottom section of the core, raising the total measured soil profile by at least $9 \mathrm{~cm}$. After subtracting the height of the measured mass wasting deposit, the top section of P8 is lowered by $9 \mathrm{~cm}$, giving a more accurate representation of sediment accumulation over time in the valley and fitting closer to the regression line (Figure 45). A new linear regression calculated from all 3 cores after raising of $\mathrm{P} 2$ and removal of the height of mass wasting deposit from $\mathrm{P} 8$ gives an $\mathrm{R}^{2}$ value of 0.8772 , and only minimally changes the sediment accumulation rate to approximately $2.12 \pm 0.17 \mathrm{~mm} / \mathrm{ka}$ (Figure 45 ). The true height of sediment added by the rapid mass wasting event is unable to be determined by OSL alone due to incomplete retrieval of the middle section of core P8 (between 10 and 20 cm depth), and therefore it is possible that the mass wasting deposit at P8 is thicker than $9 \mathrm{~cm}$, in which case the top segment of P8 could be lowered further. Additional lowering of the top section of $\mathrm{P} 8$ by $4 \mathrm{~cm}$ is plausible and would create a regression line that passes through the origin and increases the $\mathrm{R}^{2}$ value to 0.889 , strongly signifying that accumulation of sediments is generally constant for the entire valley, with slight variations across different locations in the valley that are related to mass wasting events and erosion of the valley walls. 


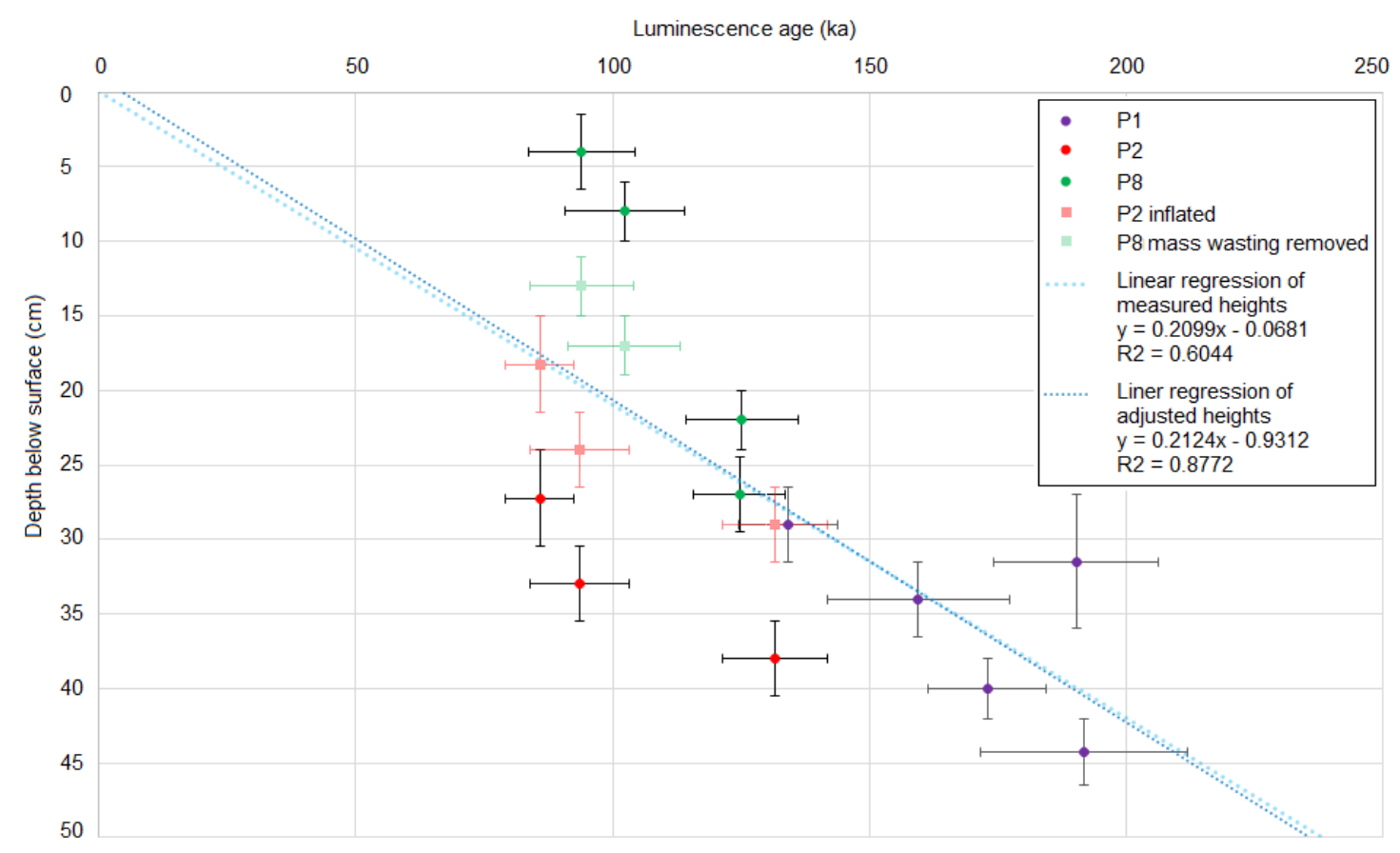

Figure 45: Plot showing that adjusted depths of P2 (per the deflation scenario) and $P 8$ (with mass wasting deposit height removed) results in all cores having OSL ages in stratigraphic order and exhibit a similar accumulation rate.

\subsubsection{Fine particle deposition rates and processes determined from meteoric ${ }^{10} \mathrm{Be}$}

Meteoric ${ }^{10} \mathrm{Be}$ profiles for all 3 cores do not exhibit the classic exponential decrease with depth that would be indicative of environments where liquid water allows the downward translocation of ${ }^{10}$ Be-rich clay particles. Instead, profiles show a high concentration of ${ }^{10} \mathrm{Be}$ at the surface, followed by an abrupt decrease in concentration by up to 2 orders of magnitude, which then stays about constant with depth (Figure 46). This type of data curve suggests that liquid water has not existed in amounts sufficient for initiating significant translocation through the soil profile for the last 200 $\mathrm{ka}$, as bounded by the OSL age of the deepest ${ }^{10} \mathrm{Be}$ sediment sample. However, infrequent clay bridges between sediment grains seen in thin section are evidence that small surface wetting events have occurred from melting of snow blown into the valley, and therefore the slight variations in measured ${ }^{10} \mathrm{Be}$ concentration with depth may be attributed to additional ${ }^{10} \mathrm{Be}$ deposited by varying amounts of occasional snow melt during the time when the sediments at those depths were exposed at the surface. 


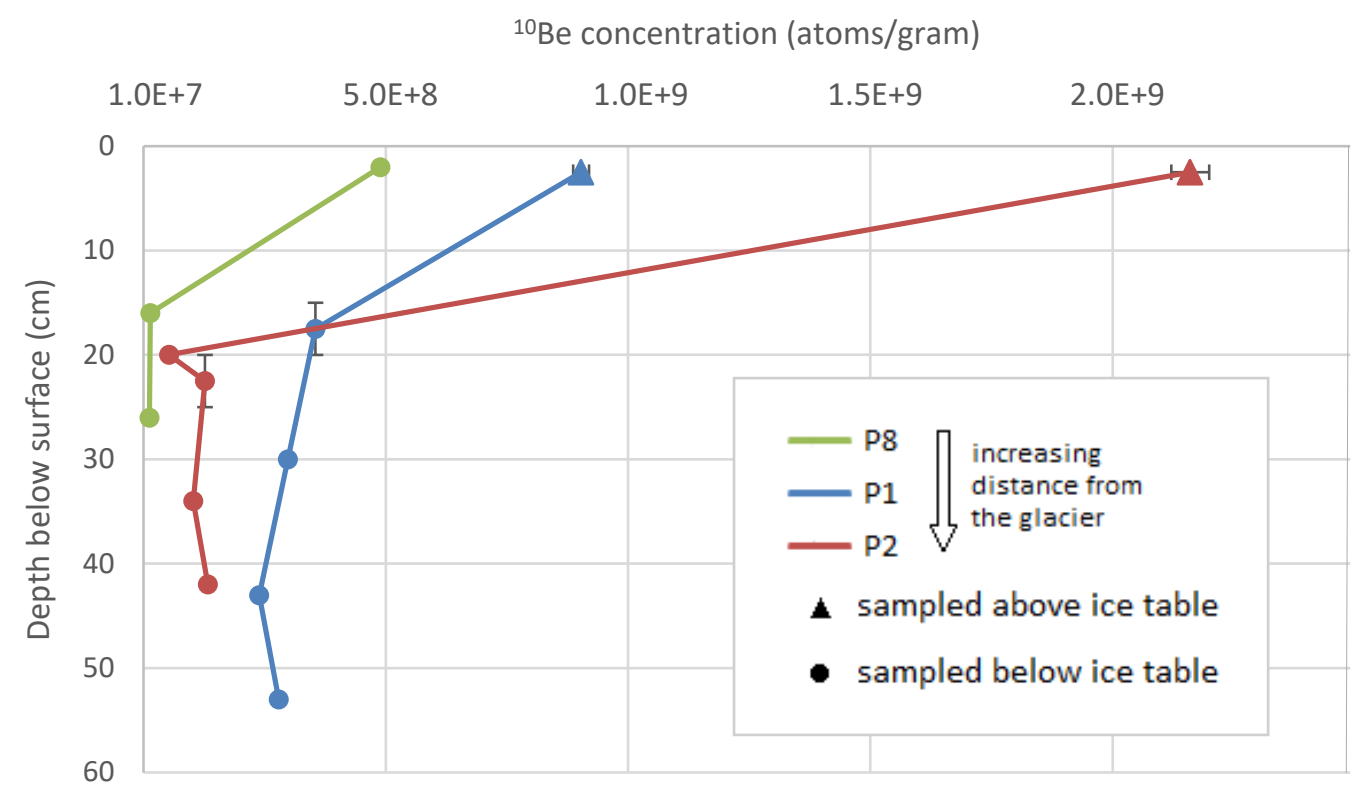

Figure 46: Meteoric ${ }^{10}$ Be concentration for $P 1, P 2$, and $P 8$. Horizontal bars represent calculated uncertainty in ${ }^{10}$ Be concentration; due to small error \%, some error bars are smaller than the data points and are not visible. Triangles represent samples taken from the loose dry sediment layer above the ice table, and circles represent samples taken from below the ice table within the frozen ground. Vertical bars represent the depth range from which the sediment sample was collected.

In the Dry Valleys, the main sources of meteoric ${ }^{10} \mathrm{Be}$ deposition are dry fallout, snow transported from the East Antarctic Ice Sheet, and ${ }^{10} \mathrm{Be}$-rich dust blown into the valley from other nearby locations (Steig et al., 1995). Together, these sources represent the ${ }^{10} \mathrm{Be}$ flux onto the ground surface, which can vary by location due to topographic differences. Schiller (2006) noted that Wright Valley receives ${ }^{10}$ Be mainly from windblown dust, with a small addition from snow fall. In University Valley, the presence of a glacier, which can only be maintained on these timescales through continual addition of snow transported in from an external source, shows that University Valley receives ${ }^{10} \mathrm{Be}$ from wind-blown snow in addition to wind-blown dust, dry fallout, and small amounts of snow fall (Fountain et al., 2016; Chinn, 1980). However, because not all of the ${ }^{10} \mathrm{Be}$ flux onto the ground surface gets deposited into the soil, the true deposition of ${ }^{10} \mathrm{Be}$ must take into account the difference in the ${ }^{10} \mathrm{Be}$ flux onto the surface and ${ }^{10} \mathrm{Be}$ removed by erosion or remobilized by wind. The uppermost $2 \mathrm{~cm}$ of surface sediment, which is classified as the "eolian zone" by Gibson et al. (1983), is 
dominated by eolian material and the mobilizing effects of strong surface winds (Figure 47). Hyper-aridity combined with strong winds lead to a strongly remobilizing environment in the upper $2 \mathrm{~cm}$ for ${ }^{10} \mathrm{Be}$ adsorbed onto fine particles (Steig et al., 1995). These ongoing conditions may cause ${ }^{10} \mathrm{Be}$ to become increasingly concentrated in the surface over time, likely accounting for why ${ }^{10} \mathrm{Be}$ concentrations at the surface in University Valley are orders of magnitude higher than concentrations in the subsurface.

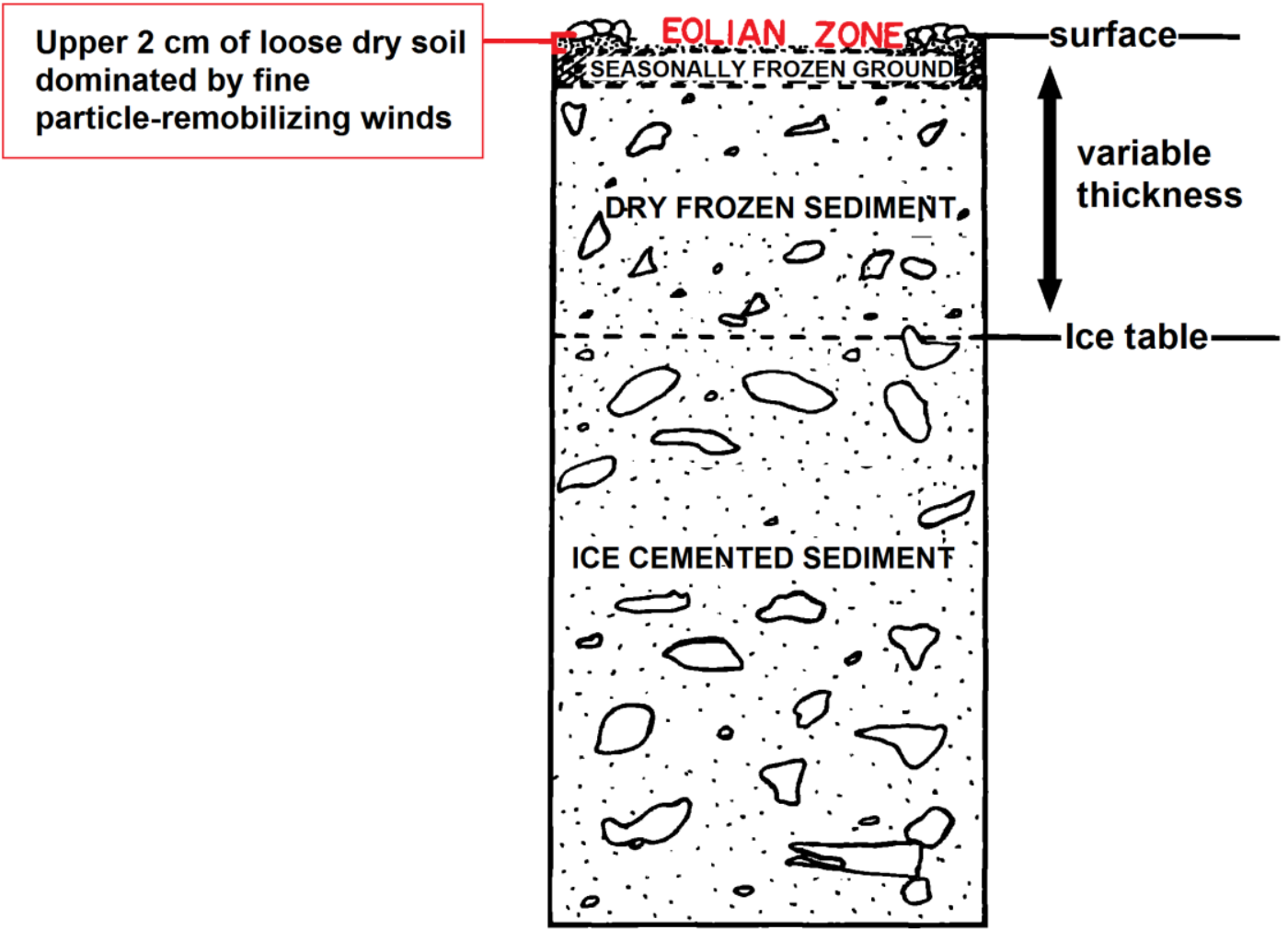

Figure 47: Schematic diagram of idealized Antarctic Dry Valley soil profile showing eolian zone and variable depth to the ice table. Modified from Campbell and Claridge (2006) and Gibson et al. (1983).

The maximum measured surface concentration of ${ }^{10} \mathrm{Be}$ in University Valley was $2.17 * 10^{9}$ atoms/g. For comparison, this value is one order of magnitude higher than the surface concentration of $3^{*} 10^{8}$ atoms/g measured in Wright Valley by Schiller (2006). Bockheim and McLeod (2006) described that eolian deflation surfaces in Wright Valley are apparent evidence that substantial wind activity constantly 
mobilizes fine particles, and therefore these eolian deflation surfaces may be indicative of erosional processes that remove ${ }^{10} \mathrm{Be}$ from Wright Valley. ${ }^{10} \mathrm{Be}$ removal from eolian deflation areas provide an explanation for why the measured concentrations in Wright Valley are one order of magnitude lower than in University Valley where eolian deflation surfaces have not been described. This difference could potentially be due to the size and shape of Wright Valley, which is not enclosed by a head or foot wall on either end, possibly causing it to effectively act as a wind tunnel where wind can freely flow through the valley and remove fine particles from the valley; in contrast, University Valley, which is much smaller and higher in elevation, additionally has a headwall that prevents through-flowing wind, which may account for less wind erosion in University Valley than in Wright Valley. For these reasons, the amount of ${ }^{10} \mathrm{Be}$ removed from University Valley by wind appears to be minimal. Therefore, with constant ${ }^{10} \mathrm{Be}$ influx into the valley and no significant flux outward, University Valley may represent a catchment area for ${ }^{10} \mathrm{Be}$-rich dust and aerosols in which accumulation of ${ }^{10} \mathrm{Be}$ onto the ground surface is faster than incorporation of ${ }^{10} \mathrm{Be}$ into the soil profile, with the excess ${ }^{10} \mathrm{Be}$ at the surface unable to be mobilized out of the valley.

Although definite soil ages have not been established in Wright Valley, cosmogenic surface exposure dating using in-situ ${ }^{10} \mathrm{Be}$ and ${ }^{3} \mathrm{He}$ have shown that many surfaces in the Dry Valleys have surface ages of 2 to 6 Ma BP (Schäfer et al. 1999), and surfaces in Wright Valley are estimated to be approximately 3.9 Ma from K/Ar dating of the Hart Ash contained in the shallow subsurface of Lower Wright Valley (Schiller, 2009; Bockheim and McLeod, 2006; Hall et al., 1993). The half-life of ${ }^{10} \mathrm{Be}$ is $\sim 1.39 * 10^{6}$ years (Dunai, 2010), and therefore soils in Wright Valley are likely old enough to experience noticeable ${ }^{10} \mathrm{Be}$ loss though the radioactive decay of ${ }^{10} \mathrm{Be}$ into ${ }^{10} \mathrm{~B}$ (Boron10). Sediments in University Valley, which are less than $200 \mathrm{ka}$, are too young for radioactive decay of ${ }^{10} \mathrm{Be}$ to be a noticeable factor in the removal of ${ }^{10} \mathrm{Be}$. The lack of noticeable ${ }^{10} \mathrm{Be}$ removal by wind or radioactive decay in University Valley may explain the high surface concentrations of ${ }^{10} \mathrm{Be}$ in University Valley compared to Wright Valley. 
Though ${ }^{10} \mathrm{Be}$ flux onto the ground surface should be the same at all core sites in University Valley, slightly different deposition rates were observed for each of the 3 measured cores. Previous Dry Valleys studies have shown that ${ }^{10} \mathrm{Be}$ deposition into the soil profile is not indicative of atmospheric flux onto the ground surface (Steig et al., 1995, 2000); findings from this study support those claims and are possibly indicative of local differences within the valley such as differing proximity to the glacier, surface morphology, variable winds, and depth to the ice table.

The measured ${ }^{10} \mathrm{Be}$ concentration at the surface of $\mathrm{P} 2$ was the highest out of the three cores, which could be a result of surface morphology where a depression exists in the valley. Similar to how University Valley can be a catchment for ${ }^{10} \mathrm{Be}$, this depression could simply act as a local catchment for ${ }^{10} \mathrm{Be}$-rich dust and snow, which would increase the amount of ${ }^{10} \mathrm{Be}$ collecting on the surface at P2. Grain size analysis by sieve stack shows that $\mathrm{P} 2$ contains a higher weight percentage of particles in the $<45$ $\mu \mathrm{m}$ fine fraction than the other two cores (Appendix A), indicating that the depression at $\mathrm{P} 2$ is a catchment for ${ }^{10} \mathrm{Be}$-rich dust. Additionally, measured ion data shows that P2 has significantly elevated concentrations of anions and cations compared to other cores (Figure 30 and Figure 31); since respective ratios of measured cations at P2 trend toward the concentrations expected from seawater as opposed to dolerite (Figure 34), it can be inferred that the main source of ions at P2 is wind-blown snow, indicating that the depression at P2 is a catchment for ${ }^{10} \mathrm{Be}$-rich snow. Although sediments were sieved to theoretically remove the grain-size dependent fraction of ${ }^{10} \mathrm{Be}$-rich dust, melting of snow at the surface of the depression is sufficient to wet the dusty surface sediments and create ${ }^{10} \mathrm{Be}$-rich clay coatings on sediment grains, which were seen in thin section. Because the sediment samples for ${ }^{10} \mathrm{Be}$ measurements were sieved without the use of water, these ${ }^{10} \mathrm{Be}$-rich clay coatings remained on grain surfaces after sieving, which likely caused the high ${ }^{10} \mathrm{Be}$ concentration in the surface of $\mathrm{P} 2$ where clay coatings were observed. Clay coatings were not observed in the lower depths of $\mathrm{P} 2$, and thus sieving would have effectively removed ${ }^{10} \mathrm{Be}$-rich dust from sediments at those depths, which may explain why the subsurface ${ }^{10} \mathrm{Be}$ concentrations at $\mathrm{P} 2$ were two orders of magnitude lower than the ${ }^{10} \mathrm{Be}$ concentration measured at the surface. 
Despite P2 having the highest surface concentration of ${ }^{10} \mathrm{Be}$ out of all three cores, subsurface concentrations at $\mathrm{P} 2$ were lower than the subsurface concentrations at P1. As per the model proposed for how the surface at P2 became a depression (Figure 44), it could be the case that sediments deposited at a faster rate within the depression at P2 compared to on level ground at P1. Due to this faster deposition, sediments at P2 would not have been exposed to the surface for as much time as the slower accumulating sediments at P1. Therefore, these quicker-depositing sediments at P2 would not accumulate as much ${ }^{10} \mathrm{Be}$ from dry fallout or aerosols as the slowerdepositing sediments at $\mathrm{P} 1$.

Meteoric ${ }^{10} \mathrm{Be}$ profiles represent sediments collected from both above and below the ice table (Figure 46). The uppermost surface samples measured from P1 and P2 are from the "eolian zone" and consist of loose dry surface material that is not cemented by ice (Figure 47). Due to a shallow $2 \mathrm{~cm}$ ice table at P8, loose surface material from P8 was not collected for analysis. Therefore, the ${ }^{10} \mathrm{Be}$ concentration at $2 \mathrm{~cm}$ depth from P8 represents the concentration sampled from the ice table within the icecemented sediments. Having a shallow subsurface that is cemented by ice may explain why the measured near-surface concentration of P8 is one order of magnitude lower than the surface concentrations of the other two cores. With a shallow ice table of only $2 \mathrm{~cm}$ below the surface, fine particles and sediments have likely been unable to infiltrate the ice to be deposited into the soil profile at P8 ever since the ice table reached its present-day depth up to $94 \mathrm{ka}$ BP (as bounded by the youngest measured OSL age for P8). Additionally, with a layer of overlying soil preventing further ${ }^{10} \mathrm{Be}$ accumulation in the $2 \mathrm{~cm}$ depth sediments, the measured near-surface ${ }^{10} \mathrm{Be}$ concentration at P8 is unlikely to be as high as the ${ }^{10} \mathrm{Be}$ concentrations measured directly from the surface at the other two cores.

Lower ${ }^{10} \mathrm{Be}$ concentrations in the subsurface at P8 compared to the other two cores can be explained by a rapid mass wasting event followed shortly by ice-cementing of the sediments. The two deepest measured ${ }^{10} \mathrm{Be}$ samples in P8 lie within the depths measured by OSL that have identical burial ages, which show near instantaneous sediment deposition. With rapid mass movement, existing meteoric ${ }^{10} \mathrm{Be}$ in the sediment would be diluted and become homogenized by mixing during transport. 
Then, due to rapid deposition, sediments below the surface of this mass wasting deposit would not be exposed to the atmosphere long enough to accumulate as much ${ }^{10} \mathrm{Be}$ as the other two cores, resulting in comparatively lower ${ }^{10} \mathrm{Be}$ concentrations at P8. Subsequent infiltration of the ice table into these sediments, as seen by the shallow $2 \mathrm{~cm}$ ice table depth at P8, would preserve these comparatively lower concentrations and prevent further ${ }^{10} \mathrm{Be}$ from incorporating into the sediment.

Sediment accumulation at P8 has likely ceased after formation of the ice table at least $10 \mathrm{ka} \mathrm{BP}$, which is the minimum bound on the age of the ice table in University Valley based on the timescale required for the development of polygonal ground, as suggested by Mellon et al. (2003). However, small fluctuations in ice table depth over the last 94 ka may have allowed small amounts of ${ }^{10} \mathrm{Be}$ to infiltrate sediments down to $2 \mathrm{~cm}$ depth, which could explain why the uppermost concentration of ${ }^{10} \mathrm{Be}$ in P8 is still one order of magnitude higher than in the subsurface. Alternatively, the uppermost concentration could instead represent the high ${ }^{10} \mathrm{Be}$ concentration of the loose dry surface at a particular time during the past $10 \mathrm{ka}$ to $94 \mathrm{ka}$ that was then infiltrated by the ice-table, which could have effectively frozen the entire soil profile at P8 and preserved these ${ }^{10} \mathrm{Be}$ concentrations. Subsequent remobilizing effects from strong winds and hyper-aridity may have prevented ${ }^{10} \mathrm{Be}$ from being incorporated into the subsurface of $\mathrm{P} 8$ for the last 10 to $84 \mathrm{ka}$, resulting in the observed lower ${ }^{10} \mathrm{Be}$ concentrations at P8 compared to the other cores.

The ${ }^{10} \mathrm{Be}$ flux measured at Taylor Dome by Steig (1996) can be used to estimate the amount of time that the "excess" constantly remobilized meteoric ${ }^{10} \mathrm{Be}$ has been accumulating in the surface eolian zone in University Valley (i.e. the amount of time that the rate of ${ }^{10} \mathrm{Be}$ flux onto the ground surface has exceeded the rate of ${ }^{10} \mathrm{Be}$ incorporation into the soil profile). Because University Valley is located less than 100 $\mathrm{km}$ away from Taylor Dome, it can be assumed that the ${ }^{10} \mathrm{Be}$ flux at Taylor Dome is similar and applicable to University Valley, since the global fallout rate for meteoric ${ }^{10}$ Be fluctuates only minimally over distances of several hundred km (Schiller et al., 2006; Willenbring and von Blanckenburg, 2010). By using Equation 5 from Willenbring and von Blanckenburg (2010) on the measured surface concentration of $9.13 * 10^{8}$ atoms $/ g$ for $\mathrm{P} 1$ (which appears to be most representative of general surface 
topography and ${ }^{10} \mathrm{Be}$ concentration out of the 3 cores) in University Valley with the total ${ }^{10} \mathrm{Be}$ flux of $1.3 * 10^{5}$ atoms $/ \mathrm{cm}^{2} /$ a measured by Steig (1996), it was calculated that it would take a maximum of $55.8 \mathrm{ka}$ to accumulate the measured amount of ${ }^{10} \mathrm{Be}$ in the eolian zone surface sediments if there was no ${ }^{10} \mathrm{Be}$ loss into the subsurface $\left({ }^{10} \mathrm{Be}\right.$ loss $=0$ ). The Beryllium inventory $I$ was calculated by multiplying the ${ }^{10} \mathrm{Be}$ concentration with the soil density of $\sim 1.57 \mathrm{~g} / \mathrm{cm}^{3}$ and the $5 \mathrm{~cm}$ thickness of the measured surface layer.

From subsurface ${ }^{10} \mathrm{Be}$ concentrations and the $2.099 \mathrm{~mm} / \mathrm{ka}$ sediment deposition rate determined from OSL ages, an average rate of ${ }^{10} \mathrm{Be}$ incorporation into the subsurface for University Valley was calculated to be approximately $4.51 * 10^{4}$ atoms $/ \mathrm{cm}^{2} / \mathrm{a}$. This calculated rate of meteoric ${ }^{10} \mathrm{Be}$ incorporation into the soil profile was then subtracted from the ${ }^{10} \mathrm{Be}$ flux onto the surface, in order to obtain an accumulation time for the excess constantly remobilized meteoric ${ }^{10} \mathrm{Be}$ at the ground surface that additionally accounts for loss of ${ }^{10} \mathrm{Be}$ into the subsurface (i.e. ${ }^{10} \mathrm{Be}$ incorporated into the soil profile) in University Valley. This is shown by Equation 5 from Willenbring and von Blanckenburg (2010).

$$
t=\frac{-\ln \left(1-\frac{I \cdot \lambda}{Q-\operatorname{Be} \operatorname{loss}}\right)}{\lambda}
$$

Where:

$\mathbf{t}$ is the amount of time that ${ }^{10} \mathrm{Be}$ has been accumulating in excess at the ground surface,

In is the natural $\log$,

$\lambda$ is the decay constant of ${ }^{10} \mathrm{Be}$ (equal to $\ln |2| \div$ half-life of ${ }^{10} \mathrm{Be}$ ),

I is the ${ }^{10} \mathrm{Be}$ inventory, which is the ${ }^{10} \mathrm{Be}$ concentration $*$ density of soil $*$ depth,

$\mathbf{Q}$ is the ${ }^{10} \mathrm{Be}$ flux onto the ground surface. 
In University Valley, where sediment ages are too young for ${ }^{10} \mathrm{Be}$ decay to be a significant contributing factor, the key part of this equation could be conceptually presented as Equation 6.

$$
\text { excess }{ }^{10} \text { Be at the surface }=\frac{\text { amount of }{ }^{10} \mathrm{Be} \text { in the surface soils }}{\left(\begin{array}{l}
{ }^{10} \text { Be flux onto } \\
\text { ground surface }
\end{array}\right)-\left(\begin{array}{l}
\text { rate of }{ }^{10} \mathrm{Be} \\
\text { incorporation into } \\
\text { the subsurface }
\end{array}\right)}
$$

Performing the calculation from Equation 5 shows that meteoric ${ }^{10} \mathrm{Be}$ in University Valley has been accumulating in excess at the surface for roughly $86.1 \mathrm{ka}$, which agrees with the near-surface measured OSL age of $94 \mathrm{ka}$ and supports the $10 \mathrm{ka}$ minimum age of the ice table proposed by Mellon et al. (2013). If this calculated "excess" surface ${ }^{10} \mathrm{Be}$ accumulation time is correct, then the age of the ice table in University Valley could be closer to $86.1 \mathrm{ka}$, after which time ${ }^{10} \mathrm{Be}$ incorporation into the subsurface significantly slowed or possibly ceased.

This may also account for the abrupt change from high surface ${ }^{10} \mathrm{Be}$ concentrations to low subsurface concentrations. After being infiltrated by the ice table, sediments would have becomes ice-locked, which would prevent remobilization or translocation of ${ }^{10} \mathrm{Be}$ in the ice-cemented soil profile, and additionally block subsequent ${ }^{10} \mathrm{Be}$-rich dust and aerosols from entering the soil profile. Consequently, the ${ }^{10} \mathrm{Be}$-rich loose surface sediments would be constantly mobilized within the valley by frequent strong winds that can reach up to $30 \mathrm{~m} / \mathrm{s}$ in the Dry Valleys (Doran et al., 2002a, b; Nylen et al., 2004; Speirs et al., 2010; Steig et al., 1995). The combination of continual ${ }^{10} \mathrm{Be}$ flux into the valley, no ${ }^{10} \mathrm{Be}$ flux out of the valley, and persistent dust-remobilizing wind conditions would result in increasingly high ${ }^{10} \mathrm{Be}$ concentrations at the ground surface that abruptly decrease in concentration at the ice table and remain constant with depth into the frozen soil profile. 
In summary, measured ${ }^{10} \mathrm{Be}$ concentrations in University Valley reveal that the rate of ${ }^{10} \mathrm{Be}$ flux onto the ground surface has exceeded rates of ${ }^{10} \mathrm{Be}$ incorporation into the subsurface for potentially $86.1 \mathrm{ka} .{ }^{10} \mathrm{Be}$ concentration measurements are up to 2 orders of magnitude higher in University Valley than in other areas of the Dry Valleys where ${ }^{10} \mathrm{Be}$ removal by wind erosion is a significant factor, possibly indicating that University Valley is a catchment for eolian transported dust and aerosols. Due to conditions in the valley being unfavorable for liquid water to exist except in infrequent transient small amounts, the measured data show that there is no downward translocation of ${ }^{10} \mathrm{Be}$, and instead shows constant deposition of ${ }^{10} \mathrm{Be}$ over time that possibly ceases or slows around $86.1 \mathrm{ka}$ due to infiltration of the ice table and strong dust-remobilizing winds.

\subsection{Chemical weathering and aerosol deposition insights from geochemical analysis of sediments}

The observed constant ratio of the measured anions $\mathrm{NO}_{3}{ }^{-}$and $\mathrm{SO}_{4}{ }^{2-}$ for all cores and depths (Figure 32) indicates that the deposition process and source of these ions has been constant for at least the last $200 \mathrm{ka}$. Concentrations of these anions do not plot near the concentration that would be expected for seawater, suggesting that the major source of these anions in University Valley is not marine aerosols. Instead, deposition of aerosols from an atmospheric source are the more likely source of $\mathrm{NO}_{3}{ }^{-}$and $\mathrm{SO}_{4}{ }^{2-}$ (e.g. Bockheim, 1997; Witherow et al., 2006; Bao et al., 2000; Jackson et al., 2015).

The measured anion $\mathrm{Cl}^{-}$showed a different trend than $\mathrm{NO}_{3}{ }^{-}$and $\mathrm{SO}_{4}{ }^{2-}$. All cores contained significantly less $\mathrm{Cl}^{-}$than $\mathrm{NO}_{3}{ }^{-}$and $\mathrm{SO}_{4}{ }^{2-}$, pointing either to $\mathrm{Cl}^{-}$being almost equally depleted for all cores, or to $\mathrm{NO}_{3}{ }^{-}$and $\mathrm{SO}_{4}{ }^{2-}$ being equally enriched across all cores. However, the ratio of $\mathrm{Cl}^{-}$to all other measured ions was consistently low compared to seawater, which suggests that $\mathrm{Cl}^{-}$is comparatively depleted for the entire valley. Other studies have similarly observed that $\mathrm{Cl}^{-}$tends to be depleted in the high elevation Dry Valleys and abundant in the lower elevation Dry Valleys that are closer to the coast (e.g. Witherow et al., 2006; Bao et al., 2008; Bockheim, 1997; Jackson et al., 2015). Because $\mathrm{Cl}^{-}$originates from seawater, this difference in $\mathrm{Cl}^{-}$distribution by 
elevation is tied to the process by which $\mathrm{Cl}^{-}$is transported inland. $\mathrm{Cl}^{-}$in this region originates from the Ross Sea and is transported by moist air masses to the Dry Valleys; however, a large portion of $\mathrm{Cl}^{-}$is lost during the transport up to the higher elevation valleys, resulting in $\mathrm{Cl}^{-}$depositing mainly in the lower elevation valleys (Campbell and Claridge, 1998). Thus, the observed depletion of $\mathrm{Cl}^{-}$in University Valley does not signify a selective $\mathrm{Cl}^{-}$depletion process, but rather a lack of $\mathrm{Cl}^{-}$deposition into the valley.

Cation ratios for all cores were between the concentrations expected for seawater and dolerite, indicating that the cations present in University Valley are derived from both marine aerosols and dolerite eroding from the valley walls. These findings agree with those of Claridge and Campbell (1977), which found that mineral weathering and atmospheric deposition are prominent sources of salts in the Dry Valleys. This mixed source of ions shows that there is some degree of chemical weathering occurring within the valley that leaches ions from dolerite grains. Dolerite is especially susceptible to surface modification from the oxidizing conditions of the Dry Valleys, which is a process that has been shown to progress in the absence of water (Salvatore, 2014). The observation of rust on dolerite grains seen in thin section (Figure 48) offers visual representation of the chemical weathering occurring in University Valley and supports suggestions by Salvatore et al. (in press) that anhydrous alteration products dominate dolerite surfaces in the Dry Valleys. 


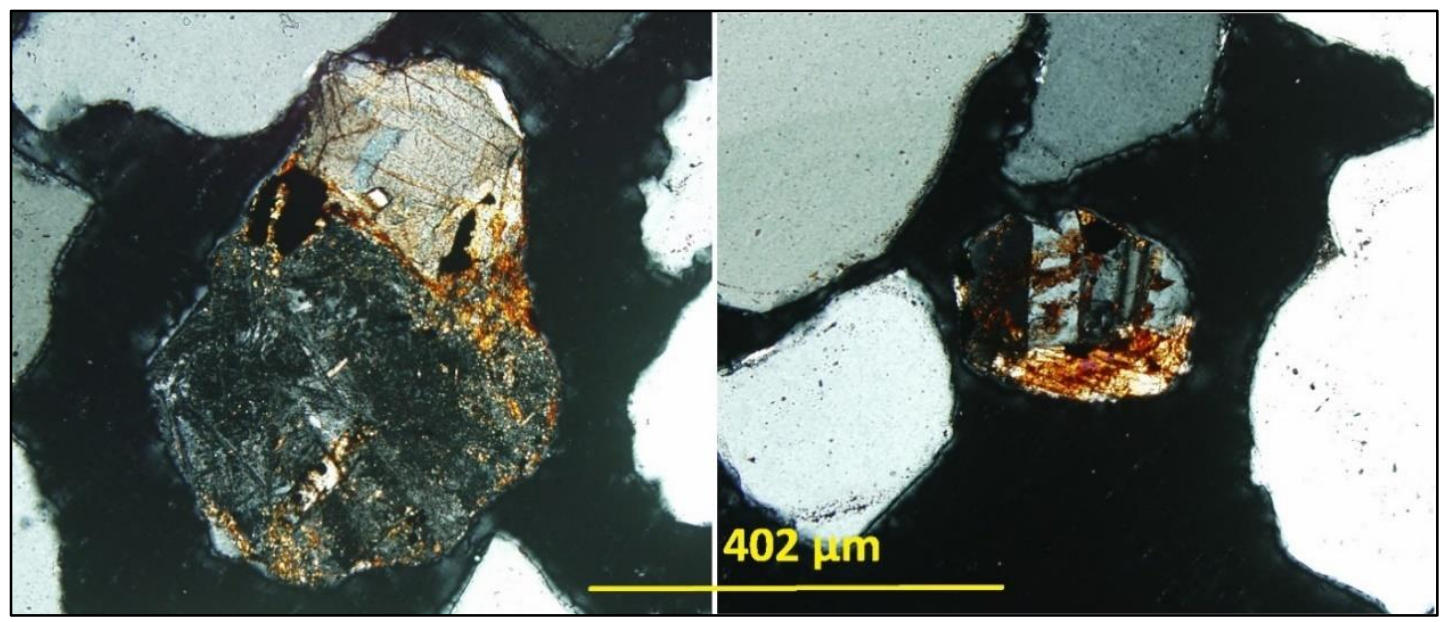

Figure 48: Photomicrographs of rusted dolerite grains in thin section, indicating the occurrence of chemical weathering. Sample: P8 $64 \mathrm{~cm}$ depth. 100x magnification, cross polarized light.

Constant ratios of $\mathrm{Na}^{+}$to $\mathrm{Mg}^{2+}$ and of $\mathrm{Fe}^{2+}$ to $\mathrm{Si}^{4+}$ with depth for all cores (Figure 49) imply that chemical weathering has been ongoing for at least the past $200 \mathrm{ka}$ at a generally constant rate for nearly all locations in the valley. For some cations, certain cores exhibited deviations from the general trend that were not tied to changes in depth, and therefore only signify changes in chemical weathering occurring at that particular location instead of a general change of climatic conditions for the entire valley. Ratios of $\mathrm{Ca}^{2+}$ to all other cations show that the concentration of $\mathrm{Ca}^{2+}$ is strongly location dependent, with most cores exhibiting a unique ratio of $\mathrm{Ca}^{2+}$ to other ions (Figure 20). However, this observed location dependency seems unrelated to proximity to the glacier. The three trend-groupings of cores show that each group falls along one of three transects down the length of the valley (Figure 50). P2 and P5, which consistently contained the same ratios of ions (i.e. plotted along the same line), were both located on the transect that follows the central axis of the valley. P6, P7, and P8 generally showed a similar trend, and were all located on the transect adjacent to the south facing valley wall. P1 and P4 displayed the same trend and were located on the transect adjacent to the north facing valley wall. Although these trends by transect could be related to distance from the glacier, the three observed trends are significantly different; if these trends were indeed a function of distance down valley, the data would likely exhibit a gradual shift in the individual core trends with increasing distance down the valley instead of three distinct groupings. 


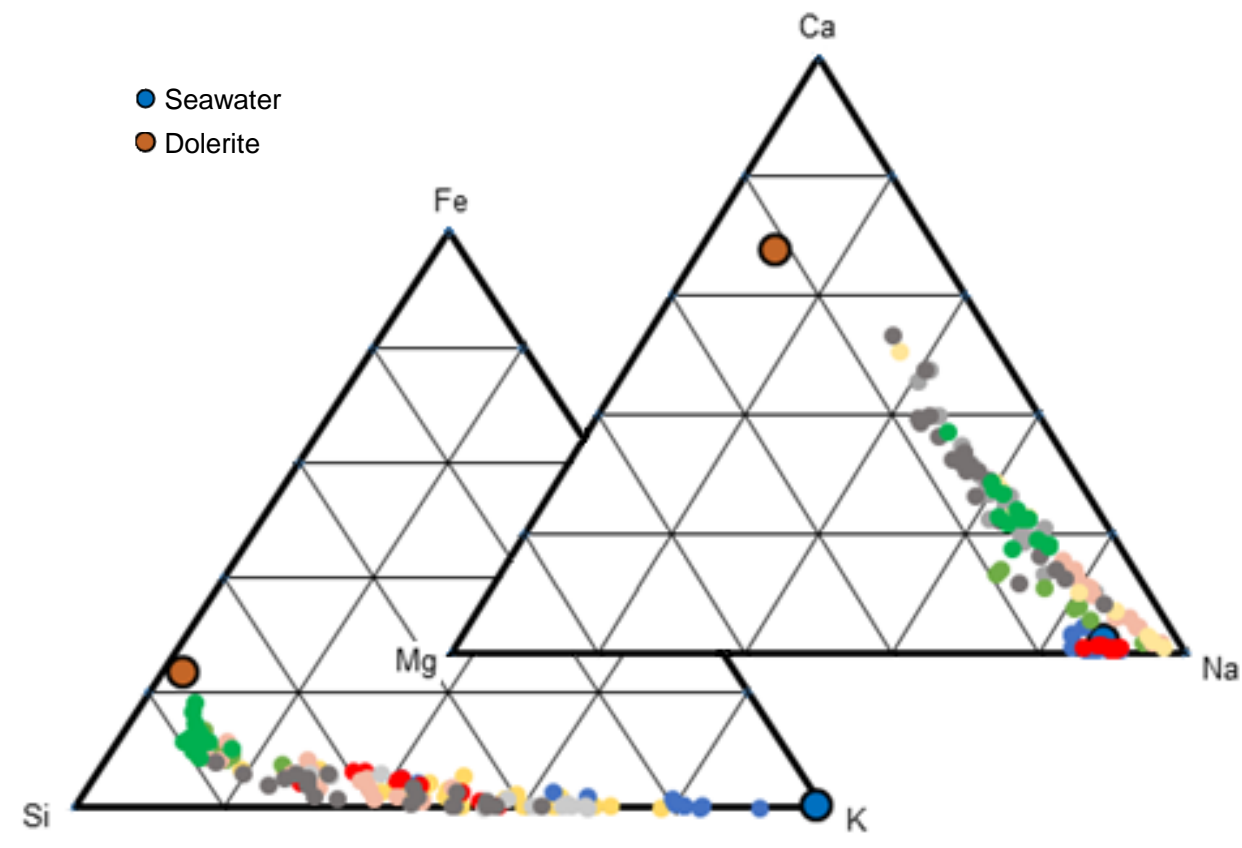

Figure 49: Ternary plots showing constant ratios of $\mathrm{Na}^{+}$to $\mathrm{Mg}^{2+}$ and of $\mathrm{Fe}^{2+}$ to $\mathrm{Si}^{4+}$ with depth for all cores. 


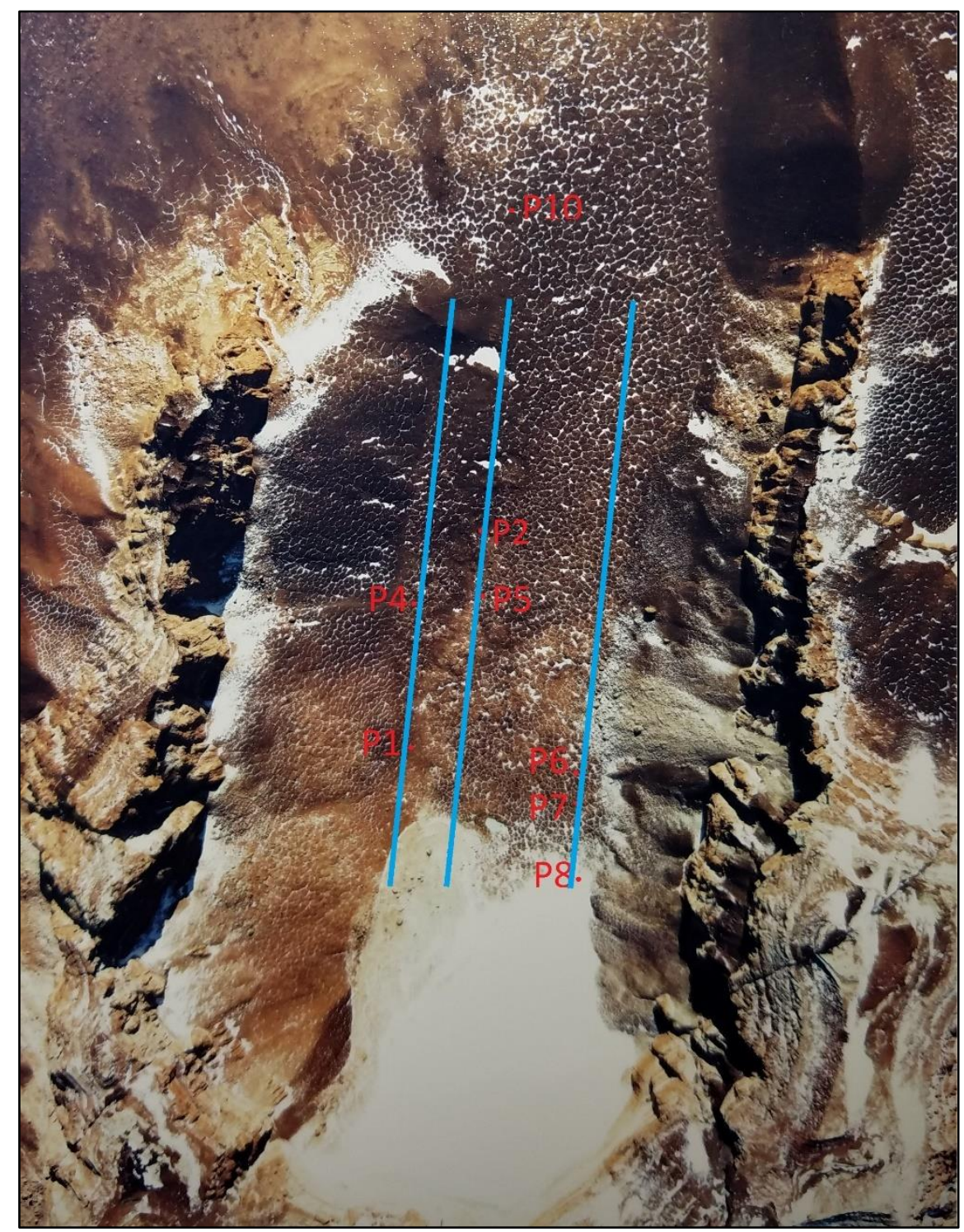

Figure 50: Aerial photograph of University Valley showing location of cores along three geochemical-trend transects depicted by blue lines. Modified from photo by NZ Aerial Mapping Limited for the Long-Term Ecological Research (LTER) program of Taylor Valley (photo taken November 1993).

It is interesting to note that the trends observed for the ratios of $\mathrm{Sr}^{2+}$ to all other cations exhibited the same location dependency as $\mathrm{Ca}^{2+}$ and displayed the same groupings of cores, despite $\mathrm{Sr}^{2+}$ occurring in trace amounts and $\mathrm{Ca}^{2+}$ occurring in abundance throughout the valley. Furthermore, the ratio of $\mathrm{Sr}^{2+}$ to $\mathrm{Ca}^{2+}$ was constant with depth in each individual core.

This relationship between ion ratio and location, in the absence of down-valley trends, 
shows that the weathering and sedimentation processes in these deposits are unrelated to glacial activity. These surface deposits may instead be related to breakdown of the valley walls, in which mass wasting and erosion of the valley walls cause each transect to have a slightly different rate of sedimentation, which subsequently plays a role in the degree of chemical weathering occurring at these locations. Mass wasting or dislodgement of large clasts or blocks could explain why location trends can exist in a setting where strong winds would otherwise redistribute fine-grained surface sediments and ions. Large blocks or sediment masses that dislodge from the valley walls require wind speeds higher than are present in University Valley to initiate remobilization. As a result, sediments are incorporated into the soil profile at the original site of deposition. During incorporation into the subsurface, large clasts break down in-situ from thermal contraction and expansion and salts within rocks and pore spaces, a process that is a dominant mode of physical erosion and mechanical breakdown of rocks throughout the Dry Valleys (Figure 40) (Bao and Marchant, 2006). This process is especially effective in the weathering and breakdown of coarsely crystalline rocks such as dolerite (Selby, 1971; Selby and Wilson, 1971). As these clasts break down into smaller particles, cracks and fresh surfaces are formed where brine films, though occurring in small amounts, are able to infiltrate and effectively increase chemical weathering and the redistribution of ions (Jackson et al., 2015; Dickinson and Rosen, 2002; Fischer, 1987, Gibson 1983; Ugolini and Anderson, 1972, 1973). This process may additionally be influenced by grain shape. Mazzullo et al. (1992) have found that rounder grains are preferentially transported compared to grains that are less round. Likewise, spherical particles are transported preferentially over blade-shaped and disc-shaped particles (Swanson, 1972). As seen by grain roundness and sphericity measurements, dolerite grains exhibit low degrees of rounding and sphericity, and therefore are unable to be transported as easily by the winds in University Valley. Together, these processes suggest why chemical weathering appears to vary by location, which is significant in the absence of water.

Orientation of the valley and aspect of the valley walls additionally play an important role in the different rates of weathering occurring in University Valley. Wind direction and solar heating, which are largely controlled by the orientation of the valley, can 
accelerate mass wasting and erosion of certain areas of the valley more than others. McKay et al. (2009) measured temperature changes of up to $10^{\circ} \mathrm{C}$ per minute on rock surfaces in the McMurdo Dry Valleys, and found that the temperature differential required to initiate cracking was commonly exceeded. Because the orientation of University Valley results in uneven amounts of sunlight exposure, temperature differential effects on mechanical breakdown of the walls and sediment deposits vary by location. This effect can be seen in photographs of the valley (Figure 51), in which the north facing wall of the valley shows a different degree of erosion and mass wasting than the south facing wall of the valley. It can also be seen that the amount of exposed dolerite (i.e. outcrops of dolerite sills), which are a significant source of ions in the valley, varies between the two walls. These factors support the observation that geochemical trends seem to be related to location in the valley along one of three transects.

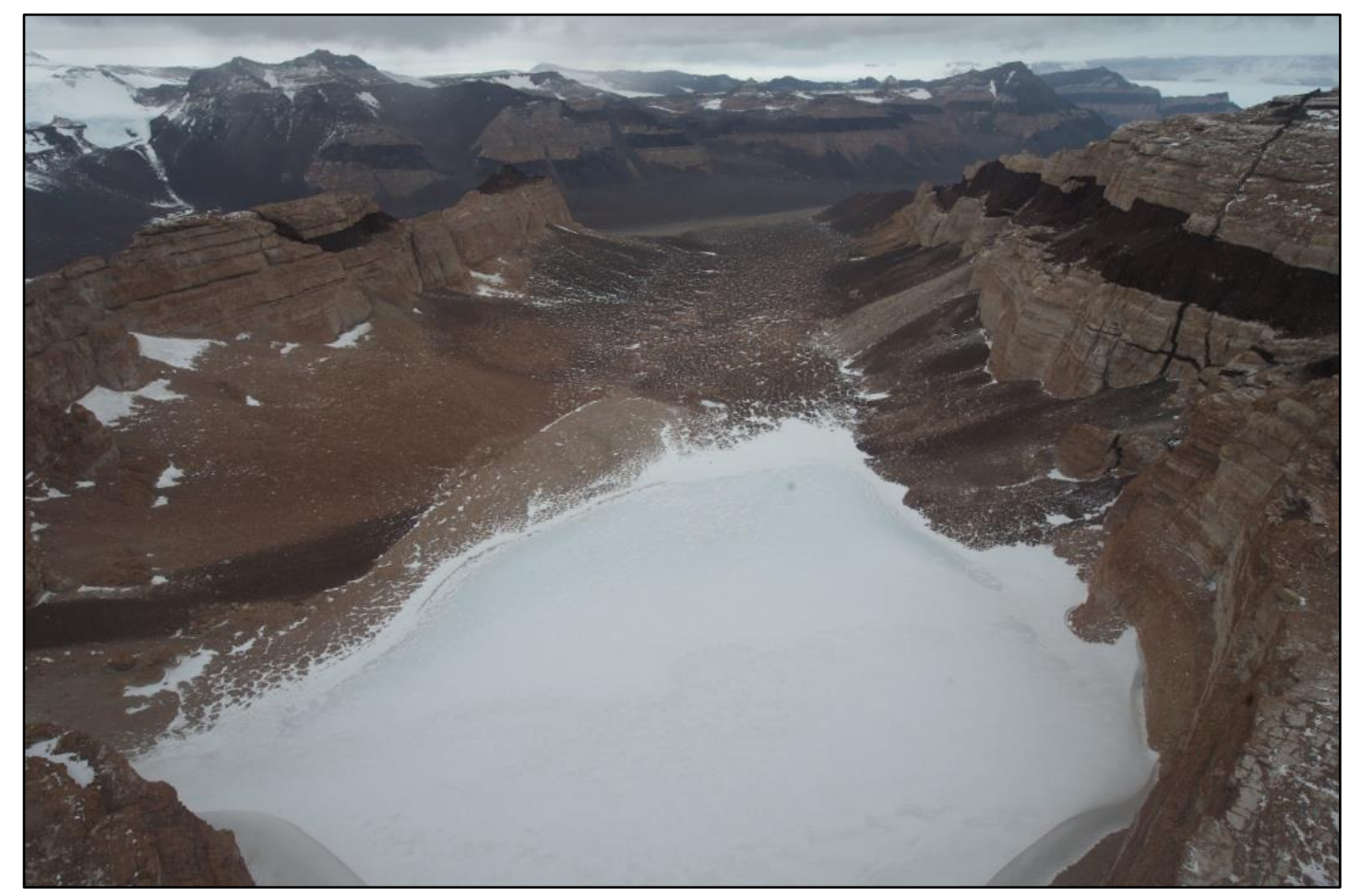

Figure 51: View to the west looking down the axis of University Valley. North (sun) facing wall is on the left. Courtesy of Alfonso Davila (2009). 
For all cores, no trends with depth for ion ratios or ion concentrations were observed. Witherow (2006) and Salvatore (2013) showed that a major source of ion deposition in the Dry Valleys is snow, which University Valley receives occasionally by wind transport from the East Antarctic Ice Sheet; because the rate of snow fall varies over time, this may explain why ion data for all cores exhibit a general trend for the entire valley while also showing small-scale variations in ion concentrations and ratios with depth. Moreover, cores that tended to show wider variations in ion ratios and concentrations, such as P1 and P4, were located in the zone that is not permanently frozen, where it is possible for small amounts of intermittent liquid water from melting snow to slightly translocate leached ions in the shallow subsurface (Lacelle et al., 2016). Over time, as the ice table grows in height as sediments accumulate, the concentration of leached ions in the soil is preserved as the soil profile becomes frozen. This lack of relationship between ion concentration and depth may also represent small fluctuations in height of the ice table, which rises and falls over time, and could be a process that decreases and concentrates all ions seemingly randomly with depth. Jackson et al. (2016) described geochemical trends with depth in the loose dry sediments overlying the ice table in University Valley, and similarly noted that all trends disappeared for sediments sampled beneath the ice table. Further study of the behavior of the ice table over time is needed to understand the impact of ice table activity on geochemistry of the sediments.

In terms of general variations, the measured ion data for P10 was peculiar compared to all other cores for two reasons. Firstly, ion concentrations in P10 tended to cluster instead of displaying linear trends, despite covering a larger depth range than the other cores. Secondly, concentrations of $\mathrm{Fe}^{2+}$ and $\mathrm{Si}^{4+}$ were significantly higher in P10 than in the other cores. Higher concentrations of $\mathrm{Fe}^{2+}$ and $\mathrm{Si}^{4+}$ could partially reflect differences in lithology, since P10 contained over twice as much dolerite as all other cores. This might explain why ratios of $\mathrm{Fe}^{2+}$ and $\mathrm{Si}^{4+}$ to the other ions in $\mathrm{P} 10$ were closer to the ratios expected from dolerite (Figure 33). Since weathered rinds on dolerite grains in the Dry Valleys have been found to be enriched in Fe and Si (Glasby et al., 1981; Talkington et al., 1982), comparatively high concentrations of $\mathrm{Fe}^{2+}$ and $\mathrm{Si}^{4+}$ in P10 could additionally indicate that weathering has occurred over a longer period of time at $\mathrm{P} 10$ or that $\mathrm{P} 10$ underwent higher intensity weathering than at other 
core sites. Because all locations in the valley experience the same general surface conditions, comparatively high $\mathrm{Fe}^{2+}$ and $\mathrm{Si}^{4+}$ concentrations at $\mathrm{P} 10$ may be indicative of more mature sediments, and therefore the sediments at P10 (located at the mouth of the valley) are likely older than the sediments located further up valley. This observation is supported by previous soil studies, which found that soils with high ion content tended to also have old ages (e.g. Witherow, 2006; Campbell and Claridge, 1968; Bockheim 1979, 1982, 1990). For the remaining ions that were more soluble $\left(\mathrm{Ca}^{2+}, \mathrm{Mg}^{2+}, \mathrm{K}^{+}\right.$, and $\left.\mathrm{Na}^{+}\right)$, the observed clustering at relatively low concentrations in P10, despite spanning a larger depth range than the other cores, may represent a leaching maximum due to maturity of the sediments at that location. As sediments undergo chemical weathering, less stable ions such as $\mathrm{Ca}^{2+}, \mathrm{Mg}^{2+}, \mathrm{K}^{+}$, and $\mathrm{Na}^{+}$are leached out of the sediments first (in the form of ion-oxides), followed by $\mathrm{Fe}^{2+}$ and $\mathrm{Si}^{4+}$ after extended periods of weathering (Nicholls, 1963). The high solubility of $\mathrm{Ca}^{2+}, \mathrm{Mg}^{2+}, \mathrm{K}^{+}$, and $\mathrm{Na}^{+}$results in these ions being easily washed out and depleted over time while the less soluble $\mathrm{Fe}^{2+}$ and $\mathrm{Si}^{4+}$ ions remain on grain surfaces and increase in concentration over time, which is seen in the data at P10.

Lastly, one minor peculiarity was observed in the ion ratios for certain depths of P8. In the depth range of the OSL-determined rapid mass wasting event, there was an increase in concentration for all ions, but the ion ratios trended toward seawater instead of dolerite. Because dolerite content of the sediments stayed constant in and above this mass wasting deposit, one possible explanation for this shift in ion ratios could be that nearly-instantaneous deposition of large amounts of sediment prevents most of the sediment grains from being exposed to the atmosphere at the ground surface. Nearly-instantaneous dumping of sediments minimizes the possibility for grains in the interior of the rapid mass wasting deposit to interact with surface processes that aid in weathering such as the oxidizing conditions of the Antarctic environment, condensation of water vapor onto grain surfaces, contraction-expansion cycles from solar heating, or contact with transient meltwater from occasional snow patches (Salvatore, 2013; Head et al., 2011; Cooper, 1996; Allen and Conca, 1991). In contrast, gradual deposition would allow nearly all grains to be exposed to the atmospheric influences at the ground surface and undergo faster chemical weathering. Therefore, despite the presence of dolerite in the rapid mass wasting deposit at P8, the 
majority of those dolerite grains likely experienced comparatively less chemical weathering, explaining why ion ratios in this mass wasting deposit do not trend toward the concentrations expected from dolerite. This finding implies that chemical weathering in University Valley occurs at a faster rate at the ground surface where it is facilitated by interactions with the atmospheric processes than in the subsurface where exposure to these erosive forces is minimized.

Overall, the measured ion data revealed 6 main findings: (1) atmospheric deposition of anions is prominent and uniform in the valley; (2) chemical weathering has been occurring throughout the entire valley for at least $200 \mathrm{ka}$ at a generally constant rate; (3) small variations in chemical weathering rate and ion deposition seem to be location dependent by one of three transects down the valley; (4) trend-transects down the valley vary based on influences from the valley walls such as erosion intensity and the amount of exposed dolerite; (5) exposure of sediments to the atmosphere and contraction-expansion induced breakdown of dolerite are large contributors to the ions present in the sediments; (6) variation in deposited ions may be due to ion sensitivity to redistributional effects of ice table activity that can erase original geochemical signatures, or due to small amounts of intermittent liquid water from melting snow slightly translocating leached ions in the dry shallow subsurface and then becoming ice-locked as the ice table infiltrates upwards through the soil profile.

\subsection{Chronological events of the last $200 \mathrm{ka}$}

To create a better understanding of how University Valley as a system works through time, findings of this study can be combined to reconstruct the recent history the valley. Chronological events of the sedimentation processes occurring in University Valley over the last $200 \mathrm{ka}$ are as follows:

University Glacier retreated to its present-day location at least $200 \mathrm{ka}$ BP. Aerosols, wind-blown dust, and sediments eroding from the valley walls have been depositing onto the valley floor for the last $200 \mathrm{ka}$ at a constant rate of approximately $2.1 \mathrm{~mm} / \mathrm{ka}$. Small fluctuations in the general sedimentation rate result from different topography 
along the valley floor, local events such as mass wasting of the valley walls, or ablation of subsurface bodies of ice. Concurrently, prevailing winds transport snow from the East Antarctic Ice Sheet into the valley, effectively recharging University Glacier and keeping it in overall equilibrium. Although fluctuating amounts of snow fall have caused the extent of the glacier to fluctuate, the general position of University Glacier has remained stable, allowing the preservation of close-proximity surface features such as the OSL-dated rapid mass wasting event at P8 that occurred approximately $125 \mathrm{ka} \mathrm{BP}$.

Between $94 \mathrm{ka}$ and $10 \mathrm{ka}$ BP (as bounded by the youngest OSL age at P8 where the ice table has infiltrated up to $2 \mathrm{~cm}$ below the surface, and the minimum timeframe required for polygon development proposed by Mellon et al., 2013), the ice table infiltrated to its present-day depth below the surface, simultaneously contributing to the formation of polygonal patterned ground on the valley floor. Near the glacier where the ice table is shallow or breaches the surface, significant sediment accumulation has possibly ceased or greatly slowed since the emplacement of the ice table, while in all other areas of the valley sediments continue to accumulate at a steady rate from erosion of the valley walls.

Conditions favorable for supporting long-standing liquid water have not existed in University Valley during the last $200 \mathrm{ka}$, with transient liquid water only occurring in small amounts from occasional melting of snow. Despite the general absence of liquid water, chemical weathering of sediments has been occurring at a steady rate from condensation of water vapor from the atmosphere onto sediment grains, facilitated by exposure of sediments to the oxidizing atmosphere and thermal contraction-expansion processes driven by solar heating.

Although global scale changes in climate have occurred over the last $200 \mathrm{ka}$, these changing conditions have had overall negligible effects on the sedimentation processes occurring in University Valley. 


\section{Chapter 7. Conclusions}

\section{$\underline{\text { Sedimentation rate }}$}

Sediments in University Valley have accumulated at a rate of approximately 2.1 $\mathrm{mm} / \mathrm{ka}$ for the last $200 \mathrm{ka}$, as determined by OSL. The general trends in OSL ages, anion concentrations, meteoric ${ }^{10} \mathrm{Be}$ concentrations, and dolerite content for all cores show that sediment deposition is gradual, and when considered over long periods of time ( 200 ka) is overall similar for most areas in valley. Minor variations from this $2.1 \mathrm{~mm} / \mathrm{ka}$ accumulation rate result from different topography along the valley floor, local events such as mass wasting of the valley walls, or ablation of subsurface bodies of ice. Orientation of the valley and aspect of the valley walls, which affect wind direction and solar heating, can accelerate mass wasting and erosion of certain areas of the valley more than others, but these events are small-scale and infrequent, and therefore do not change the general sediment accumulation rate of the entire valley.

\section{$\underline{\text { Sediment source }}$}

Variations in measured dolerite content of the sediments throughout the valley correlates to the amount of dolerite cropping out from the valley walls. Additionally, pre-rounded quartz sand grains show relict quartz overgrowths identical to those found in the Beacon Heights orthoquartzite that crops out in University Valley. These features show that the sediments on the valley floor originate from the valley walls. As seen from the measured young OSL ages and general low degree of chemical alteration, these sediments are relatively immature. Because clays are a product of intense weathering and are indicative of mature sediments, the clays found in these sediment deposits most likely originate from an external source that were blown into the valley by persistent strong winds.

\section{$\underline{\text { Role of wind in the valley }}$}

Remobilization of sediments within the valley by wind is limited, as seen by low degrees of rounding on dolerite grains, dolerite content of sediments relating to nearby amounts of dolerite outcrops in the valley walls, and the location dependency of 
measured ion content. However, wind constantly remobilizes fine particles and dust throughout the valley, as seen by high ${ }^{10} \mathrm{Be}$ concentrations at the surface compared to the subsurface.

\section{Influence of orientation of the valley on sedimentation}

The orientation of University Valley plays an important role in the inflow of wind, which controls the amount of snow, dust, and aerosols that get deposited in the valley. Additionally, the orientation of the valley affects the angle and amount of incoming solar radiation, which controls the intensity of breakdown of each of the valley walls by thermal heating.

\section{Local topographical influences on sedimentation}

Topographical features within the valley influence the rate of sediment and fine particle accumulation. In areas where a depression in the ground surface exists, such as $\mathrm{P} 2$, the rate of sediment and fine particle accumulation accelerates as the depression acts as a sediment trap. In areas where the local topography is a mound, such as the mass wasting deposit at P8, further sediment accumulation is reduced.

\section{$\underline{\text { Availability and role of liquid water }}$}

Infrequent clay bridges seen in thin section show that small, infrequent, transient surface wetting events have occurred over the last $200 \mathrm{ka}$. High anion concentrations are associated with high surface meteoric ${ }^{10} \mathrm{Be}$ measurements and the presence of translocated clay in the form of clay bridges and clay coatings; together, these indicate that the source of these surface wetting events is the melting of wind-blown snow from the coastal regions that also carry anions and meteoric ${ }^{10} \mathrm{Be}$ into the valley. Patterns in meteoric ${ }^{10} \mathrm{Be}$ measurements for all cores show that these wetting events are not sufficient to translocate fine particles deep in the soil profile, which confirms that the role of liquid water as a transporting agent is negligible. It is possible that these small surface wetting events are sufficient to cause minor migration of ions through the top few centimeters of the loose dry surface soils, which may account for the observed minor fluctuations in ion content of many cores. However, because no trends are 
visible with depth in the ice-cemented soil, it can be concluded that any ion mobilization through the soil profile ceases at the ice table.

\section{$\underline{\text { Role and activity of the ice table }}$}

The primary role of the ice table in sedimentation is to function as a cementing agent that protects ice-cemented sediments from being remobilized, while additionally preventing translocation of fine particles or mobilization of ions through the soil profile. This effect is seen most apparently in the sudden transition between high surface ${ }^{10} \mathrm{Be}$ concentrations to low ${ }^{10} \mathrm{Be}$ concentrations just a couple centimeters below the surface. Additionally, in the loose dry surface layer, ions and clays appear to undergo minimal mobilization from infrequent small surface wetting events; however, once sediments have been infiltrated by the ice table, all mobilization stops, and the existing concentrations of fine particles and ions in the soil profile become preserved. The observed patterns in ion concentration and meteoric ${ }^{10} \mathrm{Be}$ measured from within the ice-cemented ground suggest that the ice table gradually infiltrated and froze the soil profile when ion concentrations in the soils reached similar values. This indicates that the ice table has stayed at about the same depth below the surface over the last $200 \mathrm{ka}$, likely meaning that the ice table has risen at about the same rate as sediment accumulation in the valley.

\section{Dominant factors in chemical weathering}

In the absence of liquid water, chemical weathering in University Valley appears to be controlled by two main components: dolerite content of the sediments, and exposure to the atmosphere at the ground surface. As seen by the ratios of measured ions, the majority of cations measured from the sediments are the product of chemical weathering of dolerite. In general, sediments that contain a higher percentage of dolerite (such as in P10) have ion ratios closer to those found in dolerite than sediments that contain less dolerite (all other cores). However, to leach ions from the dolerite, sediments must be exposed at the ground surface where interactions with the atmosphere induce chemical weathering. As seen by ion ratios in the rapid mass wasting deposit at P8, the portion of the deposit that was exposed at the surface leached more ions from dolerite than in the deeper parts of the deposit that were only briefly 
exposed at the surface, despite uniform dolerite content for all depths within the mass wasting deposit. This indicates that chemical weathering occurs mainly by interactions between dolerite rocks and the atmosphere. In order for chemical weathering to occur, water in some form must be present; in the absence of liquid water, water in vapor form is the reagent in chemical weathering. When sediments are exposed at the ground surface, water vapor from the atmosphere condenses onto grain surfaces, creating thin [brine] films that have the same chemical weathering effects as liquid water.

\section{Concluding remarks}

This thesis explored sedimentation processes in University Valley, one of the hyperarid, cryotic, wind-dominated high-elevation Dry Valleys of Antarctica. Contrary to the current understanding that sedimentation processes such as chemical weathering require widespread liquid water, this thesis has shown that these processes persist in the general absence of liquid water by means of condensation of water vapor from the atmosphere onto sediment grain surfaces. Combined with the oxidizing atmosphere, water vapor that has condensed into thin films on grain surfaces acts as a chemical reagent in a manner that is equivalent to that of liquid water. Under these unique atmospheric and surface conditions, liquid water plays a negligible role in sedimentation and translocation processes, eolian forces dominate fine particle remobilization, and thermal heating from solar radiation controls mechanical breakdown and disintegration of rocks.

Most importantly, while previous studies have obtained maximum sediment age estimates by use of surface exposure dating, this thesis determined definitive ages and rates for these sedimentation processes by use of Optically Stimulated Luminescence dating of the subsurface sediments. These ages and sedimentation rates, which are critical for understanding the timescales over which these processes occur, show that surfaces in the Dry Valleys, although presumed to be ancient and unchanged, are remarkably young and sedimentologically active.

Because University Valley represents one of the closest terrestrial analogs to the surface of Mars, findings from this thesis and may be applicable to understanding the 
timescales and the processes that control anhydrous sedimentation on the surface of Mars. 


\section{Chapter 8. Future work}

This study has shown that the location of the ice table and presence of water condensation are critical to sedimentation and weathering in this environment, and raises new questions such as how stable the depth of the ice table is, and if liquid water does in fact exist in the active layer. Future work in University Valley will be necessary to illuminate these remaining uncertainties. Further study of the ice table is needed to understand its behavior over time and its effects on chemical weathering processes. Greater sampling resolution and longer sediment cores that span both above and below the ice table will provide a better view of the processes occurring in the dry soil layer and in the frozen ground. Finally, surface monitoring in University Valley may help to understand the frequency, location, and amount of liquid present during surface wetting events. 


\section{References}

Aitken, M. J. (1998). An introduction to optical dating: The dating of Quaternary sediments by the use of photon-stimulated luminescence. Oxford; New York: Oxford University Press.

Allen, C.C., Conca, J.L. (1991). Weathering of basaltic rocks under cold, arid conditions: Antarctica and Mars. Proc. Lunar Planet. Sci. Conf., 21, pp. 711-717. Arden L. Albee. (2003). The Unearthly Landscapes of Mars. Scientific American, $13(3 \mathrm{~s}), 34$.

Bao, H., and Marchant, D. R. (2006). Quantifying sulfate components and their variations in soils of the McMurdo Dry Valleys, Antarctica. Journal of Geophysical Research, 111, D16301.

Bao, H., Campbell, D. A., Bockheim, J. G. \& Thiemens, M. T., (2000). Origins of sulphate in Antarctic dry-valley soils as deduced from anomalous $17 \mathrm{O}$ compositions. Nature, 407(6803), 499.

Barrett, P. (1981). History of the Ross Sea region during the deposition of the Beacon Supergroup 400 - 180 million years ago. Journal of the Royal Society of New Zealand, 11(4), 447-458.

Bédard, J., Marsh, B., Hersum, T., Naslund, H., \& Mukasa, S. (2007). Large-scale Mechanical Redistribution of Orthopyroxene and Plagioclase in the Basement Sill, Ferrar Dolerites, McMurdo Dry Valleys, Antarctica: Petrological, Mineral-chemical and Field Evidence for Channelized Movement of Crystals and Melt. Journal of Petrology, 48(12), 2289-2326.

Bockheim, J. (1982). Properties of a chronosequence of ultraxerous soils in the transantarctic mountains. Geoderma, 28(3-4), 239-255.

Bockheim, J. (1990). Soil development rates in the Transantarctic Mountains. Geoderma, 47(1), 59-77. 
Bockheim, J. (1995). Permafrost distribution in the southern circumpolar region and its relation to the environment: A review and recommendations for further research. Permafrost and Periglacial Processes, 6(1), 27-45.

Bockheim, J. (2002). Landform and Soil Development in the McMurdo Dry Valleys, Antarctica: A Regional Synthesis. Arctic, Antarctic, and Alpine Research, 34(3), 308-317.

Bockheim, J. G, \& McLeod, M.. (2006). Soil formation in Wright Valley, Antarctica since the late Neogene. Geoderma, 137(1), 109-116.

Bockheim, J., Kurz, M., Soule, S., \& Burke, A. (2009). Genesis of active sand-filled polygons in lower and central Beacon Valley, Antarctica. Permafrost and Periglacial Processes, 20(3), 295-308.

Bockheim, J. G. (2015). The Soils of Antarctica. Springer eBooks.

Boggs, S. (2006). Principles of sedimentology and stratigraphy (4th ed.). Upper Saddle River, N.J.: Pearson Prentice Hall.

Bourles, D., Raisbeck, G.M., \& Yiou, F. (1989). ${ }^{10} \mathrm{Be}$ and ${ }^{9} \mathrm{Be}$ in marine sediments and their potential for dating. Geochimica Et Cosmochimica Acta, 53(2), 443-452.

Bristow, C. S., Augustinus, P. C., Wallis, I. C., Jol, H. M. \& Rhodes, E. J. (2010). Investigation of the age and migration of reversing dunes in Antarctica using GPR and OSL, with implications for GPR on Mars. Earth and Planetary Science Letters, 289(1), 30-42.

Burt, T., \& Williams, P. (1976). Hydraulic conductivity in frozen soils. Earth Surface Processes, 1(4), 349-360.

Campbell, I., \& Claridge, G. (1981). Soil research in the Ross Sea region of Antarctica. Journal of the Royal Society of New Zealand, 11(4), 401-410.

Campbell, I. B., Claridge, G. G. C., Campbell, D. I. and Balks, M. R. (1998). The Soil Environment of the McMurdo Dry Valleys, Antarctica. In Ecosystem Dynamics in a Polar Desert: the McMurdo Dry Valleys, Antarctica (ed J. C. Priscu), American Geophysical Union, Washington, D. C. 
Campbell, I., \& Claridge, G. (2006). Permafrost properties, patterns and processes in the Transantarctic Mountains region. Permafrost and Periglacial Processes, 17(3), 215-232.

Claridge, G.G.C \& Campbell, I.B., 1977. The salts in Antarctic soils, their distribution and relationship to soil processes. Soil Science, v. 123, p. 377-384.

Chinn, T. J. (1980). Glacier balances in the Dry Valleys area, Victoria Land, Antarctica.World Glacier Inventory - Proceedings of the Riederalp Workshop, September 1978. IAHS Publication 126: 237-247.

Cooper, R. F., Fanselow, J. B., \& Poker, D. B. (1996). The mechanism of oxidation of a basaltic glass: Chemical diffusion of network-modifying cations. Geochimica Et Cosmochimica Acta, 60(17), 3253-3265.

Darvill, C.M. (2013). Section 4.2.10: Cosmogenic nuclide analysis. In: Clarke, L. (Ed.) Geomorphological Techniques (Online Edition). London, UK: British Society for Geomorphology.

Dickinson, W. W. and Rosen, M. R. (2003). Antarctic permafrost: An analogue for water and diagenetic minerals on Mars. Geological Society of America, 31(3), 199202.

Dickinson, W. (2006). Deep weathering and mineralization in the Sirius Group: A Martian analogue in the Dry Valleys, Antarctica. Geochimica Et Cosmochimica Acta, 70(18), A141.

Dickinson, W. W., Schiller, M., Ditchburn, B. G., Graham, I. J., \& Zondervan, A. (2012). Meteoric Be-10 from Sirius Group suggests high elevation McMurdo Dry Valleys permanently frozen since 6Ma. Earth and Planetary Science Letters, 355356, 13-19.

Deuerling, K. (2010). Aeolian Sediments of the McMurdo Dry Valleys, Antarctica. M.Sc., Ohio State University.

Doran, P. T., Berger, G.W., Lyons, W.B., Wharton Jr., R.A., Davisson, M.L., Southon, J., Dibb, J.E. (1999). Dating Quaternary lacustrine sediments in the 
McMurdo Dry Valleys, Antarctica. Palaeogeography, Palaeoclimatology, Palaeoecology, 147(3), 223-239.

Doran, P. T., McKay, C. P., Clow, G. D., Dana, G. L., Fountain, A. G., Nylen, T. and Lyons, W. B. (2002). Valley floor climate observations from the McMurdo dry valleys, Antarctica, 1986-2000. Journal of Geophysical Research, 107(D24), 4772.

Doran, P. T., McKay, C., Fountain, A., Nylen, T., McKnight, D., Jaros, C., \& Barrett, J. (2008). Hydrologic response to extreme warm and cold summers in the McMurdo Dry Valleys, East Antarctica. Antarctic Science, 20(5), 499-509.

Duller, G.A.T. (2008). Luminescence Dating: guidelines on using luminescence dating in archaeology. Swindon: English Heritage.

Dunai, T.J. (2010). Cosmogenic Nuclides: Principles, Concepts and Applications in the Earth Surface Sciences. [eBook] Cambridge: Cambridge University Press.

Fisher, D. A. (1987). Enhanced flow of Wisconsin ice related to solid conductivity through strain history and recrystallization. The Physical Basis of Ice Sheet Modelling. In: Proceedings of the Vancouver Symposium. IAHS Publ. No. 170.

Folk, R. L. (1951) Stages of textural maturity in sedimentary rocks, J. Sed. Res., 21, 127-130.

Fountain, A. G., Nylen, T., Monaghan, A., Basagic, H., \& Bromwich, D. (2010). Snow in the McMurdo Dry Valleys, Antarctica. International Journal of Climatology, 30(5), 633-642.

Fountain, A. G., Levy, J. S., Gooseff, M. N., \& Van Horn, D. (2014). The McMurdo Dry Valleys: A landscape on the threshold of change. Geomorphology, 225, 25-35.

Fountain, A.G., Basagic, H.J., and Niebuhr, S. (2016) Glaciers in equilibrium, McMurdo Dry Valleys, Antarctica. Journal of Glaciology, pp. 1-14.

Gibson, E. K., S. J. Wentworth, and D. S. McKay (1983), Chemical weathering and diagenesis of a cold desert soil from Wright Valley, Antarctica: An analog of Martian weathering processes, Journal of Geophysical Research, 88(S02), A912A928. 
Gillies, J., Nickling, W., \& Tilson, M. (2013). Frequency, magnitude, and characteristics of aeolian sediment transport: McMurdo Dry Valleys, Antarctica. Journal of Geophysical Research: Earth Surface, 118(2), 461-479.

Glasby, G., Mcpherson, J., Kohn, B., Johnston, J., Keys, J., Freeman, A., \& Tricker, M. (1981). Desert varnish in southern Victoria Land, Antarctica. New Zealand Journal of Geology and Geophysics, 24(3), 389-397.

Greeley, R., Lancaster, N., Lee, S., Thomas, P. (1992). Martian aeolian processes, sediments, and features. In: Kieffer, H. H., Jakosky, B. M., Snyder, C. W., Mathews, M. S. (eds.), Mars. Tucson: University of Arizona Press, pp.1-33.

Guelke-Stelling, M., \& Blanckenburg, F. (2012). Fe isotope fractionation caused by translocation of iron during growth of bean and oat as models of strategy I and II plants. Plant and Soil, 352(1), 217-231.

Hagedorn, B., Sletten, R. S., Hallet, B., McTigue, D. F., \& Steig, E. J. (2010). Ground ice recharge via brine transport in frozen soils of Victoria Valley, Antarctica: Insights from modeling $\delta 180$ and $\delta \mathrm{D}$ profiles. Geochimica Et Cosmochimica Acta, 74(2), 435-448.

Hall, K., Thorn, C., Matsuoka, N., \& Prick, A. (2002). Weathering in cold regions: Some thoughts and perspectives. Progress in Physical Geography, 26(4), 577-603.

Head, J., Kreslavsky, M., \& Marchant, D. (2011). Pitted rock surfaces on Mars: A mechanism of formation by transient melting of snow and ice. Journal of Geophysical Research. Planets, 116(9), Journal of Geophysical Research. Planets, 2011, Vol.116(9).

Heldmann, J., Marinova, M., Williams, K., Lacelle, D., Mckay, C., Davila, A., Pollard, W., \& Andersen, D. (2012). Formation and evolution of buried snowpack deposits in Pearse Valley, Antarctica, and implications for Mars. Antarctic Science, 24(3), 299-316.

Hergt, J.M., Chappell, B.W., Faure, G., Mensing, T. M. (1989). The geochemistry of Jurassic dolerites from Portal Peak, Antarctica. Contributions to Mineralogy and Petrology, 102(3), pp 298-305. 
Kieffer, H. H., Jakosky, B. M., Snyder, C. W., (1992). The Planet Mars: from Antiquity to Present. In: Kieffer, H. H., Jakosky, B. M., Snyder, C. W., Mathews, M. S. (eds.), Mars. Tucson: University of Arizona Press, pp.1-33.

Koeberl, C., P. Englert, J. L. Bishop, and E. K. Gibson. (2013). Subsurface Salts in Antarctic Dry Valley Soils. Lunar and Planetary Science Conference, USA, Texas: The Woodlands.

Lacelle, D., Davila, A. F., Fisher, D., Pollard, W. H., Dewitt, R., Heldmann, J., Marinova, M. M., Mckay, C. P. (2013). Excess ground ice of condensation-diffusion origin in University Valley, Dry Valleys of Antarctica: Evidence from isotope geochemistry and numerical modeling. Geochimica Et Cosmochimica Acta, 120, 280-297.

Lacelle, D., Lapalme, C., Davila, A., Pollard, W., Marinova, M., Heldmann, J., \& McKay, C. (2016). Solar Radiation and Air and Ground Temperature Relations in the Cold and Hyper-Arid Quartermain Mountains, McMurdo Dry Valleys of Antarctica. Permafrost and Periglacial Processes, 27(2), 163-176.

Levy, J. (2013). How big are the McMurdo Dry Valleys? Estimating ice-free area using Landsat image data. Antarctic Science, 25(1), 119-120.

Marchant, D., Denton, G., \& Swisher, C. (1993). Miocene-Pliocene-Pleistocene Glacial History of Arena Valley, Quartermain Mountains, Antarctica. Geografiska Annaler. Series A, Physical Geography, 75(4), 269-302.

Marchant, D.R. \& Denton, G.H. (1996). Miocene and Pliocene paleoclimate of the Dry Valleys region, Southern Victoria land: A geomorphological approach. Marine Micropaleontology, 27(1), 253-271.

Marchant, D.R., Denton, G., Swisher, C., \& Potter, N. (1996). Late Cenozoic Antarctic paleoclimate reconstructed from volcanic ashes in the Dry Valleys region of southern Victoria Land. Geological Society of America. Geological Society of America Bulletin, 108(2), 181.

Marchant, D.R., Lewis, A.R., Phillips, W.M., Moore, E.J., Souchez, R.A., Denton, G.H., Sudgen, D.E., Pottern, N., \& Landis, G.P. (2002). Formation of patterned ground and sublimation till over Miocene glacier ice in Beacon Valley, southern 
Victoria Land, Antarctica. The Geological Society of America Bulletin, 114(6), 718730. ta

Marchant, D.R., \& Head, J.W. (2007). Antarctic dry valleys: Microclimate zonation, variable geomorphic processes, and implications for assessing climate change on Mars. Icarus, 192(1), 187-222.

Margerison, H. R., Phillips, W. M., Stuart, F. M., \& Sugden, D. E. (2005).

Cosmogenic $3 \mathrm{He}$ concentrations in ancient flood deposits from the Coombs Hills, northern Dry Valleys, East Antarctica: Interpreting exposure ages and erosion rates. Earth and Planetary Science Letters, 230(1-2), 163-175.

Marinova, M. M., Mckay, C. P., Pollard, W. H., Heldmann, J. L., Davila, A. F., Andersen, D. T., Jackson, W. A., Lacelle, D., Paulsen, G., Zacny, K. (2013). Distribution of depth to ice-cemented soils in the high-elevation quartermain mountains, McMurdo dry valleys, Antarctica. Antarctic Science, 25(4), 575-582.

Marshall, J. R. (1987). Clastic particles. 1st ed. New York: Van Nostrand Reinhold Co.

Masarik, J., \& Beer, J. (1999). Simulation of particle fluxes and cosmogenic nuclide production in the Earth's atmosphere. Journal of Geophysical Research, 104, 1209912111.

McKay, C. P., Mellon, M. T. and Friedmann, E. I. (1998). Soil Temperature and Stability of Ice-cemented Ground in McMurdo Dry Valleys. Antarctica. Antarctic Science, 10, 31-38.

Mckay, C. P., Molaro, J. L. \& Marinova, M. M., (2009). High-frequency rock temperature data from hyper-arid desert environments in the Atacama and the Antarctic Dry Valleys and implications for rock weathering. Geomorphology, 110(3), 182-187.

McKay, C.P. (2009). Snow recurrence sets the depth of dry permafrost at high elevations in the McMurdo Dry Valleys of Antarctica. Antarctic Science, 21(1), 8994.

McKay, C.P. (2015). Testing the Doran summer climate rules in Upper Wright Valley, Antarctica. Antarctic Science, 27(4), pp. 411-415. 
Mellon, M., Mckay, C., \& Heldmann, J. (2014). Polygonal ground in the McMurdo Dry Valleys of Antarctica and its relationship to ice-table depth and the recent Antarctic climate history. Antarctic Science, 26(4), 413-426.

Michalski, G., Bockheim, J., Kendall, C., \& Thiemens, M. (2005). Isotopic composition of Antarctic Dry Valley nitrate: Implications for $\mathrm{NO}_{\mathrm{y}}$ sources and cycling in Antarctica. Geophysical Research Letters, 32(13).

Middleton, J. L., Ackert, R. P., \& Mukhopadhyay, S. (2012). Pothole and channel system formation in the McMurdo Dry Valleys of Antarctica: New insights from cosmogenic nuclides. Earth and Planetary Science Letters, 355-356, 341-350.

Milodowski, A. E., Northmore, K. J., Kemp, D. J., Entwisle, D. A., Gunn, D. A., Jackson, P. D., Boardman, D. I., Zoumpakis, A., Rogers, C. D. F., Dixon, N., Jefferson, I., Smalley, I. J., Clarke, M. (2015). The mineralogy and fabric of 'Brickearths' in Kent, UK and their relationship to engineering behaviour. Bulletin of Engineering Geology and the Environment, 74(4), 1187-1211.

Nicholls, G.D., (1963). Environmental studies in sedimentary geochemistry. Science Progress, 51.

Nordstrom, D., Plummer, L.N., Wigley, T., Wolery, T., Ball, J., Jenne, E., Bassett, R., Crerar, D., Florence, T., Fritz, B., Hoffman, M., Holdren, G., Mattigod, L.G. Jr., S., McDuff, R., Morel, F., Reddy, M., Sposito, G. (1979). A comparison of computerized chemical models for equilibrium calculations in aqueous systems. American Chemical Society Symposium Ser., 93, pp. 857-89.

Nylen, T. H., and Fountain, A. G. (2004). Climatology of katabatic winds in the McMurdo dry valleys, southern Victoria Land, Antarctica. Journal of Geophysical Research. 109, D03114.

Pawley, S. M., Toms, P., Armitage, S.J., \& Rose, J. (2010). Quartz luminescence dating of Anglian Stage (MIS 12) fluvial sediments: Comparison of SAR age estimates to the terrace chronology of the Middle Thames valley, UK. Quaternary Geochronology, 5(5), 569-582.

Pettijohn, F. J. (1975). Sedimentary Rocks, New York: Harper and Row. 
Preusser, F., Degering, D., Fuchs, M., Hilgers, A., Kadereit, A., Klasen, N., Krbetschek, M., Richter, D., Spenger, J. Q. G. (2008). Luminescence dating: basics, methods and applications. Eiszeitalter und Gegenwart, Quaternary Science Journal, 57, pp. 95-149.

Pringle, D. J., Dickinson, W.W., Trodahl, H. J., and Pyne, A. R. (2003). Depth and seasonal variations in the thermal properties of Antarctic Dry Valley permafrost from temperature time series analysis. Journal of Geophysical Research, 108(B10), 2474.

Putkonen, J., Morgan, D., \& Balco, G. (2014). Boulder weathering in McMurdo Dry Valleys, Antarctica. Geomorphology, 219, 192-199.

Ramsey, M. A. (2015). OSL dating of high-elevation alluvial sediments: McMurdo dry valleys, Antarctica. Available from ProQuest Dissertations \& Theses Global.

Russell, R., \& Taylor, R. (1937). Roundness and Shape of Mississippi River Sands. The Journal of Geology, 45(3), pp. 225-267.

Salvatore, M.R., Mustard, J.F., Head, J.W., Cooper, R.F., Marchant, D.R., \& Wyatt, M.B. (2013). Development of alteration rinds by oxidative weathering processes in Beacon Valley, Antarctica, and implications for Mars. Geochimica Et Cosmochimica Acta, 115, 137-161.

Salvatore, M., Mustard, J., Head, J., Marchant, D., \& Wyatt, M. (2014).

Characterization of spectral and geochemical variability within the Ferrar Dolerite of the McMurdo Dry Valleys, Antarctica: Weathering, alteration, and magmatic processes. Antarctic Science, 26(1), 49-68.

Schäfer, J. M., Ivy-Ochs, S., Wieler, R., Leya, I., Baur, H., Denton, G. H., \& Schlüchter, C. (1999). Cosmogenic noble gas studies in the oldest landscape on earth: Surface exposure ages of the Dry Valleys, Antarctica. Earth and Planetary Science Letters, 167(3), 215-226.

Schiller, M. (2007). Testing the Antiquity of McMurdo Dry Valley Soil Surfaces with Atmospheric ${ }^{10} \mathrm{Be}$. Ph.D. Victoria University of Wellington. 
Schiller, M., W. Dickinson, R. G. Ditchburn, I. J. Graham, and A. Zondervan (2009), Atmospheric ${ }^{10} \mathrm{Be}$ in an Antarctic soil: Implications for climate change. Journal of Geophysical. Research., 114, F01033.

Schneiderhöhn, P. (1954). Eine vergleichende Studie über Methoden zur quantitativen Bestimmung von Abrundung und Form an Sandkörnern. Heidelberger Beiträge zur Mineralogie und Petrographie, 4, pp. 172-191.

Sizemore, H. G. \& Mellon, M. T. (2008). Laboratory characterization of the structural properties controlling dynamical gas transport in Mars-analog soils. Icarus, 197(2), 606-620.

Socki, R., McKay, D., Wentworth, S., \& Gibson, E. (2004). Zeolite Formation and Weathering Processes in Dry Valleys of Antarctica: Martian Analogs. European Geosciences Union 1st General Assembly, 25-30 Apr. 2004; Nice; France.

Speirs, J. C., D. Steinhoff, H. A. McGowan, D. H. Bromwich, and A. J. Monaghan (2010). Foehn winds in the McMurdo Dry Valleys, Antarctica: The origin of extreme warming events. Journal of Climate, 23(13), 3577-3598.

Steig, E.J. (1996). Beryllium-10 in the Taylor Dome ice core: applications to Antarctic glaciology and paleoclimatology. Ph.D. Department of Geological Sciences, University of Washington, Seattle, WA, USA.

Steig, E.J., Morse, D.L., Waddington, E.D., Stuiver, M., Grootes, P.M., Mayewski, P.A., Twickler, M.S. and Whitlow, S.I. (2000). Wisconsinan and Holocene climate history from an ice core at Taylor Dome, western Ross Embayment, Antarctica. Geografiska Annaler: Series A, Physical Geography, 82(2-3), 213-235.

Steinhoff, D., Bromwich, D., \& Monaghan, A. (2013). Dynamics of the Foehn Mechanism in the McMurdo Dry Valleys of Antarctica from Polar WRF. Quarterly Journal of the Royal Meteorological Society, 139(675), 1615-1631.

Stuiver, M. (1994). Atmospheric 14C as a proxy of solar and climatic change. In: Nesme-Ribes (Ed.), The Solar Engine and Its Influence on Terrestrial Atmosphere and Climate. Berlin: Springer Verlag, pp. 203-220.

Syvitski, J.P.M. (1991). Principles, methods, and application of particle size analysis. New York: Cambridge University Press. 
Talkington, R., Mayewski, P., \& Gaudette, H. (1982). Geochemical and glaciogeomorphic implications of basalt weathering in the Queen Maud Mountains, Antarctica. Geological Magazine, 119(6), 553-566.

Tamppari, L.K., Anderson, R.M ; Archer, P.D ; Douglas, S ; Kounaves, S.P ; Mckay, C.P ; Ming, D.W ; Moore, Q ; Quinn, J.E ; Smith, P.H ; Stroble, S ; Zent, A.P. (2012). Effects of extreme cold and aridity on soils and habitability: McMurdo Dry Valleys as an analogue for the Mars Phoenix landing site. Antarctic Science, 24(3), 211-228.

Tessier, A., Campbell, P. G. C., Bisson, M. (1979). Sequential extraction procedure for the speciation of particulate trace metals. Anal. Chem., 51 (7), pp. 844-851.

Tester, M., \& Morris, C. (1987). The penetration of light through soil. Plant, Cell \& Environment, 10(4), 281-286.

Toner, J., Sletten, R., \& Prentice, M. (2013). Soluble salt accumulations in Taylor Valley, Antarctica: Implications for paleolakes and Ross Sea Ice Sheet dynamics. Journal of Geophysical Research: Earth Surface, 118(1), 198-215.

Ugolini, F. C., \& Bockheim, J. G. (2008). Antarctic soils and soil formation in a changing environment: A review. Geoderma, 144(1), 1-8.

Valletta, R. D., Willenbring, J. K., Lewis, A. R., Ashworth, A. C., \& Caffee, M. (2015). Extreme decay of meteoric beryllium-10 as a proxy for persistent aridity. Scientific Reports, 5.

Van der Plas, L., and Tobi, A. C. (1965). A chart for judging the reliability of point counting results. American journal of science, 263, pp. 87-90.

Wadell, H. (1932). Volume, Shape, and Roundness of Rock Particles. The Journal of Geology, 40(5), 443-451.

Wentworth, C. (1922). A Scale of Grade and Class Terms for Clastic Sediments. The Journal of Geology, 30(5), 377-392.

West, L.T., Wilding, L.P. \& Calhoun, F.G. (1987). Argillic horizons in sandy soils of the Sahel, West Africa. In Fedoroff, N., Bresson, L.M. \& Courty, M.A. (eds.), Micromorphologie des Sols, Soil Micromorphology. Paris: AFES, pp. 221-225. 
Willenbring, J. K. \& Von Blanckenburg, F. (2010). Meteoric cosmogenic Beryllium10 adsorbed to river sediment and soil: Applications for Earth-surface dynamics. Earth Science Reviews, 98(1), 105-122.

Witherow, R. A.; Lyons, W. B.; Bertler, N. A. N.; Welch, K. A.; Mayewski, P. A.; Sneed, S. B.; Nylen, T.; Handley, M. J.; and Fountain, A. (2006). The Aeolian Flux of Calcium, Chloride and Nitrate to the McMurdo Dry Valleys Landscape: Evidence from Snow Pit Analysis. Earth Science Faculty Scholarship, Paper 99.

Wittmann, H., Von Blanckenburg, F., Bouchez, J., Dannhaus, N., Naumann, R., Christl, M., \& Gaillardet, J. (2012). The dependence of meteoric ${ }^{10} \mathrm{Be}$ concentrations on particle size in Amazon River bed sediment and the extraction of reactive ${ }^{10} \mathrm{Be} /{ }^{9} \mathrm{Be}$ ratios. Chemical Geology, pp. 318 319, 126.

You, C. F., Lee, T. \& Li, Y. H. (1989). The partition of Be between soil and water. Chemical Geology, 77(2), 105-118.

Zamora, F., Lewis, Adam, Day, Stephanie, Lepper, Kenneth, \& Norland, Jack. (2013). Alluvial Fans in the McMurdo Dry Valleys: A Proxy for Melting along Terrestrial Margins of the East Antarctic Ice Sheet. M.Sc. North Dakota State University of Agriculture and Applied Science. 


\section{Appendix}

Appendix A: Grain size analysis

\begin{tabular}{|c|c|c|c|c|c|c|c|c|c|c|c|c|c|}
\hline Mesh size & $\begin{array}{l}-1.0 \Phi \\
(2.0 \\
\mathrm{mm}) \\
\end{array}$ & $\begin{array}{l}-0.5 \Phi \\
(1.4 \\
\mathrm{mm}) \\
\end{array}$ & $\begin{array}{l}0 \Phi \\
(1.0 \\
\mathrm{mm})\end{array}$ & $\begin{array}{l}0.5 \Phi \\
(710 \\
\mu \mathrm{m})\end{array}$ & $\begin{array}{l}1.0 \Phi \\
(500 \mu \mathrm{m})\end{array}$ & $\begin{array}{l}\frac{P 1}{1.5} \Phi \\
(355 \\
\mu \mathrm{m}) \\
\end{array}$ & $\begin{array}{l}2.0 \Phi \\
(250 \\
\mu \mathrm{m})\end{array}$ & $\begin{array}{l}2.5 \Phi \\
(180 \\
\mu \mathrm{m})\end{array}$ & $\begin{array}{l}3.0 \Phi \\
(125 \\
\mu \mathrm{m}) \\
\end{array}$ & \begin{tabular}{|l}
$3.5 \Phi$ \\
$(90 \mu \mathrm{m})$ \\
\end{tabular} & $\begin{array}{l}4.0 \Phi \\
(45 \mu \mathrm{m})\end{array}$ & $\begin{array}{l}4.0 \Phi \\
(45 \mu \mathrm{m})\end{array}$ & $\begin{array}{l}\text { Total \% } \\
\text { retained }\end{array}$ \\
\hline Depth & & & & & & & & & & & & & \\
\hline $30 \mathrm{~cm}$ & 1.9 & 1.9 & 2.6 & 3.7 & 10.8 & 19.0 & 15.1 & 9.5 & 7.1 & 3.6 & 7.7 & 15.2 & 98.1 \\
\hline $50 \mathrm{~cm}$ & 0.0 & 0.0 & 0.0 & 1.2 & 7.0 & 45.5 & 37.4 & 4.1 & 0.4 & 0.2 & 0.2 & 3.0 & 99.0 \\
\hline $70 \mathrm{~cm}$ & 0.0 & 0.6 & 3.4 & 6.7 & 18.1 & 25.0 & 17.2 & 10.1 & 6.1 & 2.7 & 3.4 & 5.3 & 98.6 \\
\hline $85 \mathrm{~cm}$ & 0.0 & 0.6 & 2.7 & 5.9 & 17.6 & 25.7 & 17.7 & 9.9 & 5.3 & 1.9 & 2.0 & 9.4 & 98.8 \\
\hline $100 \mathrm{~cm}$ & 0.0 & 0.0 & 0.0 & 0.0 & 0.0 & 0.1 & 0.7 & 43.3 & 19.3 & 13.9 & 11.7 & 5.7 & 94.7 \\
\hline $110 \mathrm{~cm}$ & 2.5 & 3.6 & 4.5 & 7.2 & 15.3 & 21.3 & 14.8 & 8.6 & 5.2 & 2.2 & 2.8 & 9.7 & 97.8 \\
\hline $125 \mathrm{~cm}$ & 2.9 & 5.2 & 6.1 & 7.9 & 14.5 & 20.6 & 13.9 & 7.9 & 5.0 & 2.4 & 3.4 & 7.3 & 97.1 \\
\hline $140 \mathrm{~cm}$ & 1.1 & 0.4 & 2.8 & 4.9 & 16.0 & 25.1 & 15.8 & 7.5 & 3.5 & 1.1 & 1.4 & 19.0 & 98.8 \\
\hline
\end{tabular}

Table 1: Grain size for P1 according to sieve stack measurements. Shown is the percentage of total sample mass retained per sieve.

\begin{tabular}{|c|c|c|c|c|c|c|c|c|c|c|c|c|c|}
\hline Mesh size & $\begin{array}{l}-1.0 \Phi \\
(2.0 \\
\mathrm{mm})\end{array}$ & $\begin{array}{l}-0.5 \Phi \\
(1.4 \\
\mathrm{mm})\end{array}$ & $\begin{array}{l}\mathbf{0} \Phi \\
(1.0 \\
\mathbf{m m})\end{array}$ & $\begin{array}{l}0.5 \Phi \\
(710 \\
\mu \mathrm{m})\end{array}$ & $\begin{array}{l}1.0 \Phi \\
(500 \mu m)\end{array}$ & $\begin{array}{l}\frac{P 2}{1.5} \Phi \\
(355 \\
\mu \mathrm{m})\end{array}$ & $\begin{array}{l}2.0 \Phi \\
(250 \\
\mu \mathrm{m})\end{array}$ & $\begin{array}{l}2.5 \Phi \\
(180 \\
\mu \mathrm{m})\end{array}$ & $\begin{array}{l}3.0 \Phi \\
(125 \\
\mu \mathrm{m})\end{array}$ & $\begin{array}{l}3.5 \Phi \\
(90 \mu \mathrm{m})\end{array}$ & $\begin{array}{l}4.0 \Phi \\
(45 \mu \mathrm{m})\end{array}$ & $\begin{array}{l}4.0 \Phi \\
(45 \mu \mathrm{m})\end{array}$ & $\begin{array}{l}\text { Total \% } \\
\text { retained }\end{array}$ \\
\hline Depth & & & & & & & & & & & & & \\
\hline $20 \mathrm{~cm}$ & 2.0 & 1.4 & 2.8 & 2.8 & 9.7 & 17.4 & 14.3 & 8.5 & 5.5 & 2.5 & 4.0 & 22.9 & 93.9 \\
\hline $32 \mathrm{~cm}$ & 2.8 & 2.6 & 2.2 & 3.7 & 11.9 & 20.8 & 14.8 & 9.4 & 5.5 & 1.7 & 2.4 & 20.8 & 98.6 \\
\hline $38 \mathrm{~cm}$ & 0.9 & 1.2 & 0.8 & 2.2 & 9.7 & 21.1 & 19.2 & 12.7 & 6.5 & 2.0 & 2.8 & 18.5 & 97.6 \\
\hline $50 \mathrm{~cm}$ & 1.2 & 1.0 & 1.5 & 3.0 & 9.7 & 21.0 & 17.8 & 16.1 & 8.7 & 2.0 & 1.9 & 13.9 & 97.7 \\
\hline
\end{tabular}

Table 2: Grain size for P2 according to sieve stack measurements. Shown is the percentage of total sample mass retained per sieve. 


\begin{tabular}{|c|c|c|c|c|c|c|c|c|c|c|c|c|c|}
\hline Mesh size & $\begin{array}{l}-1.0 \Phi \\
(2.0 \\
\mathbf{m m}) \\
\end{array}$ & $\begin{array}{l}-0.5 \Phi \\
(1.4 \\
\mathbf{m m}) \\
\end{array}$ & $\begin{array}{l}0 \Phi \\
(1.0 \\
\mathrm{mm}) \\
\end{array}$ & \begin{tabular}{|l}
$0.5 \Phi$ \\
$(710$ \\
$\mathbf{u m})$ \\
\end{tabular} & $\begin{array}{l}0.5 \Phi \\
(710 \\
\mu \mathrm{m})\end{array}$ & $\begin{array}{l}\underline{\text { P8 }} \\
1.0 \Phi \\
(500 \mu m)\end{array}$ & $\begin{array}{l}1.5 \Phi \\
(355 \\
\mu \mathrm{m}) \\
\end{array}$ & $\begin{array}{l}2.0 \Phi \\
(250 \\
\mu \mathrm{m})\end{array}$ & \begin{tabular}{|l}
$2.5 \Phi$ \\
$(180$ \\
$\mu \mathrm{m})$ \\
\end{tabular} & $\begin{array}{l}3.0 \Phi \\
(125 \\
\mu \mathrm{m}) \\
\end{array}$ & $\begin{array}{l}3.5 \Phi \\
(90 \mu \mathrm{m})\end{array}$ & $\begin{array}{l}4.0 \Phi \\
(45 \mu \mathrm{m}) \\
\end{array}$ & $\begin{array}{l}\text { Total \% } \\
\text { retained }\end{array}$ \\
\hline Depth & & & & & & & & & & & & & \\
\hline $2 \mathrm{~cm}$ & 3.1 & 2.1 & 5.0 & 6.1 & 12.0 & 20.3 & 15.6 & 10.4 & 7.4 & 3.2 & 4.2 & 8.4 & 97.7 \\
\hline $12 \mathrm{~cm}$ & 1.7 & 8.6 & 8.3 & 8.0 & 13.3 & 20.4 & 14.1 & 8.0 & 5.3 & 2.3 & 3.1 & 5.4 & 98.4 \\
\hline $27 \mathrm{~cm}$ & 0.2 & 2.1 & 8.1 & 5.9 & 12.4 & 20.4 & 15.2 & 9.2 & 6.2 & 3.2 & 4.9 & 11.7 & 99.3 \\
\hline $32 \mathrm{~cm}$ & 2.7 & 1.6 & 1.8 & 2.4 & 12.2 & 24.7 & 21.1 & 14.9 & 8.7 & 2.3 & 2.3 & 4.4 & 99.0 \\
\hline $52 \mathrm{~cm}$ & 0.5 & 1.4 & 1.6 & 2.8 & 13.1 & 25.5 & 20.8 & 12.9 & 7.4 & 2.0 & 2.0 & 8.6 & 98.5 \\
\hline $67 \mathrm{~cm}$ & 0.2 & 0.5 & 0.5 & 1.4 & 9.1 & 22.9 & 23.9 & 16.1 & 9.4 & 2.4 & 2.2 & 10.1 & 98.6 \\
\hline
\end{tabular}

Table 3: Grain size for P8 according to sieve stack measurements. Shown is the percentage of total sample mass retained per sieve.

\begin{tabular}{|c|c|c|c|c|c|c|c|c|c|c|c|c|c|}
\hline Mesh size & \begin{tabular}{|l}
$-1.0 \Phi$ \\
$(2.0$ \\
$\mathrm{mm})$ \\
\end{tabular} & $\begin{array}{l}-0.5 \Phi \\
(1.4 \\
\mathrm{mm}) \\
\end{array}$ & $\begin{array}{l}0 \Phi \\
(1.0 \\
\text { mm) } \\
\end{array}$ & $\begin{array}{l}0.5 \Phi \\
(710 \\
\text { um) } \\
\end{array}$ & $\begin{array}{l}0.5 \Phi \\
(710 \\
\mu \mathrm{m})\end{array}$ & $\begin{array}{l}\underline{P 10} \\
1.0 \Phi \\
(500 \mu \mathrm{m})\end{array}$ & $\begin{array}{l}1.5 \Phi \\
(355 \\
\mu \mathrm{m}) \\
\end{array}$ & $\begin{array}{l}2.0 \Phi \\
(250 \\
\mu \mathrm{m})\end{array}$ & $\begin{array}{l}2.5 \Phi \\
(180 \\
\mu \mathrm{m}) \\
\end{array}$ & $\begin{array}{l}3.0 \Phi \\
(125 \\
\mu \mathrm{m}) \\
\end{array}$ & $\begin{array}{l}3.5 \Phi \\
(90 \mu \mathrm{m}) \\
\end{array}$ & $\begin{array}{l}4.0 \Phi \\
(45 \mu \mathrm{m}) \\
\end{array}$ & $\begin{array}{l}\text { Total \% } \\
\text { retained }\end{array}$ \\
\hline Depth & & & & & & & & & & & & & \\
\hline $18 \mathrm{~cm}$ & 0.3 & 3.6 & 5.2 & 7.7 & 15.9 & 23.1 & 15.8 & 9.1 & 5.2 & 2.1 & 1.7 & 7.2 & 96.7 \\
\hline $44 \mathrm{~cm}$ & 0.0 & 5.9 & 7.5 & 7.0 & 15.7 & 20.9 & 15.0 & 8.2 & 5.0 & 2.3 & 2.2 & 6.8 & 96.5 \\
\hline $72 \mathrm{~cm}$ & 0.0 & 5.8 & 6.5 & 9.8 & 18.7 & 23.2 & 14.2 & 7.2 & 4.4 & 2.0 & 1.9 & 4.4 & 98.1 \\
\hline $101 \mathrm{~cm}$ & 0.0 & 4.8 & 7.9 & 10.1 & 17.5 & 20.4 & 11.7 & 6.6 & 4.6 & 2.7 & 4.2 & 7.5 & 97.9 \\
\hline $126 \mathrm{~cm}$ & 0.3 & 7.3 & 8.6 & 9.9 & 15.7 & 17.7 & 11.3 & 6.3 & 4.7 & 2.7 & 4.3 & 10.1 & 98.9 \\
\hline $155 \mathrm{~cm}$ & 0.0 & 2.7 & 6.7 & 10.3 & 19.3 & 20.7 & 11.9 & 5.7 & 3.5 & 1.7 & 3.3 & 11.7 & 97.5 \\
\hline $183 \mathrm{~cm}$ & 0.4 & 4.1 & 6.6 & 10.3 & 18.1 & 20.6 & 12.0 & 6.6 & 4.7 & 2.6 & 3.6 & 8.8 & 98.3 \\
\hline
\end{tabular}

Table 4: Grain size for P10 according to sieve stack measurements. Shown is the percentage of total sample mass retained per sieve. 


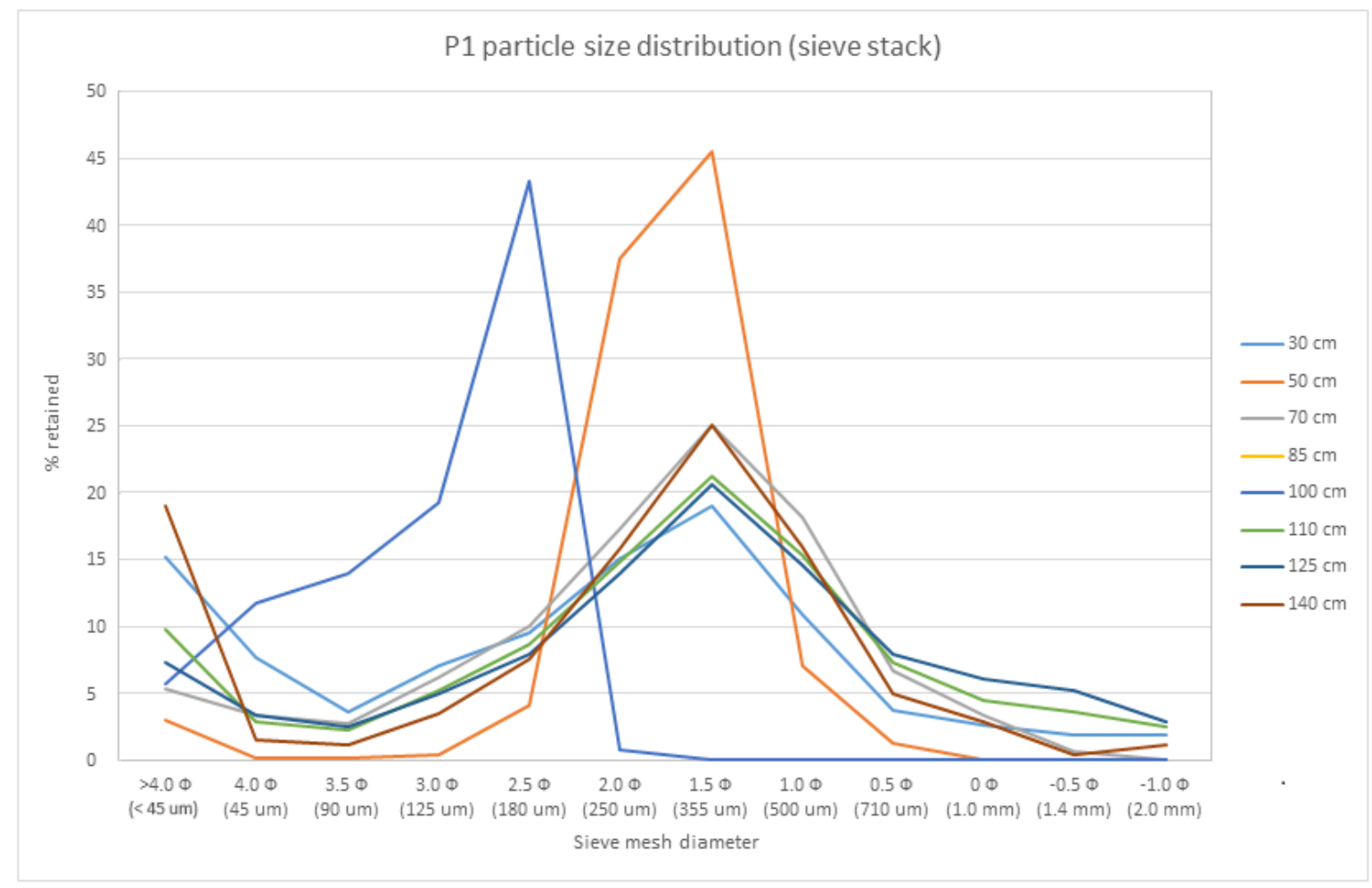

Figure 1: P1 particle size distribution as determined by sieve stack measurements.

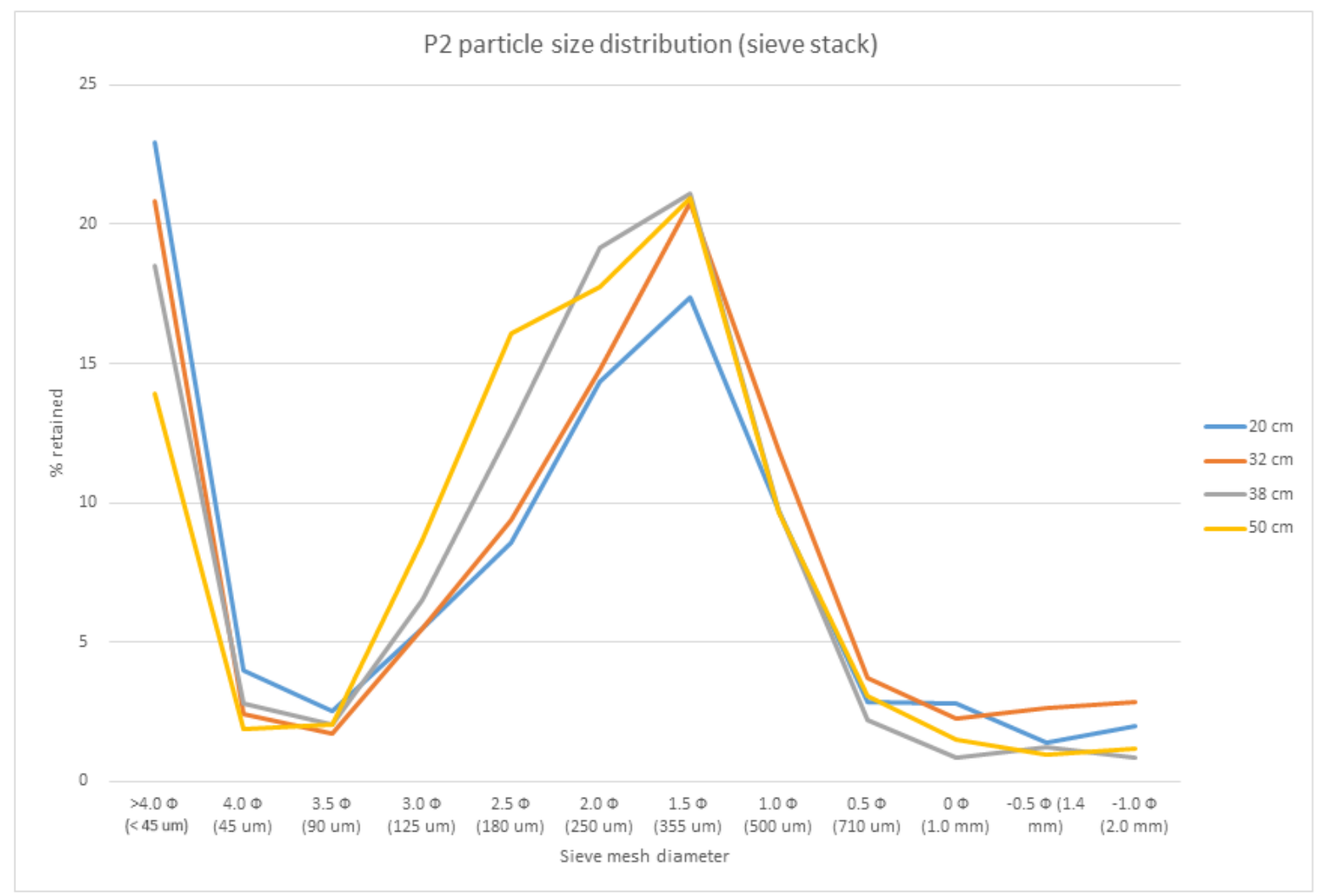

Figure 2: P2 particle size distribution as determined by sieve stack measurements. 


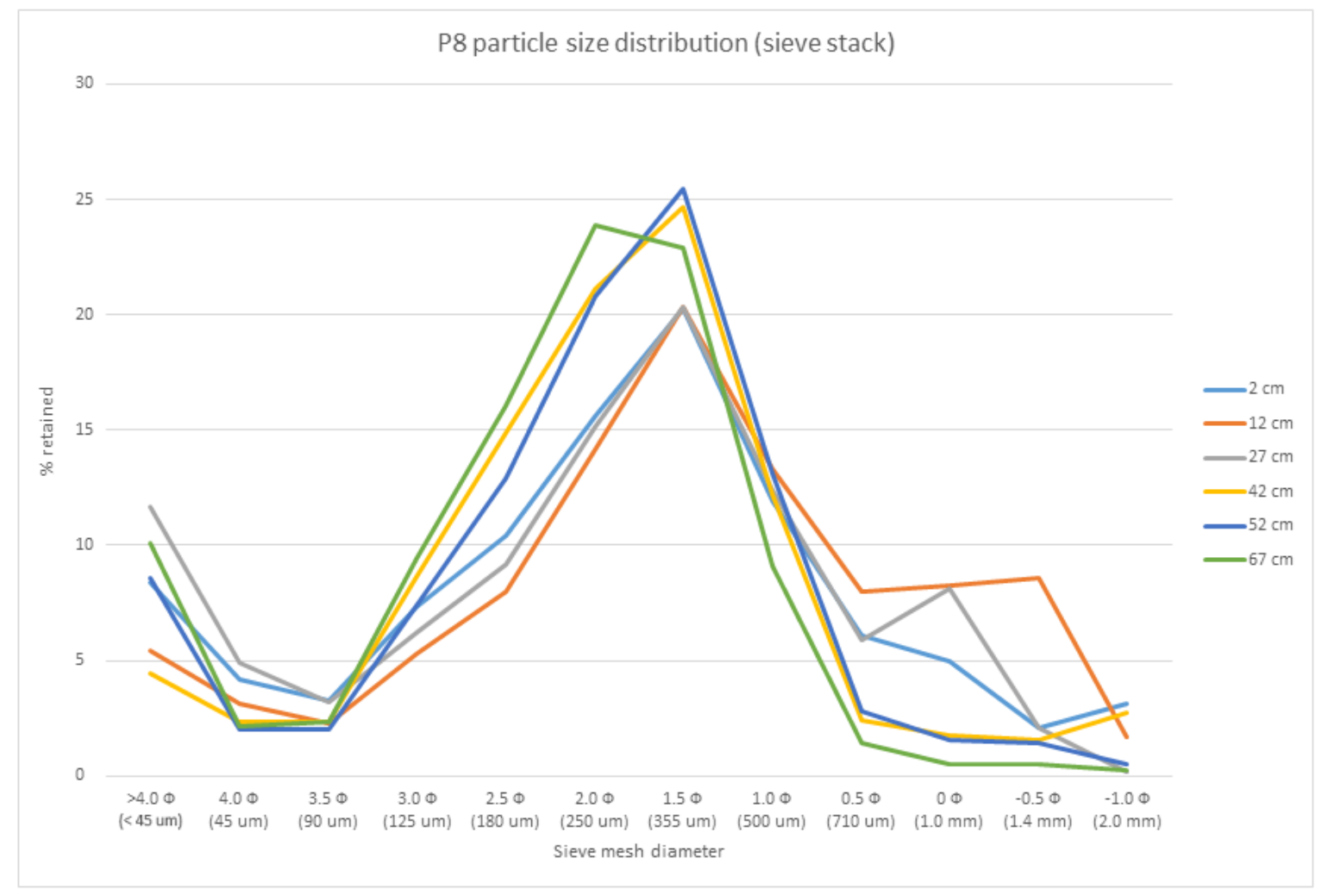

Figure 3: P8 particle size distribution as determined by sieve stack measurements.

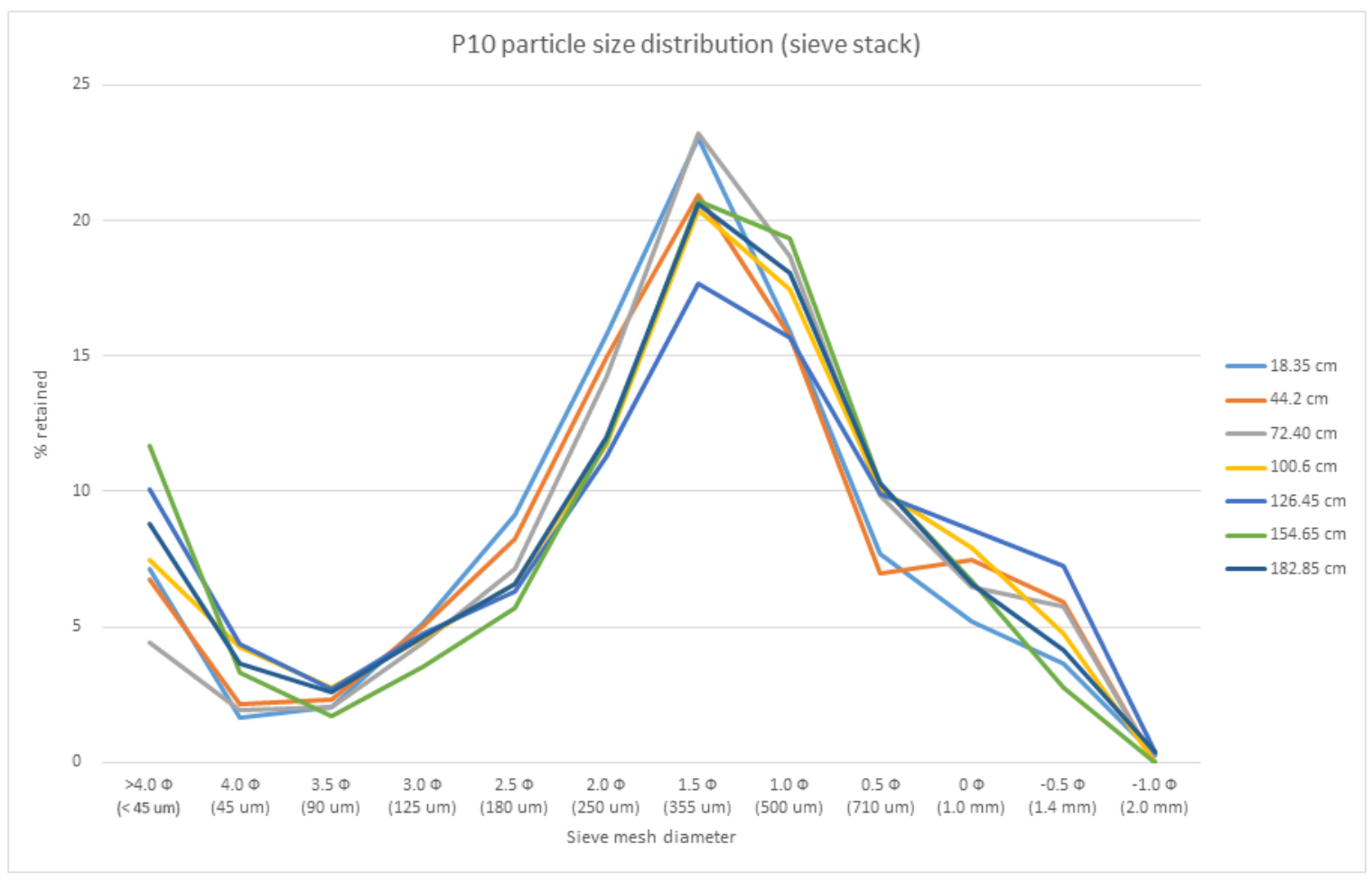

Figure 4: P10 particle size distribution as determined by sieve stack measurements. 
P1 particle size distribution (laser sizer)

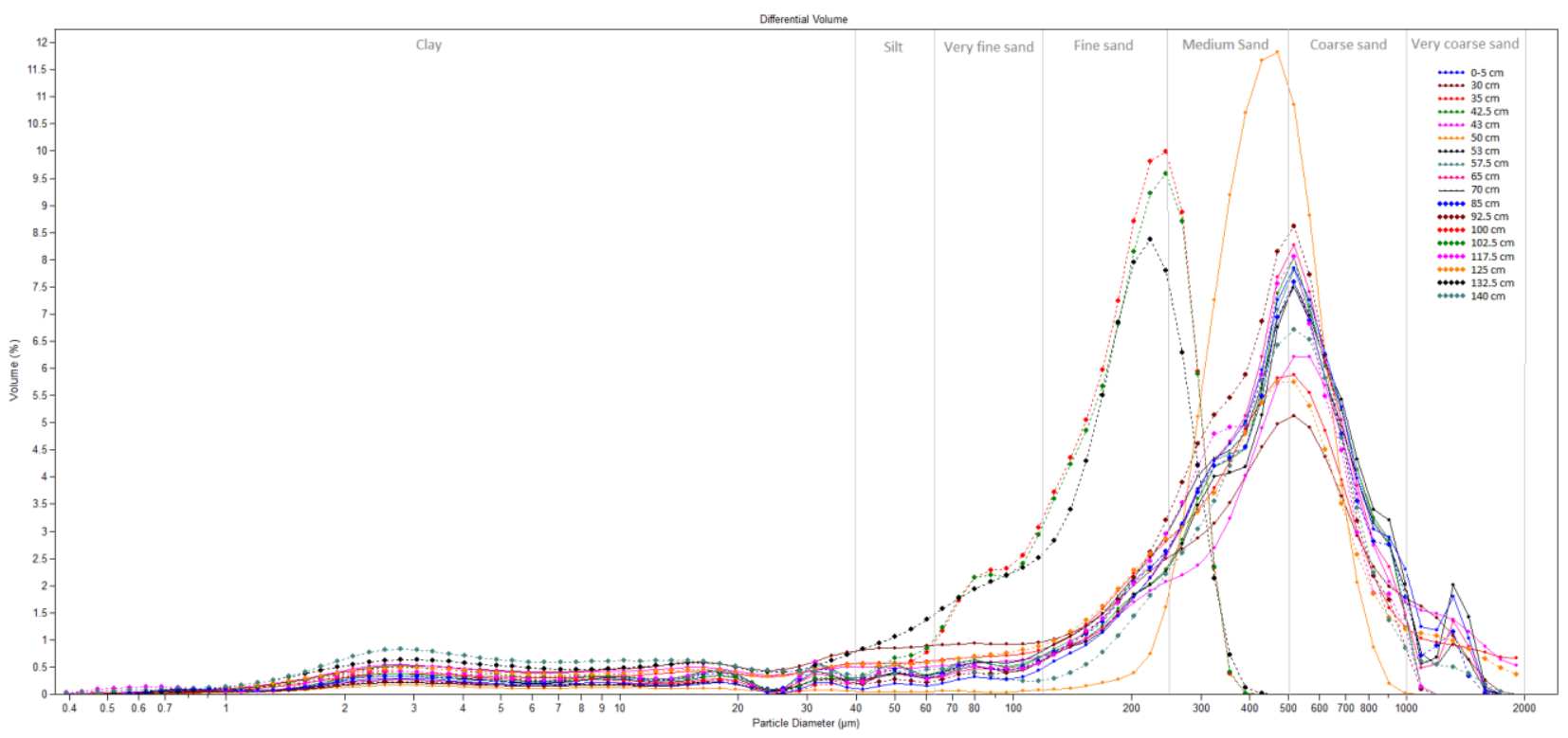

Figure 5: P1 particle size distribution as determined by laser sizer measurements.

P2 particle size distribution (laser sizer)

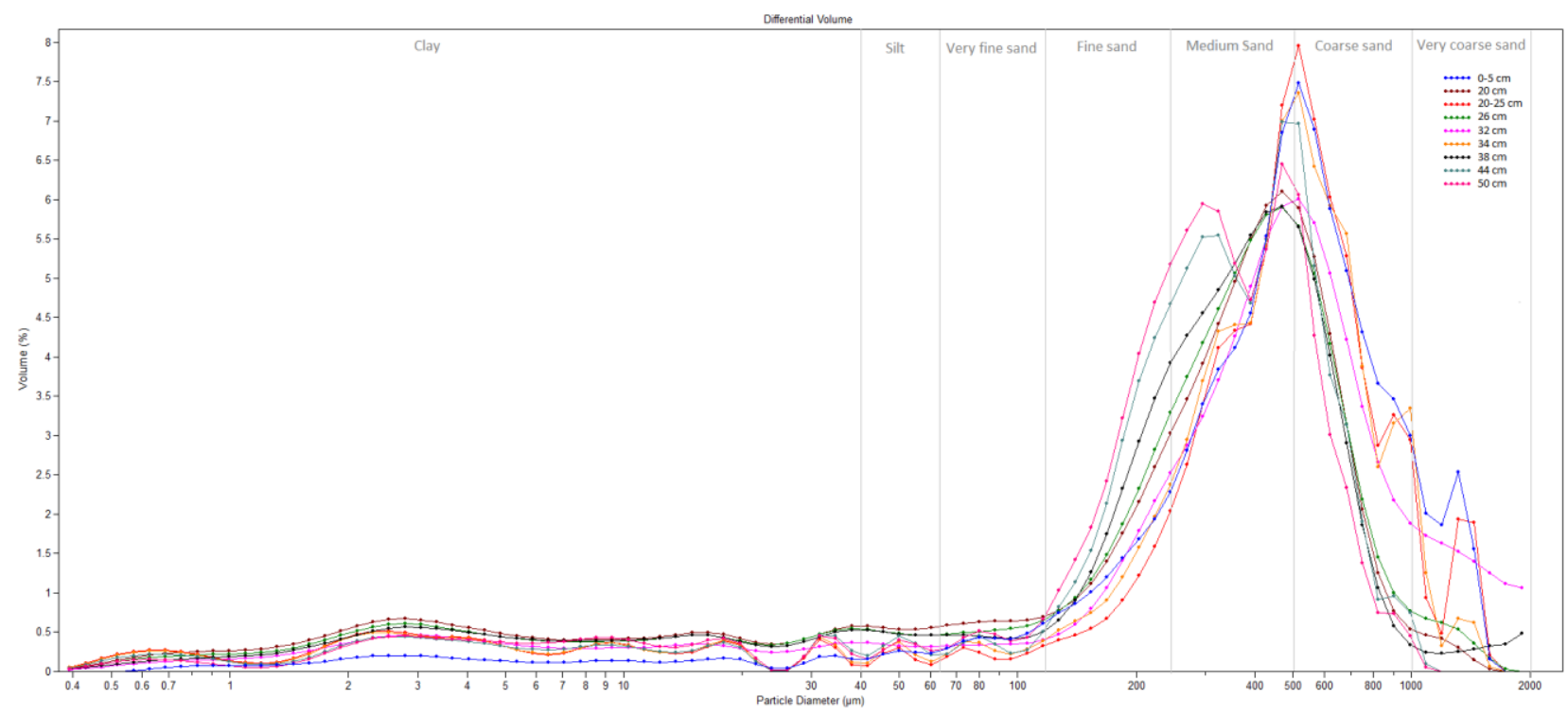

Figure 6: P2 particle size distribution as determined by laser sizer measurements. 
P4 particle size distribution (laser sizer)

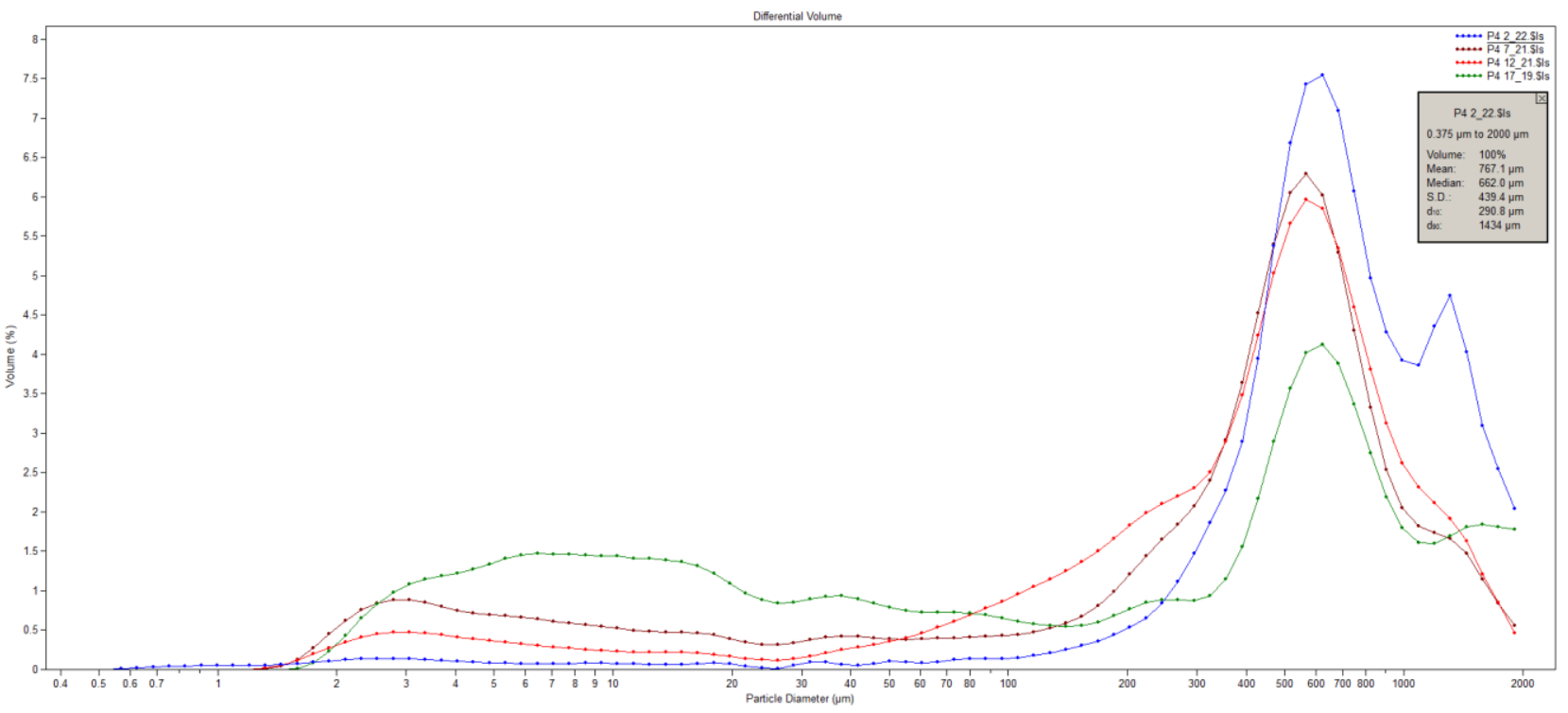

Figure 7: P4 particle size distribution as determined by laser sizer measurements.

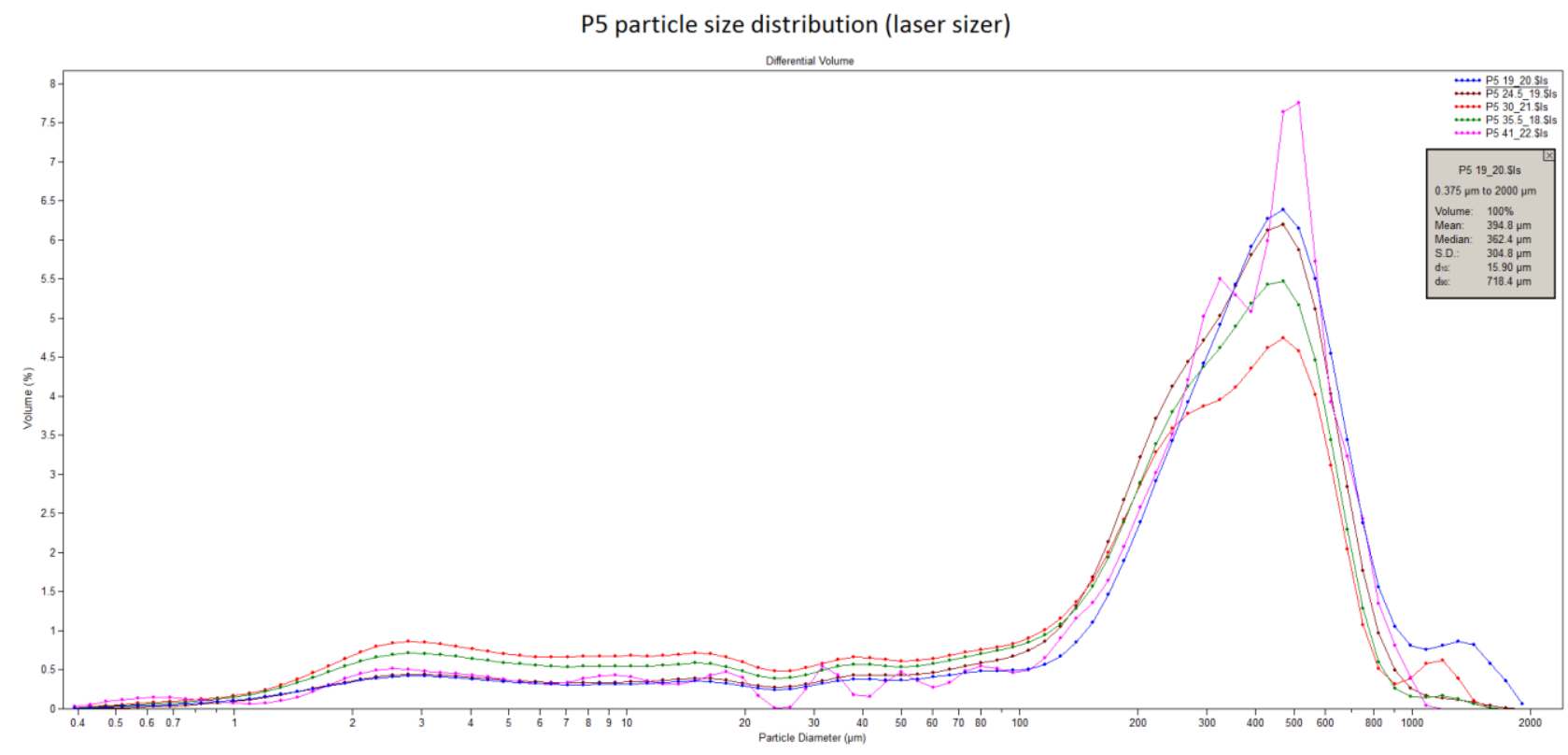

Figure 8: P5 particle size distribution as determined by laser sizer measurements. 
P6 particle size distribution (laser sizer)

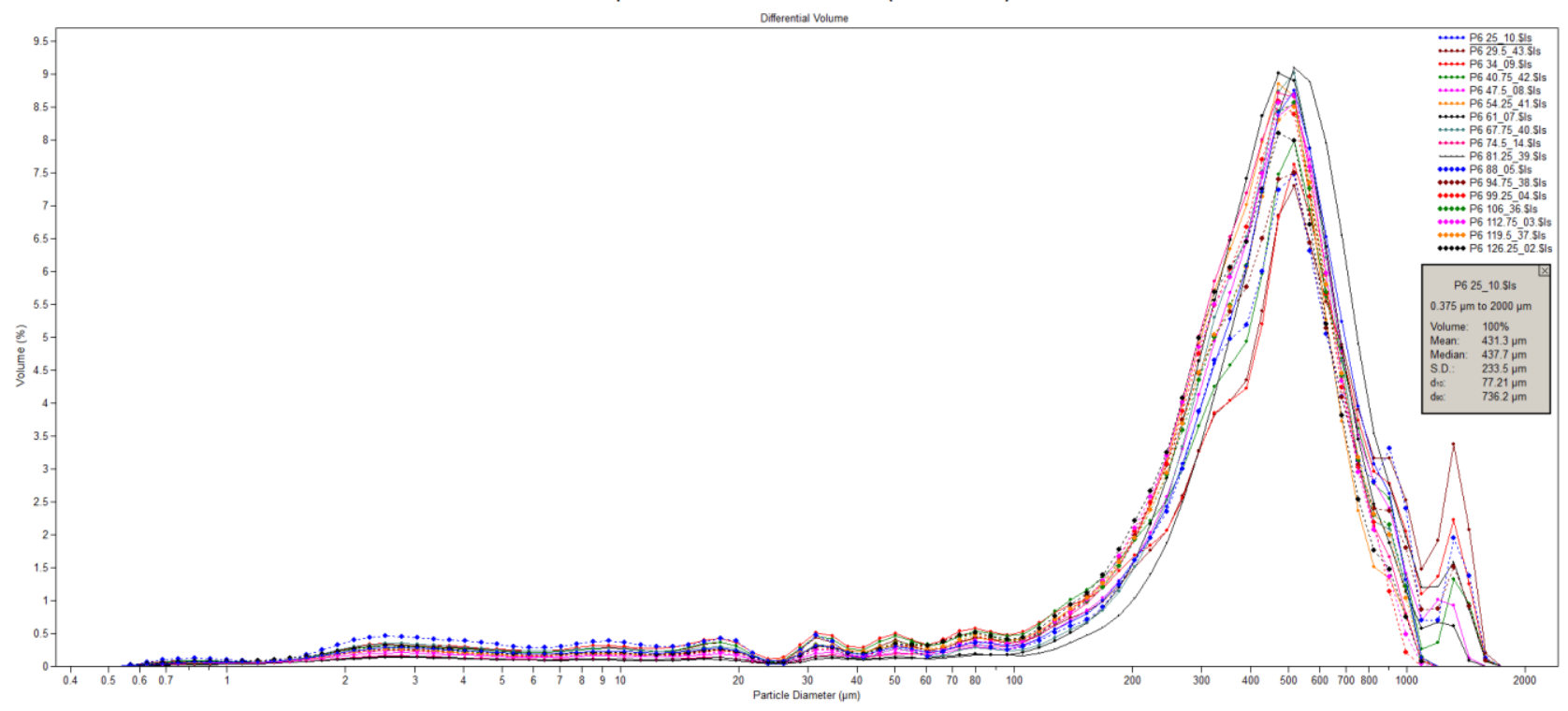

Figure 9: P6 particle size distribution as determined by laser sizer measurements.

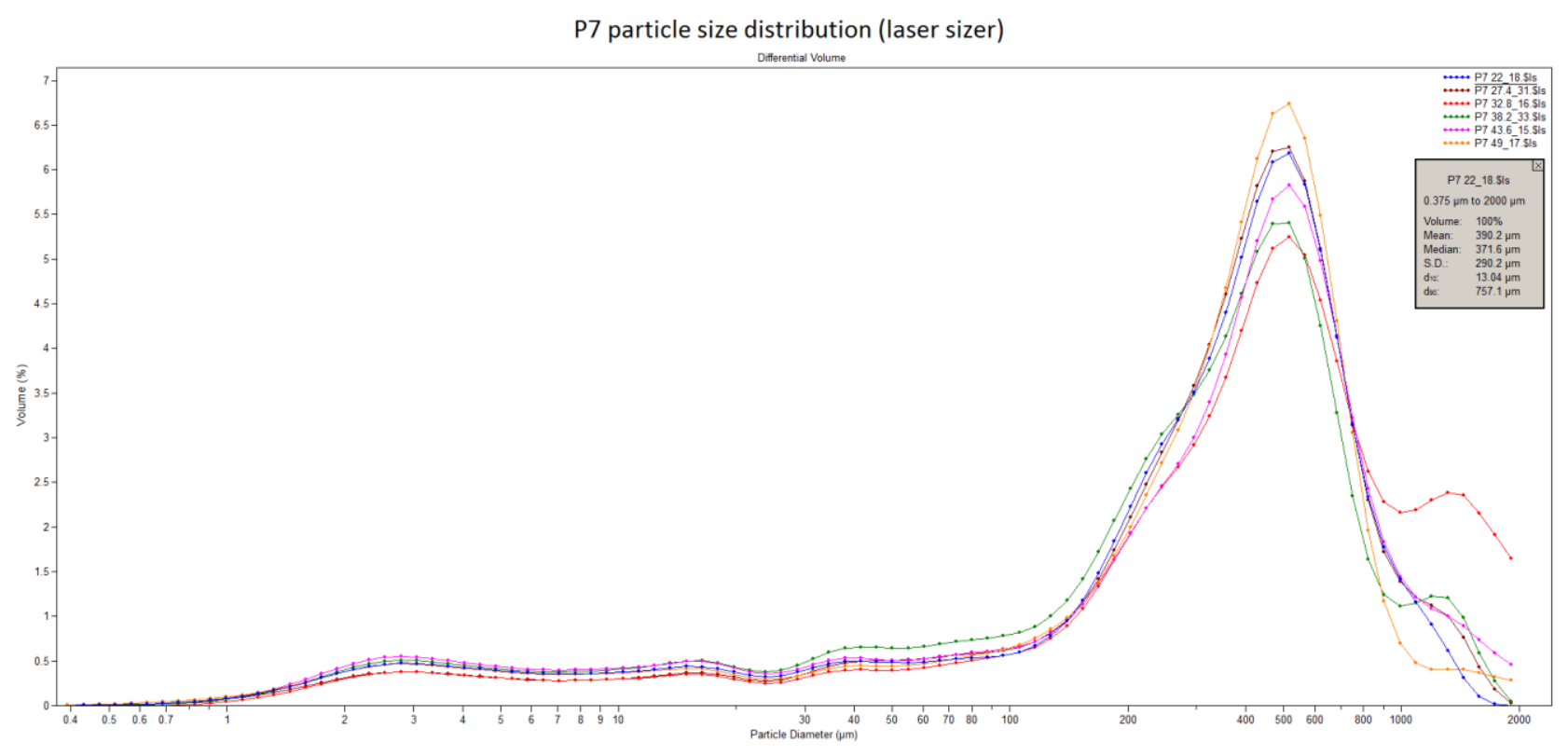

Figure 10: P7 particle size distribution as determined by laser sizer measurements. 
P8 particle size distribution (laser sizer)

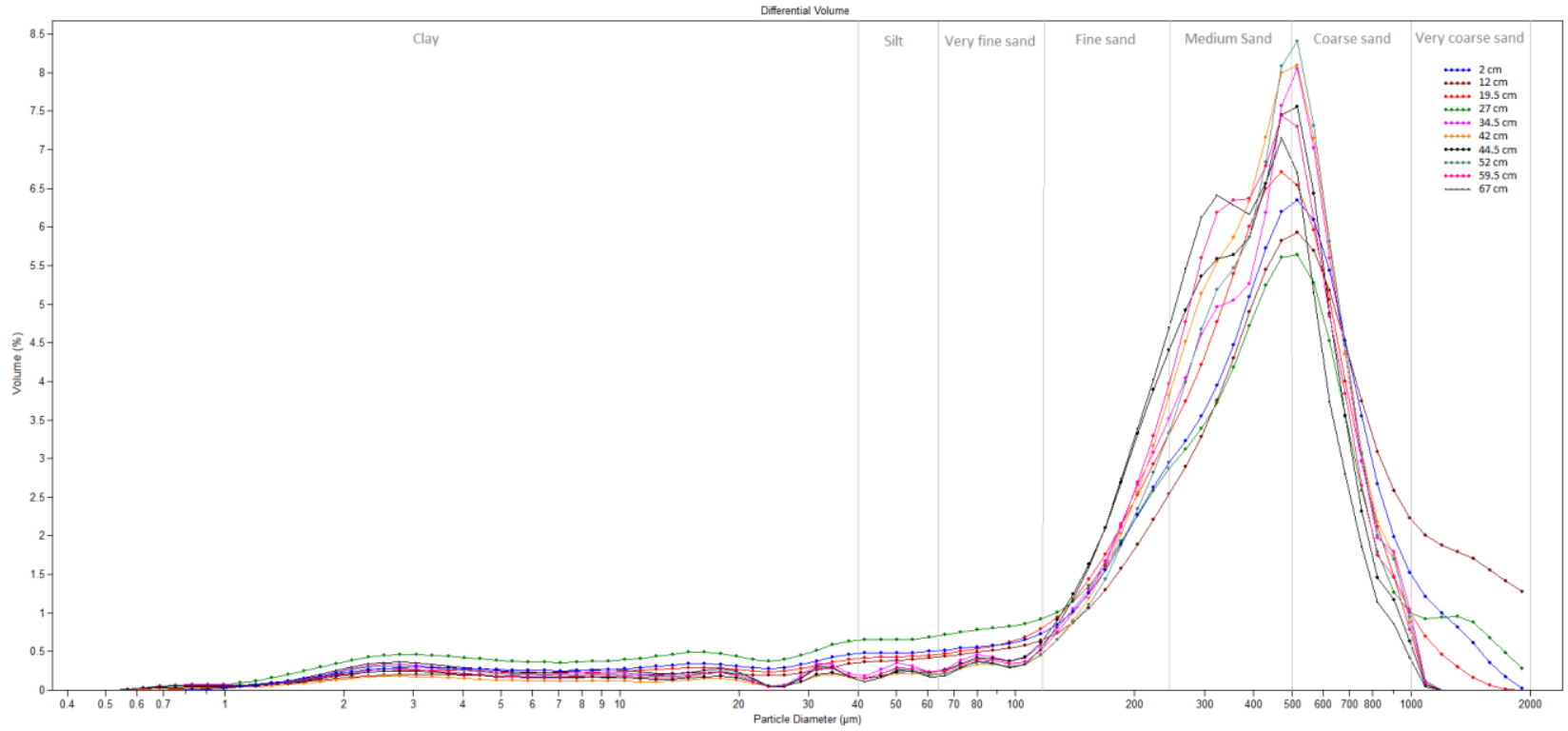

Figure 11: P8 particle size distribution as determined by laser sizer measurements.

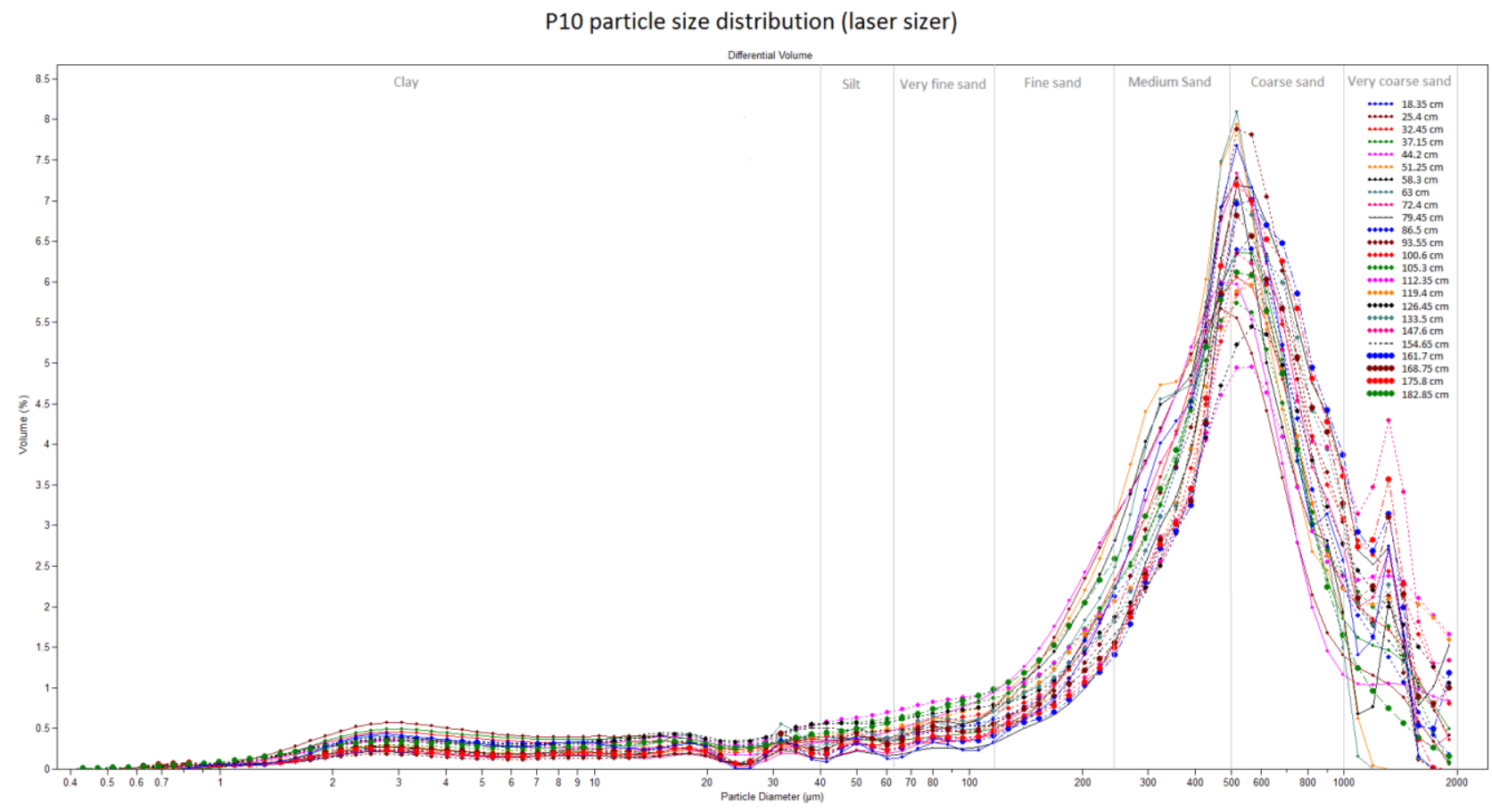

Figure 12: P10 particle size distribution as determined by laser sizer measurements. 
Appendix B: Sediment characteristics

\section{Grain roundness and sphericity}

\begin{tabular}{|c|c|c|c|c|c|c|}
\hline \multirow{2}{*}{$\begin{array}{l}\text { Core and } \\
\text { depth }\end{array}$} & \multicolumn{2}{|l|}{ Quartz } & \multicolumn{2}{|l|}{$\mathrm{K}$ feldspar } & \multicolumn{2}{|l|}{ Dolerite } \\
\hline & Roundness & Sphericity & Roundness & Sphericity & Roundness & Sphericity \\
\hline $\mathrm{P} 130 \mathrm{~cm}$ & 4.17 & 4.37 & 3.57 & 4.14 & 2.08 & 3.33 \\
\hline $\mathrm{P} 170 \mathrm{~cm}$ & 3.86 & 3.84 & 3.92 & 4.00 & 2.71 & 3.24 \\
\hline $\mathrm{P} 185 \mathrm{~cm}$ & 4.04 & 3.87 & 4.00 & 3.82 & 2.76 & 3.33 \\
\hline $\mathrm{P} 1100 \mathrm{~cm}$ & 3.84 & 3.69 & 3.67 & 3.56 & 2.95 & 3.33 \\
\hline $\mathrm{P} 1110 \mathrm{~cm}$ & 4.05 & 3.95 & 3.89 & 3.89 & 3.00 & 3.22 \\
\hline $\mathrm{P} 1125 \mathrm{~cm}$ & 3.77 & 4.18 & 3.57 & 4.29 & 2.41 & 3.12 \\
\hline $\mathrm{P} 1140 \mathrm{~cm}$ & 3.91 & 4.07 & 4.25 & 3.88 & 2.35 & 3.50 \\
\hline $\mathrm{P} 28 \mathrm{~cm}$ & 3.85 & 3.93 & 3.77 & 4.00 & 2.67 & 3.17 \\
\hline $\mathrm{P} 220 \mathrm{~cm}$ & 4.09 & 4.13 & 4.00 & 4.11 & 2.87 & 3.13 \\
\hline $\mathrm{P} 238 \mathrm{~cm}$ & 3.69 & 3.88 & 3.46 & 3.54 & 2.58 & 3.08 \\
\hline $\mathrm{P} 250 \mathrm{~cm}$ & 4.20 & 4.16 & 4.00 & 4.00 & 2.79 & 3.21 \\
\hline $\mathrm{P} 250 \mathrm{~cm}$ & 3.82 & 3.97 & 3.58 & 3.92 & 2.95 & 3.52 \\
\hline P8 $2 \mathrm{~cm}$ & 3.88 & 3.92 & 3.55 & 3.45 & 2.29 & 3.00 \\
\hline $\mathrm{P} 812 \mathrm{~cm}$ & 4.15 & 4.15 & 3.73 & 3.64 & 2.34 & 3.17 \\
\hline $\mathrm{P} 827 \mathrm{~cm}$ & 3.73 & 4.29 & 3.54 & 4.08 & 2.70 & 3.20 \\
\hline $\mathrm{P} 842 \mathrm{~cm}$ & 3.81 & 3.91 & 3.00 & 3.67 & 3.00 & 3.63 \\
\hline $\mathrm{P} 852 \mathrm{~cm}$ & 3.46 & 3.53 & 3.43 & 3.29 & 2.50 & 2.60 \\
\hline P8 $67 \mathrm{~cm}$ & 3.48 & 3.73 & 3.36 & 3.27 & 2.80 & 2.60 \\
\hline $\mathrm{P} 1018 \mathrm{~cm}$ & 4.25 & 4.09 & 4.33 & 4.00 & 3.13 & 3.25 \\
\hline $\mathrm{P} 1044 \mathrm{~cm}$ & 3.91 & 4.03 & 3.43 & 3.86 & 2.50 & 3.35 \\
\hline $\mathrm{P} 1072 \mathrm{~cm}$ & 4.08 & 4.12 & 3.92 & 4.15 & 2.42 & 3.35 \\
\hline $\mathrm{P} 10101 \mathrm{~cm}$ & 4.01 & 4.15 & 3.80 & 3.87 & 2.69 & 3.17 \\
\hline $\mathrm{P} 10126 \mathrm{~cm}$ & 3.96 & 4.10 & 4.00 & 4.00 & 2.50 & 3.18 \\
\hline $\mathrm{P} 10155 \mathrm{~cm}$ & 3.90 & 4.13 & 3.71 & 4.00 & 2.70 & 3.41 \\
\hline $\mathrm{P} 10181 \mathrm{~cm}$ & 4.10 & 4.01 & 3.89 & 3.89 & 2.75 & 3.00 \\
\hline
\end{tabular}

Table 5: Grain roundness and sphericity by lithology from grain mounts of P1, P2, P8, P10. Each number pair is the average of up to 100 grains per slide. 


\section{Porosity}

\begin{tabular}{|c|c|c|}
\hline Polygon - depth & $\begin{array}{l}\text { Avg. } \\
\text { porosity } \\
{[\%]}\end{array}$ & $\begin{array}{l}\text { Error } \\
{[\%]}\end{array}$ \\
\hline $\mathrm{P} 1-25 \mathrm{~cm}$ & 20.3 & 1.6 \\
\hline $\mathrm{P} 1-36 \mathrm{~cm}$ & 16.7 & 1.3 \\
\hline $\mathrm{P} 1-38 \mathrm{~cm}$ & 35.3 & 2.8 \\
\hline $\mathrm{P} 1-48 \mathrm{~cm}$ & 27.3 & 2.2 \\
\hline $\mathrm{P} 2-20 \mathrm{~cm}$ & 12.3 & 1.0 \\
\hline $\mathrm{P} 2-34 \mathrm{~cm}$ & 10.7 & 1.0 \\
\hline $\mathrm{P} 2-42 \mathrm{~cm}$ & 32.0 & 2.6 \\
\hline $\mathrm{P} 3-50 \mathrm{~cm}$ & 28.3 & 2.3 \\
\hline $\mathrm{P} 3-57 \mathrm{~cm}$ & 27.3 & 2.2 \\
\hline P5 $-20.5 \mathrm{~cm}$ & 17.5 & 1.4 \\
\hline P5 $-23.5 \mathrm{~cm}$ & 27.3 & 2.2 \\
\hline P5 $-21.5 \mathrm{~cm}$ & 17.7 & 1.4 \\
\hline P8 - $2 \mathrm{~cm}$ & 32.7 & 2.6 \\
\hline $\mathrm{P} 8-18 \mathrm{~cm}$ & 19.3 & 1.6 \\
\hline P8 - $28 \mathrm{~cm}$ & 11.7 & 1.0 \\
\hline
\end{tabular}

Table 6: Porosity measured from thin sections. Each value was determined through 300 point counts. 


\section{Dolerite content}

\begin{tabular}{|c|c|}
\hline $\begin{array}{l}\text { Polygon - } \\
\text { depth }\end{array}$ & $\begin{array}{l}\text { Avg. dolerite } \\
\text { content [\%] }\end{array}$ \\
\hline $\mathrm{P} 1-30 \mathrm{~cm}$ & 10.0 \\
\hline $\mathrm{P} 1-50 \mathrm{~cm}$ & 9.3 \\
\hline $\mathrm{P} 1-70 \mathrm{~cm}$ & 9.0 \\
\hline $\mathrm{P} 1-85 \mathrm{~cm}$ & 7.7 \\
\hline $\mathrm{P} 1-100 \mathrm{~cm}$ & 12.0 \\
\hline $\mathrm{P} 1-110 \mathrm{~cm}$ & 8.3 \\
\hline $\mathrm{P} 1-125 \mathrm{~cm}$ & 10.0 \\
\hline $\mathrm{P} 1-140 \mathrm{~cm}$ & 9.3 \\
\hline $\mathrm{P} 2-20 \mathrm{~cm}$ & 10.0 \\
\hline $\mathrm{P} 2-32 \mathrm{~cm}$ & 5.0 \\
\hline $\mathrm{P} 2-38 \mathrm{~cm}$ & 8.0 \\
\hline $\mathrm{P} 2-50 \mathrm{~cm}$ & 5.0 \\
\hline $\mathrm{P} 2-18.5 \mathrm{~cm}$ & 11.3 \\
\hline $\mathrm{P} 8-2 \mathrm{~cm}$ & 7.3 \\
\hline $\mathrm{P} 8-12 \mathrm{~cm}$ & 7.3 \\
\hline $\mathrm{P} 8-27 \mathrm{~cm}$ & 10.7 \\
\hline $\mathrm{P} 8-42 \mathrm{~cm}$ & 1.7 \\
\hline $\mathrm{P} 8-52 \mathrm{~cm}$ & 1.0 \\
\hline P8 - $67 \mathrm{~cm}$ & 1.0 \\
\hline $\mathrm{P} 10-44 \mathrm{~cm}$ & 10.0 \\
\hline $\mathrm{P} 10-72 \mathrm{~cm}$ & 19.3 \\
\hline $\mathrm{P} 10-101 \mathrm{~cm}$ & 22.3 \\
\hline $\mathrm{P} 10-126 \mathrm{~cm}$ & 26 \\
\hline $\mathrm{P} 10-155 \mathrm{~cm}$ & 26 \\
\hline P10 - $183 \mathrm{~cm}$ & 21.3 \\
\hline
\end{tabular}

Table 7: Dolerite content measured from thin sections. Each value was determined through 300 point counts. 
Appendix C: Optically Stimulated Luminescence

Equivalent Core surface [cm] Dose [Gy]
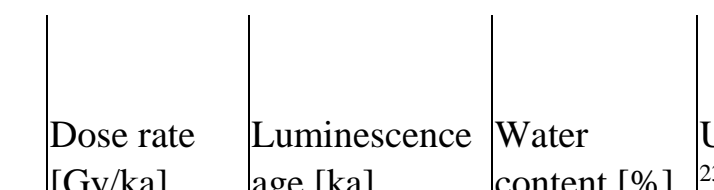

\begin{tabular}{l|l}
$\mathrm{U}$ from & $\begin{array}{l}\mathrm{U} \text { from } \\
{ }^{226} \mathrm{Ra},{ }^{214} \mathrm{~Pb},{ }^{214} \\
\mathrm{Bi}\end{array} \mid$
\end{tabular}

from

Th from [Gy/ka]

\begin{tabular}{l|l|l|l} 
age [ka] & content [\%] & ${ }^{234} \mathrm{Th}[\mathrm{ppm}]$ & {$[\mathrm{ppm}]$} \\
\hline
\end{tabular}

${ }^{210} \mathrm{~Pb}[\mathrm{ppm}]$ [ppm]

$\mathrm{K}[\%]$

\begin{tabular}{|c|c|c|c|c|c|c|c|c|c|c|}
\hline \multirow[t]{5}{*}{$\overline{\mathrm{P} 1}$} & $26.5-31.5$ & $179.17 \pm 11.00$ & $1.34 \pm 0.05$ & $133.7 \pm 9.6$ & 14.1 & $1.08 \pm 0.13$ & $1.16 \pm 0.08$ & $0.96 \pm 0.10$ & $4.14 \pm 0.06$ & $0.65 \pm 0.02$ \\
\hline & $31.5-36.5$ & $213.66 \pm 22.59$ & $1.34 \pm 0.05$ & $159.4 \pm 17.9$ & 14.1 & $1.08 \pm 0.13$ & $1.16 \pm 0.08$ & $0.96 \pm 0.10$ & $4.14 \pm 0.06$ & $0.65 \pm 0.02$ \\
\hline & $38-42$ & $221.06 \pm 13.62$ & $1.31 \pm 0.04$ & $168.7 \pm 11.6$ & 13.2 & $1.14 \pm 0.12$ & $1.09 \pm 0.07$ & $1.12 \pm 0.09$ & $4.13 \pm 0.06$ & $0.62 \pm 0.01$ \\
\hline & $42-46.5$ & $230.92 \pm 23.58$ & $1.20 \pm 0.04$ & $192.4 \pm 20.8$ & 15.7 & $0.98 \pm 0.10$ & $0.93 \pm 0.06$ & $0.94 \pm 0.08$ & $3.91 \pm 0.05$ & $0.58 \pm 0.01$ \\
\hline & $27-36$ & $248.83 \pm 17.40$ & $1.38 \pm 0.05$ & $180.3 \pm 14.2$ & 17.5 & $1.37 \pm 0.14$ & $1.20 \pm 0.08$ & $1.15 \pm 0.10$ & $4.41 \pm 0.06$ & $0.71 \pm 0.02$ \\
\hline \multirow[t]{3}{*}{$\overline{\mathrm{P} 2}$} & $24-30.5$ & $148.61 \pm 10.02$ & $1.87 \pm 0.07$ & $79.5 \pm 6.1$ & 14.9 & $1.19 \pm 0.13$ & $1.38 \pm 0.08$ & $1.14 \pm 0.10$ & $5.58 \pm 0.07$ & $1.15 \pm 0.02$ \\
\hline & $30.5-35.5$ & $200.67 \pm 20.13$ & $2.13 \pm 0.07$ & $94.2 \pm 9.9$ & 13.5 & $1.42 \pm 0.14$ & $1.19 \pm 0.07$ & $1.26 \pm 0.10$ & $5.83 \pm 0.08$ & $1.39 \pm 0.03$ \\
\hline & $35.5-40.5$ & $274.24 \pm 25.90$ & $2.03 \pm 0.06$ & $135.1 \pm 13.5$ & 12.3 & $1.19 \pm 0.14$ & $1.26 \pm 0.08$ & $1.10 \pm 0.11$ & $5.48 \pm 0.08$ & $1.28 \pm 0.03$ \\
\hline \multirow[t]{4}{*}{$\overline{\mathrm{P} 8}$} & $2.0-6.0$ & $143.03 \pm 14.72$ & $1.46 \pm 0.05$ & $98.0 \pm 10.7$ & 15.5 & $1.20 \pm 0.13$ & $1.17 \pm 0.08$ & $1.28 \pm 0.11$ & $4.51 \pm 0.06$ & $0.76 \pm 0.02$ \\
\hline & $6.0-10.0$ & $148.18 \pm 15.03$ & $1.45 \pm 0.05$ & $102.2 \pm 11.0$ & 15.5 & $1.20 \pm 0.13$ & $1.17 \pm 0.08$ & $1.28 \pm 0.11$ & $4.51 \pm 0.06$ & $0.76 \pm 0.02$ \\
\hline & $19.5-24.5$ & $205.05 \pm 14.28$ & $1.61 \pm 0.06$ & $127.4 \pm 10.0$ & 15.5 & $1.19 \pm 0.11$ & $1.15 \pm 0.07$ & $1.09 \pm 0.08$ & $5.31 \pm 0.06$ & $0.90 \pm 0.02$ \\
\hline & $24.5-29.5$ & $211.29 \pm 17.64$ & $1.61 \pm 0.06$ & $131.2 \pm 11.9$ & 15.5 & $1.19 \pm 0.11$ & $1.15 \pm 0.07$ & $1.09 \pm 0.08$ & $5.31 \pm 0.06$ & $0.90 \pm 0.02$ \\
\hline
\end{tabular}

Table 8: OSL raw data for the cores P1, P2 and P8. 
Below are plots of luminescence growth curves (on the left) and equvilent dose distrubtions (on the right) of measured coarse grain 125-200 $\mu$ m quartz samples. The samples are given with their respectice lab codes and measured source dose rates (Ds). Lx is the sample's luminescence signal in response to different lab radiation doses, while Tx is its signal in response to a fixed dose used to determine sensitivity changes.

Lab code WLL 1161, Ds 4.43:
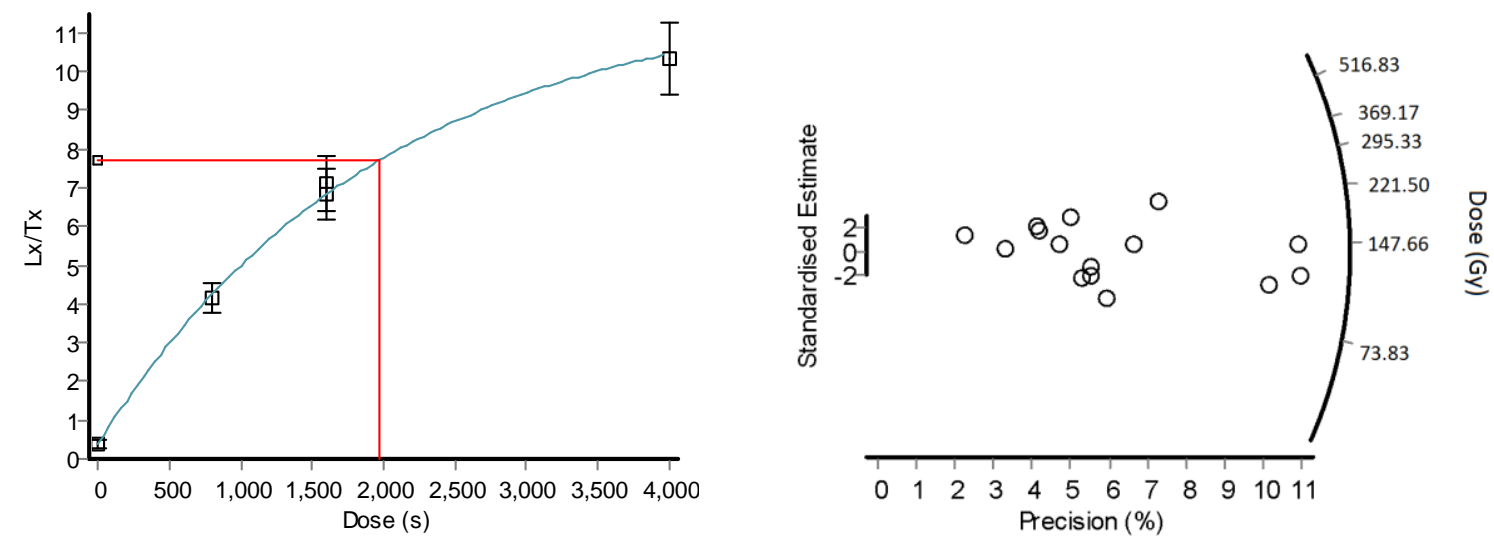

Figure 13: Luminescence growth curve and equivalent dose distribution for P8 2-6 cm.

Lab code WLL 1162, Ds 4.43:
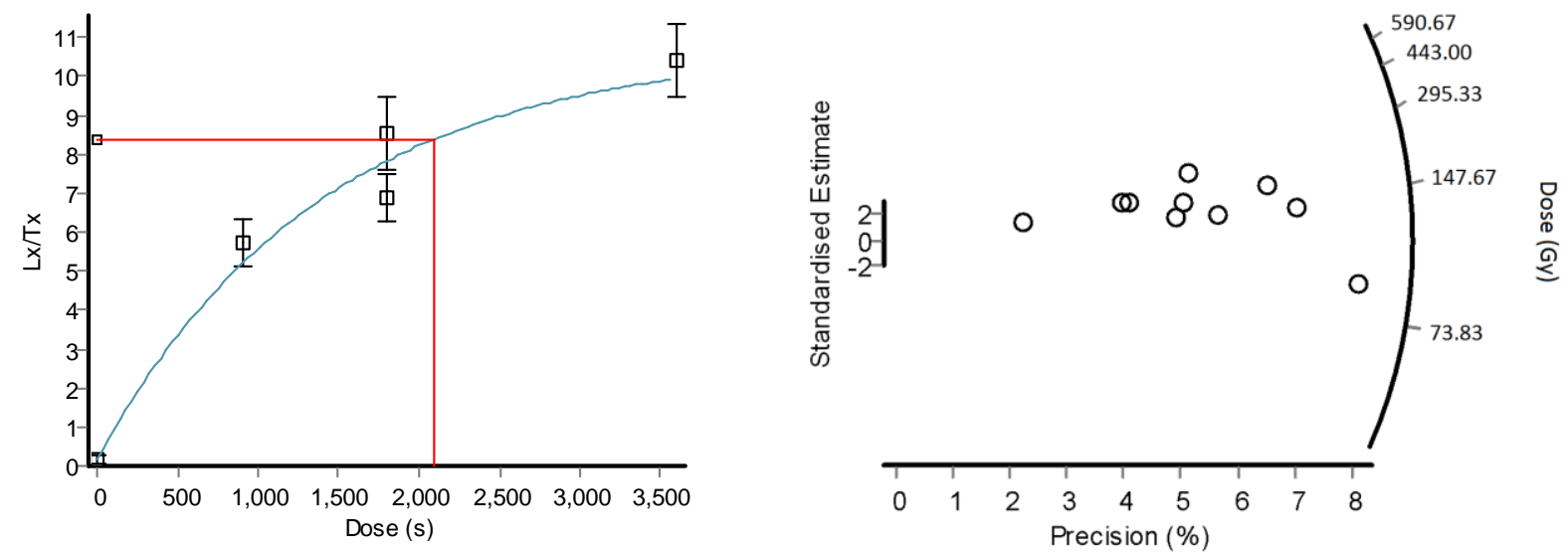

Figure 14: Luminescence growth curve and equivalent dose distribution for P8 6-10 cm. 
Lab code WLL 1163, Ds 4.43:
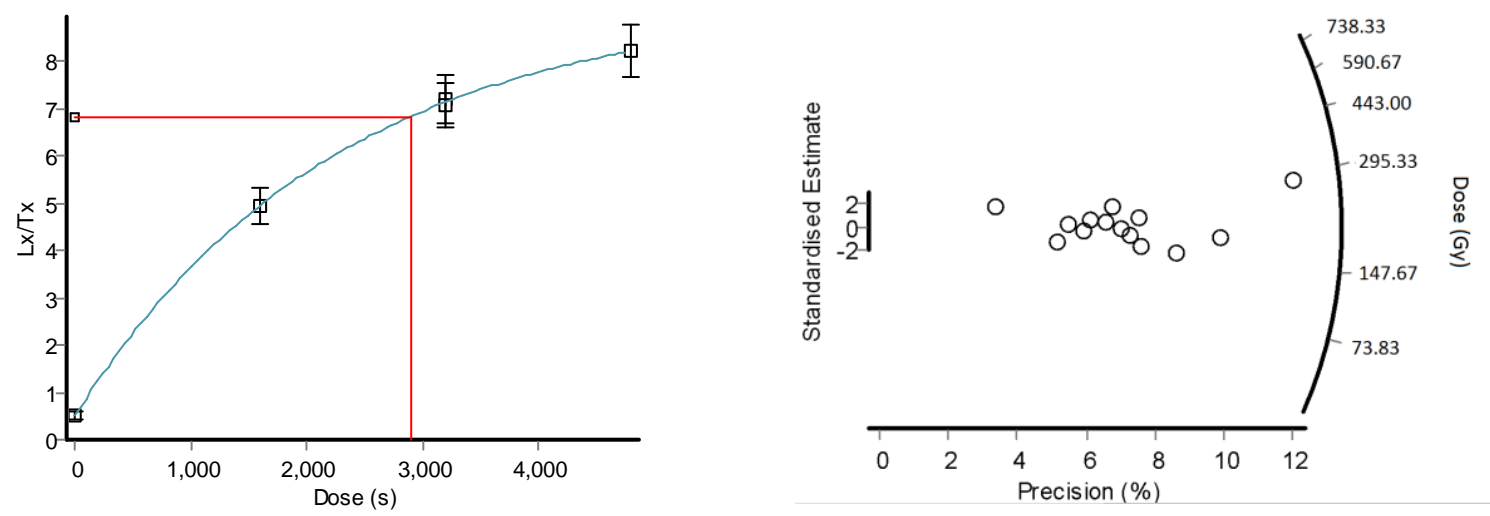

Figure 15: Luminescence growth curve and equivalent dose distribution for P8 19.5-24.5 cm.

Lab code WLL 1164, Ds 4.43:
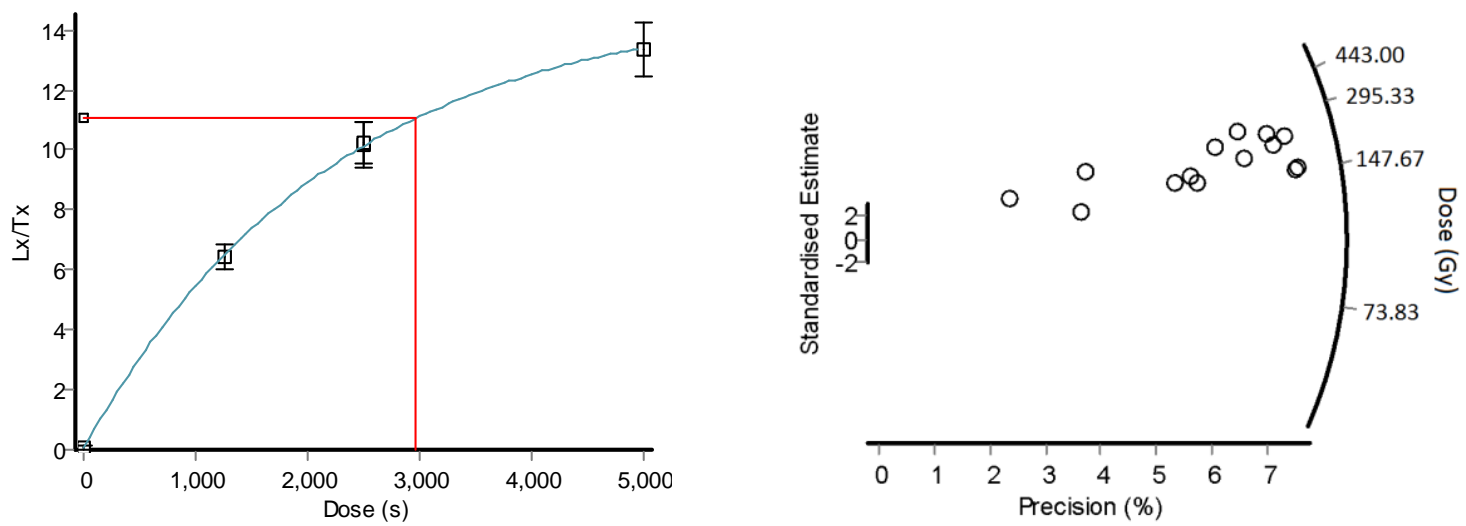

Figure 16: Luminescence growth curve and equivalent dose distribution for P8 24.5-29.5 cm.

Lab code WLL 1173, Ds 5.12:
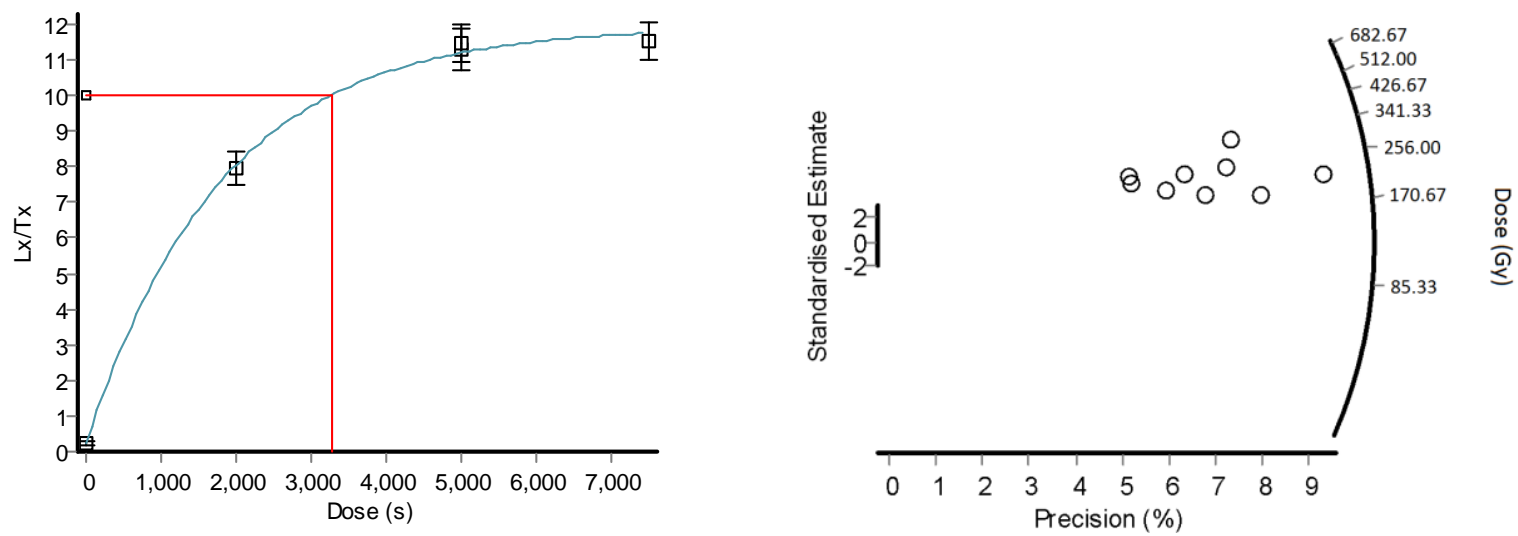

Figure 17: Luminescence growth curve and equivalent dose distribution for P1 Secondary 27-36 $\mathrm{cm}$. 
Lab code WLL 1174, Ds 5.13:
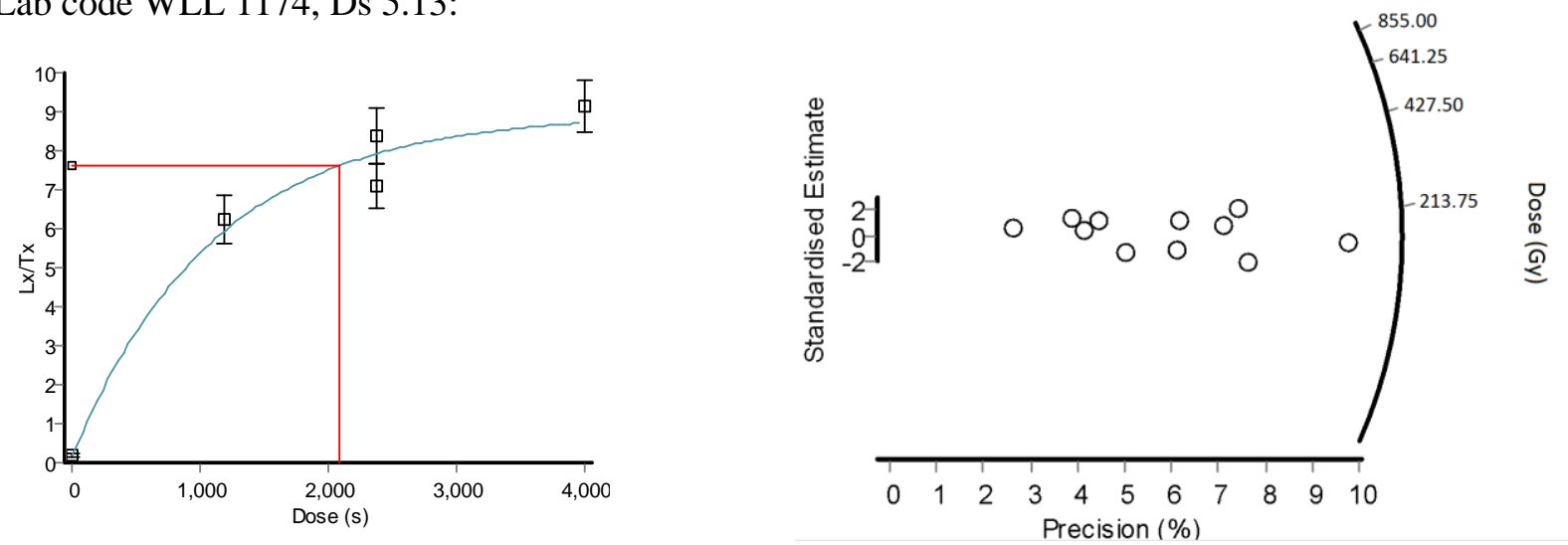

Figure 18: Luminescence growth curve and equivalent dose distribution for P1 Primary 26.5-31.5 $\mathrm{cm}$.

Lab code WLL 1175, Ds 5.12:
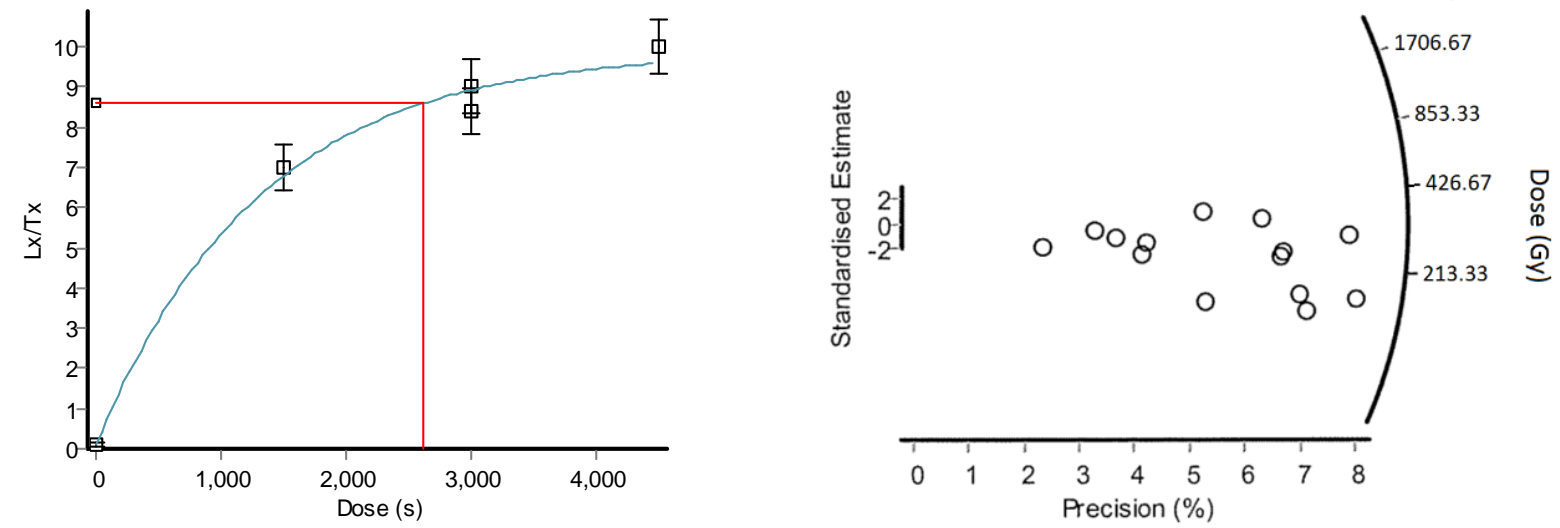

Figure 19: Luminescence growth curve and equivalent dose distribution for P1 Primary 31.5-36.5 $\mathrm{cm}$.

Lab code WLL 1176, Ds 5.12:
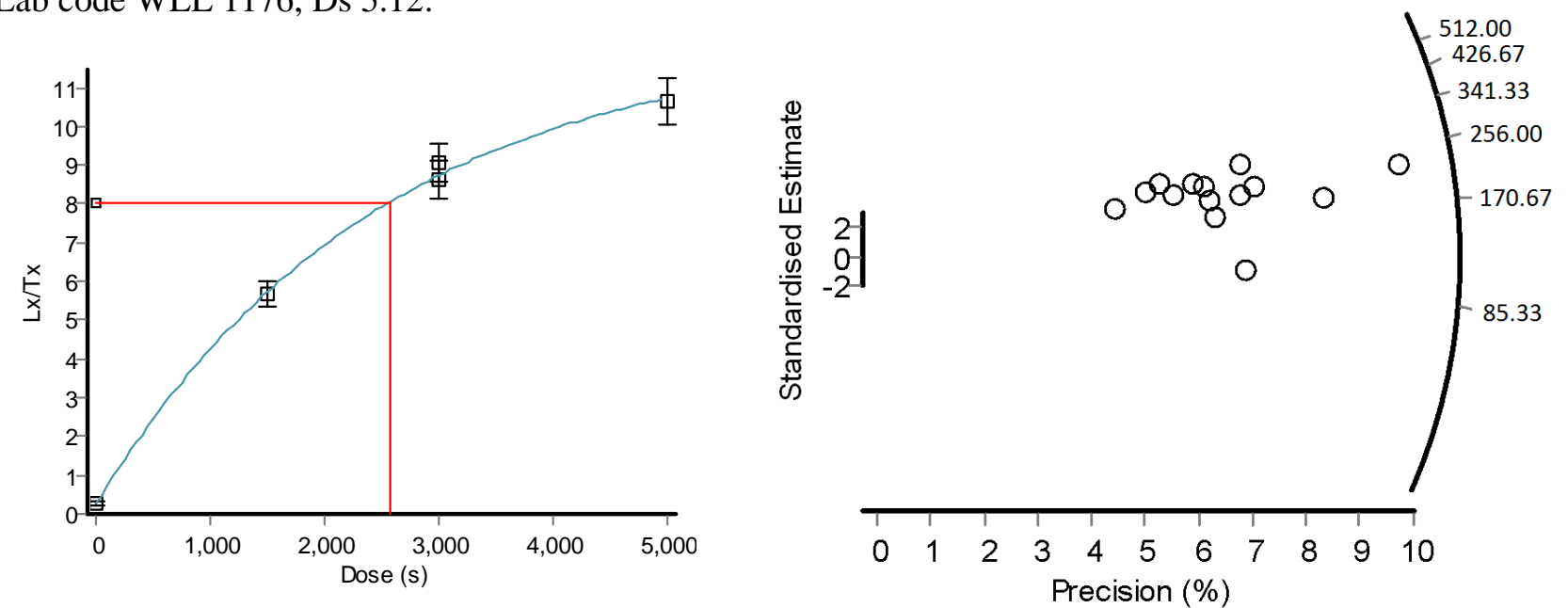

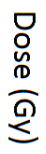

Figure 20: Luminescence growth curve and equivalent dose distribution for P1 Primary 30-40 cm. 
Lab code WLL 1177, Ds 5.13:
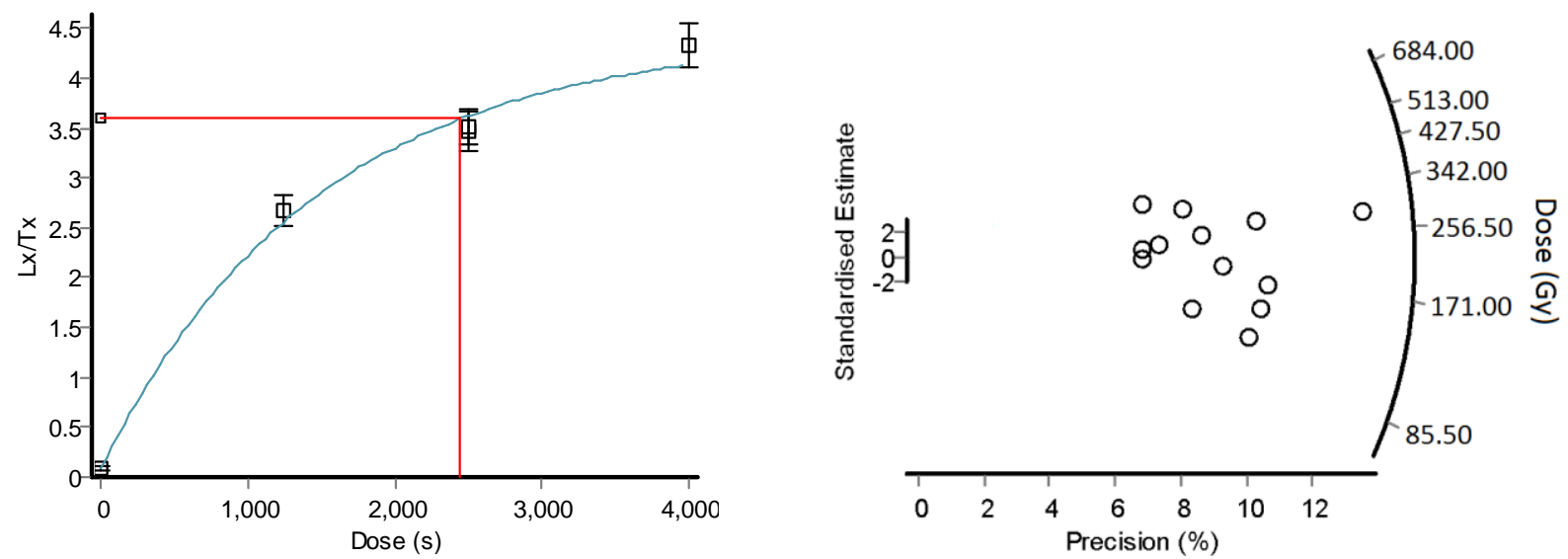

Figure 21: Luminescence growth curve and equivalent dose distribution for P1 Primary $42-46 \mathrm{~cm}$.

Lab code WLL 1182, Ds 5.12:
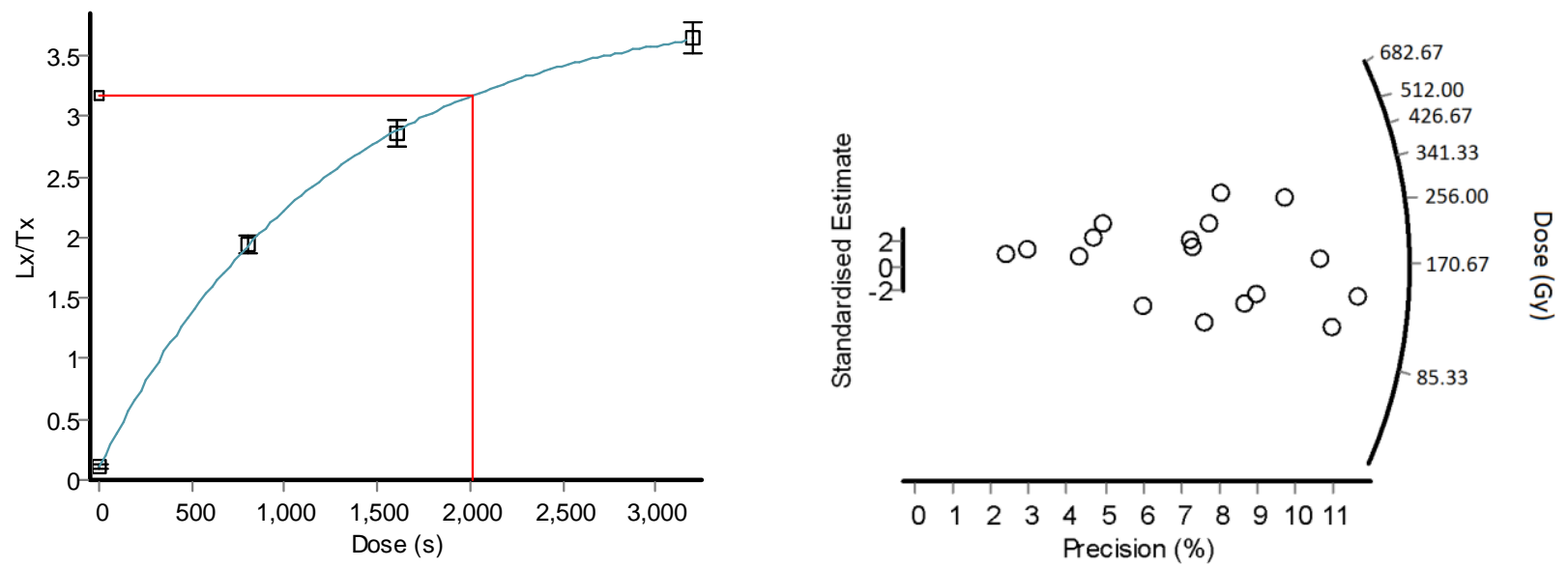

Figure 22: Luminescence growth curve and equivalent dose distribution for P2 30.5-35.5 cm. 
Lab code WLL 1183, Ds 5.11:
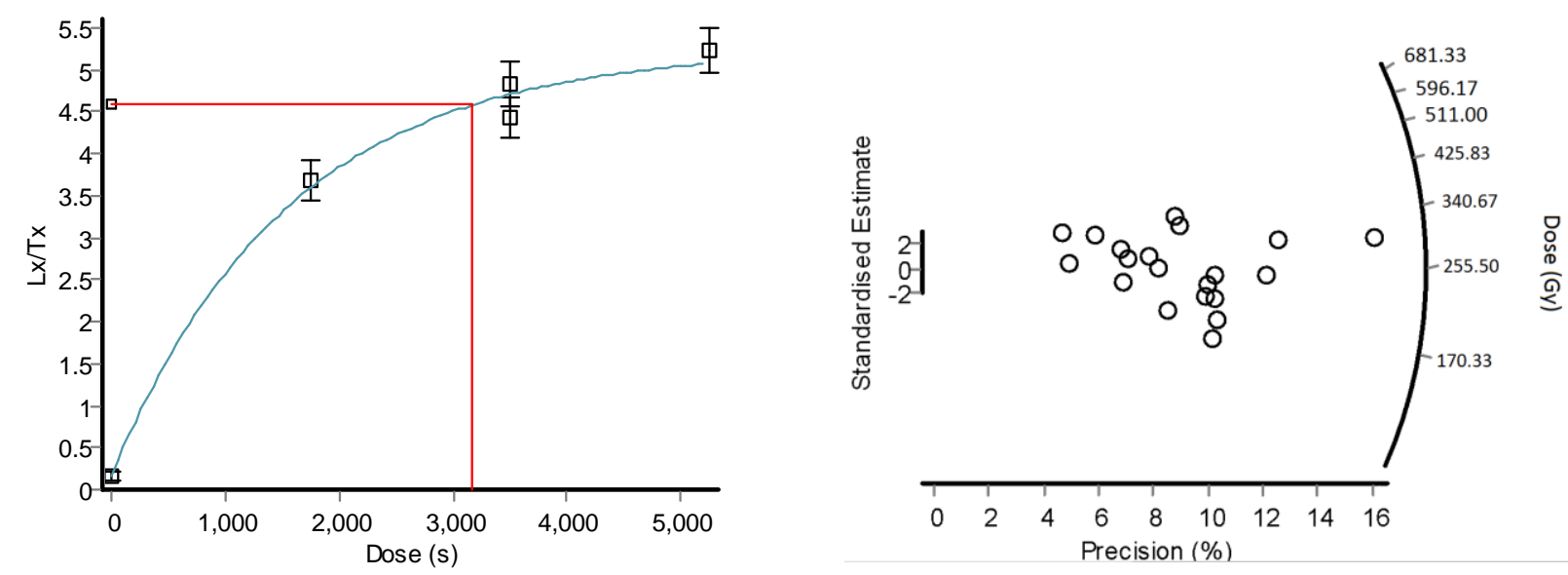

Figure 23: Luminescence growth curve and equivalent dose distribution for P2 35.5-40.5 cm.

Lab code WLL 1184, Ds 5.11:
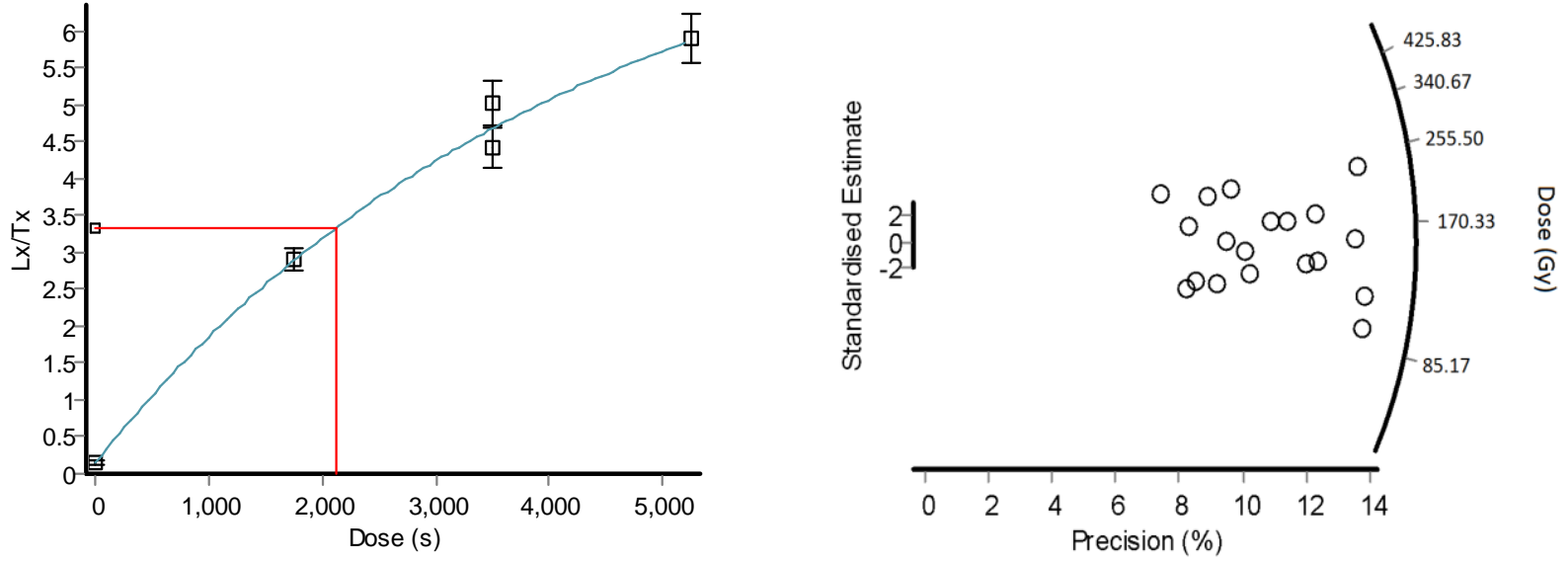

Figure 24: Luminescence growth curve and equivalent dose distribution for P2, P2 24-30.5 cm. 
Appendix D: Meteoric Beryllium-10

\begin{tabular}{|c|c|c|c|c|c|c|c|c|c|c|}
\hline $\begin{array}{l}\text { Lab } \\
\text { ID }\end{array}$ & $\begin{array}{l}\text { Core } \\
\text { and depth }\end{array}$ & ${ }^{10} \mathrm{Be} /{ }^{9} \mathrm{Be}$ & $\begin{array}{c}\text { ERROR } \\
\%\end{array}$ & $\begin{array}{l}\text { "Bor" } \\
\text { Count }\end{array}$ & $\begin{array}{c}\text { Weight Sample } \\
\mathrm{g}\end{array}$ & $\begin{array}{c}\text { Weight Carrier } \\
\text { Solution } \\
\text { mg }\end{array}$ & $\begin{array}{c}\text { Weight }{ }^{9} \mathrm{Be} \\
\text { added by Carrier } \\
\mathrm{g}\end{array}$ & $\begin{array}{c}{ }^{9} \text { Be added } \\
\text { by Carrier } \\
\text { atoms }\end{array}$ & $\begin{array}{c}\text { Blank }{ }^{10} \mathrm{Be} \\
\text { added by Carrier } \\
\text { atoms }\end{array}$ & $\begin{array}{c}{ }^{10} \mathrm{Be} \text { added } \\
\text { by Carrier Error } \\
\text { atoms }\end{array}$ \\
\hline TB2235 & P1 $0-5$ & $4.87 \mathrm{E}-11$ & 1.80 & 1.47 & 0.74 & 0.2069 & $2.069 \mathrm{E}-04$ & $1.383 \mathrm{E}+19$ & $1.327 \mathrm{E}+05$ & $6.593 \mathrm{E}+04$ \\
\hline TB2236 & P1 15-20 & $1.98 \mathrm{E}-11$ & 1.80 & 1.98 & 0.75 & 0.2069 & $2.069 \mathrm{E}-04$ & $1.382 \mathrm{E}+19$ & $1.327 \mathrm{E}+05$ & $6.590 \mathrm{E}+04$ \\
\hline$\overline{\mathrm{TB} 2237}$ & P1 30 & $1.50 \mathrm{E}-11$ & 1.84 & 2.10 & 0.67 & 0.2066 & $2.066 \mathrm{E}-04$ & $1.380 \mathrm{E}+19$ & $1.325 \mathrm{E}+05$ & $6.582 \mathrm{E}+04$ \\
\hline TB2238 & P1 43 & $1.30 \mathrm{E}-11$ & 2.01 & 2.19 & 0.72 & 0.2064 & $2.064 \mathrm{E}-04$ & $1.379 \mathrm{E}+19$ & $1.324 \mathrm{E}+05$ & $6.577 \mathrm{E}+04$ \\
\hline TB2239 & P1 53 & $1.49 \mathrm{E}-11$ & 2.02 & 2.06 & 0.71 & 0.2066 & $2.066 \mathrm{E}-04$ & $1.380 \mathrm{E}+19$ & $1.325 \mathrm{E}+05$ & $6.582 \mathrm{E}+04$ \\
\hline TB2240 & P2 0-5 & $1.16 \mathrm{E}-10$ & 1.80 & 2.99 & 0.73 & 0.2064 & $2.064 \mathrm{E}-04$ & $1.379 \mathrm{E}+19$ & $1.324 \mathrm{E}+05$ & $6.576 \mathrm{E}+04$ \\
\hline TB2241 & $\mathrm{P} 220$ & $3.30 \mathrm{E}-12$ & 3.00 & 2.31 & 0.73 & 0.2068 & $2.068 \mathrm{E}-04$ & $1.382 \mathrm{E}+19$ & $1.326 \mathrm{E}+05$ & $6.588 \mathrm{E}+04$ \\
\hline TB2242 & P2 20-25 & $7.41 \mathrm{E}-12$ & 1.98 & 2.12 & 0.75 & 0.2065 & $2.065 \mathrm{E}-04$ & $1.380 \mathrm{E}+19$ & $1.324 \mathrm{E}+05$ & $6.579 \mathrm{E}+04$ \\
\hline TB2243 & P2 34 & $6.09 \mathrm{E}-12$ & 1.80 & 9.78 & 0.74 & 0.2057 & $2.057 \mathrm{E}-04$ & $1.374 \mathrm{E}+19$ & $1.319 \mathrm{E}+05$ & $6.552 \mathrm{E}+04$ \\
\hline TB2244 & $\mathrm{P} 242$ & $7.52 \mathrm{E}-12$ & 1.80 & 5.90 & 0.72 & 0.2051 & $2.051 \mathrm{E}-04$ & $1.370 \mathrm{E}+19$ & $1.315 \mathrm{E}+05$ & $6.533 \mathrm{E}+04$ \\
\hline TB2245 & P8 2 & $2.70 \mathrm{E}-11$ & 1.80 & 8.32 & 0.75 & 0.2068 & $2.068 \mathrm{E}-04$ & $1.382 \mathrm{E}+19$ & $1.326 \mathrm{E}+05$ & $6.588 \mathrm{E}+04$ \\
\hline TB2246 & P8 16 & $1.21 \mathrm{E}-12$ & 2.49 & 5.17 & 0.68 & 0.2069 & $2.069 \mathrm{E}-04$ & $1.382 \mathrm{E}+19$ & $1.327 \mathrm{E}+05$ & $6.591 \mathrm{E}+04$ \\
\hline TB2247 & P8 26 & $1.21 \mathrm{E}-12$ & 2.72 & 3.43 & 0.75 & 0.2072 & $2.072 \mathrm{E}-04$ & $1.384 \mathrm{E}+19$ & $1.329 \mathrm{E}+05$ & $6.600 \mathrm{E}+04$ \\
\hline
\end{tabular}

Table 9: Meteoric Beryllium measurement raw general sample and carrier data from ETH Zurich, Switzerland. 


\begin{tabular}{|c|c|c|c|c|c|c|c|c|}
\hline $\begin{array}{l}\text { Lab } \\
\text { ID }\end{array}$ & $\begin{array}{c}\text { Core } \\
\text { and depth }\end{array}$ & $\begin{array}{c}{ }^{10} \text { Be sample } \\
\text { uncorrected } \\
\text { atoms }\end{array}$ & $\begin{array}{c}{ }^{10} \text { Be Error } \\
\text { uncorrected } \\
\text { atoms }\end{array}$ & $\begin{array}{c}{ }^{10} \text { Be sample } \\
\text { Blank } \\
\text { corrected } \\
\text { atoms }\end{array}$ & $\begin{array}{c}{ }^{10} \mathrm{Be} \text { Blank } \\
\text { Error Corrected } \\
\text { atoms }\end{array}$ & $\begin{array}{c}\text { Rel. Total } \\
\text { Error } \\
\%\end{array}$ & $\begin{array}{c}{ }^{10} \mathrm{Be} \\
\text { Sample Conc } \\
\text { atoms } / \mathrm{g}\end{array}$ & $\begin{array}{l}{ }^{10} \text { Be Sample } \\
\text { Conc Error }\end{array}$ \\
\hline$\overline{\mathrm{TB} 2235}$ & P1 $0-5$ & $6.74 \mathrm{E}+08$ & $1.21 \mathrm{E}+07$ & $6.74 \mathrm{E}+08$ & $1.21 \mathrm{E}+07$ & 1.8 & $9.13 \mathrm{E}+08$ & $1.64 \mathrm{E}+07$ \\
\hline$\overline{\text { TB2236 }}$ & P1 15-20 & $2.73 \mathrm{E}+08$ & $4.92 \mathrm{E}+06$ & $2.73 \mathrm{E}+08$ & $4.92 \mathrm{E}+06$ & 1.8 & $3.65 \mathrm{E}+08$ & $6.58 \mathrm{E}+06$ \\
\hline TB2237 & P1 30 & $2.08 \mathrm{E}+08$ & $3.83 \mathrm{E}+06$ & $2.08 \mathrm{E}+08$ & $3.83 \mathrm{E}+06$ & 1.8 & $3.08 \mathrm{E}+08$ & $5.69 \mathrm{E}+06$ \\
\hline TB2238 & P1 43 & $1.80 \mathrm{E}+08$ & $3.61 \mathrm{E}+06$ & $1.80 \mathrm{E}+08$ & $3.61 \mathrm{E}+06$ & 2.0 & $2.49 \mathrm{E}+08$ & $5.01 \mathrm{E}+06$ \\
\hline TB2239 & P1 53 & $2.06 \mathrm{E}+08$ & $4.18 \mathrm{E}+06$ & $2.06 \mathrm{E}+08$ & $4.18 \mathrm{E}+06$ & 2.0 & $2.89 \mathrm{E}+08$ & $5.85 \mathrm{E}+06$ \\
\hline TB2240 & P2 0-5 & $1.60 \mathrm{E}+09$ & $2.87 \mathrm{E}+07$ & $1.60 \mathrm{E}+09$ & $2.87 \mathrm{E}+07$ & 1.8 & $2.17 \mathrm{E}+09$ & $3.91 \mathrm{E}+07$ \\
\hline TB2241 & P2 20 & $4.56 \mathrm{E}+07$ & $1.37 \mathrm{E}+06$ & $4.55 \mathrm{E}+07$ & $1.37 \mathrm{E}+06$ & 3.0 & $6.25 \mathrm{E}+07$ & $1.88 \mathrm{E}+06$ \\
\hline TB2242 & P2 20-25 & $1.02 \mathrm{E}+08$ & $2.02 \mathrm{E}+06$ & $1.02 \mathrm{E}+08$ & $2.02 \mathrm{E}+06$ & 2.0 & $1.37 \mathrm{E}+08$ & $2.71 \mathrm{E}+06$ \\
\hline$\overline{\text { TB2243 }}$ & P2 34 & $8.37 \mathrm{E}+07$ & $1.51 \mathrm{E}+06$ & $8.36 \mathrm{E}+07$ & $1.51 \mathrm{E}+06$ & 1.8 & $1.13 \mathrm{E}+08$ & $2.03 \mathrm{E}+06$ \\
\hline TB2244 & P2 42 & $1.03 \mathrm{E}+08$ & $1.85 \mathrm{E}+06$ & $1.03 \mathrm{E}+08$ & $1.86 \mathrm{E}+06$ & 1.8 & $1.43 \mathrm{E}+08$ & $2.57 \mathrm{E}+06$ \\
\hline TB2245 & P8 2 & $3.73 \mathrm{E}+08$ & $6.71 \mathrm{E}+06$ & $3.73 \mathrm{E}+08$ & $6.71 \mathrm{E}+06$ & 1.8 & $4.99 \mathrm{E}+08$ & $8.99 \mathrm{E}+06$ \\
\hline TB2246 & P8 16 & $1.68 \mathrm{E}+07$ & $4.18 \mathrm{E}+05$ & $1.67 \mathrm{E}+07$ & $4.23 \mathrm{E}+05$ & 2.5 & $2.45 \mathrm{E}+07$ & $6.23 \mathrm{E}+05$ \\
\hline TB2247 & P8 26 & $1.68 \mathrm{E}+07$ & $4.57 \mathrm{E}+05$ & $1.67 \mathrm{E}+07$ & $4.61 \mathrm{E}+05$ & 2.8 & $2.23 \mathrm{E}+07$ & $6.17 \mathrm{E}+05$ \\
\hline
\end{tabular}

Table 10: Meteoric Beryllium measurement ${ }^{10}$ Be sample and carrier data from ETH Zurich, Switzerland. 


\begin{tabular}{|c|c|c|c|c|c|c|}
\hline Lab ID & $\begin{array}{l}\text { Blank } \\
\text { number }\end{array}$ & ${ }^{10} \mathrm{Be} /{ }^{9} \mathrm{Be}$ & $\begin{array}{l}\text { ERROR } \\
{[\%]}\end{array}$ & $\begin{array}{l}\text { "Bor" } \\
\text { [Count] }\end{array}$ & $\begin{array}{l}\text { CARRIER Weight } \\
{[\mathrm{mg}]}\end{array}$ & 9Be added $[\mathrm{g}]$ \\
\hline TB2221 & Blank 1 & $4.41 \mathrm{E}-15$ & 31.6 & 3.25 & 0.286 & $2.86 \mathrm{E}-04$ \\
\hline TB2234 & Blank 2 & $8.15 \mathrm{E}-15$ & 31.8 & 0.93 & 0.307 & $3.07 \mathrm{E}-04$ \\
\hline TB2248 & Blank 3 & $1.58 \mathrm{E}-14$ & 16.9 & 7.05 & 0.204 & 2.04E-04 \\
\hline
\end{tabular}

Table 11: Meteoric ${ }^{10}$ Be blank sample results. 
P1 Meteoric ${ }^{10}$ Be particle size distribution

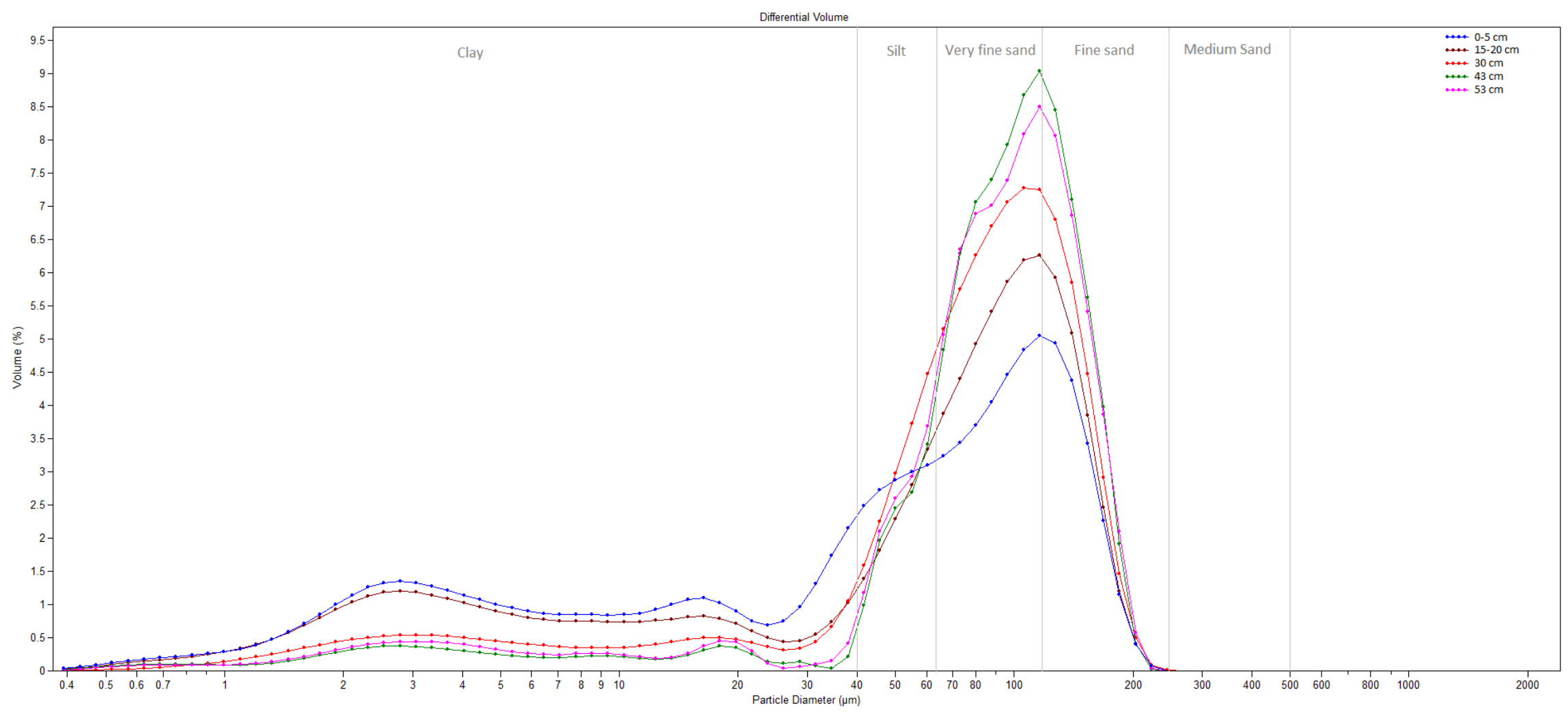

Figure 25: Grain size distribution of samples from P1 submitted for meteoric ${ }^{10}$ Be analysis after sieving to elimate effects of grain size dependency on ${ }^{10}$ Be concentration. 
P2 Meteoric ${ }^{10} \mathrm{Be}$ particle size distribution

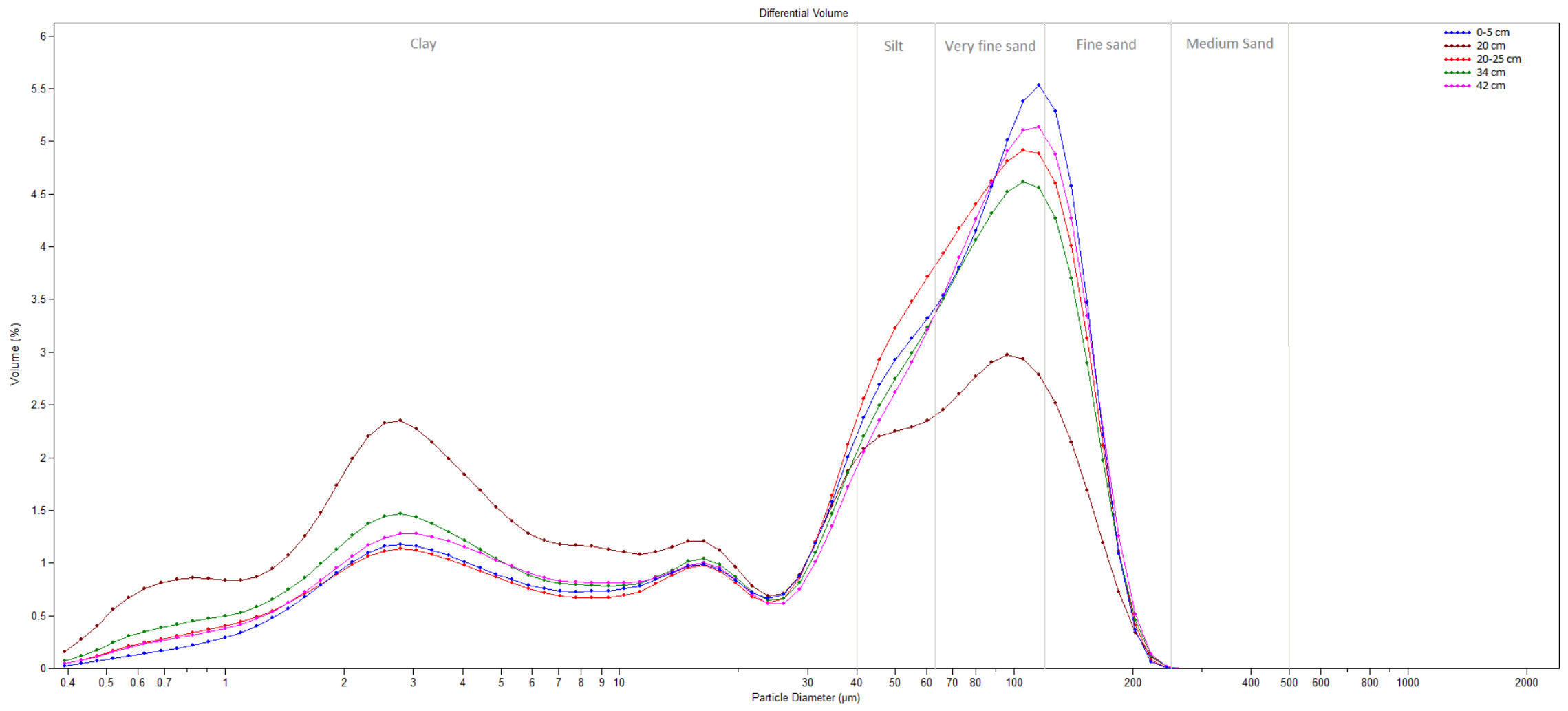

Figure 26: Grain size distribution of samples from P2 submitted for meteoric ${ }^{10}$ Be analysis after sieving to elimate effects of grain size dependency on ${ }^{10}$ Be concentration. 
P8 Meteoric ${ }^{10}$ Be particle size distribution

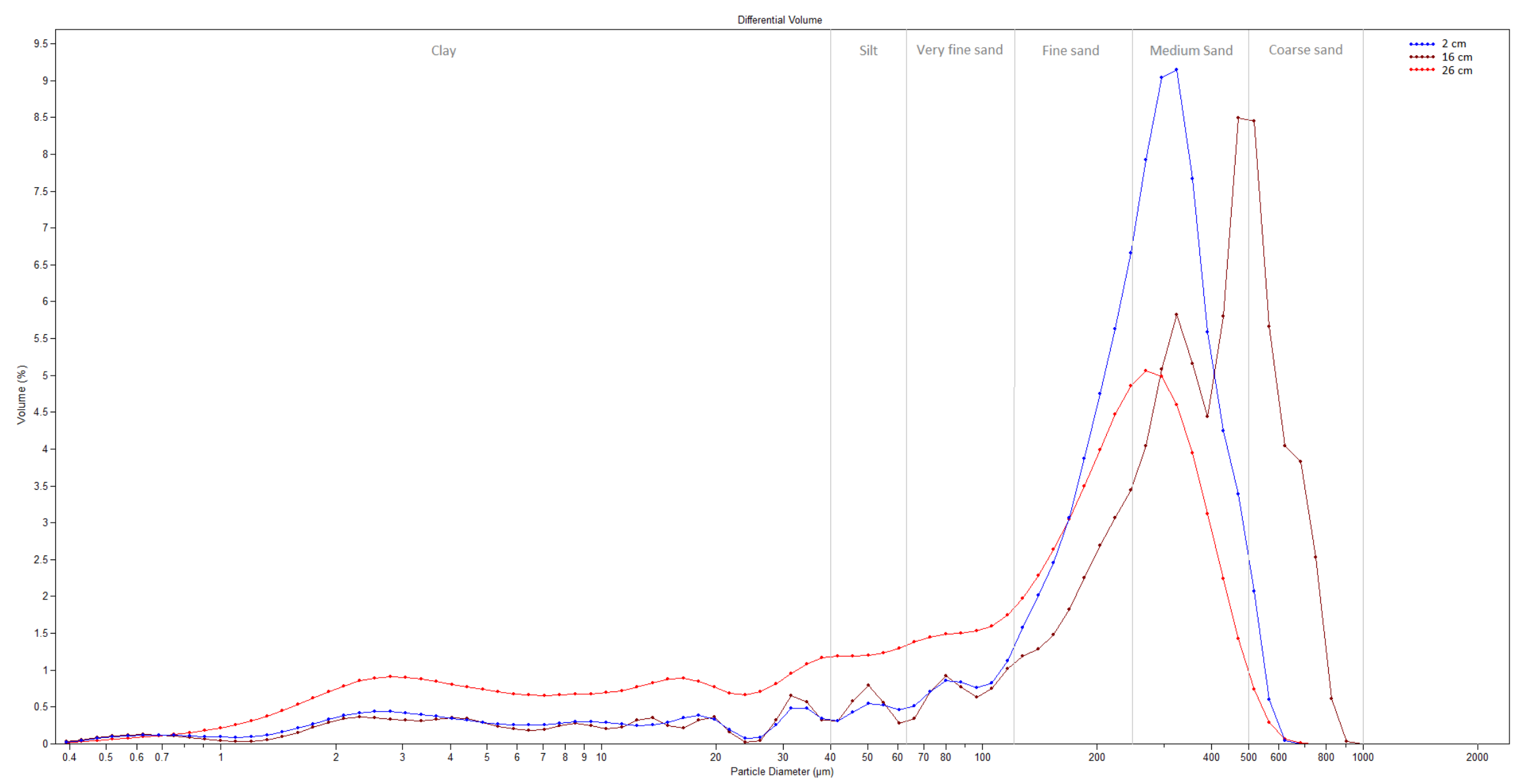

Figure 27: Grain size distribution of samples from P8 submitted for meteoric ${ }^{10}$ Be analysis after sieving to elimate effects of grain size dependency on ${ }^{10}$ Be concentration. 
Appendix E: Soil geochemistry

\begin{tabular}{|c|c|c|c|c|c|c|}
\hline $\begin{array}{l}\text { depth below } \\
\text { surface }\end{array}$ & Core & $\begin{array}{l}\mathrm{Cl}^{-} \\
\mathrm{ppm}\end{array}$ & $\begin{array}{l}\mathrm{SO}^{2-} \\
\mathrm{ppm}\end{array}$ & $\begin{array}{l}\text { NO3- }^{-} \\
\text {ppm }\end{array}$ & Total anion & $\begin{array}{l}\text { content } \\
\mathrm{ppm}\end{array}$ \\
\hline $30 \mathrm{~cm}$ & P1-C1-0 & 6.4 & 274.1 & 24.6 & - & 305.1 \\
\hline $32.5 \mathrm{~cm}$ & $\mathrm{P} 1-\mathrm{C} 1-2$ & 9.1 & 182.9 & 37.8 & - & 229.8 \\
\hline $35 \mathrm{~cm}$ & P1-C1-4 & 9.6 & 203.0 & 29.2 & - & 241.7 \\
\hline $37.5 \mathrm{~cm}$ & P1-C1-6 & 13.6 & 200.8 & 43.1 & - & 257.4 \\
\hline $40 \mathrm{~cm}$ & P1-C1-8 & 18.2 & 539.1 & 56.2 & - & 613.5 \\
\hline $42.5 \mathrm{~cm}$ & P1-C1-10 & 12.8 & 173.2 & 43.9 & - & 229.9 \\
\hline $45 \mathrm{~cm}$ & P1-C1-12 & 6.3 & 288.1 & 16.2 & - & 310.6 \\
\hline $47.5 \mathrm{~cm}$ & P1-C1-14 & 12.1 & 182.4 & 34.1 & - & 228.6 \\
\hline $50 \mathrm{~cm}$ & $\mathrm{P} 1-\mathrm{C} 1-16$ & 3.2 & 64.8 & 9.8 & - & 77.8 \\
\hline $52.5 \mathrm{~cm}$ & P1-C1-18 & 14.7 & 166.6 & 44.1 & - & 225.5 \\
\hline $55 \mathrm{~cm}$ & P1-C1-21 & 1.7 & 51.4 & 4.5 & - & 57.5 \\
\hline $57.5 \mathrm{~cm}$ & P1-C1-23 & 6.2 & 95.1 & 19.8 & - & 121.2 \\
\hline $60 \mathrm{~cm}$ & P1-C1-25 & 7.1 & 131.4 & 22.3 & - & 160.8 \\
\hline $62.5 \mathrm{~cm}$ & P1-C1-27 & 2.7 & 42.0 & 7.9 & - & 52.6 \\
\hline $65 \mathrm{~cm}$ & P1-C1-29 & 2.2 & 24.3 & 8.4 & - & 34.8 \\
\hline $67.5 \mathrm{~cm}$ & P1-C1-31 & 10.5 & 63.8 & 29.4 & - & 103.7 \\
\hline $70 \mathrm{~cm}$ & P1-C1-34 & 3.1 & 24.1 & 8.7 & - & 35.9 \\
\hline $72.5 \mathrm{~cm}$ & P1-C1-36 & 2.2 & 43.2 & 6.8 & - & 52.3 \\
\hline $75 \mathrm{~cm}$ & P1-C1-38 & 2.5 & 22.4 & 6.7 & - & 31.6 \\
\hline $77.5 \mathrm{~cm}$ & P1-C1-40 & 5.3 & 45.4 & 15.5 & - & 66.2 \\
\hline $80 \mathrm{~cm}$ & P1-C1-42 & 2.3 & 23.2 & 5.8 & - & 31.3 \\
\hline $82.5 \mathrm{~cm}$ & P1-C1-44 & 8.2 & 61.3 & 24.2 & - & 93.7 \\
\hline $85 \mathrm{~cm}$ & P1-C1-46 & 15.8 & 143.2 & 48.7 & - & 207.7 \\
\hline $87.5 \mathrm{~cm}$ & P1-C1-48 & 11.0 & 50.6 & 32.4 & - & 94.0 \\
\hline $90 \mathrm{~cm}$ & P1-C1-50 & 2.2 & 19.1 & 5.4 & - & 26.7 \\
\hline $20 \mathrm{~cm}$ & P2-C2--0 & 129.0 & 38.8 & 355.6 & - & 523.4 \\
\hline $23 \mathrm{~cm}$ & P2-C2--2 & 197.6 & 53.6 & 517.1 & - & 768.2 \\
\hline $26 \mathrm{~cm}$ & P2-C2--4 & 58.7 & 23.8 & 152.6 & - & 235.2 \\
\hline $29 \mathrm{~cm}$ & P2-C2--6 & 96.6 & 34.5 & 262.5 & - & 393.6 \\
\hline $32 \mathrm{~cm}$ & P2-C2--8 & 88.5 & 48.1 & 237.4 & - & 373.9 \\
\hline $35 \mathrm{~cm}$ & P2-C2--10 & 89.8 & 76.4 & 254.5 & - & 420.7 \\
\hline $38 \mathrm{~cm}$ & P2-C2--12 & 147.1 & 157.8 & 527.2 & - & 832.1 \\
\hline
\end{tabular}




\begin{tabular}{|c|c|c|c|c|c|c|}
\hline $41 \mathrm{~cm}$ & $\mathrm{P} 2-\mathrm{C} 2--14$ & 46.0 & 38.2 & 116.0 & - & 200.2 \\
\hline $44 \mathrm{~cm}$ & $\mathrm{P} 2-\mathrm{C} 2--16$ & 76.6 & 47.9 & 210.7 & - & 335.2 \\
\hline $47 \mathrm{~cm}$ & P2-C2--18 & 93.8 & 41.2 & 278.9 & - & 413.9 \\
\hline $50 \mathrm{~cm}$ & $\mathrm{P} 2-\mathrm{C} 2--20$ & 56.4 & 25.4 & 154.8 & - & 236.5 \\
\hline $2 \mathrm{~cm}$ & P4-C1-0 & 1.5 & 3.0 & 2.4 & - & 6.9 \\
\hline $4.5 \mathrm{~cm}$ & P4-C1-2 & 0.8 & 3.9 & 1.5 & - & 6.2 \\
\hline $7 \mathrm{~cm}$ & P4-C1-4 & 1.7 & 2.3 & 2.2 & - & 6.2 \\
\hline $9.5 \mathrm{~cm}$ & P4-C1-6 & 3.9 & 5.9 & 8.4 & - & 18.2 \\
\hline $12 \mathrm{~cm}$ & P4-C1-8 & 4.9 & 12.0 & 10.6 & - & 27.6 \\
\hline $14.5 \mathrm{~cm}$ & P4-C1-10 & 3.8 & 46.1 & 8.6 & - & 58.5 \\
\hline $17 \mathrm{~cm}$ & $\mathrm{P} 4-\mathrm{C} 1-12$ & 18.3 & 24.9 & 37.9 & - & 81.1 \\
\hline $19 \mathrm{~cm}$ & P5-C1-0 & 26.4 & 12.7 & 104.8 & - & 143.9 \\
\hline $21.75 \mathrm{~cm}$ & P5-C1-2 & 25.7 & 26.1 & 106.6 & - & 158.4 \\
\hline $24.5 \mathrm{~cm}$ & P5-C1-4 & 22.5 & 19.4 & 89.5 & - & 131.4 \\
\hline $27.25 \mathrm{~cm}$ & P5-C1-6 & 25.7 & 13.6 & 119.7 & - & 159.0 \\
\hline $30 \mathrm{~cm}$ & P5-C1-8 & 22.8 & 15.9 & 110.6 & - & 149.3 \\
\hline $32.75 \mathrm{~cm}$ & P5-C1-10 & 25.1 & 11.0 & 95.9 & - & 132.1 \\
\hline $35.5 \mathrm{~cm}$ & $\mathrm{P} 5-\mathrm{C} 1-12$ & 27.5 & 17.5 & 125.6 & - & 170.6 \\
\hline $38.25 \mathrm{~cm}$ & P5-C1-14 & 14.4 & 11.3 & 74.8 & - & 100.5 \\
\hline $41 \mathrm{~cm}$ & $\mathrm{P} 5-\mathrm{C} 1-16$ & 20.4 & 22.5 & 95.6 & - & 138.5 \\
\hline $25 \mathrm{~cm}$ & P6-C3-0 & 37.9 & 77.1 & 123.7 & - & 238.7 \\
\hline $27.25 \mathrm{~cm}$ & P6-C3-4 & 14.4 & 40.5 & 46.8 & - & 101.8 \\
\hline $29.5 \mathrm{~cm}$ & P6-C3-8 & 19.8 & 74.7 & 61.2 & - & 155.6 \\
\hline $31.75 \mathrm{~cm}$ & P6-C3-12 & 14.6 & 70.9 & 50.4 & - & 135.9 \\
\hline $34 \mathrm{~cm}$ & P6-C3-16 & 13.4 & 111.9 & 43.7 & - & 169.0 \\
\hline $36.25 \mathrm{~cm}$ & P6-C3-20 & 5.5 & 54.0 & 15.6 & - & 75.1 \\
\hline $38.5 \mathrm{~cm}$ & P6-C3-24 & 4.8 & 36.7 & 13.9 & - & 55.4 \\
\hline $40.75 \mathrm{~cm}$ & P6-C3-28 & 13.5 & 45.7 & 38.6 & - & 97.8 \\
\hline $43 \mathrm{~cm}$ & P6-C3-32 & 7.2 & 26.4 & 22.0 & - & 55.7 \\
\hline $45.25 \mathrm{~cm}$ & P6-C3-36 & 1.1 & 9.8 & 2.8 & - & 13.6 \\
\hline $47.5 \mathrm{~cm}$ & P6-C3-40 & 1.9 & 12.7 & 5.4 & - & 20.0 \\
\hline $49.75 \mathrm{~cm}$ & P6-C3-44 & 3.5 & 22.9 & 10.1 & - & 36.5 \\
\hline $52 \mathrm{~cm}$ & P6-C3-48 & 8.9 & 72.6 & 27.4 & - & 108.9 \\
\hline $54.25 \mathrm{~cm}$ & P6-C3-50 & 2.2 & 18.2 & 6.8 & - & 27.3 \\
\hline $22 \mathrm{~cm}$ & P7-C1-0 & 17.8 & 19.0 & 59.4 & - & 96.2 \\
\hline $24.7 \mathrm{~cm}$ & P7-C1-2 & 30.4 & 23.1 & 101.7 & - & 155.1 \\
\hline
\end{tabular}




\begin{tabular}{|c|c|c|c|c|c|c|}
\hline $27.4 \mathrm{~cm}$ & P7-C1-4 & 32.9 & 22.9 & 105.2 & - & 161.0 \\
\hline $30.1 \mathrm{~cm}$ & P7-C1-6 & 64.5 & 212.4 & 219.4 & - & 496.4 \\
\hline $32.8 \mathrm{~cm}$ & P7-C1-8 & 39.1 & 229.3 & 133.0 & - & 401.4 \\
\hline $35.5 \mathrm{~cm}$ & P7-C1-10 & 47.8 & 373.3 & 145.7 & - & 566.9 \\
\hline $38.2 \mathrm{~cm}$ & P7-C1-12 & 13.2 & 50.0 & 44.5 & - & 107.7 \\
\hline $40.9 \mathrm{~cm}$ & P7-C1-14 & 24.4 & 291.3 & 84.5 & - & 400.2 \\
\hline $43.6 \mathrm{~cm}$ & P7-C1-16 & 56.3 & 670.1 & 205.1 & - & 931.5 \\
\hline $46.3 \mathrm{~cm}$ & P7-C1-18 & 47.0 & 402.3 & 177.1 & - & 626.4 \\
\hline $49 \mathrm{~cm}$ & P7-C1-20 & 20.2 & 159.8 & 59.7 & - & 239.7 \\
\hline $2 \mathrm{~cm}$ & P8-C3-0 & 5.6 & 15.7 & 19.1 & - & 40.4 \\
\hline $4.5 \mathrm{~cm}$ & P8-C3-2 & 3.1 & 53.4 & 9.8 & - & 66.4 \\
\hline $7 \mathrm{~cm}$ & P8-C3-4 & 3.3 & 129.4 & 9.2 & - & 141.8 \\
\hline $9.5 \mathrm{~cm}$ & P8-C3-6 & 8.9 & 192.6 & 32.3 & - & 233.8 \\
\hline $12 \mathrm{~cm}$ & P8-C3-8 & 4.3 & 58.4 & 12.9 & - & 75.6 \\
\hline $14.5 \mathrm{~cm}$ & P8-C3-10 & 2.2 & 22.1 & 6.7 & - & 30.9 \\
\hline $17 \mathrm{~cm}$ & P8-C3-12 & 8.0 & 306.4 & 25.7 & - & 340.1 \\
\hline $19.5 \mathrm{~cm}$ & P8-C3-14 & 14.2 & 76.4 & 44.6 & - & 135.3 \\
\hline $22 \mathrm{~cm}$ & P8-C3-16 & 9.1 & 73.4 & 31.4 & - & 113.9 \\
\hline $24.5 \mathrm{~cm}$ & P8-C3-18 & 10.0 & 111.9 & 28.4 & - & 150.2 \\
\hline $27 \mathrm{~cm}$ & P8-C3-20 & 10.5 & 190.6 & 37.8 & - & 238.8 \\
\hline $29.5 \mathrm{~cm}$ & P8-C3-22 & 30.1 & 207.2 & 102.1 & - & 339.4 \\
\hline $32 \mathrm{~cm}$ & P8-C3-24 & 16.2 & 171.7 & 50.5 & - & 238.5 \\
\hline $34.5 \mathrm{~cm}$ & P8-C3-26 & 2.5 & 37.5 & 8.1 & - & 48.0 \\
\hline $37 \mathrm{~cm}$ & P8-C3-28 & 1.7 & 20.6 & 4.5 & - & 26.8 \\
\hline $39.5 \mathrm{~cm}$ & P8-C3-30 & 6.3 & 95.1 & 20.4 & - & 121.8 \\
\hline $42 \mathrm{~cm}$ & P8-C3-32 & 1.0 & 9.8 & 2.1 & - & 12.9 \\
\hline $44.5 \mathrm{~cm}$ & P8-C3-46 & 4.8 & 36.5 & 14.5 & - & 55.8 \\
\hline $47 \mathrm{~cm}$ & P8-C3-48 & 6.4 & 86.6 & 20.6 & - & 113.7 \\
\hline $49.5 \mathrm{~cm}$ & P8-C3-50 & 2.4 & 25.7 & 7.7 & - & 35.8 \\
\hline $16 \mathrm{~cm}$ & $\mathrm{P} 10-\mathrm{C} 1-0$ & 1.4 & 4.3 & 1.7 & - & 7.3 \\
\hline $20.7 \mathrm{~cm}$ & $\mathrm{P} 10-\mathrm{C} 1-4$ & 4.5 & 7.4 & 7.9 & - & 19.7 \\
\hline $25.4 \mathrm{~cm}$ & P10-C1-8 & 3.4 & 4.5 & 4.6 & - & 12.5 \\
\hline $30.1 \mathrm{~cm}$ & $\begin{array}{l}\text { P10-C1- } \\
12\end{array}$ & 4.9 & 5.8 & 14.1 & - & 24.8 \\
\hline $32.45 \mathrm{~cm}$ & $\begin{array}{l}\text { P10-C1- } \\
14\end{array}$ & 2.5 & 6.3 & 4.0 & - & 12.8 \\
\hline $37.15 \mathrm{~cm}$ & $\begin{array}{l}\text { P10-C1- } \\
20\end{array}$ & 1.9 & 12.0 & 2.8 & - & 16.8 \\
\hline
\end{tabular}




\begin{tabular}{|c|c|c|c|c|c|c|}
\hline $41.85 \mathrm{~cm}$ & $\begin{array}{l}\text { P10-C1- } \\
24\end{array}$ & 3.5 & 4.0 & 6.3 & - & 13.8 \\
\hline $46.55 \mathrm{~cm}$ & $\begin{array}{l}\text { P10-C1- } \\
28\end{array}$ & 5.7 & 11.7 & 10.5 & - & 27.9 \\
\hline $51.25 \mathrm{~cm}$ & $\begin{array}{l}\text { P10-C1- } \\
32\end{array}$ & 4.1 & 5.5 & 6.7 & - & 16.3 \\
\hline $55.95 \mathrm{~cm}$ & $\begin{array}{l}\text { P10-C1- } \\
36\end{array}$ & 3.4 & 4.8 & 4.6 & - & 12.8 \\
\hline $58.3 \mathrm{~cm}$ & $\begin{array}{l}\text { P10-C1- } \\
40\end{array}$ & 2.6 & 5.1 & 3.3 & - & 11.0 \\
\hline $60.65 \mathrm{~cm}$ & $\begin{array}{l}\text { P10-C1- } \\
44\end{array}$ & 3.5 & 8.8 & 5.6 & - & 17.9 \\
\hline $63 \mathrm{~cm}$ & $\begin{array}{l}\text { P10-C1- } \\
48\end{array}$ & 5.2 & 6.8 & 8.3 & - & 20.4 \\
\hline $65.35 \mathrm{~cm}$ & $\begin{array}{l}\text { P10-C1- } \\
50\end{array}$ & 3.8 & 9.6 & 5.9 & - & 19.3 \\
\hline
\end{tabular}

Table 12: Anion concentration in ppm for all cores 


\begin{tabular}{|c|c|c|c|c|c|c|c|c|c|c|}
\hline $\begin{array}{l}\text { depth bel } \\
\text { surface }\end{array}$ & Core & $\begin{array}{l}\mathrm{Ca}^{2+} \\
\mathrm{ppm} \\
\end{array}$ & $\begin{array}{l}\mathrm{Fe}^{2+} \\
\mathrm{ppm} \\
\end{array}$ & $\begin{array}{l}\mathrm{K}^{+} \\
\mathrm{ppm} \\
\end{array}$ & $\begin{array}{l}\mathrm{Mg}^{2+} \\
\mathrm{ppm} \\
\end{array}$ & $\begin{array}{l}\mathrm{Na}^{+} \\
\mathrm{ppm} \\
\end{array}$ & $\begin{array}{l}\mathrm{Si}^{4+} \\
\mathrm{ppm} \\
\end{array}$ & $\begin{array}{l}\mathrm{Sr}^{2+} \\
\mathrm{ppm} \\
\end{array}$ & Total anion & $\begin{array}{l}\text { content } \\
\mathrm{ppm} \\
\end{array}$ \\
\hline $30 \mathrm{~cm}$ & $\mathrm{P} 1-\mathrm{C} 1-0$ & 39.58 & 0.01 & 2.96 & 5.65 & 19.69 & 1.17 & 0.04 & - & 69.12 \\
\hline $32.5 \mathrm{~cm}$ & P1-C1-2 & 28.92 & 0.01 & 4.79 & 8.56 & 42.33 & 2.29 & 0.05 & - & 86.99 \\
\hline $35 \mathrm{~cm}$ & P1-C1-4 & 35.63 & 0.30 & 5.41 & 9.10 & 35.18 & 2.68 & 0.05 & - & 88.28 \\
\hline $37.5 \mathrm{~cm}$ & P1-C1-6 & 29.27 & 0.01 & 4.66 & 9.70 & 45.33 & 1.46 & 0.05 & - & 90.52 \\
\hline $40 \mathrm{~cm}$ & $\mathrm{P} 1-\mathrm{C} 1-8$ & 102.65 & 0.39 & 8.76 & 18.80 & 52.40 & 3.37 & 0.14 & - & 186.59 \\
\hline $42.5 \mathrm{~cm}$ & P1-C1-10 & 27.82 & 0.00 & 5.48 & 7.38 & 53.96 & 1.08 & 0.06 & - & 95.79 \\
\hline $45 \mathrm{~cm}$ & $\mathrm{P} 1-\mathrm{C} 1-12$ & 5.28 & 0.43 & 1.59 & 2.28 & 24.58 & 2.64 & 0.01 & - & 36.90 \\
\hline $47.5 \mathrm{~cm}$ & $\mathrm{P} 1-\mathrm{C} 1-14$ & 29.09 & 0.01 & 5.15 & 8.53 & 41.78 & 1.45 & 0.07 & - & 86.13 \\
\hline $50 \mathrm{~cm}$ & P1-C1-16 & 12.67 & 0.15 & 2.91 & 3.35 & 13.89 & 2.55 & 0.03 & - & 35.58 \\
\hline $52.5 \mathrm{~cm}$ & P1-C1-18 & 31.44 & 0.01 & 4.11 & 9.51 & 40.39 & 1.66 & 0.07 & - & 87.17 \\
\hline $55 \mathrm{~cm}$ & P1-C1-21 & 11.71 & 0.26 & 2.61 & 2.83 & 10.50 & 2.73 & 0.03 & - & 30.60 \\
\hline $57.5 \mathrm{~cm}$ & $\mathrm{P} 1-\mathrm{C} 1-23$ & 17.62 & 0.55 & 3.53 & 4.34 & 24.20 & 2.33 & 0.04 & - & 52.64 \\
\hline $60 \mathrm{~cm}$ & $\mathrm{P} 1-\mathrm{C} 1-25$ & 18.98 & 0.03 & 2.51 & 3.99 & 12.75 & 1.68 & 0.04 & - & 39.83 \\
\hline $62.5 \mathrm{~cm}$ & P1-C1-27 & 8.13 & 0.38 & 2.56 & 2.32 & 12.45 & 2.45 & 0.02 & - & 28.37 \\
\hline $65 \mathrm{~cm}$ & P1-C1-29 & 5.42 & 0.79 & 2.45 & 1.71 & 8.80 & 3.86 & 0.02 & - & 23.14 \\
\hline $67.5 \mathrm{~cm}$ & $\mathrm{P} 1-\mathrm{C} 1-31$ & 12.87 & 0.18 & 3.01 & 4.74 & 23.85 & 2.49 & 0.03 & - & 47.12 \\
\hline $70 \mathrm{~cm}$ & $\mathrm{P} 1-\mathrm{C} 1-34$ & 26.26 & 0.16 & 3.90 & 6.14 & 22.61 & 2.06 & 0.05 & - & 61.17 \\
\hline $72.5 \mathrm{~cm}$ & $\mathrm{P} 1-\mathrm{C} 1-36$ & 8.58 & 0.20 & 1.90 & 2.49 & 10.46 & 1.84 & 0.02 & - & 25.48 \\
\hline $75 \mathrm{~cm}$ & P1-C1-38 & 2.57 & 0.42 & 1.09 & 0.94 & 5.27 & 2.15 & 0.01 & - & 12.43 \\
\hline $77.5 \mathrm{~cm}$ & $\mathrm{P} 1-\mathrm{C} 1-40$ & 9.52 & 0.32 & 2.66 & 3.66 & 18.63 & 2.58 & 0.03 & - & 37.37 \\
\hline $80 \mathrm{~cm}$ & $\mathrm{P} 1-\mathrm{C} 1-42$ & 5.61 & 0.65 & 1.97 & 2.08 & 9.74 & 3.31 & 0.02 & - & 23.32 \\
\hline $82.5 \mathrm{~cm}$ & $\mathrm{P} 1-\mathrm{C} 1-44$ & 11.72 & 0.16 & 2.84 & 4.81 & 24.72 & 2.08 & 0.03 & - & 46.39 \\
\hline $85 \mathrm{~cm}$ & $\mathrm{P} 1-\mathrm{C} 1-46$ & 25.99 & 0.67 & 4.99 & 11.22 & 54.89 & 4.01 & 0.09 & - & 101.93 \\
\hline $87.5 \mathrm{~cm}$ & P1-C1-48 & 9.01 & 0.27 & 3.06 & 5.13 & 28.79 & 2.20 & 0.03 & - & 48.56 \\
\hline $90 \mathrm{~cm}$ & $\mathrm{P} 1-\mathrm{C} 1-50$ & 3.04 & 1.26 & 2.49 & 1.29 & 4.88 & 7.07 & 0.01 & - & 20.05 \\
\hline
\end{tabular}




\begin{tabular}{|c|c|c|c|c|c|c|c|c|c|c|}
\hline $20 \mathrm{~cm}$ & P2-C2--0 & 1.03 & 0.05 & 8.43 & 11.45 & 80.79 & 1.37 & 0.02 & - & 103.05 \\
\hline $23 \mathrm{~cm}$ & P2-C2--2 & 2.56 & 0.00 & 21.40 & 38.12 & 234.39 & 1.39 & 0.05 & - & 297.90 \\
\hline $26 \mathrm{~cm}$ & P2-C2--4 & 0.73 & 2.19 & 15.25 & 10.55 & 101.13 & 13.04 & 0.03 & - & 143.00 \\
\hline $29 \mathrm{~cm}$ & P2-C2--6 & 1.59 & 0.07 & 15.69 & 21.36 & 142.03 & 2.12 & 0.04 & - & 182.96 \\
\hline $32 \mathrm{~cm}$ & P2-C2--8 & 1.55 & 0.06 & 15.32 & 22.38 & 134.72 & 2.49 & 0.03 & - & 176.53 \\
\hline $35 \mathrm{~cm}$ & $\mathrm{P} 2-\mathrm{C} 2--10$ & 1.45 & 0.13 & 12.22 & 20.82 & 129.47 & 2.13 & 0.03 & - & 166.23 \\
\hline $38 \mathrm{~cm}$ & $\mathrm{P} 2-\mathrm{C} 2--12$ & 1.87 & 0.29 & 7.72 & 20.28 & 105.38 & 2.49 & 0.02 & - & 137.93 \\
\hline $41 \mathrm{~cm}$ & P2-C2--14 & 0.88 & 1.70 & 9.86 & 9.30 & 75.41 & 9.20 & 0.01 & - & 106.35 \\
\hline $44 \mathrm{~cm}$ & $\mathrm{P} 2-\mathrm{C} 2--16$ & 6.62 & 0.72 & 11.73 & 19.16 & 105.67 & 4.68 & 0.03 & - & 148.58 \\
\hline $47 \mathrm{~cm}$ & P2-C2--18 & 8.46 & 0.35 & 11.84 & 21.24 & 120.89 & 2.05 & 0.03 & - & 164.88 \\
\hline $50 \mathrm{~cm}$ & $\mathrm{P} 2-\mathrm{C} 2--20$ & 7.04 & 0.00 & 9.28 & 11.57 & 77.57 & 1.30 & 0.02 & - & 106.80 \\
\hline $2 \mathrm{~cm}$ & P4-C1-0 & 0.80 & 0.82 & 1.04 & 0.68 & 4.83 & 3.36 & 0.00 & - & 11.60 \\
\hline $4.5 \mathrm{~cm}$ & $\mathrm{P} 4-\mathrm{C} 1-2$ & 0.22 & 0.44 & 0.45 & 0.21 & 1.39 & 2.08 & 0.00 & - & 4.73 \\
\hline $7 \mathrm{~cm}$ & P4-C1-4 & 1.31 & 1.24 & 1.25 & 0.99 & 5.14 & 4.60 & 0.01 & - & 14.59 \\
\hline $9.5 \mathrm{~cm}$ & P4-C1-6 & 2.48 & 0.93 & 2.17 & 2.01 & 7.00 & 4.43 & 0.02 & - & 19.07 \\
\hline $12 \mathrm{~cm}$ & P4-C1-8 & 1.36 & 0.81 & 1.08 & 1.58 & 12.10 & 3.69 & 0.01 & - & 20.62 \\
\hline $14.5 \mathrm{~cm}$ & P4-C1-10 & 5.52 & 1.30 & 1.52 & 4.83 & 16.04 & 5.40 & 0.02 & - & 34.68 \\
\hline $17 \mathrm{~cm}$ & P4-C1-12 & 1.25 & 4.01 & 2.27 & 2.61 & 44.73 & 11.42 & 0.01 & - & 66.65 \\
\hline $19 \mathrm{~cm}$ & P5-C1-0 & 0.64 & 0.55 & 2.58 & 3.05 & 22.36 & 4.44 & 0.01 & - & 33.56 \\
\hline $21.75 \mathrm{~cm}$ & P5-C1-2 & 0.62 & 1.28 & 5.04 & 6.64 & 60.78 & 5.86 & 0.01 & - & 80.25 \\
\hline $24.5 \mathrm{~cm}$ & P5-C1-4 & 0.65 & 0.85 & 4.72 & 5.89 & 52.68 & 4.42 & 0.01 & - & 69.29 \\
\hline $27.25 \mathrm{~cm}$ & P5-C1-6 & 1.12 & 0.63 & 3.92 & 6.42 & 61.55 & 3.78 & 0.02 & - & 77.47 \\
\hline $30 \mathrm{~cm}$ & P5-C1-8 & 0.60 & 0.13 & 4.30 & 6.73 & 56.47 & 2.59 & 0.01 & - & 70.83 \\
\hline $32.75 \mathrm{~cm}$ & P5-C1-10 & 1.26 & 0.42 & 3.36 & 6.53 & 49.32 & 2.85 & 0.01 & - & 63.71 \\
\hline $35.5 \mathrm{~cm}$ & P5-C1-12 & 0.41 & 0.01 & 1.59 & 4.81 & 28.44 & 0.87 & 0.01 & - & 36.05 \\
\hline $38.25 \mathrm{~cm}$ & P5-C1-14 & 0.66 & 0.77 & 2.89 & 4.39 & 37.30 & 3.62 & 0.01 & - & 49.67 \\
\hline $41 \mathrm{~cm}$ & P5-C1-16 & 0.81 & 0.26 & 3.66 & 5.53 & 55.88 & 2.46 & 0.02 & - & 68.61 \\
\hline $25 \mathrm{~cm}$ & P6-C3-0 & 3.22 & 0.29 & 2.77 & 4.60 & 107.55 & 1.96 & 0.01 & - & 120.32 \\
\hline
\end{tabular}




\begin{tabular}{|c|c|c|c|c|c|c|c|c|c|c|}
\hline $27.25 \mathrm{~cm}$ & P6-C3-4 & 1.73 & 0.69 & 1.63 & 1.51 & 53.51 & 2.78 & 0.01 & - & 61.79 \\
\hline $29.5 \mathrm{~cm}$ & P6-C3-8 & 7.51 & 0.12 & 2.31 & 3.74 & 65.07 & 2.51 & 0.02 & - & 81.28 \\
\hline $31.75 \mathrm{~cm}$ & P6-C3-12 & 4.40 & 0.15 & 0.89 & 2.15 & 21.54 & 1.36 & 0.01 & - & 30.39 \\
\hline $34 \mathrm{~cm}$ & P6-C3-16 & 15.77 & 0.24 & 2.19 & 6.49 & 51.43 & 2.47 & 0.03 & - & 78.55 \\
\hline $36.25 \mathrm{~cm}$ & P6-C3-20 & 7.44 & 0.47 & 1.47 & 2.95 & 25.81 & 2.75 & 0.02 & - & 40.85 \\
\hline $38.5 \mathrm{~cm}$ & P6-C3-24 & 5.54 & 0.50 & 1.56 & 2.29 & 19.97 & 2.54 & 0.01 & - & 32.39 \\
\hline $40.75 \mathrm{~cm}$ & P6-C3-28 & 6.45 & 0.43 & 2.26 & 2.80 & 26.87 & 2.68 & 0.02 & - & 41.48 \\
\hline $43 \mathrm{~cm}$ & P6-C3-32 & 0.74 & 0.54 & 0.70 & 0.48 & 9.33 & 2.49 & 0.00 & - & 14.20 \\
\hline $45.25 \mathrm{~cm}$ & P6-C3-36 & 0.31 & 0.32 & 0.34 & 0.21 & 2.64 & 1.43 & 0.00 & - & 5.13 \\
\hline $47.5 \mathrm{~cm}$ & P6-C3-40 & 0.76 & 0.91 & 0.82 & 0.50 & 9.02 & 2.98 & 0.00 & - & 14.94 \\
\hline $49.75 \mathrm{~cm}$ & P6-C3-44 & 5.83 & 0.35 & 1.80 & 2.43 & 25.03 & 2.05 & 0.02 & - & 37.44 \\
\hline $52 \mathrm{~cm}$ & P6-C3-48 & 11.75 & 0.12 & 1.95 & 4.10 & 37.38 & 1.84 & 0.03 & - & 57.07 \\
\hline $54.25 \mathrm{~cm}$ & P6-C3-50 & 13.28 & 0.06 & 1.86 & 4.69 & 36.78 & 1.54 & 0.03 & - & 58.08 \\
\hline $22 \mathrm{~cm}$ & P7-C1-0 & 1.18 & 0.35 & 1.20 & 1.04 & 23.39 & 1.98 & 0.01 & - & 28.95 \\
\hline $24.7 \mathrm{~cm}$ & P7-C1-2 & 2.61 & 0.54 & 2.15 & 2.83 & 68.20 & 3.11 & 0.01 & - & 79.37 \\
\hline $27.4 \mathrm{~cm}$ & P7-C1-4 & 1.22 & 0.87 & 4.04 & 2.54 & 87.74 & 4.27 & 0.01 & - & 100.63 \\
\hline $30.1 \mathrm{~cm}$ & P7-C1-6 & 25.15 & 0.04 & 4.52 & 13.71 & 183.81 & 1.64 & 0.07 & - & 228.82 \\
\hline $32.8 \mathrm{~cm}$ & P7-C1-8 & 28.33 & 0.06 & 3.95 & 15.92 & 127.63 & 1.46 & 0.06 & - & 177.31 \\
\hline $35.5 \mathrm{~cm}$ & P7-C1-10 & 74.83 & 0.01 & 5.23 & 21.47 & 118.17 & 2.01 & 0.12 & - & 221.72 \\
\hline $38.2 \mathrm{~cm}$ & P7-C1-12 & 32.42 & 0.10 & 2.81 & 5.38 & 13.13 & 1.47 & 0.05 & - & 55.23 \\
\hline $40.9 \mathrm{~cm}$ & P7-C1-14 & 59.29 & 0.01 & 3.33 & 14.59 & 70.95 & 1.50 & 0.09 & - & 149.66 \\
\hline $43.6 \mathrm{~cm}$ & P7-C1-16 & 107.49 & 0.00 & 5.80 & 27.08 & 137.21 & 1.90 & 0.19 & - & 279.55 \\
\hline $46.3 \mathrm{~cm}$ & P7-C1-18 & 82.39 & 0.01 & 5.11 & 22.18 & 138.20 & 1.71 & 0.15 & - & 249.62 \\
\hline $49 \mathrm{~cm}$ & P7-C1-20 & 30.83 & 0.00 & 2.55 & 10.35 & 50.19 & 1.51 & 0.06 & - & 95.45 \\
\hline $2 \mathrm{~cm}$ & P8-C3-0 & 3.47 & 0.48 & 1.67 & 3.05 & 12.16 & 3.23 & 0.03 & - & 24.02 \\
\hline $4.5 \mathrm{~cm}$ & P8-C3-2 & 3.61 & 0.34 & 1.34 & 1.30 & 4.63 & 2.23 & 0.01 & - & 13.23 \\
\hline $7 \mathrm{~cm}$ & P8-C3-4 & 38.20 & 0.15 & 2.02 & 5.77 & 13.76 & 1.39 & 0.07 & - & 61.21 \\
\hline $9.5 \mathrm{~cm}$ & P8-C3-6 & 35.94 & 0.01 & 2.70 & 9.41 & 38.25 & 1.51 & 0.09 & - & 87.75 \\
\hline
\end{tabular}




\begin{tabular}{|c|c|c|c|c|c|c|c|c|c|c|}
\hline $12 \mathrm{~cm}$ & P8-C3-8 & 9.01 & 0.11 & 1.82 & 3.90 & 22.75 & 2.43 & 0.03 & - & 40.01 \\
\hline $14.5 \mathrm{~cm}$ & P8-C3-10 & 2.22 & 0.33 & 1.07 & 1.16 & 13.27 & 1.93 & 0.01 & - & 19.90 \\
\hline $17 \mathrm{~cm}$ & P8-C3-12 & 66.77 & 0.18 & 3.16 & 10.07 & 33.00 & 2.67 & 0.12 & - & 115.80 \\
\hline $19.5 \mathrm{~cm}$ & P8-C3-14 & 6.32 & 0.00 & 1.07 & 2.90 & 19.46 & 0.76 & 0.02 & - & 30.39 \\
\hline $22 \mathrm{~cm}$ & P8-C3-16 & 8.72 & 0.65 & 2.49 & 4.38 & 31.47 & 3.63 & 0.03 & - & 51.27 \\
\hline $24.5 \mathrm{~cm}$ & P8-C3-18 & 25.18 & 0.01 & 2.25 & 6.46 & 29.38 & 1.32 & 0.05 & - & 64.57 \\
\hline $27 \mathrm{~cm}$ & P8-C3-20 & 41.46 & 0.05 & 2.82 & 10.10 & 37.85 & 2.48 & 0.09 & - & 94.70 \\
\hline $29.5 \mathrm{~cm}$ & P8-C3-22 & 37.41 & 0.01 & 3.51 & 14.78 & 62.66 & 1.52 & 0.12 & - & 119.88 \\
\hline $32 \mathrm{~cm}$ & P8-C3-24 & 38.41 & 0.40 & 3.71 & 11.12 & 39.26 & 3.24 & 0.11 & - & 96.03 \\
\hline $34.5 \mathrm{~cm}$ & P8-C3-26 & 6.01 & 0.15 & 0.82 & 1.56 & 3.86 & 1.35 & 0.02 & - & 13.64 \\
\hline $37 \mathrm{~cm}$ & P8-C3-28 & 7.79 & 0.55 & 1.33 & 2.02 & 5.95 & 3.64 & 0.02 & - & 21.08 \\
\hline $39.5 \mathrm{~cm}$ & P8-C3-30 & 26.72 & 0.03 & 2.55 & 6.20 & 17.44 & 1.77 & 0.07 & - & 54.69 \\
\hline $42 \mathrm{~cm}$ & P8-C3-32 & 4.68 & 0.90 & 1.19 & 1.36 & 4.27 & 4.38 & 0.02 & - & 16.68 \\
\hline $44.5 \mathrm{~cm}$ & P8-C3-46 & 10.59 & 0.13 & 1.42 & 2.96 & 10.00 & 2.19 & 0.04 & - & 27.21 \\
\hline $47 \mathrm{~cm}$ & P8-C3-48 & 21.12 & 0.06 & 2.18 & 5.55 & 13.93 & 1.27 & 0.06 & - & 44.06 \\
\hline $49.5 \mathrm{~cm}$ & P8-C3-50 & 4.43 & 0.21 & 0.89 & 1.15 & 4.35 & 1.93 & 0.02 & - & 12.88 \\
\hline $16 \mathrm{~cm}$ & $\mathrm{P} 10-\mathrm{C} 1-0$ & 3.05 & 1.08 & 0.85 & 0.85 & 5.21 & 4.38 & 0.01 & - & 15.29 \\
\hline $20.7 \mathrm{~cm}$ & $\mathrm{P} 10-\mathrm{C} 1-4$ & 6.56 & 1.93 & 1.19 & 1.74 & 7.84 & 6.51 & 0.02 & - & 25.71 \\
\hline $25.4 \mathrm{~cm}$ & $\mathrm{P} 10-\mathrm{C} 1-8$ & 5.56 & 4.60 & 1.95 & 2.09 & 9.56 & 12.18 & 0.02 & - & 35.90 \\
\hline $30.1 \mathrm{~cm}$ & $\mathrm{P} 10-\mathrm{C} 1-12$ & 5.46 & 1.92 & 2.10 & 1.53 & 9.51 & 6.98 & 0.02 & - & 27.40 \\
\hline $32.45 \mathrm{~cm}$ & $\mathrm{P} 10-\mathrm{C} 1-14$ & 4.22 & 2.53 & 1.87 & 1.34 & 9.62 & 8.46 & 0.02 & - & 27.88 \\
\hline $37.15 \mathrm{~cm}$ & $\mathrm{P} 10-\mathrm{C} 1-20$ & 7.04 & 1.30 & 0.98 & 1.59 & 5.32 & 4.82 & 0.02 & - & 21.00 \\
\hline $41.85 \mathrm{~cm}$ & $\mathrm{P} 10-\mathrm{C} 1-24$ & 3.08 & 1.16 & 0.61 & 0.86 & 3.88 & 4.03 & 0.01 & - & 13.54 \\
\hline $46.55 \mathrm{~cm}$ & $\mathrm{P} 10-\mathrm{C} 1-28$ & 6.25 & 3.92 & 2.17 & 2.10 & 13.20 & 11.57 & 0.03 & - & 39.01 \\
\hline $51.25 \mathrm{~cm}$ & $\mathrm{P} 10-\mathrm{C} 1-32$ & 6.09 & 2.12 & 1.31 & 1.84 & 10.39 & 7.31 & 0.02 & - & 28.91 \\
\hline $55.95 \mathrm{~cm}$ & $\mathrm{P} 10-\mathrm{C} 1-36$ & 5.66 & 1.61 & 1.10 & 1.46 & 7.50 & 5.70 & 0.02 & - & 22.89 \\
\hline $58.3 \mathrm{~cm}$ & $\mathrm{P} 10-\mathrm{C} 1-40$ & 5.57 & 4.72 & 1.47 & 2.12 & 8.81 & 10.81 & 0.02 & - & 33.48 \\
\hline $60.65 \mathrm{~cm}$ & $\mathrm{P} 10-\mathrm{C} 1-44$ & 5.96 & 1.01 & 1.06 & 1.64 & 9.22 & 4.74 & 0.02 & - & 23.54 \\
\hline
\end{tabular}




\begin{tabular}{ll|l|l|l|l|l|l|l|l|l}
$63 \mathrm{~cm}$ & P10-C1-48 & 3.18 & 1.56 & 0.83 & 1.08 & 7.44 & 4.93 & 0.01 & - & 18.90 \\
\hline $65.35 \mathrm{~cm}$ & P10-C1-50 & 5.39 & 6.83 & 1.88 & 2.80 & 11.98 & 14.21 & 0.02 & - & 43.07
\end{tabular}

Table 13: Cation concentration in ppm for all cores.

\begin{tabular}{l|l|l|l|r|r|r|r|r|r} 
& $\begin{array}{l}\mathrm{Ca}^{2+} \\
\mathrm{ppm}\end{array}$ & $\begin{array}{l}\mathrm{Fe}^{2+} \\
\mathrm{ppm}\end{array}$ & $\begin{array}{l}\mathrm{K}^{+} \\
\mathrm{ppm}\end{array}$ & $\begin{array}{l}\mathrm{Mg}^{2+} \\
\mathrm{ppm}\end{array}$ & $\begin{array}{l}\mathrm{Na}^{+} \\
\mathrm{ppm}\end{array}$ & $\begin{array}{l}\mathrm{Si}^{4+} \\
\mathrm{ppm}\end{array}$ & $\begin{array}{l}\mathrm{Sr}^{2+} \\
\mathrm{ppm}\end{array}$ & Total anion & $\begin{array}{l}\text { content } \\
\mathrm{ppm}\end{array}$ \\
\hline BLANK & -0.013 & 0.000 & 0.016 & 0.000 & 0.005 & 0.006 & 0.002 & - & 0.042 \\
\hline BLANK & -0.016 & 0.001 & 0.020 & -0.001 & -0.001 & -0.001 & 0.001 & - & 0.040 \\
\hline BLANK & 0.051 & 0.003 & 0.005 & 0.010 & 0.000 & 0.042 & 0.000 & - & 0.112 \\
\hline BLANK & -0.016 & 0.006 & 0.017 & -0.001 & 0.000 & -0.003 & 0.000 & - & 0.044 \\
\hline BLANK & -0.007 & 0.003 & 0.014 & -0.001 & 0.002 & 0.009 & 0.000 & - & 0.036 \\
\hline BLANK & -0.017 & 0.003 & 0.026 & -0.001 & 0.000 & 0.002 & 0.000 & - & 0.048 \\
\hline BLANK & -0.014 & 0.003 & 0.014 & 0.000 & 0.000 & 0.008 & 0.000 & - & 0.040 \\
\hline BLANK & -0.012 & 0.001 & 0.021 & -0.001 & 0.002 & 0.005 & 0.000 & - & 0.044 \\
\hline CHECK sample size & 1.16 & 1.05 & 0.94 & 1.11 & 1.11 & 0.02 & 1.16 & - & 6.54 \\
\hline measured & & & & & & & & & \\
\end{tabular}

Table 14: Cation concentrations of laboratory blank samples taken before each core's ion measurements. 


\section{Anion and cation concentration plots}

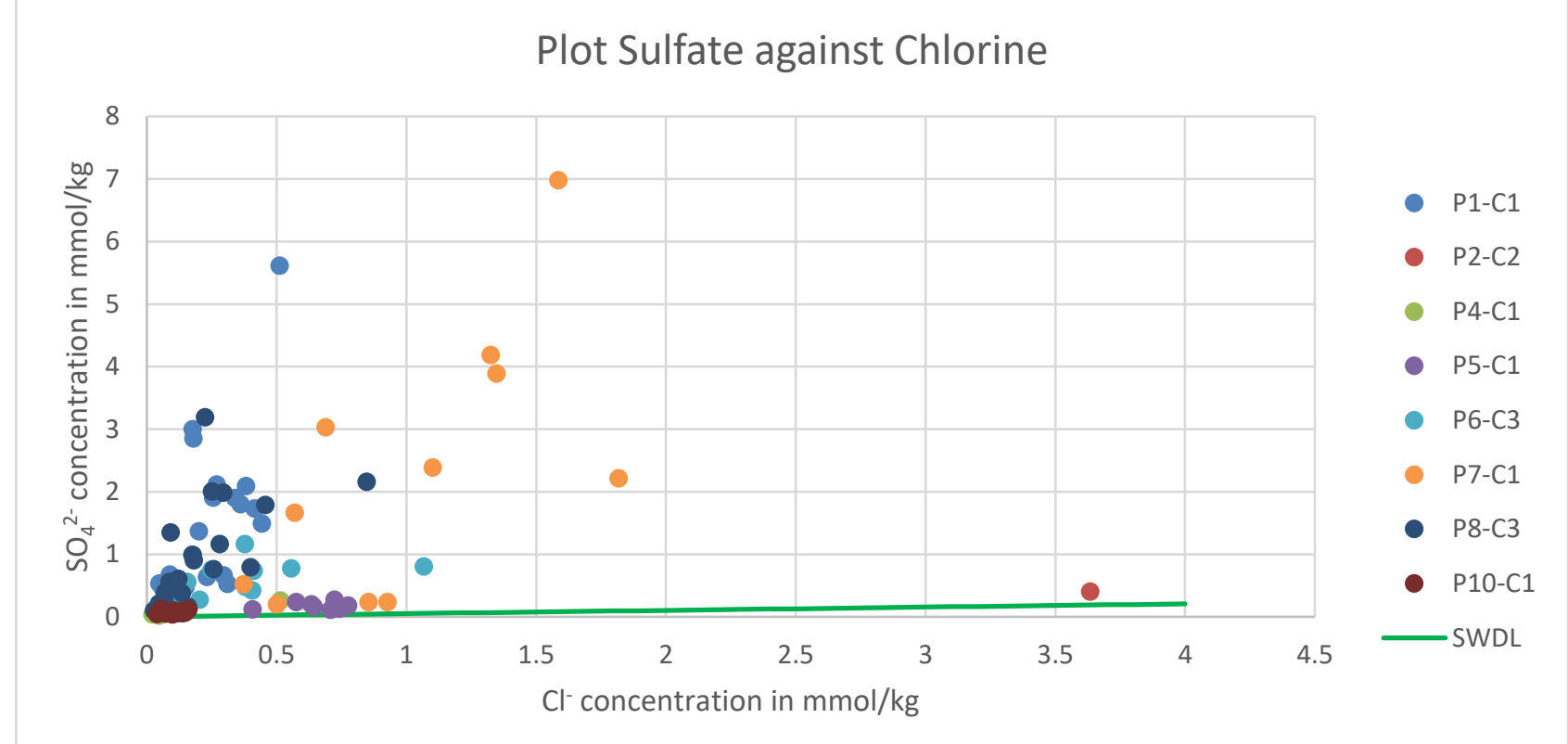

Figure 28: Plot of sulfate against chlorine concentrations in mmol/kg for all cores. SWDL is the SeaWaterDilutionLine.

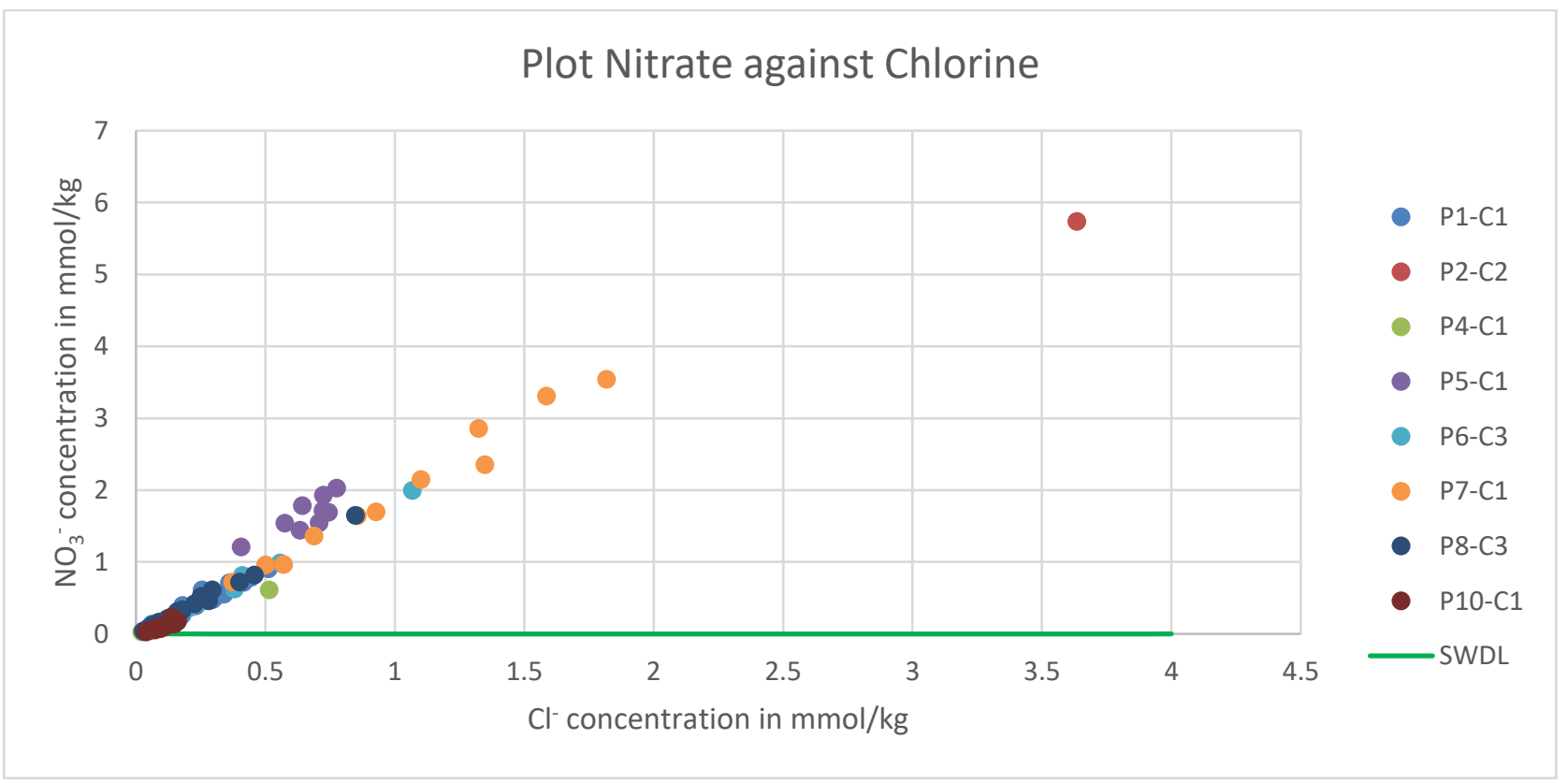

Figure 29: Plot of nitrate against chlorine concentrations in mmol/kg for all cores. SWDL is the SeaWaterDilutionLine. 


\section{Plot Sulfate against Nitrate}

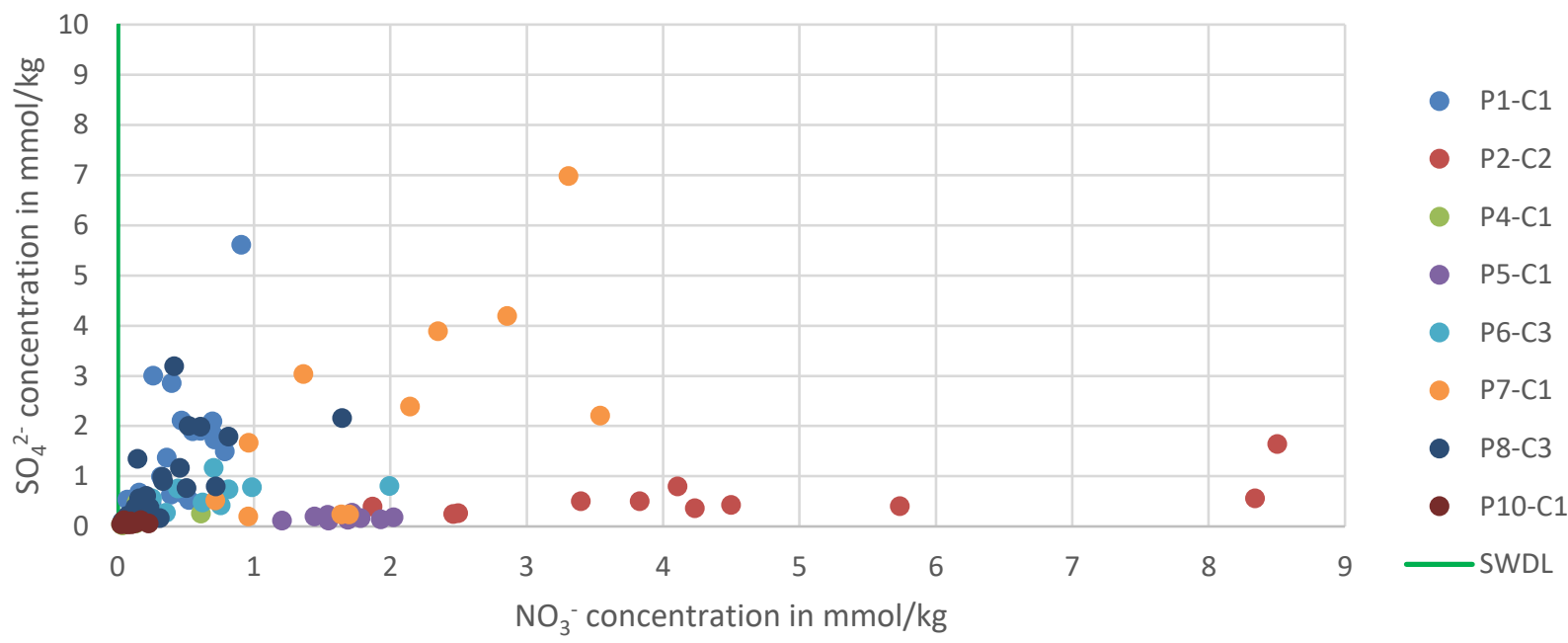

Figure 30: Plot of sulfate against nitrate concentrations in mmol/kg for all cores. SWDL is the SeaWaterDilutionLine.

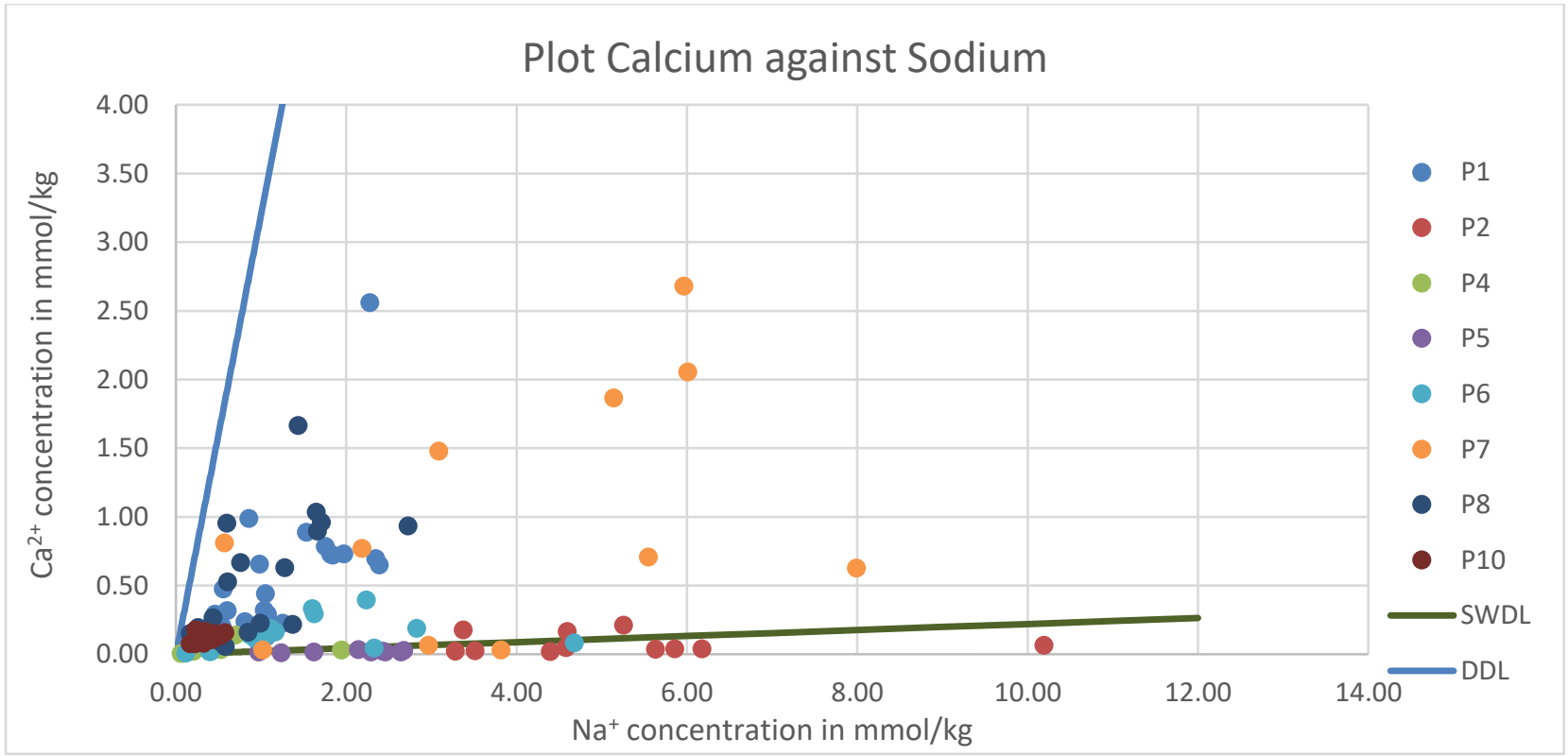

Figure 31: Plot of calcium against sodium concentrations in mmol/kg for all cores. SWDL is the SeaWaterDilutionLine and DDL is the DoleriteDilutionLine. 


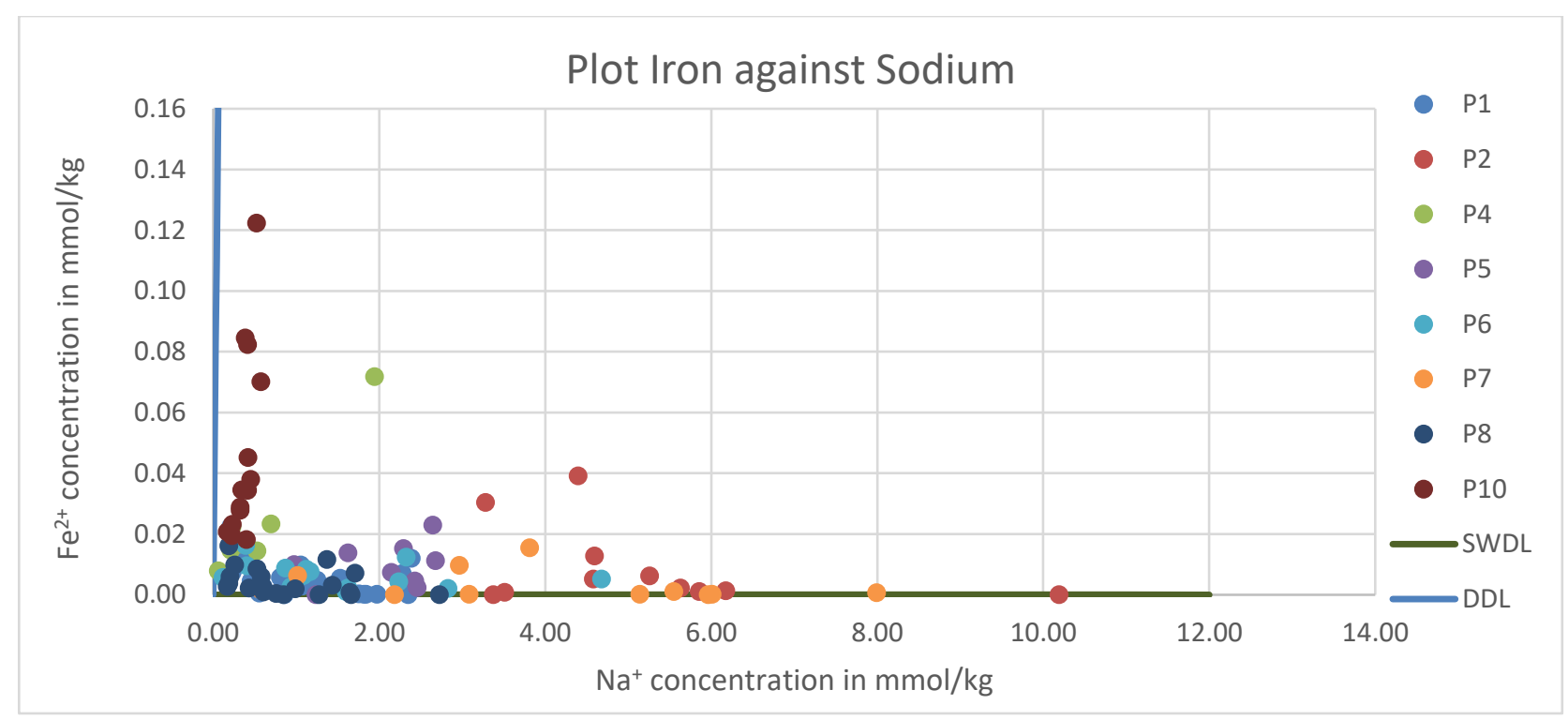

Figure 32: Plot of iron against sodium concentrations in mmol/kg for all cores. SWDL is the SeaWaterDilutionLine and DDL is the DoleriteDilutionLine.

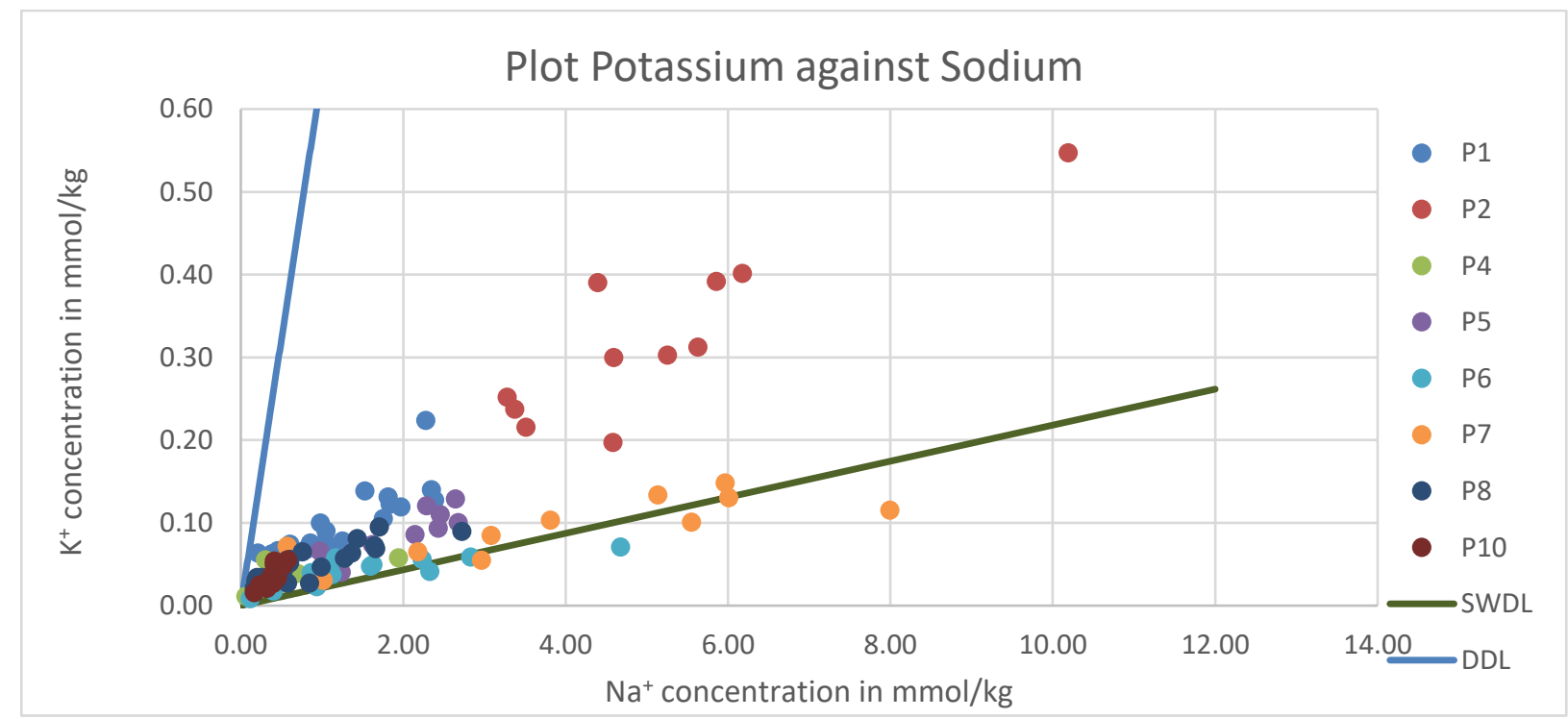

Figure 33: Plot of potassium against sodium concentrations in mmol/kg for all cores. SWDL is the SeaWaterDilutionLine and DDL is the DoleriteDilutionLine. 


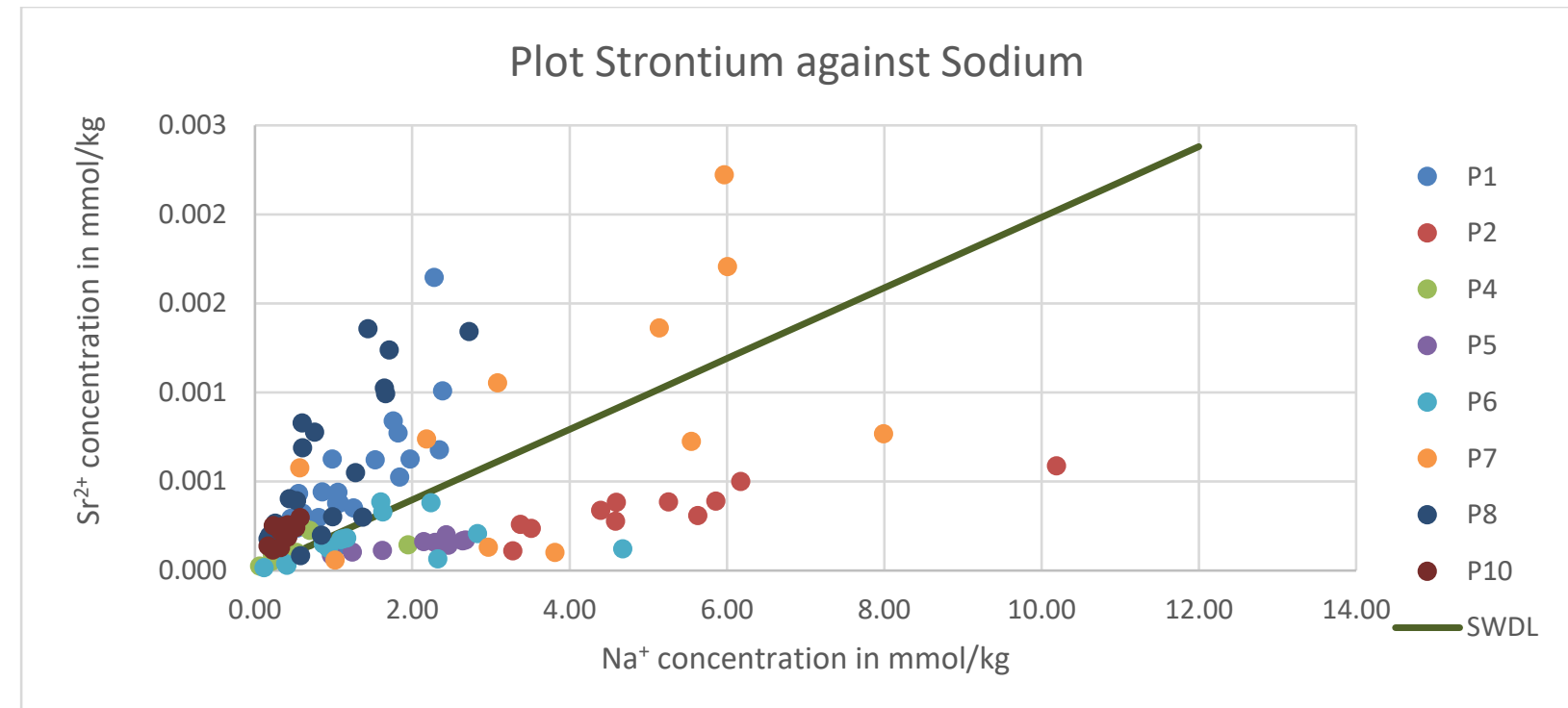

Figure 34: Plot of strontium against sodium concentrations in mmol/kg for all cores. SWDL is the SeaWaterDilutionLine.

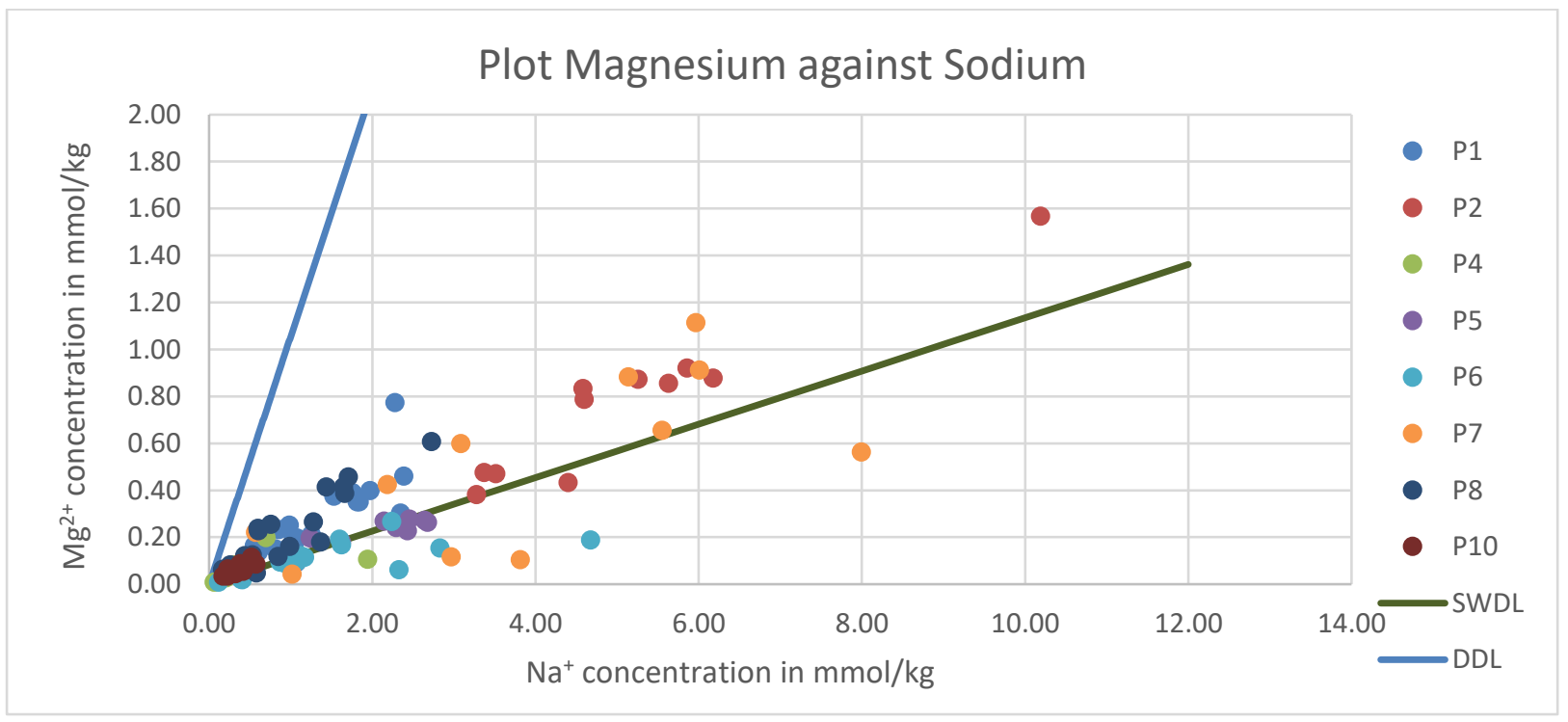

Figure 35: Plot of magnesium against sodium concentrations in mmol/kg for all cores. SWDL is the SeaWaterDilutionLine and DDL is the DoleriteDilutionLine. 


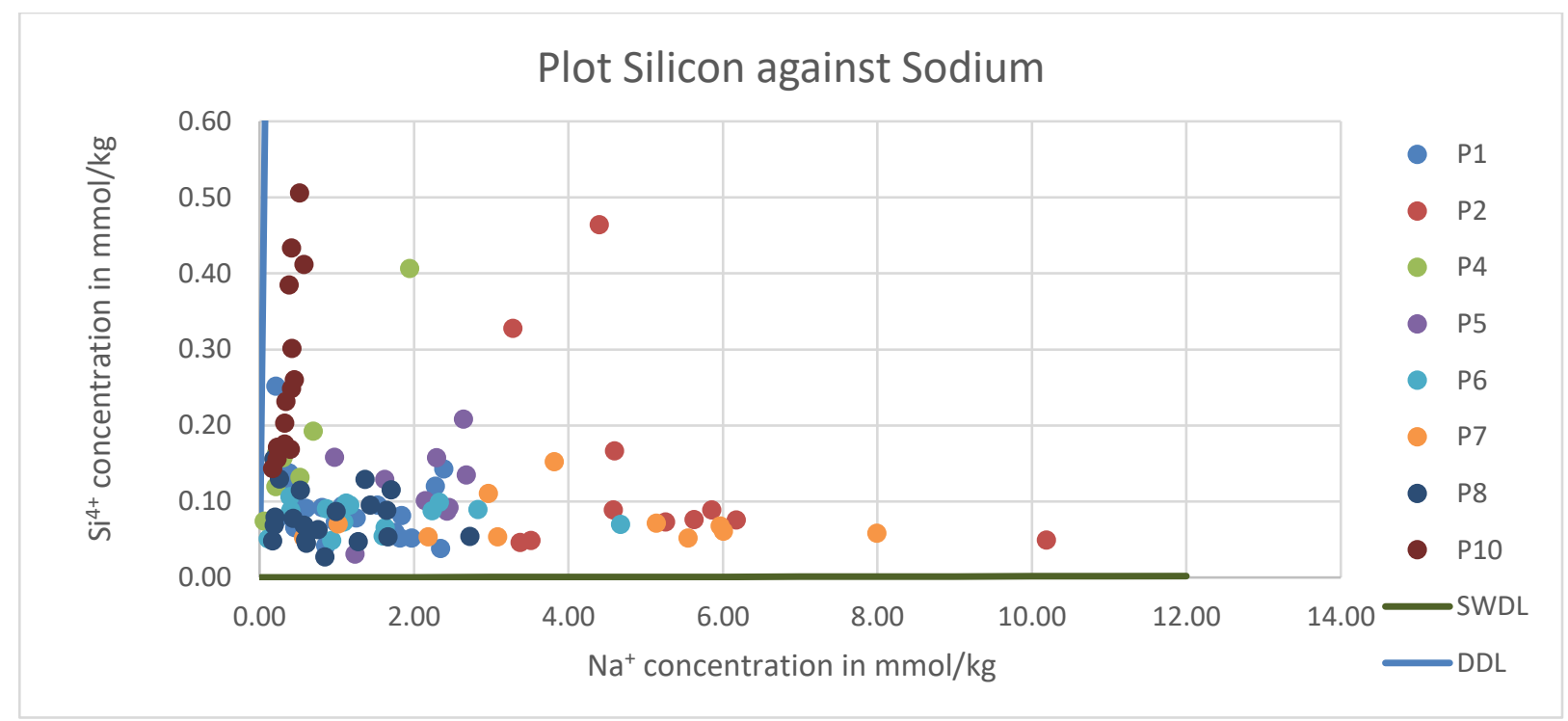

Figure 36: Plot of silicon against sodium concentrations in mmol/kg for all cores. SWDL is the SeaWaterDilutionLine and DDL is the DoleriteDilutionLine.

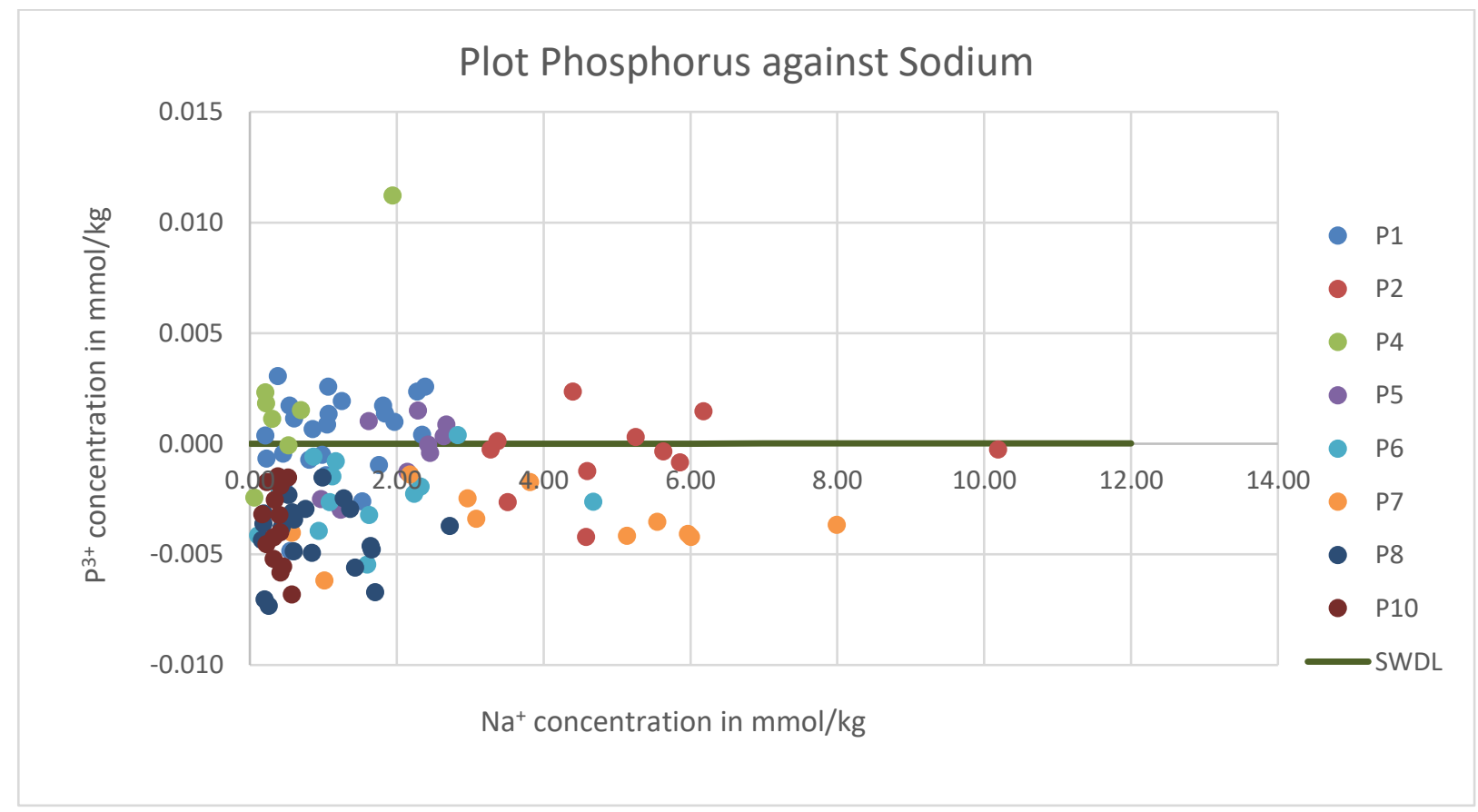

Figure 37: Plot of phosphorus against sodium concentrations in mmol/kg for all cores. SWDL is the SeaWaterDilutionLine. 


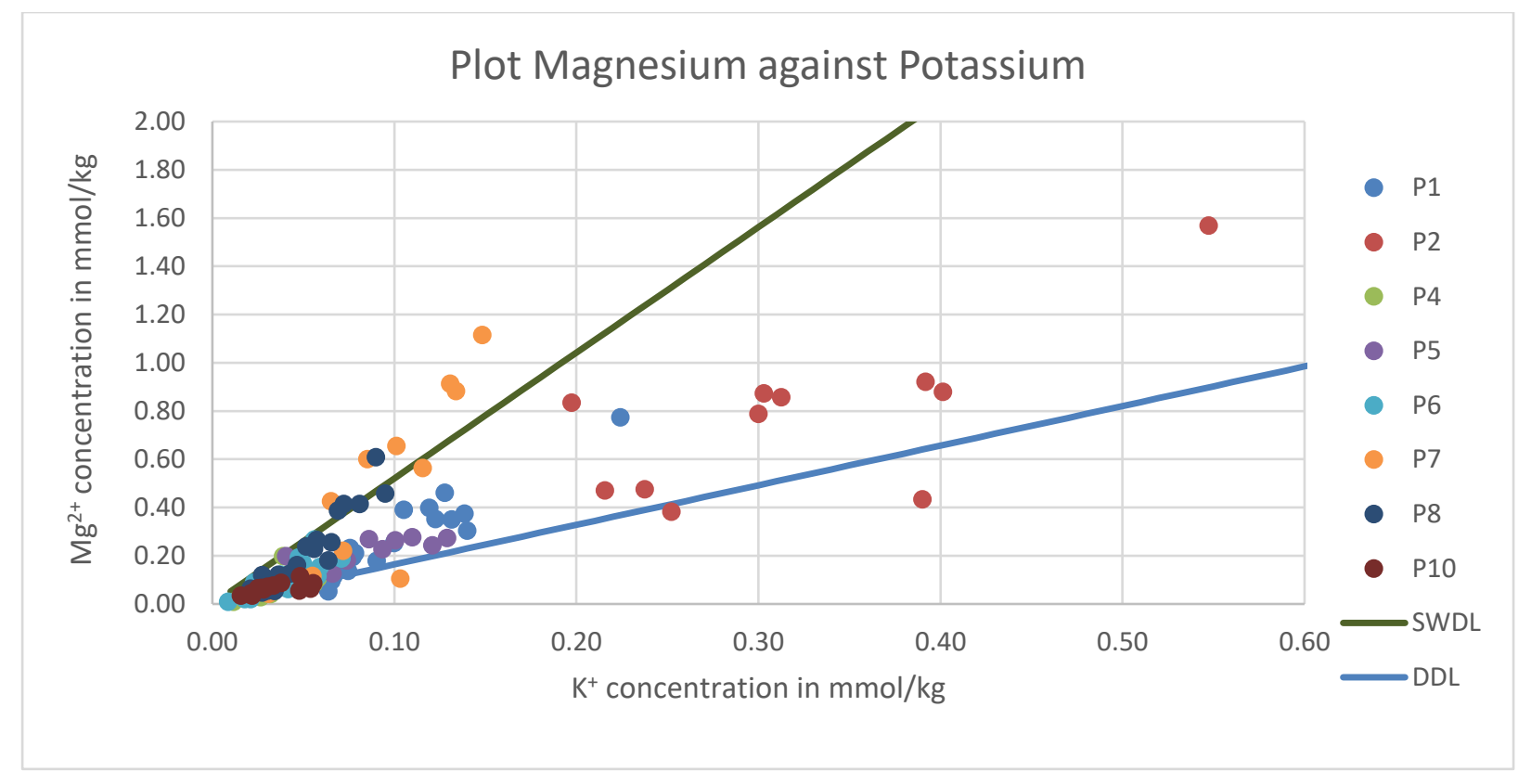

Figure 38: Plot of magnesium against potassium concentrations in mmol/kg for all cores. SWDL is the SeaWaterDilutionLine and DDL is the DoleriteDilutionLine.

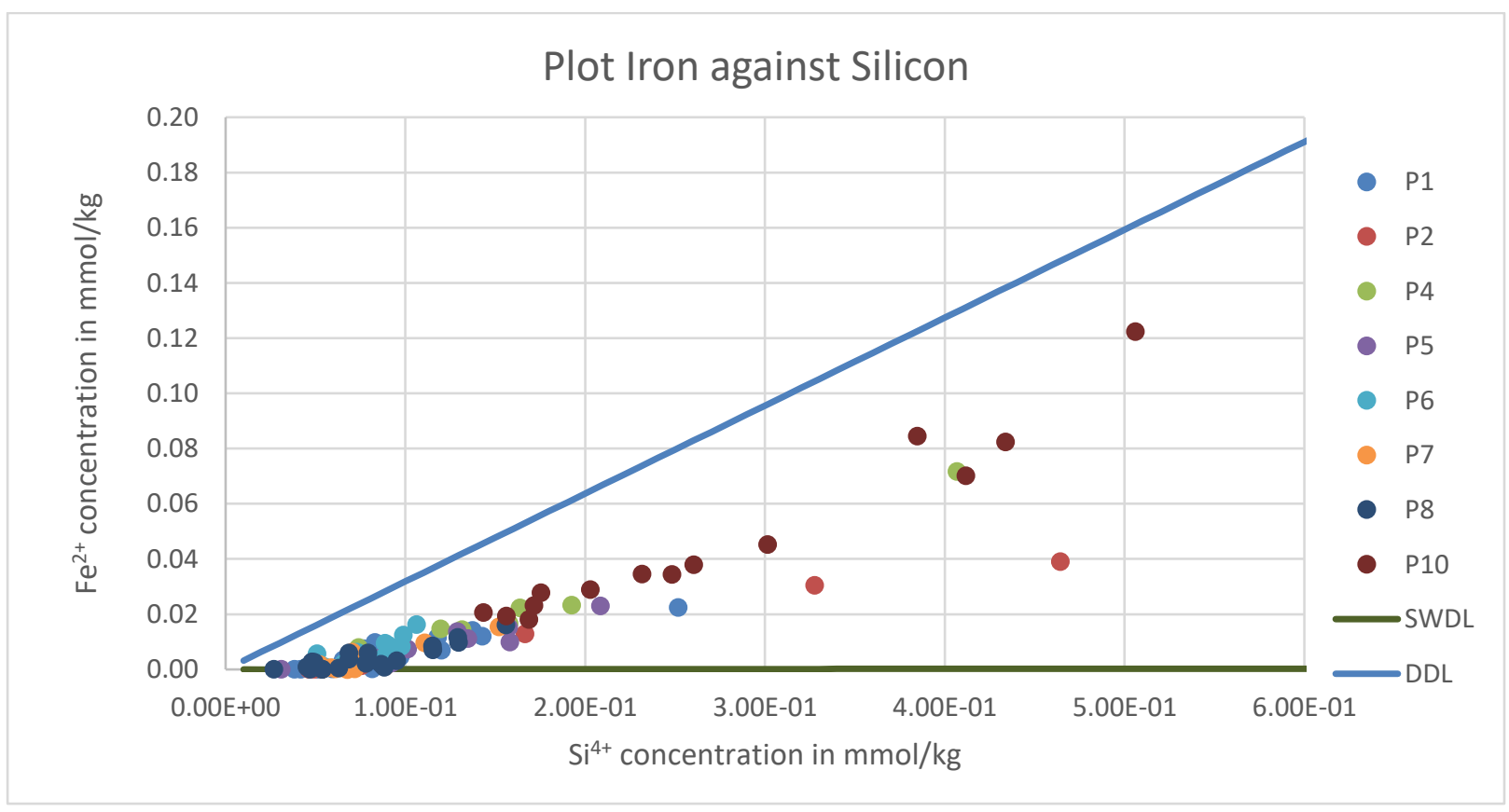

Figure 39: Plot of iron against silicon concentrations in mmol/kg for all cores. SWDL is the SeaWaterDilutionLine and DDL is the DoleriteDilutionLine. 


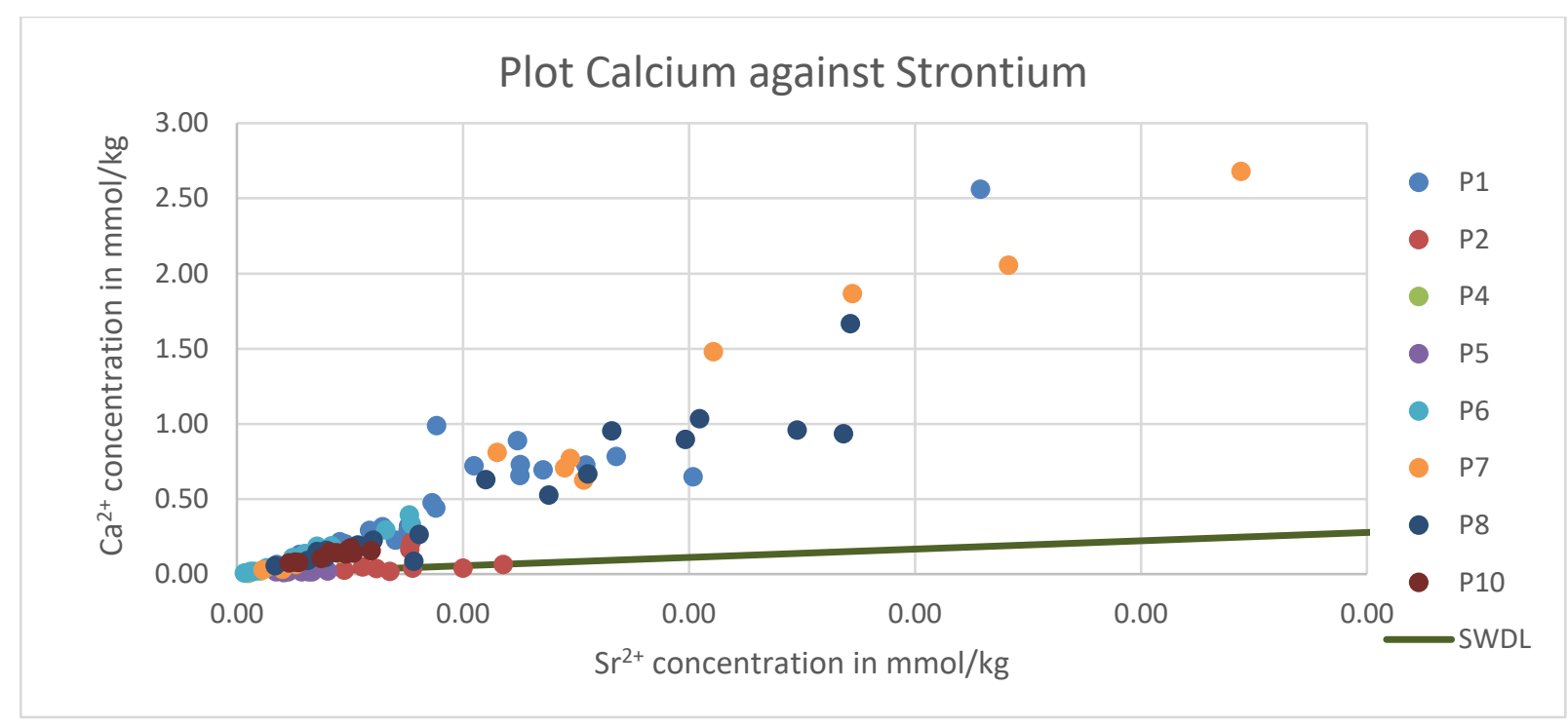

Figure 40: Plot of calcium against strontium concentrations in mmol/kg for all cores. SWDL is the SeaWaterDilutionLine.

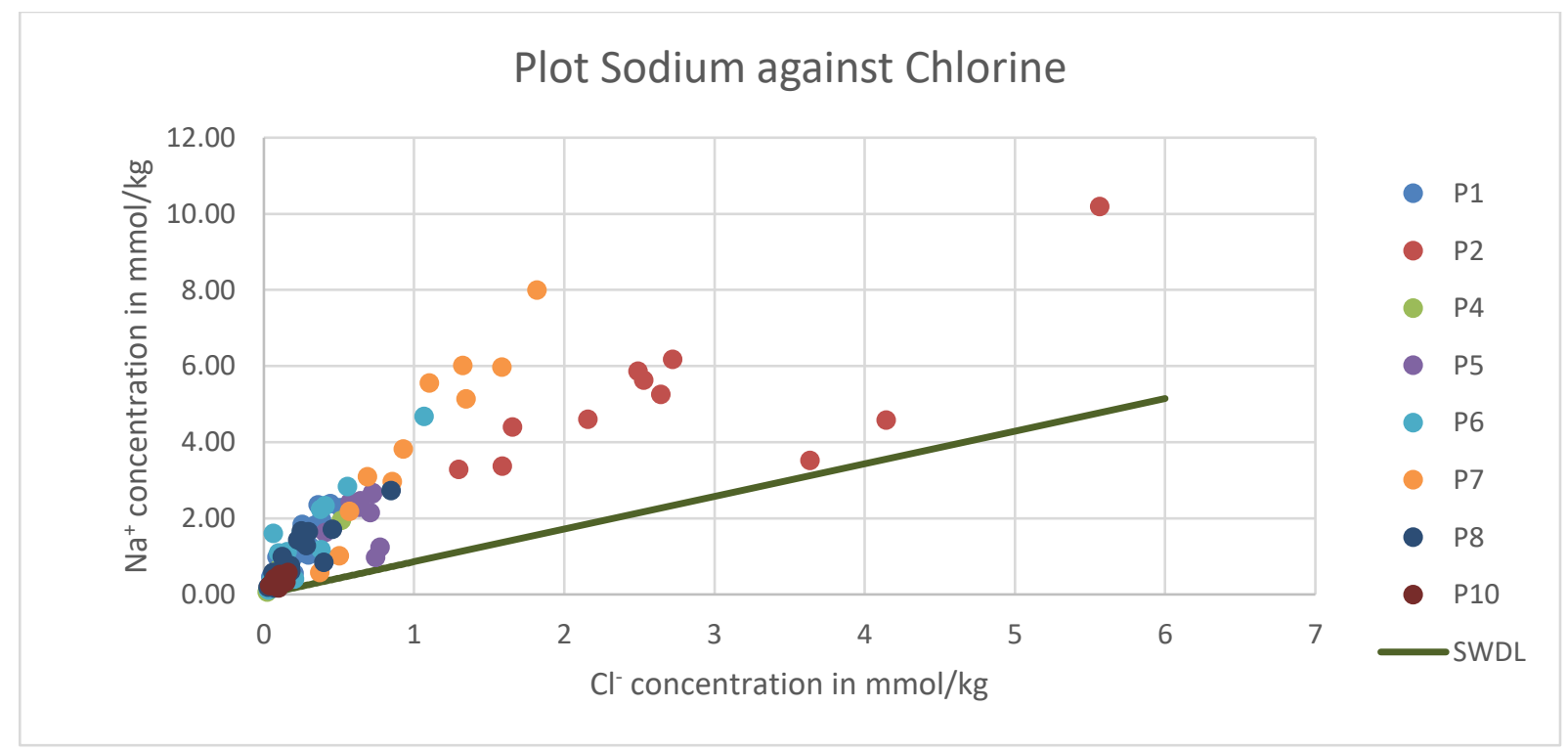

Figure 41: Plot of sodium against chlorine concentrations in mmol/kg for all cores. SWDL is the SeaWaterDilutionLine. 


\section{Plot Sodium against Nitrate}

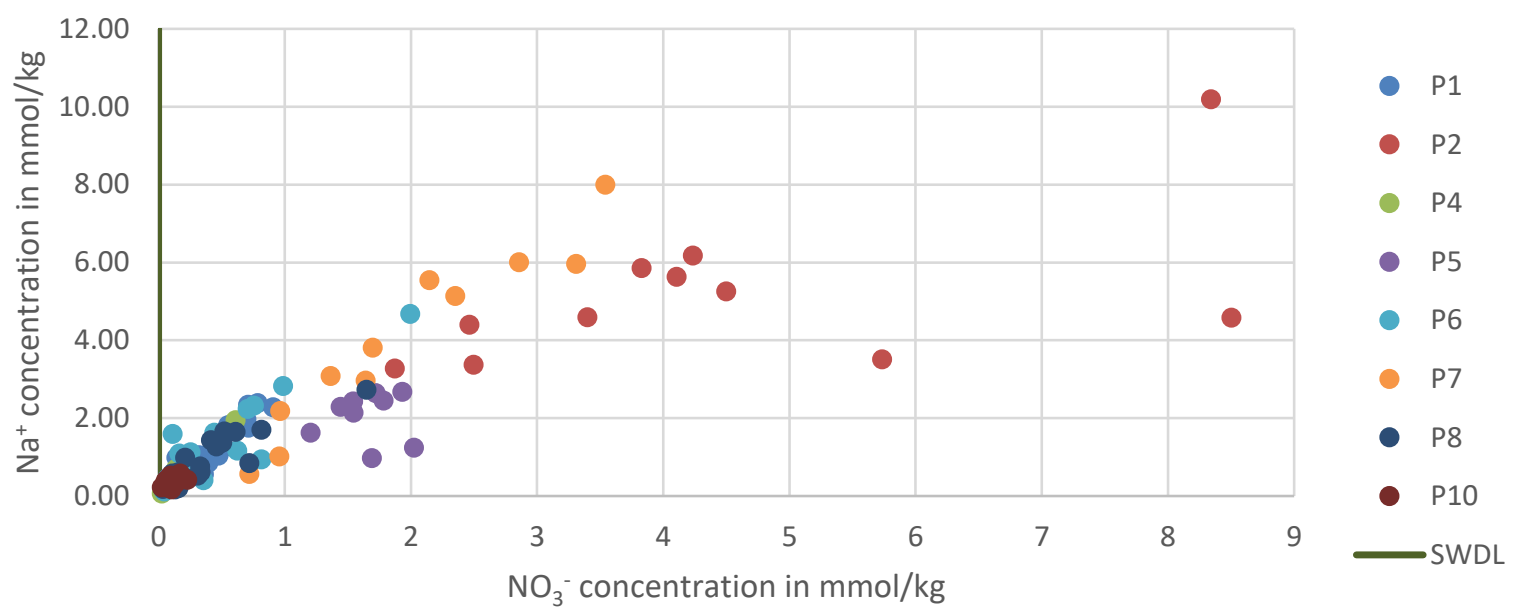

Figure 42: Plot of sodium against nitrate concentrations in mmol/kg for all cores. SWDL is the SeaWaterDilutionLine.

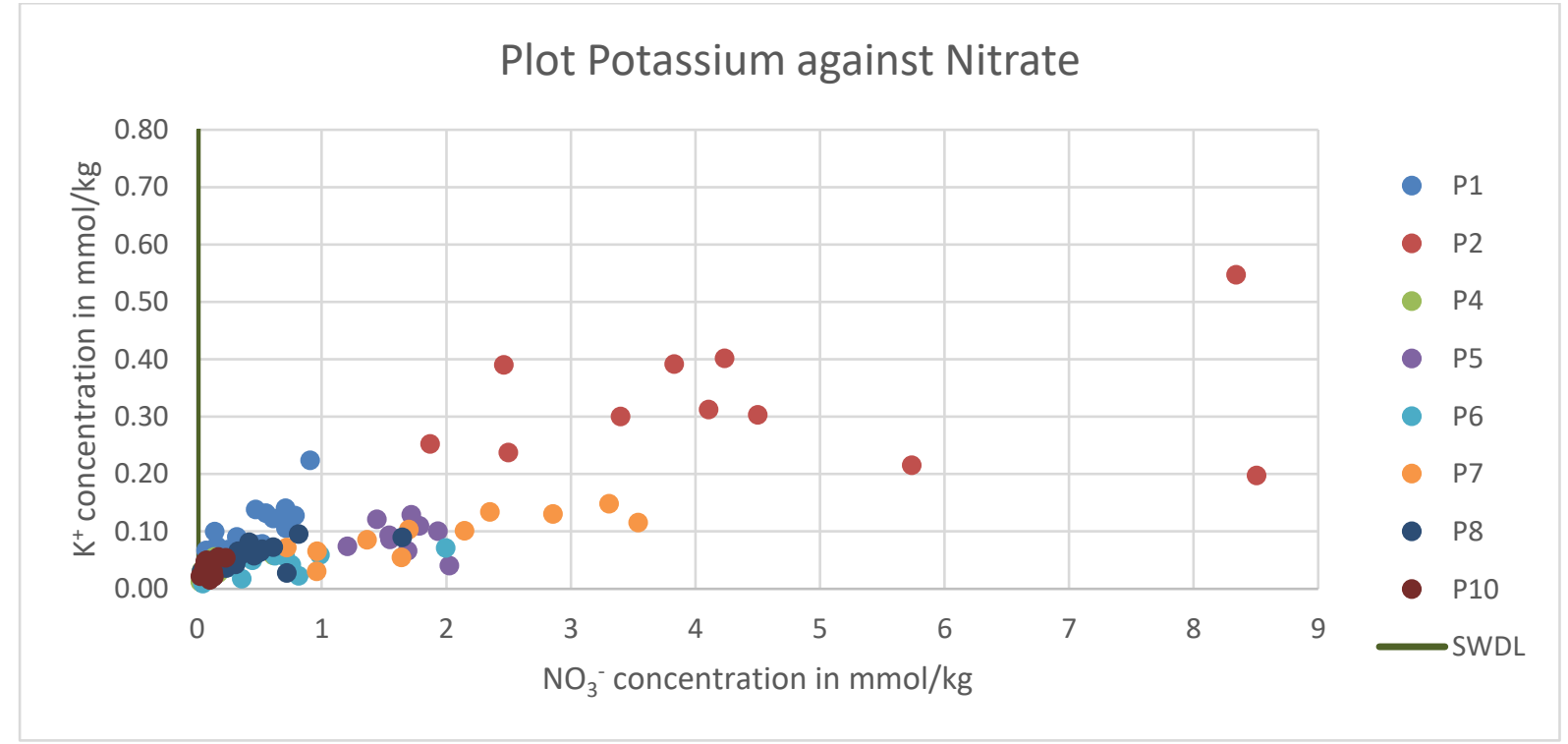

Figure 43: Plot of potassium against nitrate concentrations in mmol/kg for all cores. SWDL is the SeaWaterDilutionLine. 


\section{Plot Iron against Nitrate}

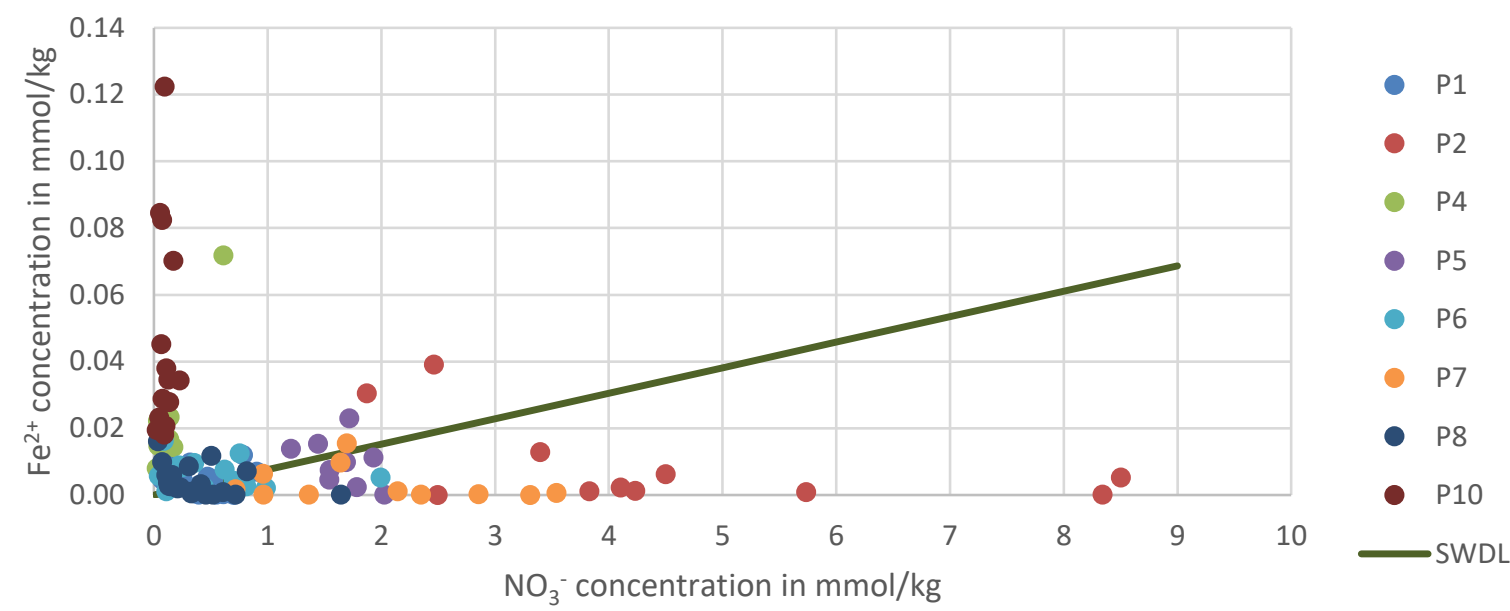

Figure 44: Plot of iron against nitrate concentrations in mmol/kg for all cores. SWDL is the SeaWaterDilutionLine.

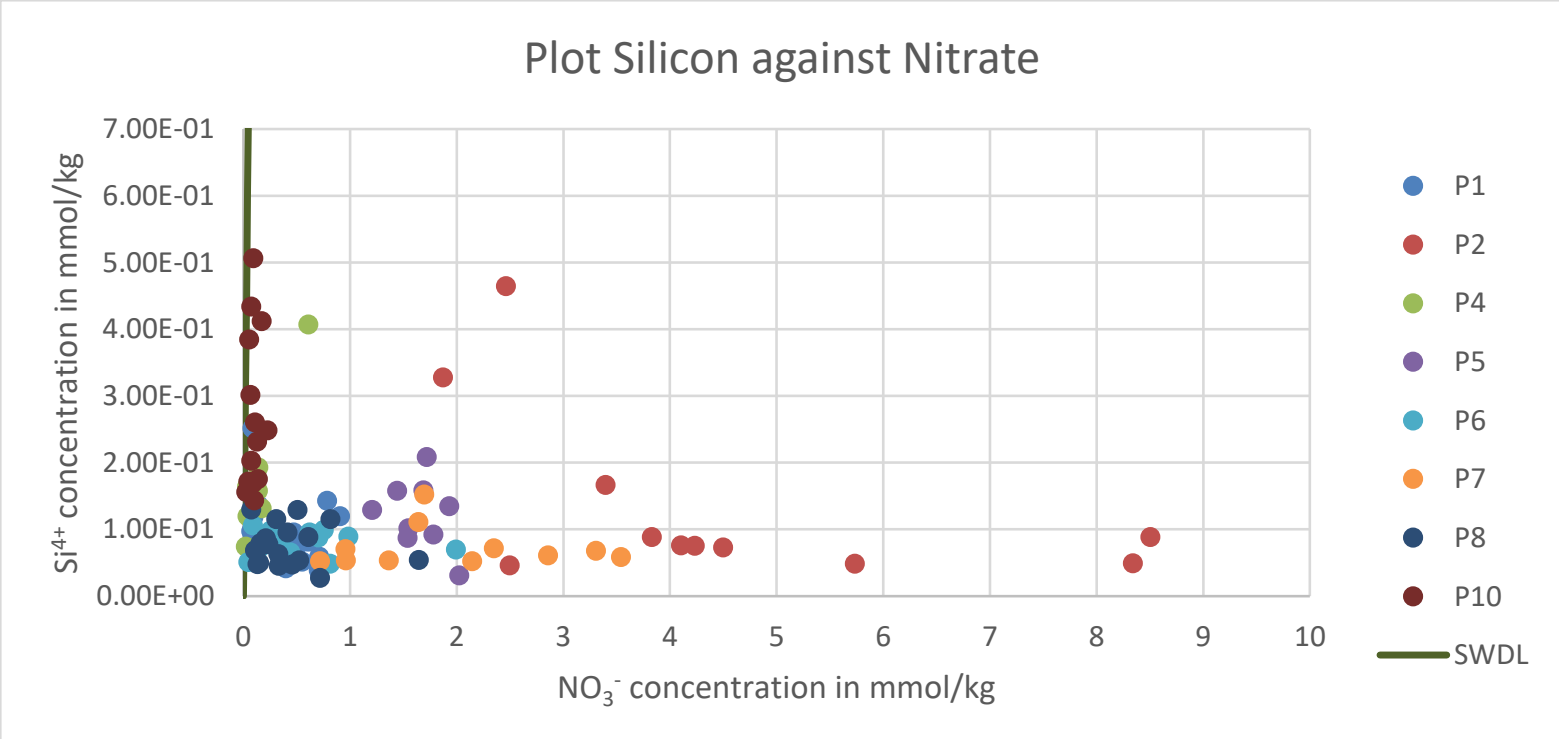

Figure 45: Plot of silicon against nitrate concentrations in mmol/kg for all cores. SWDL is the SeaWaterDilutionLine. 


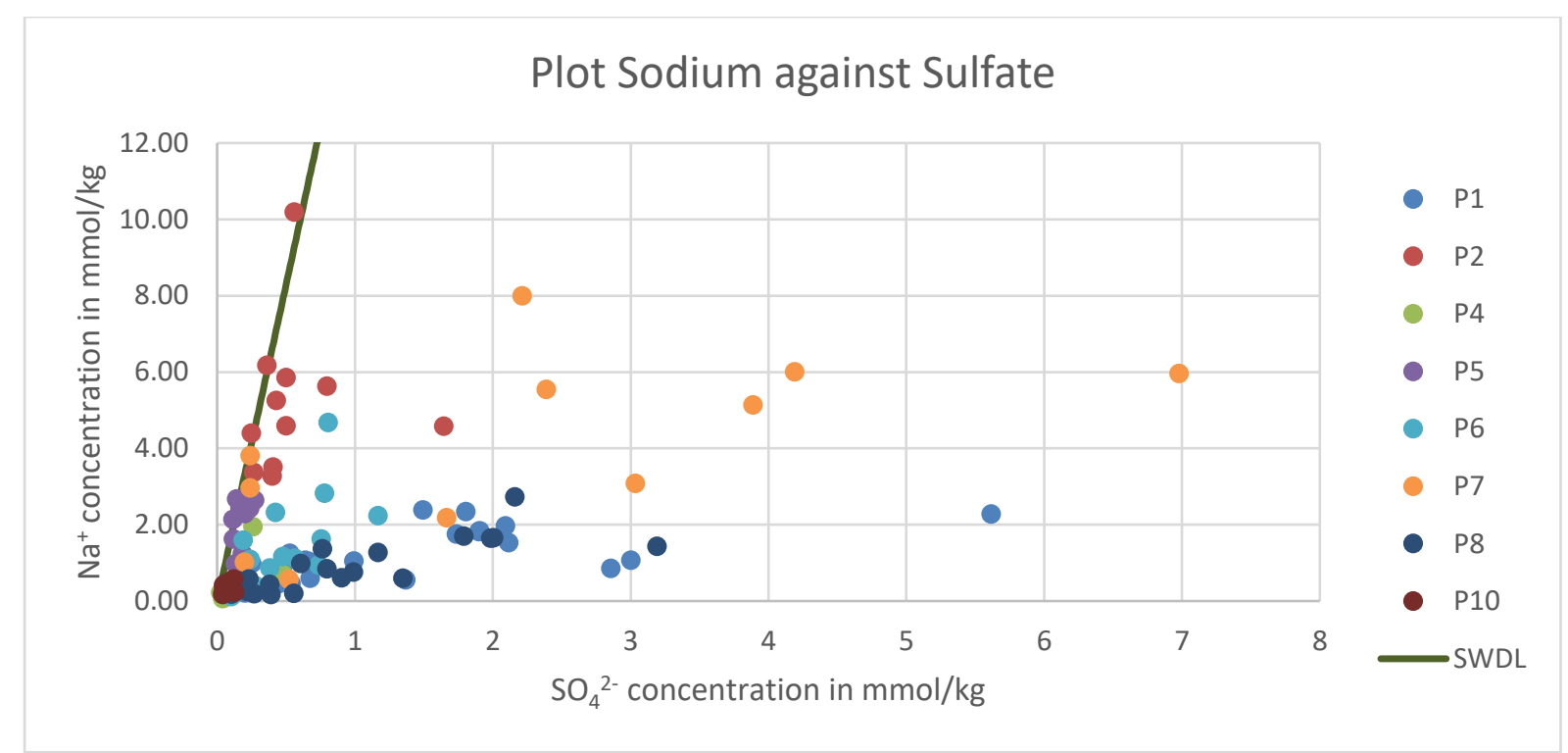

Figure 46: Plot of sodium against sulfate concentrations in mmol/kg for all cores. SWDL is the SeaWaterDilutionLine.

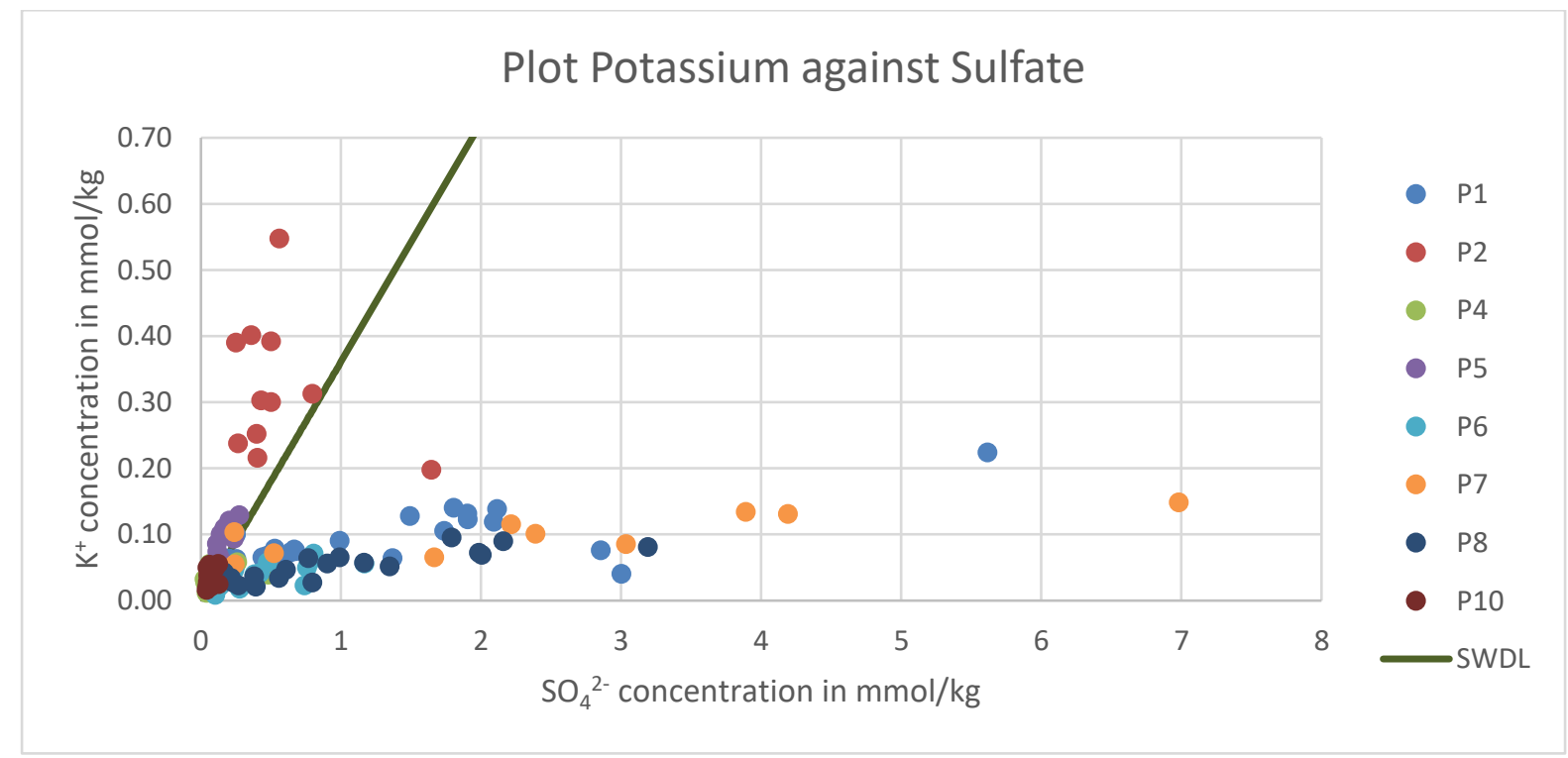

Figure 47: Plot of potassium against sulfate concentrations in mmol/kg for all cores. SWDL is the SeaWaterDilutionLine. 
Plot Magnesium against Chlorine

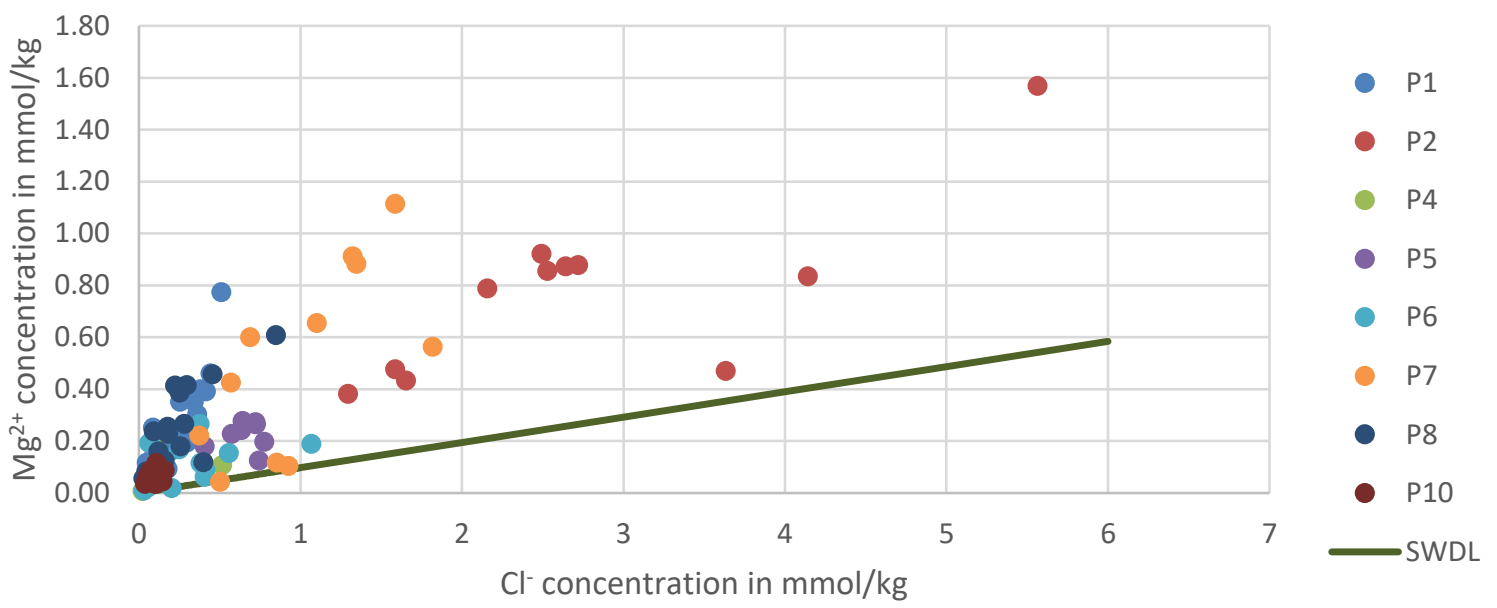

Figure 48: Plot of magnesium against chlorine concentrations in mmol/kg for all cores. SWDL is the SeaWaterDilutionLine.

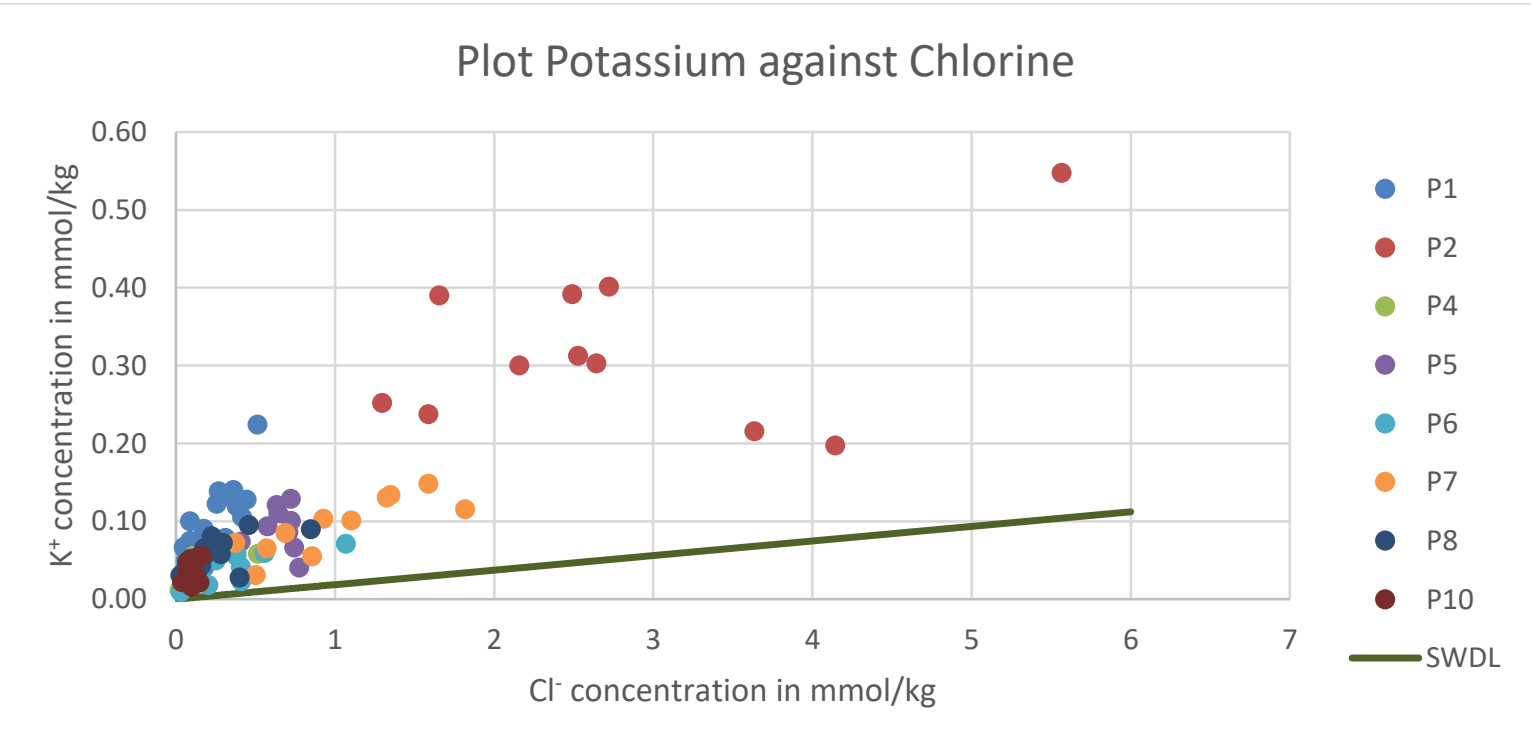

Figure 49: Plot of potassium against chlorine concentrations in mmol/kg for all cores. SWDL is the SeaWaterDilutionLine. 


\section{Plot Magnesium against Sulfate}

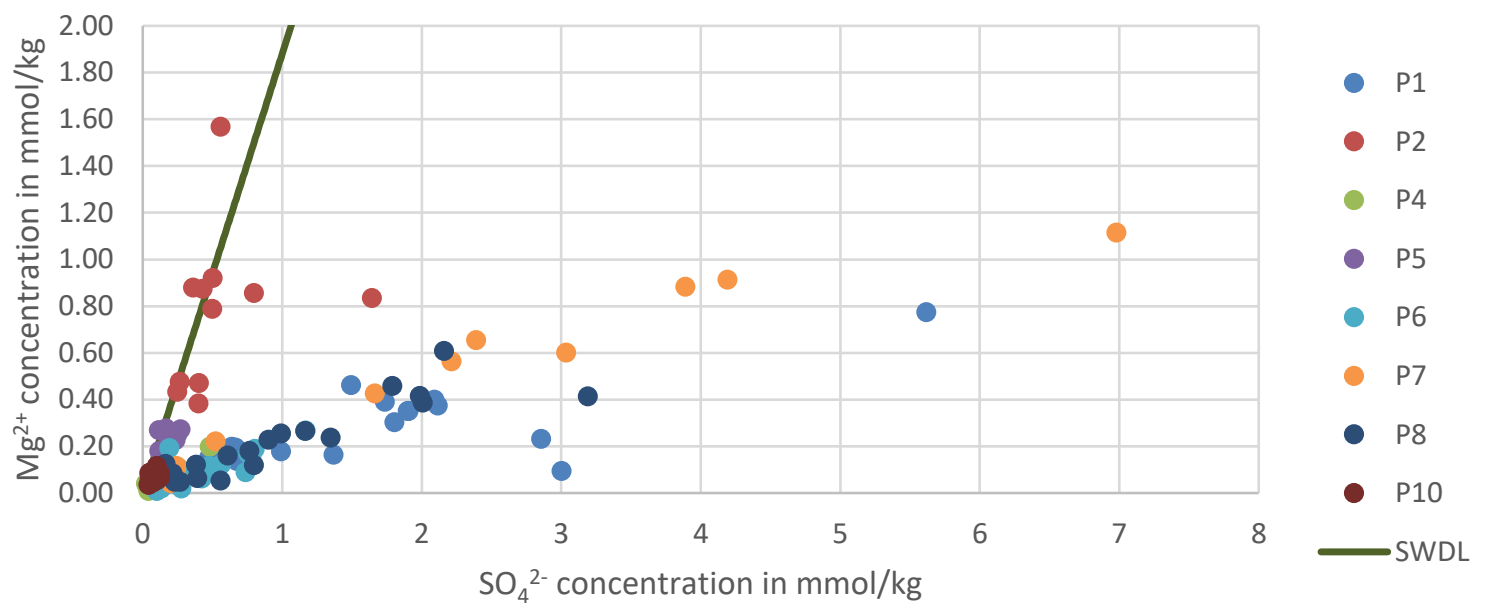

Figure 50: Plot of magnesium against sulfate concentrations in mmol/kg for all cores. SWDL is the SeaWaterDilutionLine. 